SECOND EDITION

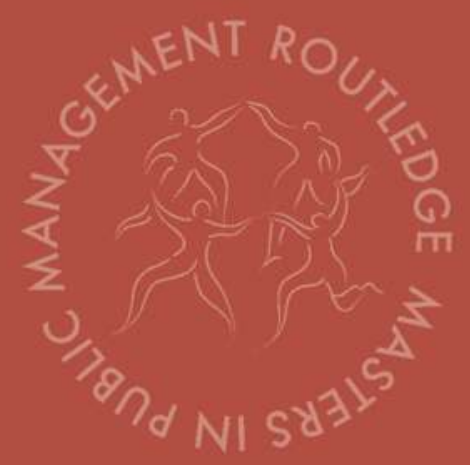

MARTIAL PASQUIER AND JEAN-PATRICK VILLENEUVE MARKETING MANAGEMENT AND COMMUNICATIONS IN THE PUBLIC SECTOR

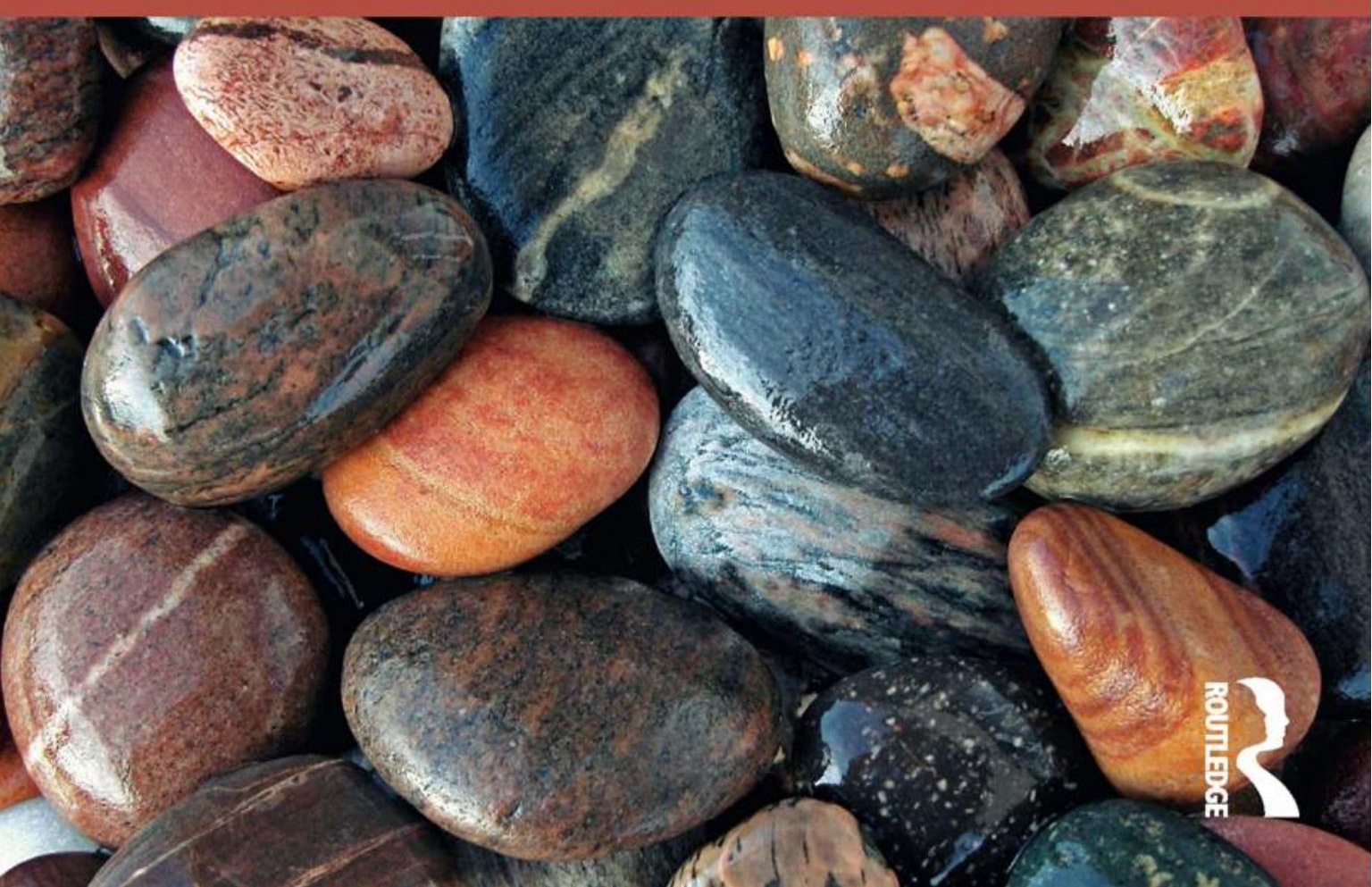




\section{Marketing Management and Communications in the Public Sector}

This updated edition of Marketing Management and Communications in the Public Sector provides a thorough overview of the major concepts in public sector marketing and communications, two fields that have continued to grow in importance for modern public administrations.

With extended coverage of topics such as social marketing and institutional communication, the authors skilfully build on the solid foundations laid down in the previous edition. Replete with real-world case studies and examples, including new material from the USA, Australia, and Asia, this book gives students a truly international outlook. Additional features include exercises and discussion questions in each chapter and an illustrative extended case study.

This refreshed text is essential reading for postgraduate students on public management degrees, and aspiring or current public managers.

Martial Pasquier is Vice-Rector of the University of Lausanne, Switzerland, and Professor of Public Management at the Swiss Graduate School of Public Administration (IDHEAP).

Jean-Patrick Villeneuve is Professor of Public Communication and Vice-Dean of the Faculty of Communication Sciences at the Università della Svizzera Italiana, Switzerland, and Adjunct Professor at Canada's École Nationale d'Administration Publique (ENAP). 


\section{ROUTLEDGE MASTERS IN PUBLIC MANAGEMENT}

\section{Edited by Stephen P Osborne}

Routledge Masters in Public Management series is an integrated set of texts. It is intended to form the backbone for the holistic study of the theory and practice of public management - as part of

- a taught Masters, MBA, or MPA course at a university or college,

- a work based, in-service, programme of education and training, or

a programme of self guided study.

Each volume stands alone in its treatment of its topic, whether it be strategic management, marketing or procurement and is co-authored by leading specialists in their field. However, all volumes in the series share both a common pedagogy and a common approach to the structure of the text. Key features of all volumes in the series include:

a critical approach to combining theory with practice which educates its reader, rather than solely teaching him/her a set of skills,

- clear learning objectives for each chapter,

- the use of figures, tables and boxes to highlight key ideas, concepts, and skills,

- an annotated bibliography, guiding students in their further reading, and

- a dedicated case study in the topic of each volume, to serve as a focus for discussion and learning.

Research Methods in Public Administration and Public Management: An Introduction

Sandra Van Thiel

Making and Managing Public Policy

Karen Johnston Miller and Duncan McTavish

Ethics and Management in the Public Sector

Alan Lawton, Karin Lasthuizen and Julie Rayner

Managing Local Governments: Designing Management Control Systems that Deliver Value

Emanuele Padovani and David W. Young

Marketing Management and Communications in the Public Sector

Martial Pasquier and Jean-Patrick Villeneuve

\section{Contracting for Public Services}

Carsten Greve

\section{Managing Change and Innovation in Public Service Organizations}

Stephen P. Osborne and Kerry Brown 


\section{MARKETING}

MANAGEMENT

AND

COMMUNICATIONS

IN THE PUBLIC

SECTOR

Second Edition

\section{Martial Pasquier and Jean-Patrick Villeneuve}

Routledge

LONDON AND NEW YORK 
Second edition published 2018

by Routledge

2 Park Square, Milton Park, Abingdon, Oxon, OX14 4RN

and by Routledge

711 Third Avenue, New York, NY 10017

Routledge is an imprint of the Taylor \& Francis Group, an informa business

(C) 2018 Martial Pasquier and Jean-Patrick Villeneuve

The right of Martial Pasquier and Jean-Patrick Villeneuve to be identified as authors of this work has been asserted by them in accordance with sections 77 and 78 of the Copyright, Designs and Patents Act 1988.

All rights reserved. No part of this book may be reprinted or reproduced or utilised in any form or by any electronic, mechanical, or other means, now known or hereafter invented, including photocopying and recording, or in any information storage or retrieval system, without permission in writing from the publishers.

Trademark notice: Product or corporate names may be trademarks or registered trademarks, and are used only for identification and explanation without intent to infringe.

First edition published by Routledge 2012

British Library Cataloguing-in-Publication Data

A catalogue record for this book is available from the British Library

Library of Congress Cataloging-in-Publication Data

Names: Pasquier, Martial, author. | Villeneuve, Jean-Patrick, author.

Title: Marketing management and communications in the public sector / Martial Pasquier and Jean-Patrick Villeneuve.

Description: 2nd Edition. | New York : Routledge, 2017. |

Series: Routledge masters in public management | Revised edition of the authors' Marketing management and communications in the public sector, 2012. |

Includes bibliographical references and index.

Identifiers: LCCN 2017000645 | ISBN 9781138655799 (hardback) |

ISBN 9781138655805 (pbk.) | ISBN 9781315622309 (ebook)

Subjects: LCSH: Government publicity. | Communication in public administration.

Classification: LCC JF1525.P8 P37 2017 | DDC 352.7/48 - dc23

LC record available at https://lccn.loc.gov/2017000645

ISBN: 978-1-138-65579-9 (hbk)

ISBN: 978-1-138-65580-5 (pbk)

ISBN: 978-1-315-62230-9 (ebk)

Typeset in Perpetua and Bell Gothic

by Florence Production Ltd, Stoodleigh, Devon, UK 


\section{Contents}

List of figures vi

List of tables viii

List of boxes ix

PART I 1

1. Public management and marketing 3

2. Marketing and public marketing 15

$\begin{array}{ll}\text { PART II } & 37\end{array}$

3. Basic marketing concepts 39

4. Marketing information research 62

5. Marketing strategy 89

6. Marketing instruments 113

$\begin{array}{ll}\text { PART III } & 139\end{array}$

7. Public communications - an introduction 141

8. Communications models and strategies 166

9. Communications instruments 186

10. Communication control 209

11. Crisis communication 222

Appendix: a case study 249

Index 259 


\section{Figures}

1.1 Management models in the public sector 6

2.1 Main orientations in marketing development 17

$\begin{array}{ll}2.2 \text { Bases of the development of public marketing } & 21\end{array}$

2.3 Public marketing and marketing for public services 28

3.1 Main marketing concepts 41

3.2 Components of a market viewed as a system 43

3.3 Comparison of American and Swiss health insurance systems 44

3.4 Comparison of an organization's product and client orientations. 46

3.5 Main tasks of marketing management 49

3.6 Ingredients in the marketing mix 51

4.1 The various types of costs involved in producing a service and making it $\begin{array}{ll}\text { available } & 65\end{array}$

4.2 Summary of the main marketing study and opinion survey methods $\quad 67$

4.3 The images of Germany, the USA and Switzerland in China 75

4.4 Example of quota sampling study 80

5.1 Strategic development processes: comparison between private and public $\begin{array}{ll}\text { organizations } & 91\end{array}$

5.2 Interaction between an organization's political and strategic levels 93

$\begin{array}{lll}5.3 & \text { Possible public organization strategies } & 94\end{array}$

5.4 Phases of marketing strategy 96

$\begin{array}{lll}5.5 & \text { Stages of marketing analysis } & 97\end{array}$

5.6 Image differential between economic sectors 103

$\begin{array}{lll}5.7 & \text { SWOT diagnosis } & 104\end{array}$

$\begin{array}{ll}5.8 \text { Example of intermediation in a market } & 109\end{array}$

$\begin{array}{ll}6.1 \text { Basic structures of marketing instruments } & 115\end{array}$

6.2 Tangible versus intangible proportion of public services 118

6.3 Components of a public service (for issuing a passport) 119

$\begin{array}{lll}6.4 & \text { Public service quality criteria } & 125\end{array}$

$\begin{array}{ll}\text { 6.5 Distribution of public services } & 131\end{array}$

$\begin{array}{lll}7.1 & \text { Elements of public communications } & 144\end{array}$

$\begin{array}{lll}8.1 & \text { Schematic model of communication } & 168\end{array}$

\section{vi}


$\begin{array}{lll}\text { 8.2 Road sign indicating a level crossing } & 168\end{array}$

$\begin{array}{ll}8.3 \text { Integrated communications model } & 169\end{array}$

$\begin{array}{ll}\text { 8.4 The European Union 50th anniversary logo } & 170\end{array}$

$\begin{array}{ll}\text { 8.5 Campaign to promote borrowing } & 171\end{array}$

$\begin{array}{ll}\text { 8.6 Steps in a communications strategy } & 173\end{array}$

$\begin{array}{ll}\text { 8.7 Target group reached and dispersion loss } & 175\end{array}$

$\begin{array}{lll}9.1 & \text { E-government and communications } & 201\end{array}$

10.1 Analytical overview of potential effects of a promotional measure 211

10.2 Synthetic model for analysing effectiveness of communication measures and advertising campaigns

10.3 Ad of a communication campaign against 'under the table' employment 218

11.1 Phases of a crisis resulting from a serious accident or incident 232

11.2 Three main phases of the crisis at the University of Geneva 235 


\section{Tables}

1.1 Comparison of public organization management models

2.1 Public-sector provider-user relationship 24

2.2 Potential areas for applying marketing to the public sector 25

2.3 Differentiating offer and personal involvement of beneficiaries 27

2.4 Characteristics of public service marketing 30

3.1 Symptoms of product orientation and client orientation 48

3.2 Typology of the actor $\quad 54$

$\begin{array}{lll}4.1 & \text { Secondary or documentary sources } & 68\end{array}$

4.2 Comparison of random sampling and quota sampling 81

5.1 Typology - segmentation criteria 98

$\begin{array}{ll}5.2 \text { Marketing strategy } & 107\end{array}$

$\begin{array}{lll}6.1 & \text { Public goods and types of price } & 127\end{array}$

$\begin{array}{lll}7.1 & \text { Levels of public communications } & 151\end{array}$

7.2 The legal bases of access-to-information rights (selection) 157

$\begin{array}{lll}7.3 & \text { Types of obstacles to transparency } & 162\end{array}$

$\begin{array}{lll}8.1 & \text { Objectives of public communications } & 178\end{array}$

9.1 The main public communications instruments 189

$\begin{array}{ll}9.2 \text { Comparative criteria of advertising media } & 193\end{array}$

$\begin{array}{ll}11.1 \text { Types of crisis } & 229\end{array}$

$\begin{array}{ll}11.2 \text { Crisis checklists } & 245\end{array}$

A.1 Number of $\$ 1$ coins produced 250 


\section{Boxes}

1.1 Example of criticism directed towards the Weberian model of administration

2.1 Most important developments in marketing 18

2.2 Introducing competition to Swiss unemployment funds 23

$\begin{array}{ll}2.3 \text { Place marketing } & 29\end{array}$

2.4 Valais tourism law 33

3.1 Principal criteria for defining a market 42

4.1 Examples of situations in which 'marketing' information must be gathered 64

4.2 Electronic observation of people's movements 69

4.3 Typical objectives for quantitative and qualitative surveys in the public sector $\quad 71$

4.4 Eurobarometer surveys conducted by the European Commission 72

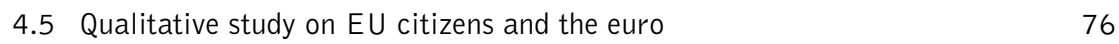

4.6 Formula to calculate samples 82

4.7 Phases of a market research study 83

4.8 Rules for designing a questionnaire 84

5.1 Segmentation of high-speed train users in Germany 100

$\begin{array}{ll}5.2 \text { Example of structuration } & 101\end{array}$

$\begin{array}{ll}5.3 & \text { Image differential between economic sectors } \\ 5.4 & 103\end{array}$

5.4 Marketing strategy for a professional career-guidance service 108

$\begin{array}{ll}6.1 \text { Process of structuring services in an administrative unit } & 121\end{array}$

6.2 Structuring services linked to the protection of cultural goods 122

$\begin{array}{ll}6.3 \text { Bicycle hire in Paris } & 128\end{array}$

$\begin{array}{lll}7.1 & \text { Examples of forms of public communications } & 143\end{array}$

$\begin{array}{ll}7.2 \text { Legal foundations of communications activities } & 147\end{array}$

$\begin{array}{ll}7.3 \text { The Gotthard Tunnel } & 150\end{array}$

8.1 The European Union 50th anniversary logo 170

8.2 Campaign to promote borrowing by the French government 171

$\begin{array}{ll}\text { 8.3 General information for the public } & 175\end{array}$

$\begin{array}{ll}8.4 \text { Smoking ban in California } & 179\end{array}$

$\begin{array}{lll}9.1 \text { Open day for justice } & 190\end{array}$ 
$\begin{array}{ll}9.2 \text { Government advertising in Singapore } & 191\end{array}$

$\begin{array}{ll}9.3 \text { Communications campaigns in Canada } & 192\end{array}$

$\begin{array}{lll}9.4 & \text { Rules for the drafting of a press release } & 197\end{array}$

$\begin{array}{ll}\text { 9.5 Rules for organizing a press conference } & 198\end{array}$

9.6 Important elements in website creation 204

$\begin{array}{lll}10.1 & \text { Monitoring information over time } & 214\end{array}$

10.2 Basic control of effectiveness of communication campaign against 'under the table' employment

$\begin{array}{ll}10.3 \text { Verifying the impact of public relations (PR) } & 219\end{array}$

$\begin{array}{lll}11.1 & \text { Crisis factors that bring major risks } & 225\end{array}$

$\begin{array}{ll}11.2 \text { A crisis caused by a serious incident } & 230\end{array}$

$\begin{array}{ll}11.3 \text { A crisis caused by an information-management problem } & 231\end{array}$

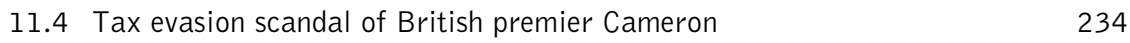

$\begin{array}{ll}11.5 & \text { Examples of errors in crisis communication } \\ 238\end{array}$

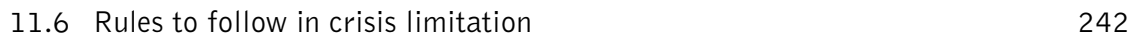

$\begin{array}{lll}11.7 & \text { Speed and intrusiveness of modern media } & 244\end{array}$ 
Part I

1 


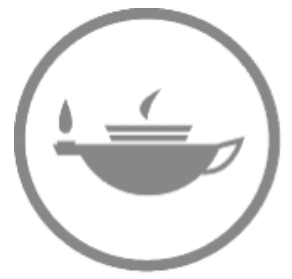

Taylor \& Francis Taylor \& Francis Group http://taylorandfrancis.com 


\section{Chapter 1}

\section{Public management and marketing}

\section{LEARNING OBJECTIVES}

By the end of this chapter you should:

- Be able to identify the distinctive features of the public sector.

- Understand the various management models used in the public sector.

- Have considered the organizational and marketing implications of a publicsector setting.

\section{KEY POINTS OF THIS CHAPTER}

- Marketing in the public sector is directly affected by the characteristics of the overall managerial framework present in a public-sector setting.

- Elements specific to public-sector organizations include: legal status, objectives, tasks, and environment.

- Three general management models can be identified in the public sector. The Weberian system (traditional and bureaucratic, which came into use in the 1920s); New Public Management (private sector inspired, which emerged in the 1990s); and Democratic Governance (participatory approach, which appeared in the 2000s).

\section{KEY TERMS}

Public service organization - a public body implementing public policies, generally through the production of goods and services, by coordinating resources available to it. The classic type of public-sector structure is considered to be a 


\section{KEY TERMS continued...}

'central public service organization'. It is directly dependent upon political authority and generally has very little autonomy regarding the way its work is systematized and carried out.

Weberian, or Classical model - a paradigm structured by sociologist Max Weber. Defining characteristics of this model include a stable, neutral civil service - hierarchically organized and specialized by function - as well as a clear separation between a function and the individual holding the position.

New Public Management - this model is inspired by private-sector practices and premised on the notion that competition in the public sector is the best guarantor of greater efficiency.

Democratic Governance - a model arising in the 1990s and 2000s - was mainly developed in reaction to criticisms levelled at New Public Management, based on notions of accountability, transparency and citizen participation.

\section{THE DEVELOPMENT AND CHARACTERISTICS OF PUBLIC ORGANIZATIONS}

Discussion of marketing in public organizations requires a two-fold understanding. First there is the role of public organizations in democratic political systems and, secondly, the way management is envisioned and defined within these organizations.

Broadly speaking, central public service organizations, defined independently of political institutions, came into being with the development of the liberal state. This is a conception of the state in which principles of liberty and individual responsibility take precedence over power of the sovereign.

The members of a state (citizens) therefore enjoy fundamental rights no power may violate. By the end of the nineteenth century and the start of the twentieth century, in many countries it had become necessary to define the boundaries of state power. This imposed the principle of the subordination of governments and central administrations not to the monarch or dictator but to the letter of the law.

As a result, relationships between the state and its citizens are generally governed by administrative law. The management of public organizations is thus greatly influenced by the application of corresponding rules of procedure. In the United States, particularly under the influence of future President Woodrow Wilson, the structure of public administration developed in a more professional and pragmatic manner (Chevallier, 2002: 16).

One further aspect to consider is the growth of the public sector. With the development of the state's economic activities - electricity, telecommunications, postal 
service, etc. - and the advent of the welfare state after World War II, government functions grew considerably. These occurrences resulted in a number of far-reaching consequences. Administrative structures diversified and the delivery of public services was entrusted to organizations with specific statuses such as publicly funded bodies, public corporations, etc. Depending on hierarchy, such administrations possessed varying degrees of managerial independence.

Subsequently, relationships between public organizations and beneficiaries of public action broadened and could no longer be based solely on administrative law. The emergence of more informal relationships meant managerial bodies were no longer linked entirely to a political process. As a result, they were more directly related to the services offered and this made it possible to take into consideration such marketing elements as analysis of user needs, differentiation of certain services, performance of communications activities, etc.

These developments intensified in the wake of frequent criticism of the classic functioning of administrations - bureaucracy, inefficiency, and so on. Solutions proposed since the 1980s have focused upon the growing autonomy of public organizations. This puts them in competition with one another, so they must adopt a 'consumer-driven' model for the provision of services. These changes, generically grouped under the term 'New Public Management', have led to the introduction of management concepts and more widespread use of marketing and its tools - satisfaction analysis, fee systems, promotional activities, development of brands, etc.

In recent decades, public organizations have undergone many changes resulting from the introduction of management methods and techniques akin to those of private enterprises. However, state structures still have several distinctive features which affect the possibilities for adopting marketing concepts and using marketing tools:

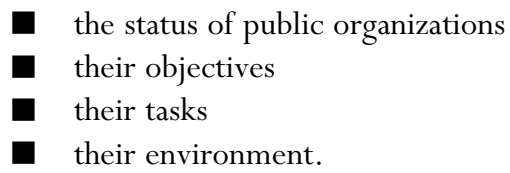

Status of public organizations: Their public nature means the behaviour of public organizations is primarily the result of the political process, subject to control or close monitoring by legislators and policymakers. It also assures public law applies in case of conflict between the organization and beneficiaries of its actions - primacy of principles over processes.

In this framework, the public organization and its employees may be called upon to use measures of constraint against individuals, organizations and institutions arrest, fines or specific prohibitions. As a result, these organizations' managerial autonomy may be severely limited by compliance with rules and procedures taking precedence over managerial choices.

Objectives: Unlike private companies, which can rank objectives in the service of maximum profitability, public organizations must generally manage a complex system 
of sometimes contradictory objectives. They must always provide high-quality services, deliver identical services to all citizens, and manage budgets with numerous constraints, etc.

Tasks: A public organization's tasks must have a legal basis such as lawfulness of action; otherwise it cannot act. In addition, unlike private organizations, it is not restricted to producing goods and services and making them available in an outputoriented logic. It must also design and implement public policies to satisfy collective needs - outcome-oriented logic. Consequently, measurement of its performance cannot be reduced to the relationship between a service and its beneficiaries. It must also include the capacity to increase collective welfare.

Environment: Generally speaking, private companies are involved in a competitive situation and choose their partners; suppliers and customers. In contrast, public organizations do not normally operate in a market situation. They cannot make services available selectively, and face a large number of stakeholders. Moreover, public organizations are increasingly compelled to be accountable not only to political authority (vertical accountability) but also to all their partners, the media and the general public (horizontal accountability).

Consequently, although marketing concepts and tools may be used by public organizations, the framework in which they are employed is highly restrictive and not at all homogeneous. Several conditions may be placed upon their use: organizations may be forbidden to develop services, differentiate services on the basis of their beneficiaries, selecting beneficiaries, etc. To quote Allison (1979): '[P]ublic and private management: are they fundamentally alike in all unimportant respects?'

\section{MANAGEMENT MODELS IN PUBLIC ORGANIZATION}

Three distinct management models can be identified in public organizations: the Weberian model, the New Public Management model and the Democratic Governance model (see Figure 1.1). The reference standard for management of public organizations was inspired by the work of sociologist Max Weber (1921). Based upon his studies of the structures of major military, religious and administrative institutions, he arrived

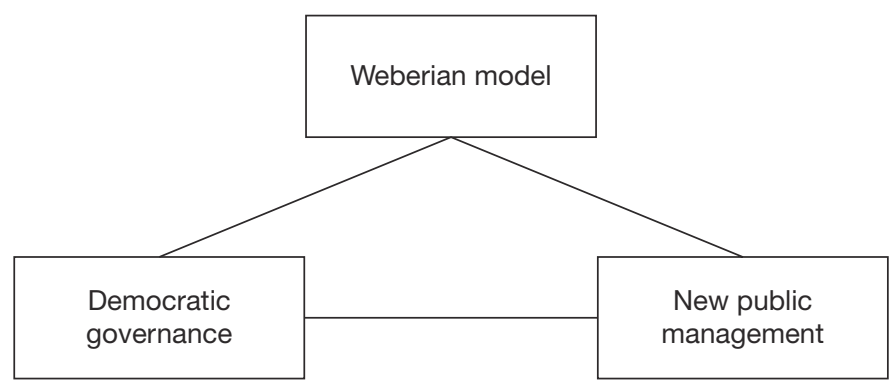

Figure 1.1 Management models in the public sector 
at a model offering means to administer laws effectively and coordinate complex activities.

The Weberian model, also known as the Classical model of public administration, is characterized by a centralized, hierarchical specialization of functions. These include professionalism, a hiring and promotion system based on competence, the impersonal nature of rules, and a clear separation between the function and its incumbent. Because this principle prohibits any personalized or differentiated professional relationship between the organization and beneficiaries of its action, it considerably limits the application of marketing concepts.

Three types of criticisms have been levelled at the Weberian model: criticisms of the model itself, its inability to account for the way organizations operate and its failure to take into account changes in the relationships between public organizations and society. Criticism focuses primarily on an assumed absence of harmony inside the organization and the existence of parallel powers acting outside the hierarchical rules.

Organizations cannot simply be summed up as a set of formal rules. Moreover, they are becoming less and less impervious to economic and social organizations and their powers. In addition, the application of bureaucratic principles can lead to measures harmful to the functioning of the politico-administrative system. Examples of this are strict application of bureaucratic rules leading to abuse of power, use of administrative jargon creating an unnecessary barrier between the administration and the individual, and so on. Box 1.1 shows a classic example of this line of criticism.

Other criticisms are directed at the manner in which public organizations operate. Such institutions frequently have no clear objectives and it is difficult to establish links between available resources and results. Moreover, they are viewed as lacking innovation and transparency regarding the quality and cost of services delivered.

Lastly, this management model has been criticized for its failure to adapt to the evolution of public organizations. Among the questions relevant to the subject of this book, we can cite costs generated by regulatory activities and misalignment between the Weberian model and the service society. However, there is one paramount question. Can the numerous economic functions such as telecommunications, electricity, etc., assumed by the State during the twentieth century, be performed at lower cost and higher quality levels for beneficiaries outside of government?

Although the Weberian model has been strongly criticized since the 1980s, it served as a reference for most Western countries throughout the twentieth century. Currently, many of its principles continue to form the functioning basis of public organizations.

In the face of these many criticisms, plus objections of a more theoretical nature arising out of neo-liberal thought (Buchanan, 1962; Dardot and Laval, 2009; Merrien, 2009), proposals for sweeping management restructuring of public organizations have been made since the mid-1980s. Such reforms have been initially implemented in a number of English-speaking countries; most notably, New Zealand (Schwartz, 1994; Kaplan and Haenlein, 2009). 


\section{BOX 1.1 EXAMPLE OF CRITICISM DIRECTED TOWARDS THE WEBERIAN MODEL OF ADMINISTRATION}

In one US state it was discovered that a certain employment office, over an 18month period, had succeeded in finding permanent jobs for many unemployed people. It was noted that not only did this office succeed in placing more jobless people than other offices, but also the new employees kept their jobs longer in comparison with those who had been placed by other offices in the same state.

During a biennial visit to examine the office's records, a state auditor found everything in order. But he also discovered that the director was using an unusual motivation system that seemed to hold the key to her success. She rewarded employees with an extra day's leave as soon as they had found jobs for a set number of jobless workers who maintained their employment longer than the average recorded for all the offices in the state.

Despite the director's success, the auditor was obliged to inform her that she was breaking the law and that she could not use such a reward system. One year later, this office's performance was slightly below the state average, in respect of both the number of placements and the average duration of them holding jobs.

Everybody firmly believed the special reward system was the catalyst for the office's earlier success and its abolition had immediately led the office into mediocrity. All they could do was nod, shrug their shoulders and say, 'It was a great idea but it was illegal.'

Source: Gortner et al. (2002)

Osborne and Gaebler's Reinventing Government: How the Entrepreneurial Spirit is Transforming the Public Sector (1993) codified these new management principles for public organizations, making them both accessible and popular. The New Public Management model places efficiency of public action at the centre of an organization's concerns and is based in large part on the management principles of private enterprise.

It purports that to be efficient and able to adapt to change, public organizations must be made autonomous and have much freer choice of management tools to perform tasks. These should include autonomous human resources management and the ability to introduce merit pay.

The process leading to greater autonomy is framed within a contractual relationship between political authority and the public organization - such as a service provision agreement. It should explicitly set out performance indicators to be used in measuring the organization's performance and its capacity for fulfilling the terms of the contract.

To ensure the organization works more efficiently, competitive principles should be introduced inside the public service, between public organizations or between public 
and private organizations. With the same aim, the activities of public organizations should be much more oriented towards users' needs.

This model, radically different from the classical model, greatly facilitates the introduction of marketing concepts and tools. For example, beneficiary satisfaction is included in performance measurement which is important to developing more personalized relations. As well, organizations have the autonomy to adapt or even differentiate services provided on the basis of their beneficiaries.

Numerous experiments with New Public Management have been carried out with the extent varying from country to country. However, assessments of the model have differed greatly (Wollmann, 2003; Boyne et al., 2003) and many criticisms have sought to put the potential benefits of the model into perspective (Pollitt and Bouckaert, 2000; Rieder and Lehmann, 2002). Chief criticisms are aimed at a legitimacy deficit in public action and a loss of democratic control.

For example, in the name of efficiency, some public organizations may prefer to concentrate on certain tasks to the disadvantage of others benefiting either few people or marginal groups. Other criticisms are aimed at the difficulty experienced by organizations forced to adapt, often in an artificial manner.

Such organizations may have to enter a falsely competitive environment or adopt opportunistic behaviour to fulfil contract terms. They may also encounter expansion of their offered services to the detriment of the requirement to produce and coordinate public policy. This results in the emergence of a new form of administration, known as managerial bureaucracy.

Since organizations must be governed by means of service provision contracts and performance indicators, they are required to develop complex information management and reporting systems. However, because of this, end results are sometimes relatively abstract in relation to their basic missions.

Faced with these criticisms and in order to respond to developments observed during the past two decades, new proposals have been made. They are intended to serve as a complement to, rather than a replacement for, the Weberian and New Public Management models.

Although they lack the homogeneity of the other models, these proposals, which can be grouped under the umbrella term 'Democratic Governance', centre on the following principles:

- accountability

- transparency

- networked governance

- co-production of public policies - from definition to delivery

- implementation and superimposition of various managerial approaches.

The accountability principle refers to an organization's capacity to account for its decisions, use of resources, and actions, not only to political authority (vertical accountability) but also to all its partners (horizontal accountability). 
The transparency principle requires an organization's processes and internal decisions to be open to third parties, whether or not they are involved in the organization (Florini, 1998; Pasquier and Villeneuve, 2007; Meijer, 2013). This transparency can be documentary, financial, legal, or deliberative.

Documentary transparency, for example, enables people to ask for documents or information held by the administration without having to justify their reasons for requesting them. Conversely, the administration cannot refuse access to such documents unless overriding public or private interests are at issue.

Networked governance consists of concluding arrangements between actors at the same or differing institutional levels for the performance of public tasks. These would entail collaboration between municipalities on waste management, or between police forces on security at very large demonstrations. Such arrangements, which may evolve over time, are necessitated by the complexity of, and changes in, our society.

Whereas the Weberian model sees beneficiaries as subjects and New Public Management views them as consumers, Democratic Governance deems that beneficiaries must be involved right from the start of the process of defining a public policy and in its implementation. This ensures that needs expressed can be met while taking into account political, social, and financial constraints. In this way beneficiaries are not merely individuals or organizations able to utilize a public service because their involvement makes them true participants in public action.

The diversity of a state's tasks, the complexity of environments in which public organizations deploy their activities, and the rate of change in its environment, mean several methods of managing public organizations must be developed. As well, several management models must be allowed to coexist in the same politico-administrative system. This principle obviously makes political control of administrative bodies more difficult, or at least more delicate.

Several public organizations operate in a highly competitive environment (e.g. universities) while others carry out their mandates outside any competitive context (e.g. state archives). It is difficult to find a single management model for such widely differing organizations.

However, the situation is sometimes even more complex. Some organizations, such as meteorological departments, must fulfil missions in a monopoly situation - weather reports, development of forecasting models, warning systems, etc. Yet, they are also required to operate in an open-market context - forecasts for specific target groups such as farmers, hoteliers, media, and so on.

In complex situations where public organizations enjoy a degree of autonomy, marketing functions come into their own. For an organization, uncertainty generally increases with autonomy. With the use of marketing tools, beneficiaries can be studied, differentiated services can be offered; access to services can be facilitated, and so on. This flexibility makes it possible to reduce risks by generating the necessary information and insights.

Table 1.1 provides an overview of the three main management models for public organizations: the Weberian model, New Public Management and Democratic 


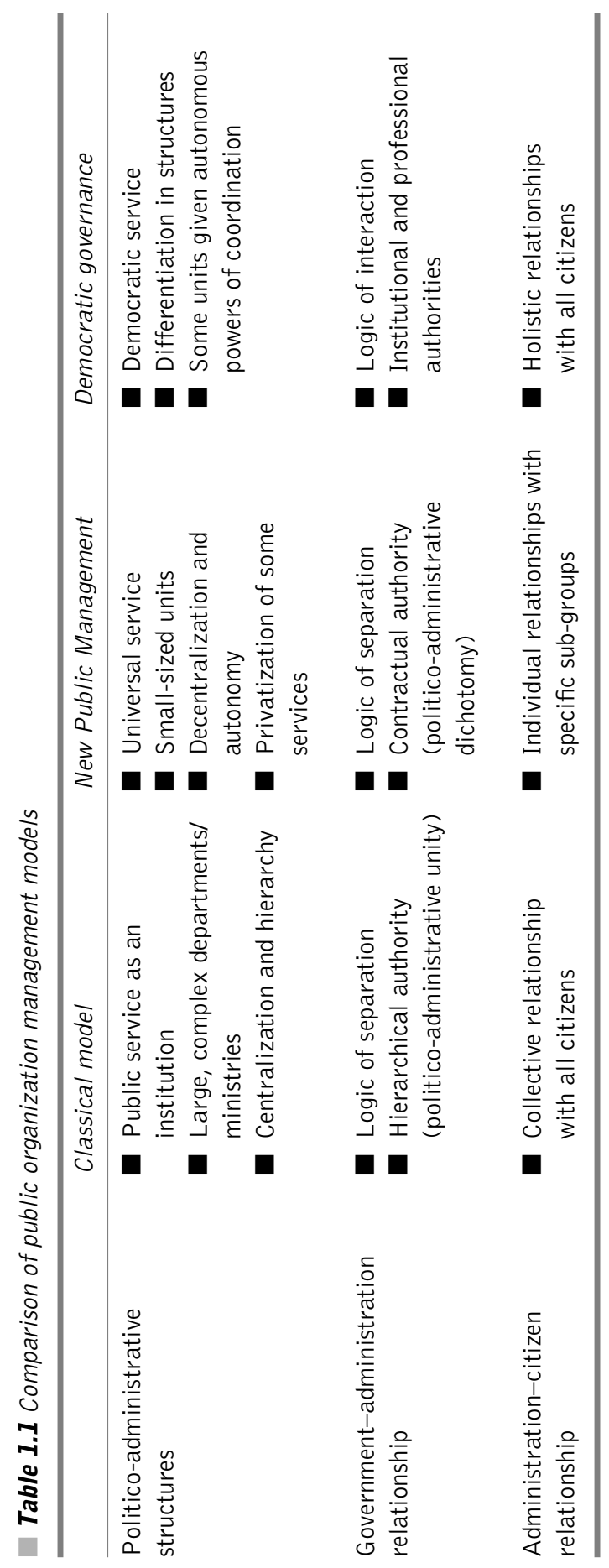


Governance. These concepts are compared with respect to administrative bodies' basic structure - size, degree of centralization and autonomy, etc. In addition, comparisons must be made on the basis of the relationships these bodies develop with supervisory authority such as political institutions and beneficiaries of services.

The last criterion, relationships with beneficiaries, is of greatest importance to this book because it will directly influence marketing activities. See Chapters 2 and 3 in particular.

In the Weberian model, an organization develops standardized services for all citizens while in marketing, considerations are virtually absent. Standing in stark contrast is the New Public Management model. Here, development and production of services are aimed at satisfying the organization's clients where a degree of individualization of the relationship can be envisaged.

In this case, marketing assumes great importance for the organization precisely because it is evaluated on its capacity to satisfy clients. Bridging the two approaches and offering greater consideration to institutional aspects, Democratic Governance allows room for a special relationship between administration and beneficiaries, while keeping this relationship within a stable institutional framework.

\section{CONCLUSIONS}

Management in the public sector has numerous specifics, making it distinct, in all important ways, from management in the private sector. These factors - status, objectives, tasks, and environment - have a greater impact on strategies and tools which can effectively be used by policy-makers and public managers.

Three specific models of public sector management, Weberian, New Public Management, and Democratic Governance, all entail specific approaches and objectives. Additionally, all define the beneficiary of public services in a slightly different way. These models - and their overlapping nature in today's public administrations - frame the way in which marketing in the public sector can be envisaged. It is on these essentials, and with corresponding limitations in mind, that this book explores the realities and possibilities of marketing in the public sector.

\section{EXERCISE 1.1}

On the basis of the description of the three models of management (Weberian, New Public Management, and Democratic Governance) identify what specific practices in your organization would fit into each of these models, focusing on elements related to:

- the organizational structure

- human resources strategies

- communication initiatives

- service delivery. 


\section{DISCUSSION QUESTIONS}

1. What are the implications, from both management and marketing standpoints, operating in an organization inspired by:

(a) The Weberian System?

(b) New Public Management?

(c) Democratic Governance?

2. Do organizations define themselves according to one particular management approach, or do they generally combine features from more than one? If so, how are these features combined in your organization?

\section{REFERENCES}

Allison, G. T., Jr. (1979) Public and Private Management: Are They Fundamentally Alike in All Unimportant Respects? Public Management Research Conference, Washington, DC, Office of Personnel Management.

Boyne, G. A., Farrel, C., Law, J., Powell, M., and Walker, R. (2003) Evaluating Public Management Reforms, Buckingham, Open University Press.

Buchanan, T. G. (1962) The Calculus of Consent: Logical Foundations of Constitutional Democracy, Ann Arbor, University of Michigan Press.

Chevallier, J. (2002) Science Administrative, Paris, Presses Universitaires de France.

Dardot, P. and Laval, C. (2009) La nouvelle raison du monde, Essai sur la société néolibérale, La Découverte, Paris, 353-400.

Florini, A. (1998) The End of Secrecy, Foreign Policy, 111, 50-63.

Gortner, H. F., Mahler, J. and Nicholson, J. B. (2002) La Gestion des Organisations Publiques, Sainte-Foy, Presses de I'Université du Québec.

Kaplan, A. M. and Haenlein, M. (2009) The Increasing Importance of Public Marketing: Explanations, Applications and Limits of Marketing within Public Administration, European Management Journal, 27, 197-212.

Meijer, A. (2013) Understanding the Complex Dynamics of Transparency, Public Administration Review, 73, 429-39.

Merrien, F.-X. (1999) La Nouvelle gestion publique : un concept mythique, Lien social et politiques, 41, 95-103.

Osborne, D. and Gaebler, T. (1993) Reinventing Government: How the Entrepreneurial Spirit is Transforming the Public Sector, New York, Penguin Group.

Pasquier, M. and Villeneuve, J.-P. (2007) Organizational Barriers to Transparency: A Typology and Analysis of Organizational Behaviour Tending to Prevent or Restrict Access to Information, International Review of Administrative Sciences, 73, 147-62.

Pollitt, C. and Bouckaert, G. (2000) Public Management Reform, A Comparative Analysis, Oxford, Oxford University Press.

Rieder, S. and Lehmann, L. (2002) Evaluation of New Public Management Reforms in Switzerland, Empirical Results and Reflections on Methodology, International Public Management Review, 3, 25-43. 
Schwartz, H. (1994) Small States in Big Troubles: State Reorganization in Australia, Denmark, New Zealand, and Sweden in the 1980s, World Politics, 46, 527-55.

Weber, M. (1921) Wirtschaft und Gesellschaft: Grundriss der Sozialökonomik, Tübingen, Mohr.

Wollmann, H. (ed.) (2003) Evaluation in Public-sector Reform: Concepts and Practice in International Perspective, Cheltenham, E. Elgar. 


\section{Marketing and public marketing}

\section{LEARNING OBJECTIVES}

By the end of this chapter you should be able to:

- Understand the evolution and transformations of the concept of marketing.

- Identify the elements leading to the development of public marketing.

- Identify situations in which public-sector marketing is possible.

- Analyse the characteristics of a public marketing setting and identify the limits they impose.

\section{KEY POINTS OF THIS CHAPTER}

- Marketing deals with three fundamental questions surrounding the notion of exchange: its nature; the partners involved; and the necessary processes for a satisfactory exchange.

- Primarily, it is the enlargement of the concept of exchange in marketing; the increasing importance of the beneficiary of public services; and the reactivity to its needs. This is why public-sector marketing has emerged.

- The logic of marketing is not applicable to all public-sector settings. Therefore, the type of exchange and nature of relationships define when marketing is possible - notably in situations of free exchange and free relationships.

- The characteristics of public marketing must be well defined in terms of market, organization, exchange and relationship. 


\section{KEY TERMS}

Marketing - the activity, set of institutions and processes for creating, communicating, delivering, and exchanging offerings which have value to customers, clients, partners, and society at large.

Exchange - trade that must respect the following criteria: two or more parties; each have something of value to the other; each derive benefits from the exchange; the exchange is voluntary. The contents of the exchange are elements being traded in a relationship. They can have tangible aspects and value, but also represent symbols, ideas, and values.

Parties to the exchange - individuals and/or an organization involved in the trade. The exchange can be 'restricted' - two parties; 'generalized' - at least three parties; or 'complex' - numerous partners and an ensemble of interconnections.

\section{INTRODUCTION}

Marketing is a widespread concept, and its role is becoming increasingly important to the commercial success of private-sector firms. Its use in the public sector is far from simple given that marketing is associated with advertising, sales, persuasion, and even manipulation.

This chapter introduces the general concept of marketing and how it has evolved. Following this, ways of using marketing in the public sector, reasons for its development, and its corresponding limitations will be discussed.

\section{THE CONCEPT OF MARKETING}

There is no single recognized definition of marketing. Depending on the object of study or the chosen theoretical orientations, marketing may take different forms. Hundreds of definitions have been proposed and analysed (Ringold and Weitz, 2007; Grundlach, 2007). The American Marketing Association (AMA, 2007), defines it as follows: 'Marketing is the activity, set of institutions and processes for creating, communicating, delivering, and exchanging offerings that have value for customers, clients, partners, and society at large.'

We first need to understand the main developments of marketing as a concept since it first appeared in the early years of the twentieth century, and identify central issues. Given the goals of this book, the next two sections concentrate on the main reasons why public-sector organizations are so interested in marketing. 


\section{Development of the concept}

The first writings about marketing were produced in the United States by Sparling (1906), Hoyt (1912), Weld (1916), Copeland (1920), and White (1921). These were followed by the Principles of Marketing, a work of synthesis by Beckman, Maynard, and Davidson in 1927. Research focused on the question of distribution - primarily of agricultural products - market observation and sales force management. Without wishing to write a history of marketing, one may highlight three developments, as illustrated in Figure 2.1.

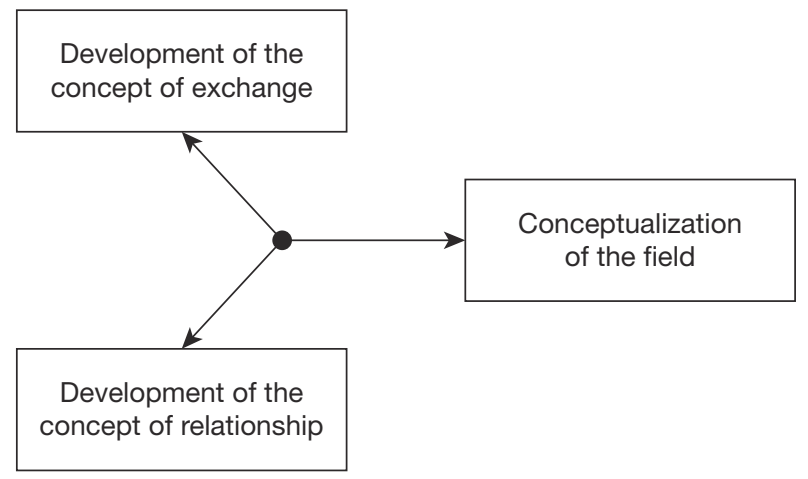

Figure 2.1 Main orientations in marketing development

Marketing developed considerably in the twentieth century with the emergence of concepts and models still used today (see Box 2.1). All these developments have continued into the present by:

- integrating deeper analyses of distribution systems and competition strategies;

- the internationalization and globalization of companies' commercial activities; marketing within companies' functions as a whole;

- new modes of communication;

- a systemic approach to ecological, judicial and societal aspects of the corporate environment.

Without questioning the conceptual developments cited above, various post-war authors looked at the content of exchange between an organization and its clients. Gardner and Levy - (1955) and Levy (1958) - first drew attention to the fact that the object of the exchange exceeded the utilitarian function of a product. They did this by integrating reflection about the brand and the symbolic element of the goods exchanged.

Kotler and Levy (1969) broadened the field of marketing study by redefining the concept of exchange content. To these authors, organizations do not merely exchange 


\section{BOX 2.1 MOST IMPORTANT DEVELOPMENTS IN MARKETING}

- Products' life-cycle (Dean, 1950)

- Market segmentation (Smith, 1956)

- McKitterick's marketing concept (1957) putting client orientation within an integrated approach

- The marketing mix, involving the homogenous regrouping of the entire range of marketing instruments (McCarthy, 1960; Borden, 1965)

- Study of lifestyles as a basis of segmentation (Lazer, 1963)

- Analysis of buyers' behaviour (Howard and Sheth, 1969)

- Positioning of the product (Ries and Trout, 1976)

- Initial reflections on the marketing of services (Shostack, 1977; Kotler and Connor, 1977) as increasingly separate from the traditional marketing of consumer goods

- Recent developments regarding the relations with customers: Relationship Marketing (Robert, Schurr, and Oh, 1987), One-to-One Marketing (Peppers and Rogers, 1993), Marketing 2.0 (Constantinides and Fountain, 2008).

products with their clients, but also symbols, ideas, and values. This broader concept of marketing has, among other things, made it possible to transpose it in other areas such as non-profit, social, political, and public sectors.

The third development concerns the relationship between the organization and its clients. With products and services of various brands becoming increasingly interchangeable, along with increasing costs of each brands' development and management, several authors (Berry, 1983; Jackson, 1985) have highlighted the importance of the relationship established within - and above all outside - the exchange rather than that of the object being exchanged.

Many clients choose a product or service not just according to the item being exchanged, but also on the basis of a relationship established before, during, and after the exchange. Organizations therefore develop marketing activities outside the moment of exchange. This is done to acquire clients and retain their loyalty, with the quality and intensity of the relationship taking precedence over the value of the object exchanged. Marketing is thus defined as a social process composed of exchanges and social relationships.

\section{Basic paradigm}

Although marketing concepts vary, it is nonetheless possible to highlight the leading questions marketing deals with today: 
- What is the nature of the content of the exchange?

- What are the relationships between the various exchange partners?

- Which processes need to be introduced for the partners to be satisfied by the exchange?

Given that marketing aims, through an exchange, to transfer something of value from an organization to a client or beneficiary, it is particularly important to look at what this 'something' involves. Initially, the development of basic marketing concentrated on material products or tangible goods. However, later studies concluded that this approach no longer sufficiently dealt with the increasingly complex reality of most organizations' marketing requirements.

In 'Marketing as Exchange' (1975), Bagozzi - carrying on where Kotler and Levy (1969) and Kotler (1972) left off - highlighted various exchange characteristics, suggesting that exchanges include a growing share of intangible and symbolic elements. Often, this can involve more than two parties at the same time.

On this basis, Bagozzi defined three types of exchange:

- 'restricted exchange' involving just two parties;

- 'generalized exchange' involving at least three parties, each making a contribution to the exchange while receiving something in return such as a gift;

- 'complex exchange' involves numerous partners organized through an ensemble of interconnections and relationships.

For example, when you order a book on the internet, various actors take part in the exchange. The order taker receives your instruction and locates the book in the company's catalogue. The publisher or distributor who has the volume in stock informs the shipper. The shipper is in charge of transporting the book you have ordered. Finally, a financial service is used to collect payment.

Redefining the object exchanged and the framework of the exchange have helped broaden the notion of marketing. Kotler (1967) notes that it can be applied to 'any social unit keen to exchange values with other social units'. Thanks to this approach, marketing can be applied not just to goods and services but also to events, persons, places, information, and ideas.

Marketing is also concerned with the relationship developed between exchange partners, independent of the content of the exchange. These include the following.

- how much one party knows about the other;

- their social relationship outside the exchange process;

- how often they meet, and what form these meetings take - physical or not;

- the formal context of the relationship. Context involves key factors which can influence the degree of client loyalty; the moral constraint of the exchange linked to the relationship with the vendor; and the perceived value of elements exchanged. 
Relational marketing thus looks to create, and above all, conduct a relationship established with a client, whether actual or potential, so that the relationship elicits and maintains the exchange process.

This relational aspect has assumed considerable importance in marketing especially in services marketing. However, the concepts used and the tools developed may be applied to any area where the relationship between parties is just as, if not more, important than the elements of exchange.

The third area marketing is concerned with the tools and processes behind a satisfactory exchange for all parties involved and how the relationship between these parties is conducted. It involves themes linked to market structure such as:

- segmentation and positioning; processes for analysing market actors - clients, competition, intermediaries, suppliers - and their behaviour;

- acquiring and managing market information;

- establishing marketing strategies;

- instruments that may enhance this offer such as price, communication, or distribution; and

- systems for controlling and piloting marketing activities.

This more instrumental approach to marketing is, of course, fundamental for organizations and a number of methods are used in both the commercial and noncommercial sectors. This tactic consists of obtaining data about clients or users, analysis of satisfaction, planning an advertising campaign, etc.

Although marketing has naturally developed its own tools (see Chapter 4), it has also extensively borrowed tools and concepts from many other fields, which provide a rich field of application.

For example, there is growing use of statistical and mathematical tools in modelling; understanding marketing phenomena; ethnological, anthropological, and semiotic contributions used to comprehend and structure the behaviour of the parties involved in an exchange. As well, aspects have been taken from management science, and applied to marketing activities such as controlling, organization, etc.

\section{FROM MARKETING TO PUBLIC MARKETING}

The application of marketing tools and concepts to the public sector has followed three trends. First, according to Kotler et al. (2002), Butler and Collins (1995), and Burton (1999), marketing should be very broadly defined, and consequently include all the exchanges between social units. The public sector may therefore be contextualized within a marketing approach, allowing all public services - social, cultural, sporting, or educational in nature - to be included in marketing.

Others have been more critical of such an acceptance of marketing, and consider exchange criteria - product, price, etc. - and relationship criteria need to be fulfilled before the corresponding tools can be applied. 


\section{Marketing}

- Broadening of the concept of exchange (from commercial to non-commercial)

- Development of the relational component of the exchange

- Use of new tools and techniques (communication, collection and analysis of data, etc.)
The exchange follows a negotiation

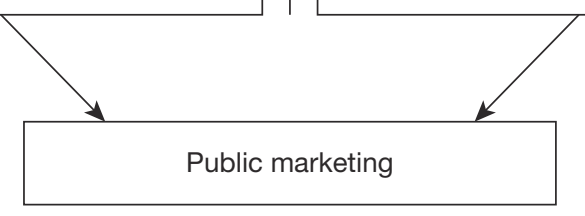

\section{Public management}

- Development of the State's economic activities (transport, energy, communication, etc.)

- Development of services to citizens

- Greater independence given to certain administrative entities (agentification)

- Importance of the satisfaction of service beneficiaries (quality management, satisfaction measurement)

- Emergence of a more individualized relationship between administration and citizen

The exchange follows a political decision

Figure 2.2 Bases of the development of public marketing

Finally, Cousins (1990) and Greffe (1999) concentrate solely on how appropriate marketing tools can apply to public body dynamics. But are such tools relevant to the context and goal? Surprisingly, the more fundamental question of pertinence does not arise in either researcher's investigation.

Applying marketing concepts to the public sector is the result of merging developments in both marketing and public management (see Figure 2.2).

Broadening the concept of marketing to include reinforcement of the relational aspect of the exchange plus the dynamic development of marketing tools and techniques enables non-commercial aspects of exchanges to be taken into account. These tools and concepts - systems for obtaining and handling information, cost-analysis systems, communication and distribution tools, etc. - may then be applied to the public sector.

At the same time, the notion of public administration and its management models have evolved considerably over the last 20 years. The State has developed its economic activities and services for citizens - requiring the use of tools, notably marketing tools, from the private sector.

Concurrently, with the creation of agencies, many administrative units have been rendered partially autonomous, providing them with the opportunity to choose alternative approaches, diverging from the traditional public administration model. Some such agencies have developed hybrid management models that reflect the public nature of their organization. This has been achieved by developing exchanges of a more 
commercial nature, but above all, by customizing the relationship with service beneficiaries.

Furthermore, given the ideas of New Public Management - and the fact that service quality is no longer measured by the authority but by the beneficiary - administrative units have been encouraged to take account of the relational aspects of the exchange. Therefore, the corresponding tools for measuring service quality and the satisfaction of beneficiaries can be applied.

Along with the above aspects, two other points should be considered in order to understand the growing use of marketing in the public sector: the growing uncertainty affecting public bodies; and the need to strengthen social ties.

Nevertheless, public bodies are politically defined and are required to improve the quality of services as well as pay attention to citizens' needs. However, because governments have introduced competition to the provision of public services, these bodies also face increasing uncertainty exacerbated by the fact that their financing is often partly dependent on results.

However, today's public bodies have the ability to reduce their financial uncertainty, to a measurable extent, by using traditional marketing tools. All they must do is better appreciate the needs and expectations of the beneficiaries of public action, detail the content of the exchange or offer, and enhance communication concerning the offer (see Box 2.2).

Along with the specific roles of public management, it is still worth considering the new functions it has assumed, notably those involving social ties. Given the destructuring of social ties, and their 'virtualization' through social networks like Facebook or Twitter, society needs to maintain - if not (re-)create - social links among its members.

Public management can play a key role here by promoting discussion, encouraging citizens' participation, seeking to remain close and accessible to persons who are socially and physically isolated, and so on. In such situations, and outside all forms of exchange, relational elements are very important and are useful lessons to be applied to relational marketing.

For two fundamental reasons, it is not possible to determine whether or not marketing can really be applied to the public sector. First, the public sector is not a homogenous entity, as it includes both services of a commercial nature - hospitals, tourism, etc. and activities involving constraints - prison, taxation, and the like. So some public sector elements are very close to the private sector with the application of marketing tools posing no real problem. For example, postal services, in many countries, remain a public entity.

Secondly, in some cases, the same public body may also offer both freely available fixed-price services; while at the same time oblige citizens to respect norms or provisions. This is true of the police, who may use force to inspect vehicles or stop drivers, arresting the latter if they break the law. Yet, the police may also charge an event-organizer for their safety services during an event. Therefore, generalizing marketing throughout the public sector, without deeper analysis of the notions of relationship and exchange is not easy. 


\section{BOX 2.2 INTRODUCING COMPETITION TO SWISS UNEMPLOYMENT FUNDS}

Like most countries, Switzerland offers unemployment benefits, providing subsidy payments to the unemployed and counselling to help them find new jobs.

The Swiss benefit-payment system involves competition between public and private funds. Each Canton is legally required to have a public fund for its residents. As well, social partners - employers' and workers' unions - may also create an unemployment fund.

The unemployed therefore have a free choice of funds. Some Cantons have only a public fund, while others have a public fund as well as more than ten private ones. Although benefit assessment may not differ from fund to fund, competition exists with regard to the service provided such as how quickly benefit is accorded and paid out, proximity to one's home, etc.

At the federal level, the State regulates the system by paying each fund compensation for services provided, based on the fund's average costs over the previous year. A fund whose operating costs were above average must therefore finance the shortfall itself. Conversely, funds whose costs were below average may keep the profit. Some public funds even pay part of this profit to their employees.

Several pre-conditions, needed to create an exchange in the broader marketing sense, have been defined by the following factors (Kotler, 1967; Kearsey and Varey, 1998; Gilly and Dean, 1984):

- At least two parties are involved.

- Each party owns something that may be of value to the other.

- Each party derives benefit - monetary value, satisfaction, etc. - from the exchange.

- The exchange must be voluntary with the parties free to accept or decline the other's offer.

Similarly, two conditions are required for us to speak of a relationship in an exchange:

- personal interaction

- freedom within the relationship - no constraint can be involved.

Although these criteria are fulfilled in a number of cases, enabling Buurma (2001) to structure the objects exchanged and steps of the exchange in the public sector, authors like Scrivens (1991) or Kearsey and Varey (1998) are highly critical. They insist that many services provided by public bodies do not fulfil these conditions.

This may be because there is no satisfaction for one of the parties in the exchange. For example, the exchange is not voluntary when a person is required to pay taxes; 
Table 2.1 Public-sector provider-user relationship

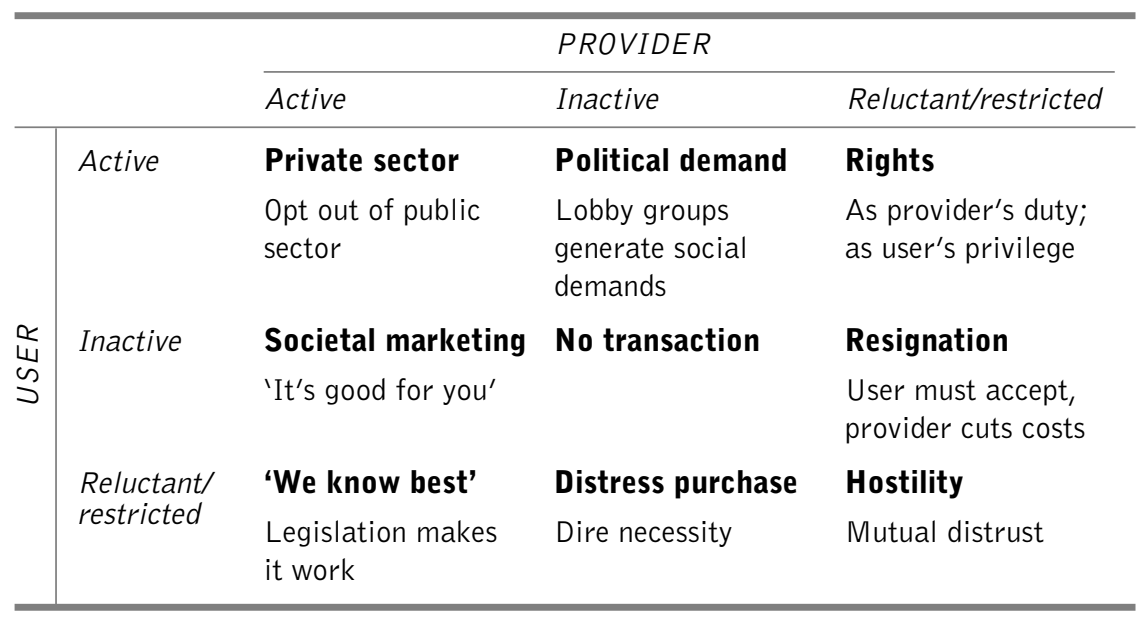

Source: Chapman and Cowdell (1998: 42).

or ordered to take their vehicle in for a Ministry of Transport test; or while the relationship involves constraint - such as when the police stop a vehicle on the road.

Chapman and Cowdell (1998) aimed to define the fields where marketing can be used by constructing a model based upon possible relationships between the user and the organization providing the service (see Table 2.1).

Although this proposition helps establish a typology of public-sector relationships, it only allows for limited integration of the exchange issue. To define situations where marketing can be applied from situations where the basic conditions are not fulfilled, we need to confront the types of exchange and the nature of the potential relationships between the parties. Table 2.2 presents the results of this confrontation.

In the first scenario, one of the participants is obliged to enter a forced relationship where there is no exchange. This frequently occurs in the public sector. A police arrest and a summons from a judge are concrete. They are important events where marketing is absent from public-sector considerations.

Obviously, there is no satisfaction for one party, or freedom within the relationship. Also, to protect people from arbitrary use of force, such situations are clearly codified in democratic systems, with strict rules about the use of force - procedural codes, administrative directives, and so on

This obviously does not mean public administration and public agents do not have to follow the elementary principles of modern society. They still must show respect to others by listening, displaying a minimum of empathy, and bearing in mind other people's characteristics, such as having a handicap or not being able to understand the language.

They also must have the ability to communicate - to clearly explain situations, delineate expectations, and justify decisions taken - all in a comprehensible fashion. 
Table 2.2 Potential areas for applying marketing to the public sector

\begin{tabular}{l|l|l|l}
\hline & $\begin{array}{l}\text { Absence of } \\
\text { exchange }\end{array}$ & $\begin{array}{l}\text { Forced } \\
\text { exchange }\end{array}$ & $\begin{array}{l}\text { Free } \\
\text { exchange }\end{array}$ \\
\hline $\begin{array}{l}\text { Forced } \\
\text { relationship }\end{array}$ & No marketing & Selective use of marketing tools \\
\hline $\begin{array}{l}\text { Semi-free } \\
\text { relationship } \\
\text { tools }\end{array}$ & $\begin{array}{l}\text { Elements of } \\
\text { relational } \\
\text { marketing }\end{array}$ & $\begin{array}{l}\text { Possible application of the conceptual } \\
\text { approach to marketing and corresponding } \\
\text { tools }\end{array}$ \\
\cline { 1 - 2 } Free relationship & & \\
\hline
\end{tabular}

As well, they must point out individual's rights etc. But, even if some of these elements are used in relational marketing principles, they are nonetheless not enough for such public service activities to be approached from a marketing standpoint.

In a situation where exchange is absent but where there is no constraint, it is possible to have an approach that treats aspects of relational marketing more systematically. As we shall see later on, some activities of public bodies do not involve providing services to people; instead they develop, set up and monitor public policies.

All activities, not leading to an exchange, may involve persons or groups of people, because data will need to be collected, analysed, and discussions held with representatives of these persons, etc.

When an expanding municipality needs to review its public transport network, or organize a bid for a corresponding concession, it can issue a questionnaire. Alternatively, it could stage an information session, or encourage dialogue via an internet forum, or even the use of suggestion boxes in places like the post office or City Hall, etc. All would assist the municipality to learn about individuals' transport habits. Depending on the activity and the institutional context, relational marketing principles may be used to help establish a long-term and positive relationship.

Another situation, involving a similar lack of exchange within a relationship, can be found in social links maintained by the administration. Through its physical presence, the administration helps maintain a social link without providing a tangible service. Again, some aspects of relational marketing may be useful in providing clarity and follow-up accessibility within these relationships.

It is a different matter if the relationship involves constraint, although a degree of exchange nonetheless exists. For instance, in many countries, a periodic technical inspection of motor vehicles involves an actual service. A governing body grants permission to drive the vehicle on public roads. However the owner of that vehicle is obliged to guarantee it sufficiently meets safety norms.

Given the frequent lack of freedom in the relationship between the administration and the service beneficiary, it is not possible to apply all marketing principles such as segmentation of needs, expectations, or behaviour patterns, or the positioning of the offer. Thus there is little or no competition, no possible price differentiation for 
the service, etc. Yet administrative bodies can still apply a number of marketing tools to their mode of operation.

Service providers - for example, an operator of a service centre - can increase his use of communication tools to improve and simplify various processes with the customer. This could be done by providing the means to make appointments via the internet or by using the very latest payment/pre-payment methods. Yet another way to systematically improve service and the relationship with beneficiaries would be to introduce surveys rating customer satisfaction or quality of service. The same could be applied to the schooling of children, taxation, etc.

If the relationship is partially free and an exchange takes place, then a more constructed marketing approach can be adopted. The simplest instance occurs, when both the exchange and relationship are totally free and the public body can act largely like a private enterprise - albeit within the existing legal context. Short-term professional training courses in universities fulfil such criteria since they have tremendous latitude to accept participants or not, and they are free to decide the offer's content and form.

However, in the public sector, freedom within the relationship is often limited to accepting or not accepting the corresponding service. An excellent example is whether or not to be connected to the electricity grid or telephone network. On the other hand, the choice of operator is not always open. Therefore, the offer and terms of the exchange are imposed. The capacity of public bodies to use marketing tools, and their interest in doing so, lie in introducing differentiation criteria to the offer, and the potential involvement of beneficiaries in the exchange. Table 2.3 outlines some relevant situations.

Public bodies have more and more opportunities to introduce elements of differentiation into their offers, providing they respect the basic or minimal offer as legally stipulated. For instance, they could offer complementary or free services, or differentiate prices or access to the service:

- Differentiation in the offer of services: universities must adapt their course offers, develop a specific profile, and provide training that respects laws of the market, etc.

- Differentiation of price: public transport bodies have complex pricing systems based on socio-demographic criteria - young people, families, unemployed, pensioners etc. as well as concentration of use, and even time of use - evenings, weekends, etc.

- Differentiation in access to the service: in recent years, fiscal authorities have developed a range of ways of completing tax forms - the traditional written form, software, declaration online, etc.

The beneficiary's personal involvement is often used in marketing, especially in communication (Kapferer and Laurent, 1985). It corresponds to a person's or organization's level of engagement in the process of buying and/or consuming. If, the 
Table 2.3 Differentiating offer and personal involvement of beneficiaries

\begin{tabular}{l|l|l|l}
\hline \multicolumn{2}{c|}{} & \multicolumn{2}{|l}{ Degree of involvement in the relationship } \\
\cline { 2 - 4 } & Low & High \\
\hline \multirow{2}{*}{$\begin{array}{l}\text { Degree of } \\
\text { differentiation } \\
\text { in the offer }\end{array}$} & Hestricted marketing & $\begin{array}{l}\text { Primacy of relational } \\
\text { marketing }\end{array}$ \\
\cline { 2 - 4 } & High & $\begin{array}{l}\text { Primacy of the offer } \\
\text { and of the content of } \\
\text { the exchange }\end{array}$ & Full marketing \\
\hline
\end{tabular}

beneficiary, purchase or consumption present major risks - financial, social or personal - it is likely they will be closely involved in the decision or consumer process. They will actively research and analyse information, engage in bargaining, and so on.

If someone needs a building permit, they seek the relevant information or pay a third party such as an architect or solicitor to ensure the procedure is respected. Conversely, if the risks are limited or non-existent, people tend to reduce their involvement as much as possible, which is routine behaviour. This is the case with household waste disposal. Householders want to know when and how it is collected, and then adopt a behaviour pattern accordingly. Therefore, a distinction is usually made, between high or low involvement situations (Rossiter et al., 1991).

The first situation to consider occurs when a public body has no way of differentiating between the offer of services and the beneficiary's involvement is minimal. Marketing activities in such a case are limited to merely providing clear, transparent information, and to develop the simplest possible procedures. A good example is renewing a passport or ID card. The administration cannot differentiate this service since identical documents and fees are the same for everyone. Here, the citizen's interest is limited to wanting clear information about the process, the waiting time, cost, and above all, having access to the service as simply and quickly as possible.

The second instance again concerns a minimal level of beneficiary involvement, but a greater possibility for the public body to differentiate the service. In the occurrence of collecting household waste, most local communities have developed services such as systematic collection on a particular day of the week. Thus, scheduling information can easily be conveyed by email, SMS, or other forms of social media. Such a service would allow residents, and especially new residents, to dispose of their waste as quickly and easily as possible.

A third situation occurs when beneficiaries are strongly involved, but the organization cannot differentiate the offer. A typical example is mandatory schooling of children. Basic public school services are generally homogenous and may be only slightly differentiated. However, the involvement of parents - and pupils, when possible - means relational aspects become very important and may be considered from a marketing standpoint. 
A fourth and final illustration should also be considered. This situation occurs when the public body can differentiate its offer according to beneficiary, and when the latter is closely involved in providing the service. This involves the usual examples mentioned in articles about public marketing and concerns promoting 'places' - country, region, or town - from an economic or touristic point of view (Kotler et al., 1993; Ashworth and Kavaratzis, 2009).

Companies looking to set up in a new area seek a range of information and look to benefit from fiscal competition among regions, etc. The regions, meanwhile, adopt sophisticated marketing strategies to convince companies to select them.

\section{CHARACTERISTICS OF PUBLIC MARKETING}

\section{Public marketing and marketing of public services}

The nature of the public sector as a whole is heterogeneous. Therefore, by examining individual characteristics of each field within the sector, one may distinguish between public marketing in the narrow sense, and public service marketing in the broad sense of the term (see Figure 2.3).

Public marketing involves marketing services provided by public bodies. As well, the marketing of specific public-sector domains such as social marketing, place marketing, or museum marketing. As the characteristics of these domains are important in the development of marketing, and the corresponding organizations often enjoy a particular autonomy in performing their assigned tasks and academic studies tend to treat them in a specific way. This happens even when the proposed tools differ only slightly from one domain to the next. Box 2.3 takes the example of place marketing, which includes marketing activities aiming to promote a geographical entity such as a country, city or political region.

However, the marketing of public services is not limited to services provided by public bodies. A number of public services are delegated to non-profit organizations (NPOs), and enjoy greater autonomy in conceiving, delivering, and promoting these services. Finally, a certain number of public services, such as the post office, telecommunications or energy, are provided by public or private bodies, but are essentially based on traditional marketing.

\begin{tabular}{|l|l|l|l|}
\hline $\begin{array}{l}\text { Marketing of } \\
\text { services delivered } \\
\text { by public } \\
\text { administrations }\end{array}$ & $\begin{array}{l}\text { Marketing of specific } \\
\text { domains in the public } \\
\text { sector: social marketing, } \\
\text { place marketing, } \\
\text { museum marketing, etc. }\end{array}$ & $\begin{array}{l}\text { Marketing for non- } \\
\text { profit organizations } \\
\text { mandated to deliver } \\
\text { public services }\end{array}$ & $\begin{array}{l}\text { Marketing for highly } \\
\text { regulated sectors } \\
\text { with public services: } \\
\text { post, telecom, energy, } \\
\text { etc. }\end{array}$ \\
\hline
\end{tabular}

Figure 2.3 Public marketing and marketing for public services 


\section{BOX 2.3 PLACE MARKETING}

Place marketing is probably the sector of public marketing that has received the widest attention. The marketing of a place may be done for a number of reasons - to attract foreign investors, to draw a certain type of tourism, or to give and/or enhance a city's reputation along a certain number of lines. Many initiatives have been launched. The most famous is New York with its 'I love NY' logo.

By the mid-1970s, the State of New York was in a dire financial situation and dealing with problems of crime and general insecurity, causing businesses and tourists to stay away. At the time, according to a survey initiated by the State, the tourism industry represented a net loss of some $\$ 16$ billion. Following this, a large marketing campaign was launched to create a 'catchy' logo and slogan. The campaign was launched in 1977 with the slogan rapidly appearing on all sorts of merchandise from bumper stickers to coffee mugs. To this day, it is the most recognized emblem of the Big Apple. After the event of 9/11 the logo was updated by the creator, Milton Glaser, to 'I Love NY More than Ever'

Source: Godfrey, 1984; Bartel 2002.

\section{Main characteristics}

As described in the previous chapter, the public sector differs from the private sector on several counts. Similarly, characteristics of the marketing of public services must be differentiated from those of private products and services. Table 2.4 offers a synthetic overview of the particularities of marketing of public services by identifying four kinds of characteristics:

- Characteristics linked to the 'market': elements concerning service offer and demand.

- Characteristics linked to the organization: elements corresponding to the possibilities and limits for the organization to develop marketing activities.

- Characteristics linked to the exchange: aspects concerning elements of the exchange.

- Characteristics linked to the relationship: elements linked to the relationship between organizations and public service beneficiaries.

\section{REASONS FOR THE DEVELOPMENT OF PUBLIC MARKETING}

Fundamentals explaining the overall development of marketing in commercial organizations include development/content of exchanges, social relationships, intermediation systems, etc. However, various other elements more specifically clarify the development of marketing in the public sector. 
Table 2.4 Characteristics of public service marketing

\begin{tabular}{ll} 
'Market' & Relationships between offer and demand are particular, \\
characteristics & sometimes non-existent such as the offer and demand for a \\
paying service. In the instance of an ID card, they are practically & linear \\
& Demand does not just depend on individual needs, but also on the \\
devolution of some individual rights by the state & Access to the 'market' is limited, both at the offer level \\
& (monopoly, licences) and the demand level since the law defines \\
& access rights \\
\hline Organization's & The law defines the framework/limits of the action of the \\
characteristics & organization providing the service \\
& Limited autonomy and flexibility in conception of services, and in \\
& setting prices and possibilities of access to service \\
& The organization must tackle multiple goals, mostly of a non- \\
& commercial nature \\
& Marketing activities and measures are difficult to evaluate \\
& Sizable political control of the organization \\
\hline Relationship & Public services are collective entities - non-rival, non-exclusive, \\
characteristics & indivisible \\
& Offer is usually unique and non-competitive with no or little \\
differentiation in the offer, coupled with no or few competing \\
offers \\
No exclusion from use of services \\
Balanced exchange is problematic to estimate and attain \\
Personal involvement is often intense \\
Negotiations are collective, not individual \\
\hline
\end{tabular}

The first reason for developing public marketing can be found in increased competition in the public service offer. This approach, derived from New Public Management (NPM), seeks to offer service beneficiaries a choice between various public and/or private services. Such services may include issuing vouchers to parents of young children to be redeemed in public or private kindergartens.

This trend is accentuated by the fact that choosing the body to perform a public task as well as the relationship between the public body and the individual is subject to ever-increasing analysis and dialogue steeped in economic terms. Here, the chief points to be discussed would be cost of the transaction, agency costs, etc.

Consequently, the operator chosen to perform a public task is no longer automatically the central public administration. It can take on varied forms such as public 
or private operators, hybrid systems, etc. Furthermore, rather than assign these tasks to private operators, the State encourages competition by introducing internal markets and quasi-markets, obliging public operators to take management and marketing elements into account.

Independent of the influence of NPM, several public-sector domains have embraced direct competition. This is the circumstance, when countries, cities, and regions compete to attract or keep residents and companies, host sports or cultural events, congresses, and so on.

Even if public services are not the same as private ones, the attitude of beneficiaries as consumers is increasingly similar. In terms of service quality, information as well as the relationship with the public body, 'consumer requirements' no longer differ depending on whether they are public or private. As a result, public bodies must also take these expectations and demands into account when conceiving and providing services.

At the same time, citizens are increasingly insistent about their rights and demand more 'individual' treatment of their needs and there are various reasons for this. Although equal treatment can lead to waste of resources and economic inefficiency, the public sector must, within an increasingly difficult economic context, pursue more rational approaches when providing services - and consider other principles such as opportunity.

One may also add that, given rising citizen participation, service beneficiaries are ever keener to be associated with the conception of public services, and this is likely to alter the relationship between the public body and citizens.

The State's responsibilities in economic activities are more and more extensive the financial sector, energy, tourism, transport, postal, telecommunications, arms, etc. Yet, even if the corresponding bodies enjoy considerable management autonomy and apply traditional marketing rules, they must also bear in mind certain public service characteristics.

Finally, public bodies are looking to improve their relationship with beneficiaries. They do this for two reasons. Public bodies are judged all through their relationships with the public. This may take the form of satisfaction surveys or any number of other information-gathering tools.

However, beneficiaries' potential reactions such as demonstrations or public support may legitimize the organization's action and services. This is something that can prove decisive if funds are short. Therefore, public bodies have good reason to develop marketing activities in order to heighten service beneficiaries' awareness and boost support of the organization's activities.

\section{LIMITS OF PUBLIC MARKETING}

As we have seen in the previous section, if marketing tools - or even a thoroughgoing marketing approach - can be envisaged for public services, serious limits must be acknowledged about the use of marketing in the public sector in general. 
Some of these limitations are obvious enough and follow on from characteristics mentioned earlier. Public bodies often act in the absence of a veritable market but supply and demand can rarely be made to fit a traditional model. Nor is it easy to obtain a balanced exchange between the parties involved. The relationship between information and power is greatly in favour of the public body.

The administration's tasks are not restricted to merely providing services for beneficiaries. They also include developing public policies, for which marketing is only of limited use. Along with noting the absence of commercial aspects in the relationship between the public body and the beneficiary, other factors should also be considered.

First, the functioning of the public sector is dependent above all upon political considerations. Elections, changes of majority, specific political pressure linked to events, or the choices/inclinations of charismatic leaders, may all decisively influence public action. However, such influence is in no way derived from a coordinated marketing approach.

Limited funding, a complex political agenda, citizens' opposition to a project, etc., may well make it difficult to carry out a marketing concept when a city or region orders one. The pre-eminence of politics, with its own rationale and issues, must never be forgotten. A marketing approach here is subordinate to attaining political and public goals, rather than commercial ones. Box 2.4 provides an example of political refusal to approve plans for re-organizing tourism marketing in the Swiss Canton of Valais.

The relationship between public bodies and beneficiaries is a complex one. Beneficiaries may need to play multiple, sometimes contradictory roles, such as calling for lower taxes while demanding improved services such as nearer post offices or hospitals, longer opening hours of government offices, etc. It is difficult to take these expectations into account, especially since they vary over time and take on various forms.

For example, people who suddenly find themselves unemployed will have needs they never had thought of before. These new requirements would include receiving unemployment benefits or some social allowance while they seek a new job. They would also need advice about professional retraining and, no doubt, finding someone to listen to and empathize with them as they face a difficult situation. The skills and knowledge required to respond to these needs often exceed what is available within a single public body.

Another problem is the absence of individual needs and satisfaction in regard to collective entities. While it is certainly possible to measure people's satisfaction with a service or relationship, it is almost impossible to study this same satisfaction from a marketing point of view when the overall set-up of public services is grouped together in a public policy.

How do you measure satisfaction with a fire brigade, schooling, or justice? Partial measures for analysing needs or satisfaction cannot just be 'added together'. Doing so is not sufficient to convey a public entity's contribution to the community. People may have a high opinion of the quality of the relationship with the organization providing 


\section{BOX 2.4 VALAIS TOURISM LAW}

Valais is renowned for its internationally famous resorts - Zermatt, Verbier, and Crans-Montana, with tourism accounting for 25 per cent of the Canton's GDP. Over time, no fewer than 152 development organizations have been launched to promote tourism, usually with limited financial means.

In 2009, the Cantonal government proposed a new tourism law involving the creation of 8-12 tourist regions. To obtain the new status, a region needed to have a tourism budget of CHF5 million or more. As well, each region would have to include an internationally recognized name and have at least 700,000 overnight stays per year.

A federation of tourist regions called Promo Valais was to be set up to coordinate touristic promotions. The total budget for Valais tourism would thus have been CHF80 million, compared to CHF55 million in 2011. This budget would have been financed by a new tourist accommodation tax, plus an extra CHF10 million in annual investment by the Canton to promote the image of Valais.

This law was proposed by the government and adopted by the Cantonal parliament but on 29 November 2009, it was soundly rejected by the inhabitants of Valais. Approximately 75 per cent of those who voted said no. The introduction of a tourist accommodation tax was one of the main reasons why this draft law - aiming to coordinate marketing activities and render them more efficient - was rejected by the population.

Owners of second homes, including 20,000 Valais citizens, would have been more heavily taxed. This was because the levy was to be based not only on living space but also the number of nights spent in the Canton.

Sources: Le Nouvelliste, Le Temps, NZZ, Canton du Valais (http://www.vs.ch), Comité pour la Loi du Tourisme (www.oui-au-tourisme.ch).

a service, yet they may also consider such services superfluous. It should be remembered that the sum of individual advantages or satisfactions does not necessarily correspond with collective satisfaction when it comes to collective entities.

Even if many public bodies tend to seek, and sometimes obtain, increased management autonomy, they do not necessarily strive to use every marketing tool to maximize the value of the exchange for both parties. Chapman and Cowdell (1998) compare public bodies to animals in a zoo. These entities do not need to go looking for resources (food) since they are regularly 'fed' by budgets allocated in parliament.

There is little to encourage them to seek to increase revenue outside their budget, or reduce costs on their own accord. And, as many studies have clearly shown (Emery, 2006); the motivation of public agents lies outside a commercial framework 
- community service, ethics, etc. - and can even conflict with a more commercial approach.

More fundamentally, some criticism of the use of marketing in the public sector is due to the fact marketing participates itself in creating the need (Marion, 2004). Marketing tools serve not only to interpret signals from consumers, but clearly contribute to increasing them.

Public action derives from a publicly defined issue such as public conscience and demand, which receives a political response - voting the legal framework. In some cases, public action may aim to limit consumption rather than stimulate it. So using marketing to define general and individual needs as well as promoting services may come into conflict with the democratic process.

To conclude: there is no clear-cut answer to the best use of marketing for public services. Some marketing tools, and sometimes integrated marketing approaches, may undeniably help improve services as well as the relationship with beneficiaries. However, from a methodological point of view, marketing presupposes an understanding of individual needs, expectations and behaviour or methodological individualism. Consequently, marketing is ill-equipped for the study of collective problems and practice. Its use can only serve to complement political, sociological, cultural, and economic approaches.

\section{EXERCISE 2.1}

For a specific public service - issuing a passport - identify those elements which can and those that cannot be part of a marketing approach.

Identify what is exchanged and who are the partners to the exchange in the following situations:

- issuing a driver's licence

- providing electricity in a non-monopolistic system

- hospital care.

\section{DISCUSSION QUESTIONS}

1. What are the marketing-related initiatives present in your work place? What are the limits to applying public marketing in your own organization?

2. How does your organization envisage its relationship with the beneficiaries of your services?

3 Is the term 'marketing' officially used by your organization? Why do you believe this is the case?

4 Identify and discuss cases where the use of public marketing seemed inappropriate or questionable. 


\section{REFERENCES}

American Marketing Association (AMA) (2007) Definition of Marketing. Online at http://www.marketingpower.com/AboutAMA/Pages/DefinitionofMarketing.aspx (accessed 28 February 2011).

Ashworth, G. and Kavaratzis, M. (2009) Beyond the Logo: Brand Management for Cities, Journal of Brand Management, 18, 520-31.

Bagozzi, R. P. (1975) Marketing as Exchange, Journal of Marketing, 39, 32-9.

Bartel, C.A. (2002) I Love New York, More than Ever Changes in People's Identities as New Yorkers Following the World Trade Center Terrorist Attacks, Journal of Management Inquiry 11 (3), 240-8.

Beckman, T. N., Maynard, H. H., and Davidson, W. R. (1927) Principles of Marketing, New York, Ronald Press.

Berry, L. (1983) Relationship Marketing, Chicago, American Marketing Association.

Borden, N. H. (1965) The Concept of the Marketing Mix, in Schnertz, G. (ed.), Science in Marketing, Chichester, John Wiley \& Sons.

Burton, S. (1999) Marketing for Public Organizations: New Ways, New Methods, Public Management, 1, 373-85.

Butler, P. and Collins, N. (1995) Marketing Public Sector Services: Concepts and Characteristics, Journal of Marketing Management, 11, 83-96.

Buurma, H. (2001) Public Policy Marketing: Marketing Exchange in the Public Sector, European Journal of Marketing, 35 (1), 287-300.

Chapman, D. and Cowdell, T. (1998) New Public Sector Marketing, London, Financial Times/Pitman.

Constantinides, E. and Fountain, S. J. (2008) Web 2.0: Conceptual foundations and marketing issues, Journal of Direct, Data and Digital Marketing Practice, 9, 231-44.

Copeland, M. T. (1920) Marketing Problems, New York, A. W. Shaw.

Cousins, L. (1990) Marketing Planning in the Public and Non-profit Sectors, European Journal of Marketing, 24, 15-30.

Dean, J. (1950) Pricing Policies for New Products, Harvard Business Review, November, 45-53.

Emery, Y. (2006) Réformes de la Gestion Publique, Nouvelles Pratiques de GRH et Motivation des Agents Publics. Personalpolitik im Spannungsfeld von Veränderung und Wissens-Management, Berne: A. Hofmeister.

Gardner, B. B. and Levy, S. J. (1955) The Product and the Brand, Harvard Business Review, 33, 33-9.

Gilly, M. C. and Dean, D. L. (1984) A Market-oriented Taxonomy of Public Services: Implications for Marketing Management, in Bloch, T. M., Upah, G. D., and Zeithaml, V. A. (eds), Services Marketing in a Changing Environment, Chicago, American Marketing Association.

Godfrey, J. (1984) I Love New York, Tourism Management, 5, 148-9.

Greffe, X. (1999) Gestion Publique, Paris, Dalloz.

Grundlach, G. (2007) The American Marketing Association's 2004 Definition of Marketing: Perspectives on Its Implications for Scholarship and the Role and Responsibility of Marketing in Society, Journal of Public Policy and Marketing, 26 (2), 243-50.

Howard, J. A. and Sheth, N. J. (1969) Theory of Buyer Behaviour, New York, John Wiley \& Sons.

Hoyt, C. W. (1912) Scientific Sales Management, New Haven, Woolson. 
Jackson, B. (1985) Winning and Keeping Customers: The Dynamics of Customer Relationships, Massachusetts/Toronto, Lexington Books.

Kaplan, A. M. and Haenlein, M. (2009) The Increasing Importance of Public Marketing: Explanations, Applications and Limits of Marketing within Public Administration, European Management Journal, 27, 197-212.

Kapferer, J. N. and Laurent, G. (1985) Consumer Involvement Profiles: A New Practical Approach to Consumer Involvement, Journal of Advertising Research, 25-6, 48-56.

Kearsey, A. and Varey, J. (1998) Managerialist Thinking on Marketing for Public Services, Public Money \& Management, 51-60.

Kotler, P. (1967) Marketing Management: Analysis, Planning, and Control, Englewood Cliffs, New Jersey, Prentice-Hall.

Kotler, P. (1972) A Generic Concept of Marketing, Journal of Marketing, 36, 46-54. Kotler, P., Haider, D. H., and Rein, I. (1993) Marketing Places, New York, Free Press.

Kotler, P. and Levy, S. J. (1969) Broadening the Concept of Marketing, Journal of Marketing, 33, 10-15.

Kotler, P. and Connor, R.A. (1977) Marketing Professional Services, Journal of Marketing, 41, 71-6.

Kotler, P., Roberto, N., and Lee, N. (2002) Social Marketing: Improving the Quality of Life, Thousand Oaks, Sage.

Lazer, W. (1963) Life Style Concepts and Marketing, in A. M. Association (ed.), Toward Scientific Marketing, Chicago, Stephen A. Greyser.

Levy, S. J. (1958) Symbols by Which We Buy, Advancing Marketing Efficiency, American Marketing Association, December, 409-16.

Marion, G. (2004) Idéologie Marketing, Paris, Eyrolles.

McCarthy, E. J. (1960) Basic Marketing: A Managerial Approach, Illinois, Irwin.

McKitterick, J. B. (1957) What Is the Marketing Management Concept? In Proceedings of the American Marketing Association Conference (pp. 71-81), Chicago, American Marketing Association.

Peppers, D. and Rogers, M. (1993) The One to One Future: Building Relationship One Customer at a Time, New York: Currency Doubleday.

Ries, A. and Trout, J. (1976) Positioning: The Battle for Your Mind, New York: McGraw-Hill.

Ringold, D. J. and Weitz, B. A. (2007) The American Marketing Association Definition of Marketing: Moving from Lagging to Leading Indicator, Journal of Public Policy \& Marketing, 26, 251-60.

Robert, D. F., Schurr, P. H., and Oh, S. (1987) Developing Buyer-Seller Relationship, Journal of Marketing, 51, 11-27.

Rossiter, J., Percy, L., and Donovan, R. (1991) A Better Advertising Grid, Journal of Advertising Research, 31(5), 11-21.

Scrivens, E. (1991) Is There a Role for Marketing in the Public Sector? Public Money \& Management, 11, 17-23.

Shostack, G. L. (1977) Breaking Free from Product Marketing, Journal of Marketing, April, 73-80.

Smith, W. R. (1956) Product Differentiation and Market Segmentation as Alternative Marketing Strategies, Journal of Marketing, 21, 3-8.

Sparling, S. E. (1906) Introduction to Business Organization, New York, Kessinger.

Weld, L. D. H. (1916) Studies in the Marketing of Farm Products, New York, Macmillan.

White, P. (1921) Market Analysis, Its Principles and Methods, New York, McGraw-Hill. 
Part II 


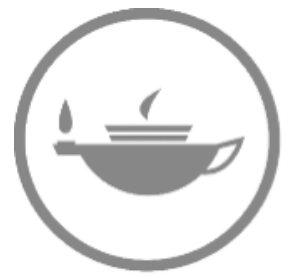

Taylor \& Francis Taylor \& Francis Group http://taylorandfrancis.com 


\section{Chapter 3}

\section{Basic marketing concepts}

\section{LEARNING OBJECTIVES}

By the end of this chapter you should be able to:

- Identify the various actors and their impact/role in your organization's marketing system.

- Classify market orientations - either product or client-oriented - and identify the pitfalls of each.

- Identify the market orientation of your organization and competitors.

- Understand the nuances of the marketing mix.

- Identify and describe the nature of the beneficiary of a public service.

\section{KEY POINTS OF THIS CHAPTER}

- There are four main concepts in marketing - the market system, market orientation, marketing management and marketing instruments.

- Among marketing instruments, the marketing mix - with its concepts of product, price, promotion, and place - is a central tool for structuring a marketing initiative.

- For the public sector, an additional concept is important: The nature of the citizen, and the way in which organizations interact with them.

\section{KEY TERMS}

Systemic analysis - analytical tools of an organization's market environment, including the organization, its competitors, marketing activities, intermediaries, prescriptors, final users, and environmental factors. It allows for the proper understanding of relationships between actors. 


\section{KEY TERMS continued...}

Market orientation - helps identify an organization's basic approach to its marketing functions. It can be product-oriented - focused on a product's technical development and overall presentation to the client. Or it could be client-oriented - the client's needs are first assessed, then the product is designed accordingly.

Marketing management - marketing tools and processes which facilitate the relationship and exchange between partners. This is a cycle composed of marketing analysis; marketing strategy; marketing planning and organization; marketing resources; and marketing control.

Marketing instruments - instruments such as marketing mix are designed to reach and convince target groups.

\section{CONCEPT OVERVIEW}

Over time, marketing has developed numerous concepts - as presented in detail by the leading works on marketing (McDonald, 2007; Kotler and Armstrong, 2009). Without seeking to be exhaustive, this chapter develops the main basic concepts which continue to serve as marketing references and are important for understanding the following chapters.

Figure 3.1 regroups these concepts synthetically. They are:

- The marketing system - taking into account all parties involved in the exchange and explaining the inter-relationships among them. Only the integration and understanding of what is at stake for partners in the exchange makes it possible to understand and if possible, anticipate their behaviour.

- Marketing orientation, put simply, means the culture adopted by an organization in its relationship with clients. Various orientations are possible and may affect both how the organization is run, and how its clients behave.

- Marketing management, involving all the decisions, processes and activities - from strategy to control of marketing activities - an organization takes and sets into motion to attain its marketing goals.

- Marketing instruments consist of the visible part of an organization's marketing, concerning elements addressed to clients. These include the concrete offer of products, services, prices, communication, agents, or distributors proposing products and services, etc.

\section{A SYSTEMIC, ANALYTICAL APPROACH}

Since the emergence of the systems theory (Bertalanffy, 1968), numerous systemic approaches have been developed - in biology, neuroscience, sociology, and psychology, 
but also in economics, management, and marketing. Systemic analysis is based on the principle that the study of a causal relationship between two elements is often not suited to conveying the functioning of an ensemble - whether this is a living being or a group of people, organizations or electronic systems. It is therefore worth looking more closely at exchanges among the parties in the system as well as studying the system's checks and balances, rather than analysing them individually.

An organization permanently interacts with other organizations - competitors, suppliers, distributors, individuals, clients, and influencers - within a market framework. Therefore, a systemic approach can be used to list and prioritize the components of the organization. These include: environment or market; the study of the relationships among these components such as competitors, distributors, clients, etc. Above all, the effects of decisions or actions taken by one of the components on the system as a whole must be analysed. That is, how the parties will react when a new service is announced, and what might be the potential consequences upon the system's equilibrium. Marketing thus becomes a sub-system of the organization, having its own sub-systems like distribution circuits and channels.

From a more practical standpoint (Kühn et al., 2006), suggest a systemic approach to marketing can be used to analyse the organization's market environment. Many marketing decisions such as launching a new product, changing price strategy, aggressive communication against a competitor, etc. can spell failure for organizations unable to anticipate or understand the actions of the other parties involved and, above all, their corresponding interactions.

Consequently it is vital to organize and understand the complex network of relationships among all those participating in the process of market exchange. Three

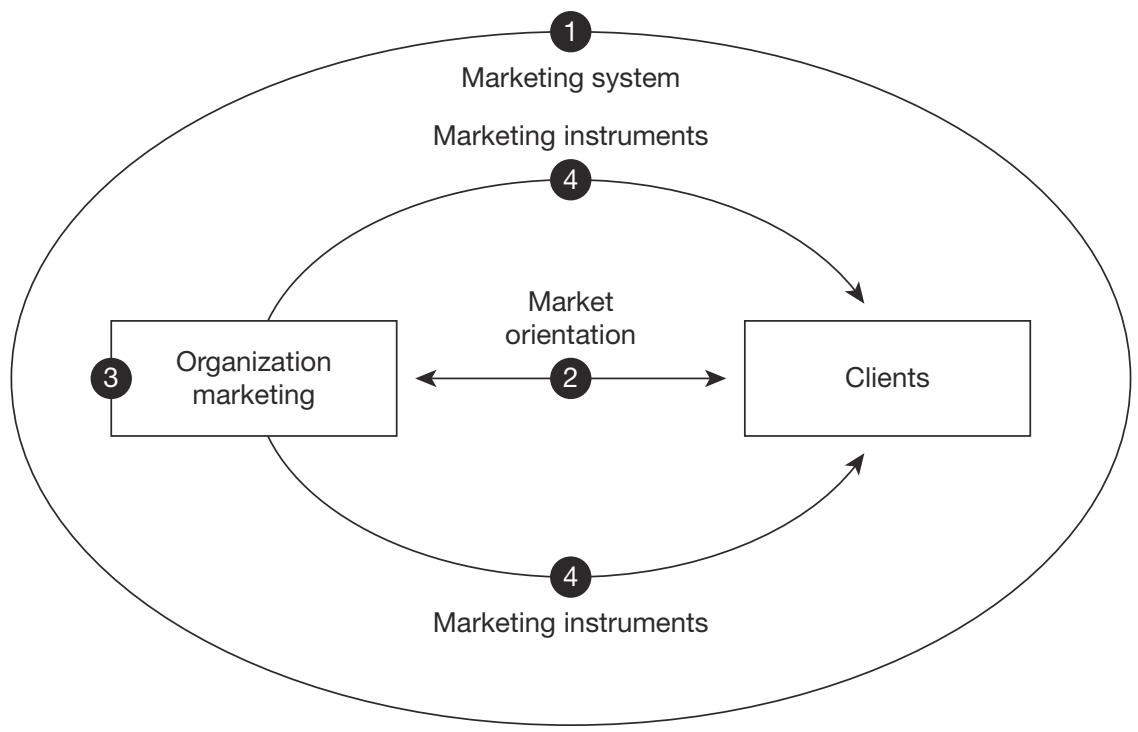

Figure 3.1 Main marketing concepts 
steps are involved: defining the market; establishing a list of the parties involved; and studying the relationship among these parties.

It is not generally easy to clearly define and delimit the market or environment within which the exchange takes place. There are three types of definition:

1. legal or judicial definition;

2. definition based on products or services;

3. definition based on needs.

Legal or judicial definitions are based on laws and regulations or their application, whereas a definition based on products and services takes into account the offer and its various forms. With postal services, for instance, the speed and class of different services such as a second-class letter weighing less than $50 \mathrm{~g}$ help define the market.

Clients' needs constitute the final way of defining a market such as the need for an administrative document to travel from one country to another. In most cases, a combination of these separate approaches is required to clearly define a market or environment to conduct an exchange (see Box 3.1).

The market system is therefore made up of organizations; individuals responsible for groups of organizations; and individuals playing a specific role in the market exchange process. Therefore, the relationship between these distinct elements corresponds to relational acts or acts linked directly to an exchange of goods, services, information, or money. Figure 3.2 presents a synthesis of the various partners in the exchange process.

Apart from the organization proposing an offer, as well as its actual and potential competitors, one should remember all intermediaries selling products or services use their own marketing measures. However, they are separate from those of the company producing them.

Product users or beneficiaries naturally constitute a major partner in this exchange. Users should nevertheless be defined in the broad sense of the term. Often indirect

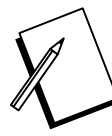

\section{BOX 3.1 PRINCIPAL CRITERIA FOR DEFINING A MARKET}

nature of service - characteristics of the offer orientation of transaction - before or after

- place of transaction

- regulatory elements

- ability to access market - barriers

- number and size of participants - structure of market.

Source: Adapted from Meffert, Burmann, and Kirchgeorg (2008: 49-51). 


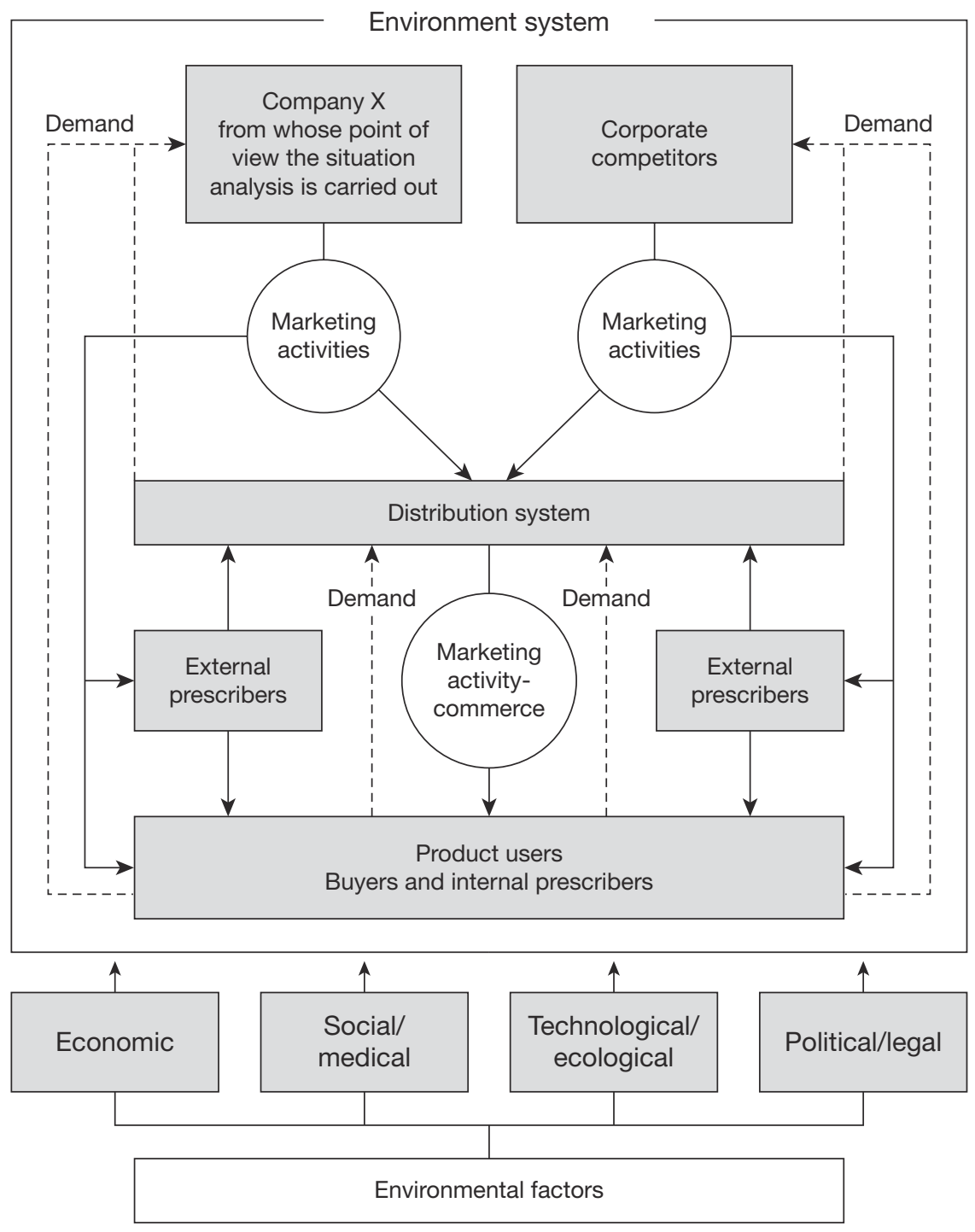

\section{Figure 3.2 Components of a market viewed as a system}

Source: Kühn and Pasquier (2016).

product-or service-beneficiaries are handled like family members or even friends and relatives. For example, anyone hospitalized after an accident benefits directly from the service; but their family, and perhaps relatives and/or employer, are indirect beneficiaries.

The final major partner consists of external prescriptors or individuals already mentioned. In many cases, decisions are largely influenced by persons who do not 
directly take part in the exchange. This would include a nurse influencing the choice of formula for an infant; the architect suggesting the choice of building materials; or journalists prompting the choice of software, etc. Although they are not buying or selling services, these persons or organizations usually have a decisive impact on decisions taken by other exchange partners.

The market as a whole, defined as a system, is not static and is influenced by several other factors. These include legal, political, economic, social, and/or technological changes. These various elements and most importantly, their impact upon system partners, therefore also require careful study.

To fully understand the usefulness of a systemic approach with regard to an ensemble of exchange relationships, a comparative example between the USA and Switzerland concerning health insurance coverage is presented in Figure 3.3. In both cases, the

\section{American system}

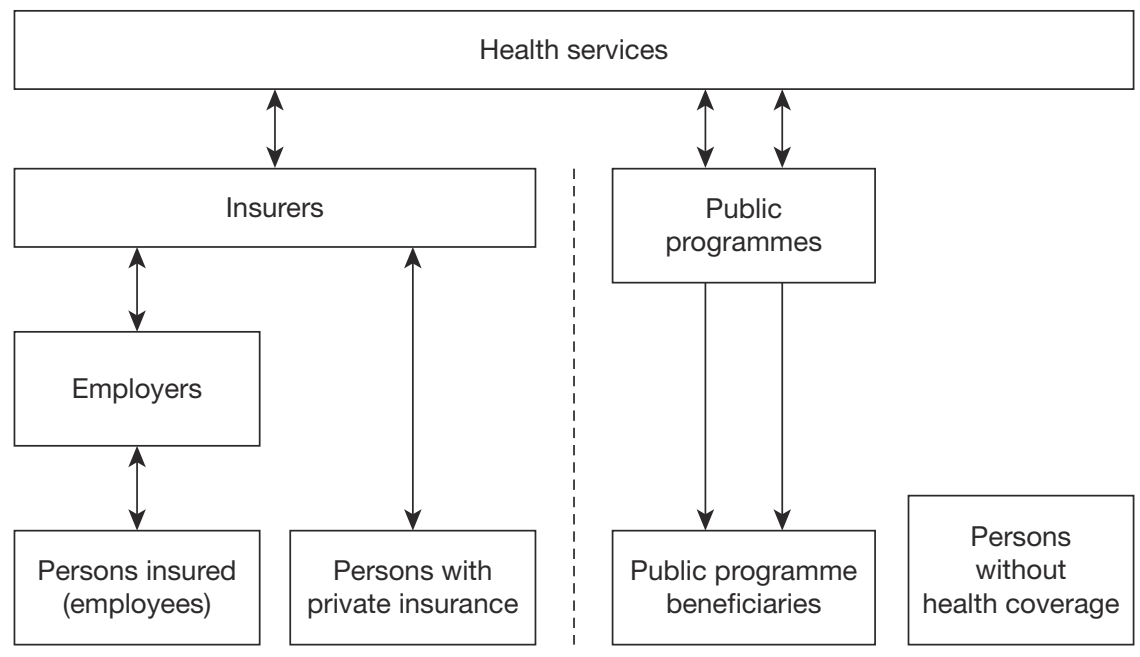

\section{Swiss system}

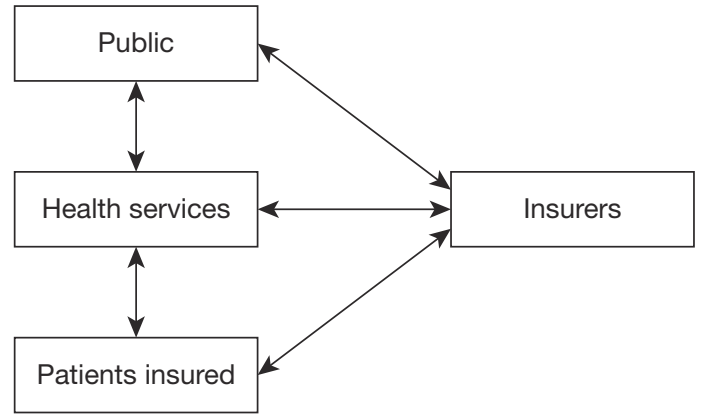

Figure 3.3 Comparison of American and Swiss health insurance systems 
system is largely privatized but, given the regulatory aspects, the system dynamic is totally different.

In the United States health insurance is largely linked to one's employment. Therefore, for health insurers, the direct client is not the beneficiary of the service but rather the employers with whom they agree overall contracts with offer and types of cover subject to negotiation.

Insurance companies also sign contracts with service suppliers - medical centres, hospitals, etc. - and may or may not include them in offers made to companies. Employees and beneficiaries have a limited choice of offers. For many, the coverage available constitutes a major share of the company's social services. But if they should lose their job, they will no longer have access since nearly 80 per cent of premiums are paid by employers.

The situation in Switzerland is very different. Health insurance is mandatory for all residents, but they have free choice of insurer. The minimal cover insurers must provide is defined by the State - but prices are mainly set by the insurers who may also offer extra protection.

There is competition among insurers to attract clients but health service providers recognized by the State may propose and charge an agreed rate for their services. Hence, insurers have virtually no effect on the latter, since the obligation to contract exists.

Without going into the political and social aspects of these systems, it should be emphasized the existence of a strongly privatized market, with a large number of offerers, means the relationship between the various parties should be understood in very different ways. Otherwise, it is impossible to understand these markets appropriately.

\section{MARKETING ORIENTATION}

\section{Types of orientation}

Marketing orientation corresponds to the philosophy of reference adopted by an organization in conducting its marketing activities. Several types of marketing orientations have been identified (Meffert et al., 2008; Kotler and Keller, 2006). See Figure 3.4.

Production orientation emphasizes a product's or service's availability. The organization's priority lies in being able to produce and distribute the goods concerned. The recent H1N1 flu epidemic tellingly illustrates such a situation. To the authorities, it was essential to organize and support the production of vaccines, then ensure their availability throughout the area where they were in charge.

Product orientation is based on the principle that the beneficiary will buy a service according to its objective characteristics such as purchase of the best service. In the private sector, this situation is increasingly rare. However, it is quite typical of public markets. The public body is obliged to choose the offerer who comes closest to fulfilling the criteria defined in the invitation to tender. Such an orientation is also generally common in the tertiary sectors. 

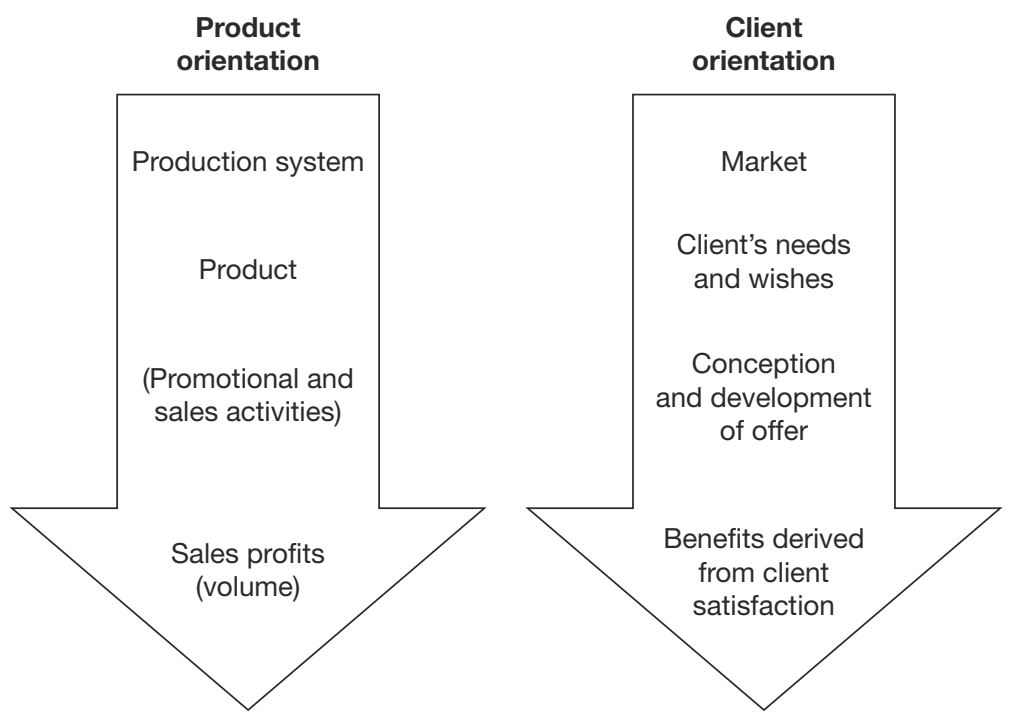

Figure 3.4 Comparison of an organization's product and client orientations

Sales orientation requires an organization to make great effort to stimulate buyers' interest in a product. Clients need to be convinced that such a purchase is worth their while. To some, such an orientation can also be found in politics, when candidates try to 'sell' their ideas by committing themselves - and vast sums of money - to persuading voters to adopt their ideas.

Finally, market or client orientation requires an organization to satisfy previously identified needs. As the saying goes - it's not a drill that's needed, but a hole in the wall. By using knowledge of clients and their needs, an organization can develop services to suit them as closely as possible. If the service really does meet a need, clients will simply buy it, without the organization having to make much effort to promote it.

This orientation - the one most frequently recommended for private bodies - was conceptualized by Narver and Slater (1990) and Kohli et al. (1993). They demonstrated that an active and positive attitude in the collection, analysis, and internal transmission of data concerning clients and other parties to the exchange allows the organization to better serve its market and improve its own performance.

It is rare to find such an absolute form of marketing orientation in an organization. It is not easy for a company to be strictly product-oriented without taking clients' needs at least partially or occasionally into account. Conversely, client orientation often presents great dangers, since clients are not always able to express their needs clearly.

This is especially so when the company is not certain the offer corresponding to those needs will continue to be bought or used by these same clients. In fact, marketing orientation depends on the branch and market on the one hand; and on the 
organization's history, culture and goals on the other. Lees-Marshment (2001) presents the various types of marketing orientation as applied to political parties.

\section{Symptoms of marketing orientation}

Although strict forms of marketing orientation are quite rare, we can still analyse the type of marketing orientation an organization is leaning towards. Kühn, Reimer, and Fasnacht (2006) suggest studying the symptoms which shed light on the marketing orientation favoured within an organization. Table 3.1 contains a list of these indicators of product and client orientations.

\section{The public sector and orientation marketing}

As a rule, the marketing philosophy of public-sector bodies is geared towards production or product. Given legal constraints and monopolistic market structures, organizations do not need to promote their services. Often they are not responsible for identifying and determining needs given that these essentials are theoretically the fruit of political debate and decisions. However, with the arrival of New Public Management and the development of public bodies, the latter are increasingly inclined to modify their marketing orientation to be more and more market- or client-oriented. This occurs for several reasons.

First, with the introduction of competition to various public-sector activities - postal service, telecommunications, hospitals, security, education, etc. - public bodies must show greater interest in clients and provide services better suited to their needs. If clients have a choice, even one limited to using a service or not, they will evaluate it according to their requirements, As a result, public bodies cannot disregard existing needs.

A second reason can be found in pressure from service beneficiaries. They or their families have become increasingly used to voicing their opinion about the services on offer. Beneficiaries will freely complain - or even take action/demonstrating - in order to oblige an organization to do things as they wish. Conversely, public-sector agents are also keen to satisfy collective and even individual needs, as well as incite the organization to adapt the service offer as necessary.

Then, the introduction of quality management norms and processes has encouraged consideration of beneficiaries' needs - although not always intentionally. These processes nearly always require beneficiaries' needs, and/or degree of satisfaction, to be assessed. So, public bodies must systematically take beneficiaries' needs into account in order to obtain certificates of conformity to quality norms.

Finally, in the wake of New Public Management, client orientation now counts among the priorities of public administration reform programmes. Now, public administration is primarily viewed as an entity responsible for making services available to citizen-clients. It advocates NPM and the reforms it has inspired. It stresses the need for these bodies to alter their approach by placing the beneficiary at the heart of their concerns. 
Table 3.1 Symptoms of product orientation and client orientation

\begin{tabular}{|c|c|c|}
\hline $\begin{array}{l}\text { Elements or } \\
\text { function }\end{array}$ & $\begin{array}{l}\text { Symptoms of products } \\
\text { orientation }\end{array}$ & $\begin{array}{l}\text { Symptoms of market } \\
\text { orientation }\end{array}$ \\
\hline Direction & $\begin{array}{l}\text { Organizational aspects are } \\
\text { dominating: production } \\
\text { specialists lead the } \\
\text { organization }\end{array}$ & $\begin{array}{l}\text { Client aspects are dominating: } \\
\text { marketing specialists lead the } \\
\text { organization }\end{array}$ \\
\hline $\begin{array}{l}\text { Programme of } \\
\text { products/services }\end{array}$ & $\begin{array}{l}\text { Narrow: selling what we } \\
\text { produce }\end{array}$ & $\begin{array}{l}\text { Large: producing what we } \\
\text { can sell }\end{array}$ \\
\hline Organization & $\begin{array}{l}\text { Centralized: organizational } \\
\text { structure based on a staff and } \\
\text { line approach; strong on } \\
\text { accounting and financial } \\
\text { controls }\end{array}$ & $\begin{array}{l}\text { Decentralized: few hierarchical } \\
\text { levels; generally organized by } \\
\text { division rather than by function } \\
\text { strategic planning }\end{array}$ \\
\hline Objectives & $\begin{array}{l}\text { Internal influences: short- } \\
\text { term objectives; importance } \\
\text { of methods }\end{array}$ & $\begin{array}{l}\text { External influences: long-term } \\
\text { objectives }\end{array}$ \\
\hline Research & Advanced technical research & Advanced market analysis \\
\hline $\begin{array}{l}\text { Further } \\
\text { development }\end{array}$ & $\begin{array}{l}\text { Proposition for functional } \\
\text { improvements or costs } \\
\text { reductions: technical tests }\end{array}$ & $\begin{array}{l}\text { Based on client proposals } \\
\text { (needs): market tests }\end{array}$ \\
\hline Production & $\begin{array}{l}\text { Production is not flexible: } \\
\text { everything is based on } \\
\text { production capabilities }\end{array}$ & $\begin{array}{l}\text { Production is flexible: } \\
\text { everything is based on market } \\
\text { opportunities }\end{array}$ \\
\hline Welcoming clients & $\begin{array}{l}\text { No parking for clients; cold } \\
\text { welcome; the client is almost } \\
\text { a burden }\end{array}$ & $\begin{array}{l}\text { Parking spaces available and } \\
\text { clearly indicated; welcoming } \\
\text { hall; phone service; the client } \\
\text { is king }\end{array}$ \\
\hline $\begin{array}{l}\text { Data regarding } \\
\text { clients and market }\end{array}$ & $\begin{array}{l}\text { Little to none; must } \\
\text { nevertheless make sure to } \\
\text { know the clients and their } \\
\text { needs }\end{array}$ & $\begin{array}{l}\text { Development of market studies; } \\
\text { qualitative and quantitative } \\
\text { data; tendency to believe that } \\
\text { market surveys have all the } \\
\text { answers }\end{array}$ \\
\hline $\begin{array}{l}\text { Marketing/ } \\
\text { communication }\end{array}$ & $\begin{array}{l}\text { Technical arguments } \\
\text { dominate }\end{array}$ & $\begin{array}{l}\text { After-sales service and client's } \\
\text { needs dominate }\end{array}$ \\
\hline After-sales service & $\begin{array}{l}\text { Only if absolutely necessary; } \\
\text { complaints are seen as } \\
\text { distractions }\end{array}$ & $\begin{array}{l}\text { Development of after-sales } \\
\text { service as the main relationship } \\
\text { with the client; complaints are } \\
\text { seen as opportunities }\end{array}$ \\
\hline
\end{tabular}




\section{MARKETING MANAGEMENT}

As outlined in Chapter 2, the concept of marketing is based on notions of exchange, relationship, the processes for carrying out these exchanges as well as corresponding relationships. Marketing management concerns the process and activities facilitating relationship and exchange between partners (see Figure 3.5). This is the most highly developed aspect of marketing. It is also the most practical one, in that it offers organizations tools for planning and undertaking marketing activities.

Like generic management tasks, marketing management involves analysing the situation, taking strategic decisions, planning and organizing activities in detail, carrying them out, and controlling them. This, in conjunction with a situation analysis, makes it possible to confirm, correct, or adapt subsequent tasks and decisions.

The first task of a managerial process involves analysing the market and environment situation - marketing analysis. In most cases, a systemic approach helps define the market, identify and analyse the leading actors, and study their relationships. The goal here lies in assessing chances and overall risks, as well as the organization's strengths and weaknesses compared to other actors - the SWOT analysis (Strength, Weaknesses, Opportunities, and Threats).

Many tools linked to the analysis of buying and consumer behaviour, competition, distribution systems and, more generally to marketing analysis, have been developed. This has made it possible to establish a basic diagnosis of the situation, based on data obtained.

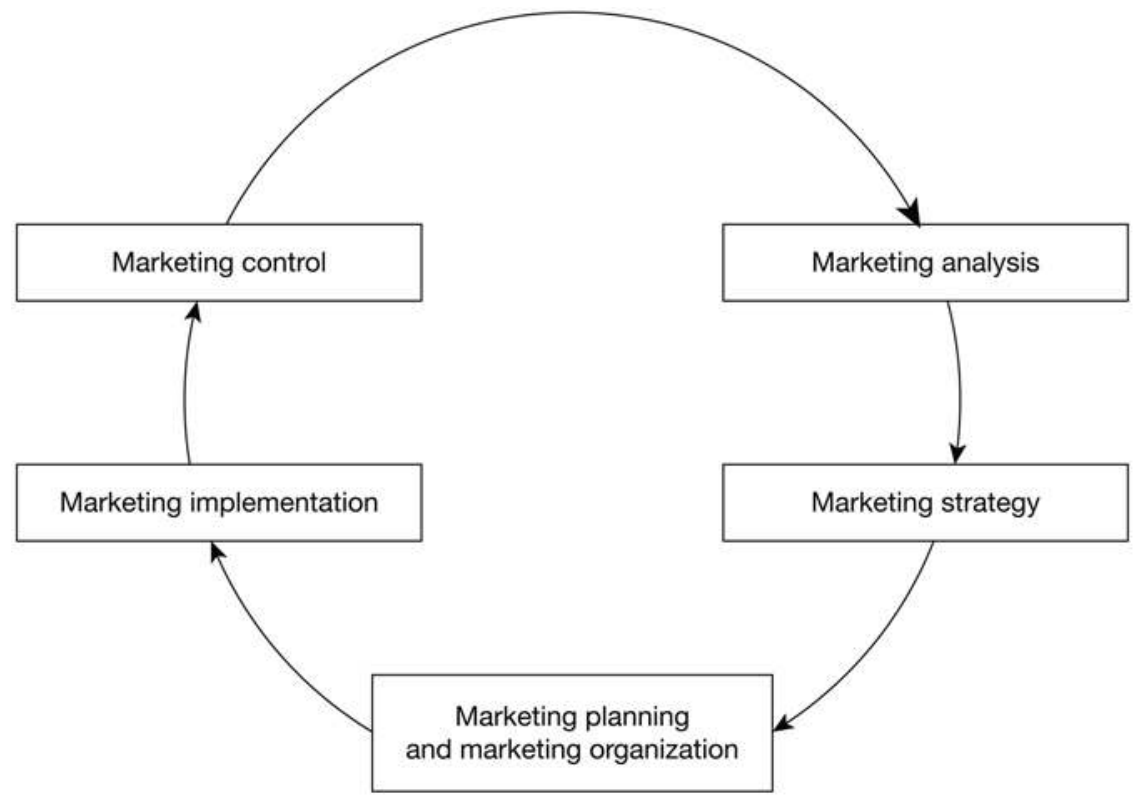

Figure 3.5 Main tasks of marketing management 
The next task, following situation analysis, is to determine primary marketing goals and the strategy needed to achieve them - marketing strategy. This phase involves defining which groups of clients or segments to target with which offer. Quantitative goals must be fixed in terms of turnover figures, market share or profit margin. Qualitative or psychographic goals correspond essentially to the positioning the company is seeking among target groups with its offer. Selecting the circuits and channels of distribution complete these strategic choices.

Based on these strategic decisions, the company identifies the instruments it will use to reach its targets - marketing planning. The marketing instruments or marketing mix (see the following section) are the tools available to the company to attain targeted goals and are visible to both clients and other market actors. They are traditionally known as the 'four Ps' - product, price, promotion, and place. Other instruments have since been proposed as additions to this list, as we shall see later.

To instigate and accomplish the actions planned, a company should dispose of and activate the following:

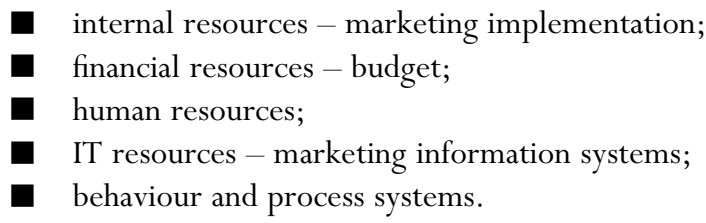

Coordinated use of these resources helps the company attain goals it has set.

Finally, the conformity and completion of decisions and actions must be studied within the framework of a marketing control system. This involves collecting and structuring the relevant information, next submitting it to marketing executives so they can evaluate the decisions made and actions carried out before taking any necessary corrective measures.

In the public sector, the market system is generally very different from the private with no competitors. Generally making the same offer to all beneficiaries, with the price set by a political authority, is a matter of course. The organization's space to manoeuvre is often reduced to activities of communication, distribution, and the resources used by the organization for developing and introducing the service. Aspects linked to the search for information and strategic considerations will be examined in more detail in Chapters 5 and 6.

\section{MARKETING INSTRUMENTS}

A central element in marketing is the marketing mix or range of instruments used to attain and convince an organization's target groups. The concept was first used by Borden (1965), and is based on an analogy between a 'cake-mix' and marketing activities. Borden metaphorically compared marketing tools to the ingredients needed to bake a cake. He suggested that only the right mix of known ingredients can yield a 


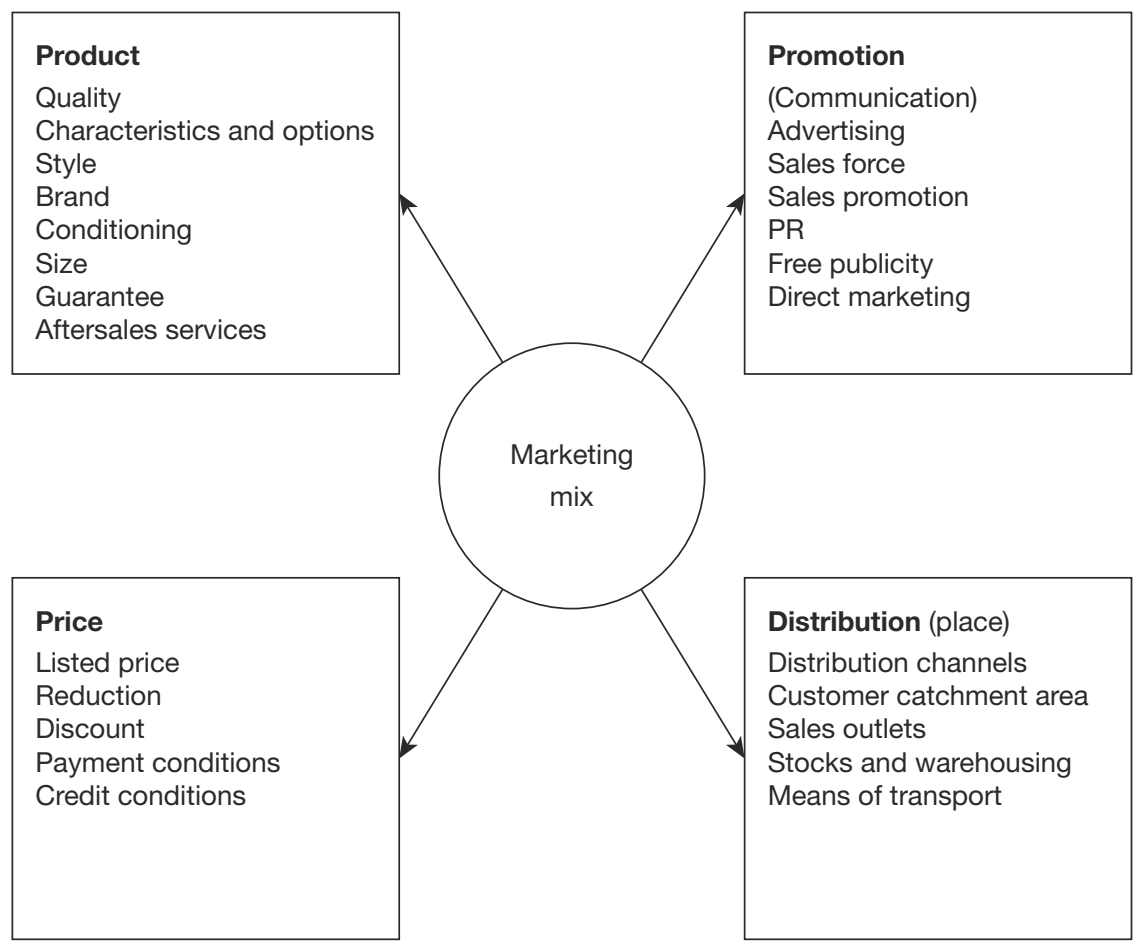

Figure 3.6 Ingredients in the marketing mix

satisfactory result. It is not so much a basic knowledge of the ingredients ensuring success but the appropriate use together in the right proportions.

McCarthy (1960) systematized the marketing mix concept by introducing the 'four Ps', corresponding to the basic instruments available: product, price, promotion, and place (see Figure 3.6).

Let us apply these elements to a service provided by the public sector - issuing an identity document for foreign travel.

The product or offer consists of the number and range of products/services available; their characteristics; possible options; guarantees; after-sales service, etc. For identity documents these may - according to the specific country - include an ID card, passport, or temporary passport, when the original is lost or stolen. The time needed to obtain the document can also be added here.

The price naturally includes the cost of the service and its different forms - cost, stated price, remuneration, etc. This also includes any reduction or discount, along with the conditions of payment or credit. The price of an identity document is fixed by the government based upon, the number of pages in a passport, or how quickly it is issued. However, the administration may accept various methods of payment - cash, credit, or debit cards, bank transfer, etc. 
Promotion consists of all the communication activities which present and seek to promote the offer as a whole. Leading communication tools include advertising, public relations, people forming the sales team, promotional activities, etc. For an identity document, the main communication activities might include an information brochure explaining procedures involved, updating the relevant website, etc.

The final group of instruments is formed by distribution (place): the systems which help the organization convey the offer to its beneficiary - logistics, storage, and warehousing, distribution channels, etc. for goods; direct relations, website, etc. for services. Principal elements of distribution for an identity document include the places the document can be physically ordered and delivered with opening times, etc.; or even the possibility of carrying out some or all of the procedure on the internet.

Although this way of categorizing marketing instruments has long been widespread, many authors (van Waterschoot and van den Bulte, 1992) have criticized its rather simplistic nature, suggesting it is no longer fully adapted to reality. Given the development of services marketing, Bitner and Booms (1981) proposed three new instruments:

- people - personnel in charge of supplying the service;

- processes - the procedure, mechanisms, and flow of activities by which services are consumed; and

- physical facilities - the ability and environment in which the service is delivered.

Other academic proposals combine these various tools, usually according to the type of market and service offered.

Irrespective of the number and structure of marketing instruments, a number of rules must be observed regarding their combined use (Kühn et al., 2006; Kotler and Keller, 2006).

The first rule lies in adapting the instruments to the market situation. What are the target groups' habits when it comes to services? How do they react to price? What are the communication-supports with which they are in contact, etc.?

All these factors may vary from situation to situation. Therefore organizations must be careful to use instruments able to reach the required targets according to their needs, expectations, and behaviour patterns. Nowadays, hardly any organization can afford to neglect internet communication.

The second rule concerns long-term harmony and consistency. As in the original sense of 'mix', marketing instruments must be combined harmoniously. Success in marketing often comes from a subtle blend of instruments that lend the offer overall coherence. For instance, for a luxury product, an aggressive price strategy should be avoided. Another example is seeking to reach a broad target group when the product is only available in a few retail outlets.

Similarly, this mix should stand the test of time and avoid sudden changes that are unpopular with buyers. Who hasn't been surprised or annoyed by a simple change to a product's packaging? Does it instigate doubt or even a change in attitude? 
The final rule to gaining respect is the need for marketing instruments to be used in a concerted fashion. Organizations often use too many instruments at once advertising, public relations, promotion at the point of sale, etc. - without having the means to ensure that each instrument attains a minimum efficiency threshold. Typically, a waste of resources is the result. So, it is usually better to concentrate on a limited number of instruments and ensure that they are effective with the target groups.

Marketing instruments applied to the public sector are outlined in Chapter 7.

\section{ORGANIZATIONS, CITIZENS, AND CONSUMERS}

The study of this relationship between the State and citizens has developed along two relatively distinct lines. The first has focused on the political relationship and the other on the administrative relationship. As students of public marketing, we shall focus on the second aspect. In this administrative relationship, the citizen as a political entity is not entirely forgotten. A citizen interacting with a public organization, the relationship will be, in some part political and even 'electoral' in nature. It is partially this public nature that will qualify much of this discussion.

\section{HISTORICAL EVOLUTION OF THE CITIZEN-PUBLIC-ADMINISTRATION RELATIONSHIP}

\section{The evolution of a relationship}

For an extended time, the relationship between citizens and public administrations had been rooted in the traditional or bureaucratic model best presented by Max Weber (1921). This ideal-type model gives a rather clear image of the main characteristics of public-sector organizations and of the end-user defined under the terminology of the administered. However, this particular construct, has since been challenged with the appearance among others of the terminologies of the user, the consumer and of the citizen-partner. Each of these represent a particular type of relationship and entail specific expectations for the relationship on the part of both the organization and the actor. These elements all have implications for marketing.

\section{A TYPOLOGY OF THE CITIZEN FOR PUBLIC MANAGERS: STRUCTURING ROLES}

The roles presented in Table 3.2 - the administered, the user, the consumer, and the citizen partner - originate mainly from analysis of experiences of the United Kingdom, Canada, the United States, and France. 
Table 3.2 Typology of the actor

\begin{tabular}{|c|c|c|c|c|}
\hline & \multicolumn{4}{|l|}{ The actor } \\
\hline & Administered & User & Consumer & Citizen-partner \\
\hline History & The state & Welfare state & $\begin{array}{l}\text { Regulatory } \\
\text { state }\end{array}$ & $\begin{array}{l}\text { Post-modern } \\
\text { state }\end{array}$ \\
\hline Key concepts & Obligation & $\begin{array}{l}\text { Right to } \\
\text { service }\end{array}$ & Choice & Participation \\
\hline Types of service & Regalian & Public & Universal & Democratic \\
\hline $\begin{array}{l}\text { Uniformity/ } \\
\text { diversity }\end{array}$ & Uniformity & $\begin{array}{l}\text { Conditional } \\
\text { diversity }\end{array}$ & Large diversity & Total diversity \\
\hline Participation & Electoral & $\begin{array}{l}\text { By the use } \\
\text { made of the } \\
\text { different } \\
\text { services and the } \\
\text { rights attached } \\
\text { to them }\end{array}$ & $\begin{array}{l}\text { Choice limited } \\
\text { to the moment } \\
\text { of consumption }\end{array}$ & $\begin{array}{l}\text { Guiding } \\
\text { administrative } \\
\text { action by its } \\
\text { involvement }\end{array}$ \\
\hline $\begin{array}{l}\text { Directionality } \\
\text { of the }\end{array}$ & Top-down & Top-down & Bottom-up & $\begin{array}{l}\text { Inward- } \\
\text { outward }\end{array}$ \\
\hline relationship & $\begin{array}{l}\text { Unilateral } \\
\text { domination }\end{array}$ & $\begin{array}{l}\text { Rights limit } \\
\text { arbitrary } \\
\text { decisions }\end{array}$ & $\begin{array}{l}\text { Apparent } \\
\text { supremacy but } \\
\text { needs defined } \\
\text { by the } \\
\text { administration }\end{array}$ & Symbiosis \\
\hline
\end{tabular}

\section{The administered}

The factors comprising the definition of the administered (inferiority, dependence) and the organization (removed, omnipotent) are central. This model is best exemplified by relationships with organizations such as justice departments and fiscal administrations. It underlines a relationship that is not reciprocal and marked by a high level of obligation on his part.

Emphasized in all these relationships are the administered's obligations to participate and to engage in the relationship with the organization. Aside from the rules and regulations bounding the relationship, the administered is powerless and has no autonomy to define the relationship in his own terms. The administered has power only insofar as he defends the strict applications of administrative law. When within his rights, he can be a powerful foe to the organization.

Nevertheless, this power is defensive, mainly negative, and cannot be projected or used proactively. This lack of power in the administrative relationship is not to be confused with the real clout the administered has in his political relationship with the public sector. 
In a relationship defined by dependence and subjugation, the actor is perceived in an almost completely uniform manner by the organization. For the organization, there is not a multitude of administered, just an administered in the singular who powerlessly sits in for all others.

The level of differentiation in the appreciation of the actor and the services to be provided is minimal. The model is based on equality before the law and the numerous governmental organizations. So any differentiation, any segmentation, is bound to be problematic.

There is no active participation on the part of the actor. The participation is happening at a higher level and in a limited way, in terms of the relationship with the political sphere, through the electoral process.

Obligation is the key construct to recognizing the administered. That obligation might be defined as the duty to engage (taxes), or an obligation to be a provider.

\section{The user}

In France, the central locus of developing the concept, the user is outlined first in the Civil Code of 1804. It is noted that the user has a real right of usage of goods belonging to others but it cannot be loaned or ceded (Title III). It is in the actor's use of public services, and the rights attached to it, that the concept of the user takes its lineage. This concept was to boom in the post-World War II years with the development of the welfare state.

This conceptualization was in stark contrast to that of the administered's legal roots, aimed mainly at circumscribing governmental action. The idea of the user and of public services allowed for the almost unlimited extension of such services. But above and beyond the simple availability of public services, the universal nature of the various service provisions - healthcare, education, social services - were also aimed at achieving wider objectives.

According to Spanou (2003), the user has the right to choose and maintain a certain critical distance. The possibilities afforded to the user were unknown by the administered. Hence, this new role gave the user wider autonomy.

Even in this role, the actor is in a situation characterized as 'administrative paternalism' (Chevallier, 1992). More autonomous, the user still does not have the power to make meaningful decisions. He has more rights but the administration continues to define the structure and modalities of the relationship.

Recognition of the diversity of the actor is conditional. The administration decides and segments the offers and thus recognizes the diversity of the user. In this sense, the user has little power in the relationship shaped and dictated by professionals within the organization.

The level and type of participation the administration allows to the user are also different and more varied than those allotted to the administered. This new form permits the user to exert pressure for increased autonomy and diversity. This voice 
has been made possible, first and foremost, by the multiplication of user associations and by pressure for greater autonomy.

One notable exception with the next model - the consumer - is the relative absence of choice for the user. The administration generally has a monopolistic role in the relationship. In such a situation voice or exit are possible even if both carry a high price in terms of being denied service or not being able to afford the same service provided by a third party. In fact, on many levels, the user remains an administered.

The directionality of the relationship is thus clear. The actor is not at the centre of the relationship. He is in a top-down affiliation where he has a very limited amount of autonomy. The 'rights guaranteed to users' in Chevallier's terms (1992) approach is the concept which accounts for all other aspects. It is by these rights the user differentiates himself from the administered. This is the case even if the distance covered is not as important as might have been earlier believed.

\section{The consumer}

The appearance of the consumer as a possible role for the actor in public-sector relationships is relatively recent. Linked in part with the rise of New Public Management and development of social consumerism, it now represents a generalized model used by administrations and assumed by actors in most OECD countries. The term is rooted in the concepts of choice, individuality, and satisfaction.

Born of the crisis of public finance, increased marketization of social interactions, the rise in neo-liberal economics and rational choice theory, New Public Management sought to bring concepts and dynamics into the public sphere that were once the exclusive domain of the private sector. It has led governments to rethink some of their approaches, most notably in terms of strategic management and service delivery in part through the development of the regulatory State (Majone, 1994).

First emerging in Anglo-Saxon countries, most notably in New Zealand, it has had, in one way or another, a direct effect on most governments, through the application of its basic premises - choice, subsidiarity, leadership and control. These dynamics have paved the way for a new understanding of the affiliation between actors and public organizations - especially the focus on the actor as consumer. This approach, in a reversal of the traditional Weberian concept of hierarchical public bureaucracy, positions the actor at the centre of the organization's concerns.

In the United States, recognition of the consumer in the public sector was first noted in Al Gore's new customer service contract, From Red Tape to Results (Gore, 1993). The actor as consumer is considered to have a 'false' autonomy. As a consumer, one could believe he is in an interaction framed along the lines of those in the private sector which include, among other things, a large choice and the possibility of exit. Autonomy, presumably full and complete on the part of the actor, is qualified as 'false'. This is because the public nature of the encounter and the particularities of specific encounters will, in many cases, limit the potential of exit and the nature of choices for the actor. 
Decisions regarding possibilities in terms of choice and exit are not defined by the actor but rather by the administration. More than anything else, the actor's autonomy depends on the goodwill of the organization. The difference with the user is in the apparent bottom-up situation of the consumer.

The consumer has, by definition, a large diversity since the concept entails tailoring of services and goods offered to the smallest possible segments. Thus for the actor, there is the multiplication of possibilities at all levels. In a relationship with the actor as a consumer, the organization is faced with as many types of consumers as there are consumers.

It represents the highest possible level of diversity. This position is more or less plausible depending on the specifics of the relationship in question.

The transformation of the actor into a consumer effectively mutes his reactions and limits his capacity to voice individual preferences. In this configuration the actor seeks, above all, satisfaction in his encounter with the public organization. This is a situation in which the actor could theoretically have voice only inasmuch as he is also a member of the political whole. This voice is not linked with the actor as a consumer. In fact, he seems to mirror the administered more than any other model.

Given the characteristics mentioned above, the actor in this configuration does not have the collective power or the option to resist the administration. The asymmetry of power remains considerable despite all the empowering language used to describe the relationship. This is, therefore, a false bottom-up situation. The actor is, in many cases, not shaping services by his preferences. Rather he sees them being dictated by the organization and this within the limits of their acceptability for him. The services are defined entirely by the organization.

The concept of choice can apply to various aspects of the relationship. There is choice over the type of service, the level of service, the provider, the type of interaction, and so on. The implicit assumption is that the actor is willing and able to actively use this tool, and he is able and willing to choose.

In many ways, the notion of choice is central to the role of the actor as a consumer. It is presented more as a way to achieve wider political aims than developing effective choice for actors at all levels (Clarke and Newman, 2005).

\section{The citizen-partner}

Advocates of NPM believed greater efficiency and better management were the answer to the current woes of political cynicism (Kelly, 2005). But supporters of Democratic Governance think one solution is foremost. This is to make the citizen a more active and engaged participant in the politico-administrative system. This would in turn increase accountability, political, and social participation, as well as restore a greater level of trust and confidence in the mechanics and dynamics of public organizations.

This approach has directly impacted public organizations' conception of 'the citizen'. Proponents of Democratic Governance believe the citizen should not be converted 
into a mere consumer of public services. Rather, they strive to make the consumer the co-producer and main partner of public organizations.

Public organizations are thus operating as part of a network, exchanging and redistributing tasks and responsibilities with the citizen-partner. Whereas NPM underscores the importance of efficiency, Democratic Governance has at its core the concepts of accountability and democratic participation.

People are not only the end-receivers of products and services but also co-producers in defining aspects of the interaction. When evaluating its impacts, the relatively recent nature of the Democratic Governance's development in the administrative context must certainly be kept in mind.

This approach has been linked to what some have called the post-modern state. This is a regime which has fully integrated the actor and other stakeholders in its decisional mechanisms. Being in the system and shaping it by their choices and voices, the actor gains a high level of autonomy. In fact, similarly to other criteria, this model is positioned at the extreme end of the spectrum.

The actor as citizen-partner exhibits a total diversity. This is the natural consequence of considering the actor as the embodiment of a singular and uniquely qualified individual who is not only a recipient of services but also a shaper and creator of these services. The citizen-partner resides within a system that is neither top-down or bottom-up. Instead, it is an inward-outward symbiotic system between actor and administration. In such a system, the level of responsibility resting on the actor's shoulders is significantly increased.

At the centre of the citizen-partner concept is the idea of participation. The notion has been studied from a number of angles, but the main attempt at structuring it as a tool for interaction is that of Arnstein (1969), who differentiates between 'token participation' at one end and 'citizen control' at the other.

Depending on the characteristics of the participatory process, it could benefit the actor only as a consumer rather than as a citizen-partner (Needham 2002).

This is because many of the procedures involved seek to 'institutionalize a network of passive individuals [rather] than create or empower active citizens' (Chandler, 2001, quoted in Needham, 2002). There is a clear distinction between voices used in the environment of the citizen-partner, allowing for discussion and debate, and the limited possibilities for the actor in his role as a consumer.

\section{CONSEQUENCES FOR MARKETING: ADAPTING TO THE PLURAL NATURE OF THE ACTOR}

Marketing being the study of relationships, proper understanding of who the organization is dealing with is crucial. It is a significant step in defining the proper shape of the relationship so as to ensure a satisfactory outcome for all involved.

Recognition of the plurality of roles played by the actor has to be acknowledged at three specific levels: (1) internally within the organization; (2) relationally in effectively shaping the relationship; and (3) at the end-point, making it a reality for the actor. 
At each of these three levels, one first needs to be aware of the situation before acting upon it. The necessary step before thinking about the actor's roles and performance evaluation is to identify the actor. Who are the beneficiaries of the organization? Who are the users, consumers, citizen-partners, administered, etc.? Such strategies are presented in Chapter 4.

A first step is to establish clearly what these roles ought to be. Taking together information regarding the actor and the organization, and fully accounting for particulars such as the type of goods and services the organization delivers, should help define which models to be favoured.

Proper respect should also be given to the historical moorings of the organization. Just as an organization cannot transform itself overnight, managers should not expect actors to make the transition immediately. Having identified the model, or models, best fitting the relationships between actor and public administration, a number of steps can then be taken to minimize the gaps likely to develop between rhetoric and action in order to ensure the most productive relationship possible between the administration and the actor.

\section{EXERCISE 3.1}

Using a process or product you have good knowledge of, identify the various steps of marketing management as shown in Figure 3.5.

\section{DISCUSSION QUESTIONS}

1. Based on the definition of a systemic analysis provided in this chapter, discuss the limits and potentials of such an approach. Is it realistic to talk of the market system in the public sector? What are the limits of this particular model in the case of your own organization?

2. Public marketing grows in importance. Make a list of the reasons that could potential explain this development. Why should an organization with a monopoly position use marketing tools?

3. The marketing mix is like baking a cake. In your opinion, what are the most important ingredients? In your experience, is one of them more likely to ruin the cake if there is too much/too little of it?

4. What impact does the language used in your communication/marketing have on perceptions of the actor and the organization?

\section{NOTE}

1. Citing Title III, 'De I'usufruit, de I'usage et de I'habitation'. 


\section{REFERENCES}

Arnstein, S. R. (1969) A Ladder of Citizen Participation, Journal of the American Institute of Planners, 35, 216-24.

Bercea, 0.-B., Bacali, L., and Lakatos E.-S. (2016) Public Marketing : A Strategic Tool for Social Economy, Review of Applied Socio-economic Research, 11, 13-21.

Bertalanffy, K. L. (1968) General System Theory: Foundations, Development, Applications, New York, George Braziller.

Bitner, J. and Booms, B. (1981) Marketing Strategies and Organizational Structures for Service Firms, in Donnelly, J. and George, W. (eds), Marketing of Services, Chicago, American Marketing Association.

Borden, N. H. (1965) The Concept of the Marketing Mix, in Schnertz, G. Science in Marketing, Chichester, John Wiley \& Sons.

Caruana, A., Ramaseshan, B., and Ewing M. T. (1999) Market Orientation and Performance in the Public Sector, Journal of Global Marketing, 12, 59-79.

Chandler, D. (2001) Active Citizens and the Therapeutic State: the Role of Democratic Participation in Local Government Reform, Policy and Politics, 29, 3-14.

Chevallier, J. (1992) Regards sur L'administré, in Chauvière, M. and Godbout, J. T. (eds.) Les Usagers Entre Marché et Citoyenneté, Paris: L'Harmattan.

Code Civil, (1804), French Government. https://www.legifrance.gouv.fr/affichCode. do?cidTexte=LEGITEXT000006070721. Visited on 20.02.17ance.

Clarke, J. and Newman, J. (2005) What's in a Name? New Labour's Citizen-Consumers and the Remaking of Public Services, paper presented to CRESC conference Culture and Social Change: Disciplinary Exchanges, University of Manchester, July.

Dahl, A. and Soss, J. (2014) Neoliberalism for the Common Good? Public Value Governance and the Downsizing of Democracy, Public Administration Review, 74, 496-504.

Enjolras, B. and Steen-Johnson, K. (2015) Democratic Governance and Citizenship, in Laville, J. L., Young, D. R., and Eynaud, P. (2015) Civil Society, the Third Sector and Social Enterprise, Governance and democracy, London, Routledge.

Giandomenico, M. (1997). From the Positive to the Regulatory State: Causes and Consequences of Changes in the Mode of Governance, Journal of Public Policy, 17, $139-67$.

Gore, A. (1993) From Red Tape to Results: Creating a Government that Works Better and Costs Less. Report of the National Performance Reviews, New York, Times Books and Random House.

Gromark, J. and Melin, F. (2013) From Market Orientation to Brand Orientation in the Public Sector, Journal of Marketing Management, 29, 1099-1123.

Haque, M. S. (2013) Rethinking Democratic Governance : Looking Back, Moving Forward, Public Administration, Governance and Globalization, 11, 265-73.

Kelly, J. M. (2005) The Dilemma of the Unsatisfied Customer in a Market Model of Public Administration, Public Administrative Review, 65, 76-84.

Kohli A. K., Jaworski, J. B., and Kumar, A. (1993) MARKOR: A Measure of Market Orientation, Journal of Marketing Research, 30, 467-77.

Kotler, P. and Amstrong, G. (2009) Principles of Marketing, New York, Pearson Education.

Kotler, P. and Keller, K. L. (2006) Marketing Management, New Jersey, Prentice Hall.

Kotler, P., Roberto, N., and Lee, N. (2002) Social Marketing: Improving the Quality of Life, Thousand Oaks, Sage. 
Kühn, R. and Pasquier, M. (2016) Marketing: Analyse et Stratégie, Zürich, Schulthess Editions Romandes.

Kühn, R., Reimer, A., and Fasnacht, R. (2006) Marketing: System, Strategie und Instrumente, Bern: Haupt Verlag Ag.

Lane, J. E. (2000) New Public Management, London, Routledge.

Lees-Marshment, J. (2001) The Marriage of Politics and Marketing, Political Studies, 49, 692-713.

Giandomenico Majone (1997). From the Positive to the Regulatory State: Causes and Consequences of Changes in the Mode of Governance. Journal of Public Policy, 17, 139-67.

Majone, G. (1994). The rise of the regulatory state in Europe. West European Politics, $17,77-101$.

Marvel, J. D. (2016) Unconscious Bias in Citizens' Evaluation of Public Sector Performance, Journal of Public Administration Research and Theory, 26, 143-58.

McCarthy, E. J. (1960) Basic Marketing: A Managerial Approach, Illinois, Irwin.

McDonald, M. (2007) Marketing Plans, Oxford, Elsevier.

Meffert, H., Burman, C. and Kirchgeorg, M. (2008) Marketing: Grundlagen Marketorientierter Unternehmensführung, Wiesbaden, Gabler Verlag.

Narver, J. C. and Slater, S. F. (1990) The Effect of a Market Orientation on Business Profitability, Journal of Marketing, 54, 20-35.

Needham, C. (2002) Empowering Citizens, Consumers, Councillors or Cabinets? The Impact of Consultation on Local Government in the United Kingdom, ECPR Joint Workshop Session, Turin, March.

Osborne, S. P., Radnor, Z., and Nasi, G. (2012) A New Theory for Public Service Management? Toward a (Public) Service-Dominant Approach, American Review of Public Administration, 43, 135-15.

Park, H. M. and Perry, J. L. (2015) The Transformation of Governance: Who Are the New Public Servants and What Difference Does it Make for Democratic Governance?, The Americain Review of Public Administration, 43 (I), 26-49.

Public and Non-Profit Service Management, Public Management Review, 14, 433-50.

Spanou, C. (2003) Citoyens et Administration: les Enjeux de L'autonomie et du Pluralisme, Paris, L'Harmattan.

Thomas, J. C. (2013) Citizen, Customer, Partner: Rethinking the Place of the Public in Public Management, Public Administration Review, 73, 786-96.

van Waterschoot, W. and van den Bulte, C. (1992) The 4P Classification of the Marketing Mix Revisited, Journal of Marketing, 56, 83-93.

Weber, M. (1921) Wirtschaft und Gesellschaft. Grundriss der Sozialökonomik, Tübingen, Mohr.

White, M. and Wintour, P. (2004) Public Services: the Choice, The Guardian, London, 24 June.

Wright, H. W., Chew, C. and Hines, A. (2012) The Relevance and Efficacy of Marketing in Public and Non-Profit Service Management, Journal of Public Management Review, 14, 433-50. 


\section{Marketing information research}

\section{LEARNING OBJECTIVES}

By the end of this chapter you should be able to:

- Identify the information needs of your organization.

- Select the appropriate information-gathering strategies and tools.

- Integrate the information gathered into the organization's managerial framework.

\section{KEY POINTS OF THIS CHAPTER}

- The objectives of organizations in seeking information can be: (1) descriptive; (2) exploratory; or (3) explanatory. One's strategy must be in line with the objectives of the information-gathering operation.

- Studies may be either primary or secondary: in primary studies, information is collected specifically for the objective defined by the organization, while secondary studies use information already collected and available.

- Data collected must be integrated into a coherent organizational information system in order to be used effectively either for policy purposes or managerial objectives.

\section{KEY TERMS}

Survey - the most widely used form of primary information gathering, entailing directly asking respondents for information about themselves, their habits and opinions. 


\section{KEY TERMS continued...}

Observations - information-gathering approach seeking to observe the behaviour of individuals without questioning them directly.

Tests - recreation of lifelike conditions in a controlled environment and analysis of the information obtained.

Sample - representative group of a given population.

\section{MARKETING INFORMATION IN THE PUBLIC SECTOR}

All organizations need information in order to take decisions, understand aspects of behaviour of people or organizations, ensure measures are implemented correctly, or evaluate such measures. Although businesses in the private sector have been conducting market research and mandating specialized research institutes at length, public-sector organizations have only adopted such practices much more recently. Box 4.1 provides examples of situations in which administrations may seek to obtain 'marketing' data in the way private companies do.

There are a number of reasons to explain the increasing use of studies by publicsector organizations to gather data on stakeholders. First, there is a substantial imbalance between the tasks the public sector has to perform and the resources available to it. Because political authorities often impart few concrete indications regarding priorities for services needing to be developed, restricted or even abolished, such decisions are often left to the discretion of public-sector organizations.

Beneficiary surveys are a source of information to help public-sector organizations arrive at and validate decisions. These would include input such as: what are the best opening hours? What procedures require simplifying? A second reason for utilizing surveys is the growing demand for accountability from public-sector organizations. As well, they are responsible for the expansion of concepts such as 'customer', 'customer orientation', and 'customer satisfaction' in the New Public Management approach. Detailed information must be gathered about services, the manner in which they are delivered; their beneficiaries and so on.

Because relations between public-sector organizations and beneficiaries have been 'marketized' and to some extent individualized, organizations are compelled to gather specific data about 'customers' to adapt services to different groups of customers as necessary. Additionally, they need to regularly check both the quality of services delivered and user satisfaction with these services. To obtain information of this kind, organizations use classic techniques such as polls and qualitative surveys.

Other reasons have to do with the economic significance, complexity and costs of activities deployed by public organizations. In such situations it is wise to make certain 


\section{BOX 4.1 EXAMPLES OF SITUATIONS IN WHICH 'MARKETING' INFORMATION MUST BE GATHERED}

- Determining the expectations of the beneficiaries of services and comparing them with the way the organization perceives and defines them

- Assessing the quality of services provided to beneficiaries, as well as beneficiaries' satisfaction with these services

- Understanding the behaviour of those who use services and their attitude towards the organization

- Assessing the effectiveness of measures taken, such as communications procedures

- Assessing priorities in light of available resources and then reducing or eliminating superfluous services

- Testing and validating new services or actions for beneficiaries.

the services developed are well thought-out, economical, and well-matched to the needs they are intended to satisfy. Otherwise there is a risk much greater costs will be incurred to remedy mistakes made. Figure 4.1 illustrates the various costs of a service, particularly those resulting from a bad match between the service provided and expectations or need.

A final explanation of increased use of marketing studies lies in the information needed to develop public policies. Public-sector organizations are faced with the complexity of a constantly changing world. As part of their function of assisting political authorities to prepare public policies, they must gather information to reduce uncertainty and allow political authorities to take enlightened decisions.

This task is partially delegated to government statistics departments, which carry out large numbers of studies every year. However, this work is increasingly performed by departments directly in charge of the public policy concerned, for reasons of knowledge of the subject matter as well as time. Many study techniques are used, ranging from surveys and electronic behaviour-observation methods to focus groups, or perhaps as part of participatory initiatives.

Generally, organizations evaluate their marketing environment to attain three types of objectives:

- Descriptive: in these cases, the need is for information to provide a description of the situation and enable strategic decisions to be taken and measures to be planned or adjusted. For example, in preparing for world fairs held at intervals in various countries around the world - Seville, 1992; Hanover, 2000; Shanghai, 2010; Milan, 2015; Astana, 2017; Dubaï, 2020) - some countries conduct studies to gauge their image as the host nation or the corresponding region. Such studies 


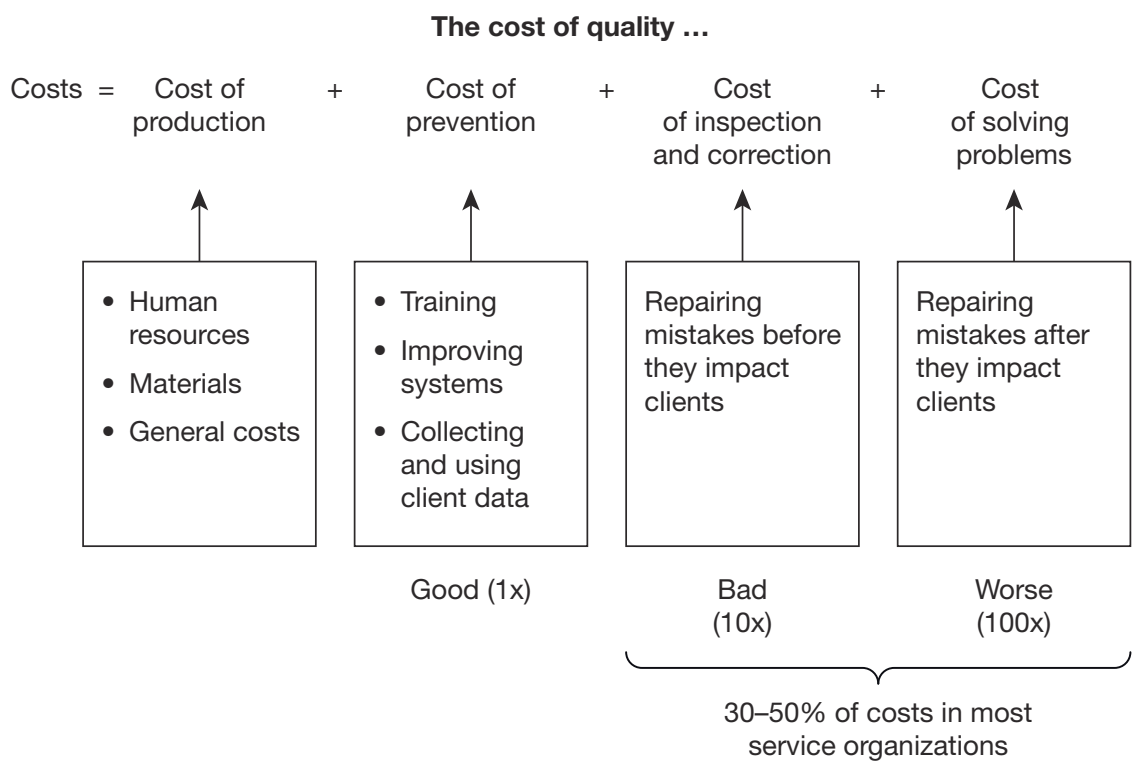

Figure 4.1 The various types of costs involved in producing a service and making it available

Source: Schmidt (2000: 4).

help them develop concepts for pavilions that will best represent them. Studies of user satisfaction with a service, or tests of a communications campaign, also build better descriptive knowledge of measures deployed.

- Objective: when a public organization has to study various possibilities for the construction of a bypass, the placing of stops on a new bus route, or the building of a new school. It can survey the residents of a district or town so needs and evaluation criteria for submitted projects can be better taken into account.

- Explanatory: in situations where a public organization is out of phase with citizens or groups of beneficiaries - where services are not being used, recurrent criticisms, etc. In this way, the reasons why people reject a proposal or a service can be investigated. In 2016 the people of the Canton of Geneva voted by $54.34 \%$ to reject a proposed expansion of a museum.

Perplexed as to why the majority of the population should oppose the project, the administration conducted a survey. Results showed the public were not opposed to support of culture or to the idea of a museum. However, they objected to the planned location on the shores of a lake and did not like the architectural concept chosen. The authorities then relaunched the project taking into account the information gathered.

The following sections begin with an overview of the main methods used for gathering information. Because of their widespread use, surveys are discussed in detail, 
followed by a summary presentation of other methods. The two subsequent sections deal with selecting samples and the process for planning a study. In conclusion, the chapter briefly looks at integrating marketing studies and opinion polls into a broader marketing information system.

\section{INFORMATION-GATHERING METHODS}

Marketing studies and opinion polls are systematic, empirical methods of gathering objective and subjective information. This is done for the purpose of increasing transparency of the field concerned as well as improving both decision taking and the development of corresponding measures (Malhotra, 2009; Kühn and Kreuzer, 2006).

The following definition highlights the goal of this particular type of research: to increase knowledge of a specific subject and the attendant decisional capacity. All too frequently, studies are developed and carried out with no link to a clearly defined problem area, or in the end, they are not used for decision making.

When no consensus can be reached on the orientation to be taken regarding a particular subject or on a decision to be taken, a study is often commissioned. Typically, this is either as a play for more time or to prevent a conflict. Many times, researchers know the information gathered will probably do nothing to improve the basis for taking a decision. The uncertainty may well be exactly the same after the study as it was before.

In this situation, the study risks being used as an alibi or a second-best solution and one that often ties up many internal resources. For this reason it is very important, before conducting a study, to make certain there is a real need for new information. In addition, assurances must be made that the new information will definitely be put to use in taking a decision, and indeed that it will improve the quality of the decision.

In the negative, it may be advisable to drop the idea of planning and conducting the study, for the time being at least. But if the study itself constitutes an objective independently of the results obtained, it then should move forward.

The methods used to collect and analyse data are many and varied. Figure 4.2 sets out the main techniques in summary fashion.

The first methodological question to be asked is whether or not data already available can meet the information needs. Here lies the distinction between primary and secondary studies.

Primary studies involve the gathering and analysis of data, collected. This is conducted specifically in connection with the defined object of study and received directly from information carriers. In other words, these are new studies carried out to obtain information not already existing.

Secondary studies involve identifying and using existing, available data such as documentary sources often requiring reinterpretation in the light of the particular information need. This is a matter of making use of information which already exists but was not originally gathered in relation to the current object of study.

Before committing substantial resources to the gathering of new data, it is important to verify whether existing data or similar data is able to cover the information need. 


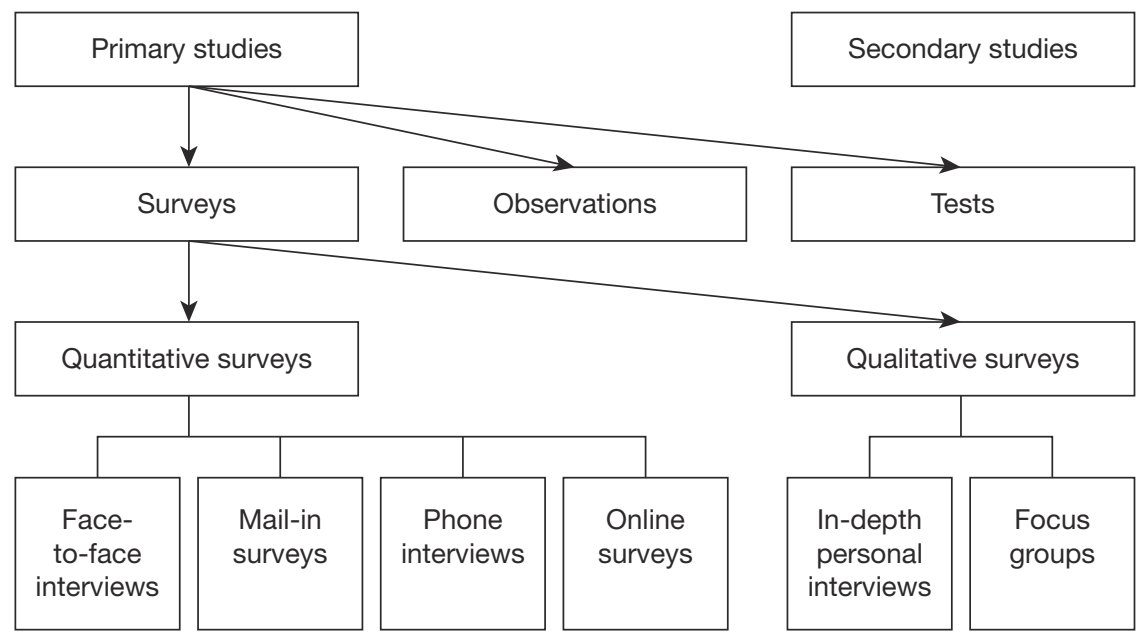

Figure 4.2 Summary of the main marketing study and opinion survey methods

Source: Kühn and Kreuzer (2006).

Currently there are increasing amounts of information, both inside and outside an organization, which is largely unused. Table 4.1 shows possible information sources to be consulted. Very often, combining several sets of existing data can bring useful answers, limiting the need for new information, and thereby saving time and resources.

When an organization must gather new information to encompass identified needs, three groups of methods can be considered - surveys, observations, and tests.

Surveys are the most widespread form of study and consist of asking people for information about themselves, their habits, opinions, attitudes, or behaviour with regard to a particular subject. In rare cases, people may also be asked to give their opinions about other people such as members of their family.

It is important to bear in mind that this type of study is based on people's statements, and hence their capacity or willingness to express their opinions about past, present, and future facts or subjects. It is easy enough to ask somebody if they smoke cigarettes, when they started smoking, and how many cigarettes they smoke each day.

However, there is an obvious difficulty in asking similar questions about the use of illegal substances such as narcotics or performance-enhancing drugs. Few people are willing to discuss topics considered socially problematic like medication, alcohol, etc.

Surveys are generally divided into two types: quantitative and qualitative. Both will be discussed in detail in the next section.

Quantitative surveys are generally used to obtain representative information from the public surveyed, such as what is the opinion of the public about a planned museum? What is the satisfaction level of those working on or using a service? What percentages of people have seen the prevention campaign ads?

Since it is neither possible nor reasonable to question the entire segment of the population concerned, very often only a representative sample is surveyed. Qualitative 
Table 4.1 Secondary or documentary sources

\begin{tabular}{|c|c|}
\hline \multirow[t]{2}{*}{$\begin{array}{l}\text { Public or para-public sources } \\
\text { (data often available at no cost) }\end{array}$} & $\begin{array}{l}\text { Data and reports from statistical } \\
\text { departments }\end{array}$ \\
\hline & $\begin{array}{l}\text { Data and reports from various public } \\
\text { organizations (customs, government } \\
\text { departments, central bank, etc.) }\end{array}$ \\
\hline \multirow{4}{*}{$\begin{array}{l}\text { Private sources (data may or may } \\
\text { not be available free of charge) }\end{array}$} & Research conducted by universities \\
\hline & $\begin{array}{l}\text { Publications and reports by marketing study } \\
\text { institutes }\end{array}$ \\
\hline & $\begin{array}{l}\text { Reports and documents of professional } \\
\text { associations }\end{array}$ \\
\hline & Publications in newspapers and journals \\
\hline \multirow{4}{*}{$\begin{array}{l}\text { Internal sources (data available } \\
\text { at no cost) }\end{array}$} & Previous market studies \\
\hline & Accounting and financial data \\
\hline & Data on customers and beneficiaries of services \\
\hline & $\begin{array}{l}\text { Data resulting from the study of existing } \\
\text { measures }\end{array}$ \\
\hline
\end{tabular}

surveys, on the other hand, normally involve a limited number of respondents. They are designed to explore deep-seated motivations, discover complex reasons underlying behaviour, and to identify possible changes, etc. Here, it is not the representativeness of opinions expressed which counts but, instead, it is their quality and diversity.

Varying methods can be used to conduct surveys. People are generally required to be physically present for qualitative surveys such as in-depth individual interviews or focus groups. Quantitative surveys can be conducted not only face to face but also by telephone, using a questionnaire sent by mail or over the internet.

The second possible method of study is observation. Studies are aimed at observing people's behaviour without their having to express their opinion. For example, the number and possibly the type of people who decide to vote electronically during elections can be observed. While observation techniques obviously do not allow opinions to be gathered, in general they are much more reliable than surveys for studying people's behaviour in that filters may come into play when who people make statements are absent.

Box 4.2 shows an example in which the study methodology, originally based on a survey, was exchanged for a behavioural observation system. Observation techniques have not been widely used until now. Recent technological and computing developments such as digital information, internet, GPS, electronic cameras, etc. have sparked a considerable rise in interest, now that specific new techniques have been developed. 


\section{BOX 4.2 ELECTRONIC OBSERVATION OF PEOPLE'S MOVEMENTS}

The study of a population's movements is of interest to both the public and private sectors. For the public sector, the planning and management of transport infrastructures is intimately tied to population movement. In the private sector, geomarketing applications generate territorial and travel-related data used to target marketing activities.

For close to half a century, the analysis of population movements was mainly carried out using personal surveys followed by telephone assessments of a sample of the population. These surveys began with asking people how far they had travelled on the day before the interview. These movements, together with the reasons and modes of transport, are then transferred onto digital mapping systems. Interestingly, these are still in play today but greatly improved methodologies are used.

Since the early 2000s, methods for recording movements have been based on GPS (global positioning system) technology. Instead of being asked about their movements of the previous day, participants in the sample are given a specially developed GPS device. All their movements for the duration of the study - usually one week - are recorded and transferred into digital mapping systems.

For one study of the public's mobility behaviour in major Swiss cities, over 10,000 people were recruited and fitted with a GPS device.

This method of observation using electronic data collection brings a number of advantages. First, all movements of the participants are gathered in a week. This is significant because mobility behaviour is not the same during the week as it is on the weekends. Second, all movements - not just main movements - are collected.

In a telephone survey, many movements such as walking the dog, visiting a friend, a spontaneous trip to a neighbourhood store, etc. are often not reported. Lastly, the information gathered is much more accurate than an observation survey because one is no longer relying upon people's memories. Their behaviour is automatically recorded by an electronic system.

The third type of study methodology is the test. This involves testing, either under laboratory conditions or in real-life situations, or recording people's reactions to concrete proposals for marketing measures. These may involve testing new designs for a community newspaper, new services, new communications campaigns on prevention, and more.

Combined with a survey or an observational study, this technique makes it possible to gather data on concrete rather than hypothetical elements. Thus, it can test the relevance, reliability or potential success of proposed measures. 
'Mystery shopping' integrates both test and observation techniques. It involves sending a trained person to play a specific role - customer, partner, or whatever other useful persona - to test an organization's attitudes and behaviours.

New technologies offer ample opportunity to record people's movements. In Switzerland, for instance, many municipalities use the Smart City program offered in cooperation with the biggest national phone operator Swisscom. The program allows public bodies to obtain mobile network data, most importantly geo-location information. The municipality of Pully uses the data for instance to plan the construction of roundabouts or one-way streets. The city of Montreux uses mobile data to understand where its visitors come from. In Belgium, the city of Charleroi in Wallonia has equipped its 400 vehicles with geo-tracking, thus providing vast information to the authorities on vehicle location, journey times or even the kilometres travelled. The aim of the program is to increase the efficiency of the municipal vehicle fleet and thus reducing public expenditures for controlling abuses of public vehicles.

\section{Surveys}

\section{Types of surveys}

As mentioned previously, surveys may be either quantitative or qualitative. Although in practice the two types are sometimes combined to create a kind of hybrid. Each type is aimed at specific objectives and has different characteristics.

Quantitative surveys are designed to measure or evaluate phenomena in such a way that the results can be extrapolated to the entire target population. This includes polling a sample of citizens to gauge the opinion of the entire population.

Surveys of this type canvass a large number of people - the representative sample - and it must be possible to easily aggregate the data gathered. A structured questionnaire is used containing a limited number of closed inquiries. These are questions having a set list of possible answers. Results are then analysed using statistical tools.

Qualitative surveys are designed to investigate in a manner to anticipate or explain, phenomena without it necessarily being possible to extrapolate the results to the entire population. A limited number of people, often less than 30, are typically involved. They are asked a large number of open questions in order to elicit detailed information.

The discussions are generally quite long, lasting up to one hour and are loosely structured. Since the analysis will focus on remarks made by interviewees, methods such as content analysis are used. User-friendly specialist software is available for some analyses to capture word frequency, and determine whether words used form part of specialized lexicons, as well as word association maps, etc.

Choosing the survey type may not always be straightforward. Sometimes it is first necessary to conduct a qualitative survey to identify problems or hypotheses and then conduct a quantitative study to validate these hypotheses. This is done by enlisting a representative sample of the population. However, it is always important to determine 
the purpose of the study and what is the best approach to garner applicable data. To accomplish this, the study team will also have to answer several questions.

- What types of answers are sought?

- Is it necessary for the results to be representative of the entire population?

- Is the quality of the data gathered sufficient to enable decisions to be made?

Box 4.3 lists typical objectives for quantitative and qualitative surveys in the public sector. Box 4.4 lists the types of quantitative and qualitative surveys conducted by the European Commission.

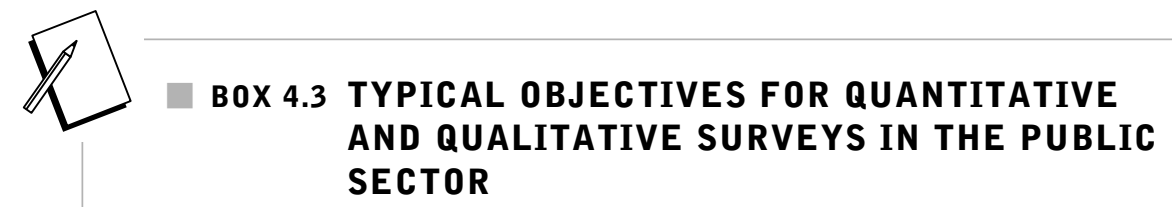

\section{Quantitative survey objectives}

- Test a communications campaign while it is running or afterwards (posttest).

- Study how a service is used by its direct or indirect beneficiaries.

- Study attitudes, opinions or behaviours of the population or certain segments of it in regard to a topical subject.

- Measure the satisfaction of users or customers.

- Gather data for use in developing public policy measures.

\section{Qualitative survey objectives}

- Test the understanding and objectives of a communications campaign (pretest).

- Anticipate potential reactions to a new policy, new service, etc.

- Identify and analyse critical user experiences of a service - both positive or negative.

- Verify the content and comprehension of documents (e.g. a website).

- Generate ideas for improving the service or relations with the public.

\section{Quantitative surveys}

Quantitative surveys can be conducted in various ways: interviews in person - faceto-face - or by telephone, by mail, and in the past few years, by internet (online). In most countries, the most widely used method is the telephone survey, for reasons of both speed and cost. However, depending on the survey's objective, the other forms should also be considered. 


\section{BOX 4.4 EUROBAROMETER SURVEYS CONDUCTED BY THE EUROPEAN COMMISSION}

The European Commission (EC) conducts a series of surveys to analyse public opinion in member countries. This system of surveys is known as the Eurobarometer (http://ec.europa.eu/public_opinion/index_en.htm). It includes four main types of surveys:

The Standard Eurobarometer was established in 1973. Each survey consists of approximately 1,000 face-to-face interviews per member state except in Germany: 2,000, Luxembourg: 600; United Kingdom 1,300, including 300 in Northern Ireland. Reports are published twice yearly.

Special Eurobarometer reports are based on in-depth thematic studies carried out for various services of the EC or other EU institutions and integrated in Standard Eurobarometer's polling waves. Special Eurobarometer reports are based on in-depth thematic surveys carried out for various EC services or other EU institutions. Special thematic questions are integrated in Standard Eurobarometer's polling waves. In November 2015, the European Commission published in the Special Eurobarometer 435 addressing the issue of climate change. Via face-to-face survey interviews $27,718 \mathrm{EU}$ citizens were asked about their view on the issue between May and June 2015. Notably, $91 \%$ of respondents considering climate change a serious problem, with $69 \%$ considering it a very serious problem. Despite the overwhelming concern about climate change, poverty, hunger, and lack of drinking are seen as an even more serious problem in most EU membership countries. However, regional variations have been observed: Nordic countries (Sweden, Finland, and Denmark) rank climate change as the most serious problem facing the world today.

Flash Eurobarometers are ad hoc, thematic telephone interviews conducted at the request of any service of the EC. Flash surveys enable the $E C$ to obtain results relatively quickly and to focus on specific target groups as and when required.

In 2016, the EU published a report on the life quality in the European cities. The report was conducted by the TNS Political \& Social on request of the European Commission. Citizens of the 79 European cities were interviewed represented by a sample of about 500 persons per city. Overall, 8 out of 10 respondents were satisfied to live in their city. Broken down by region, this number displays quite divergent results: while $99 \%$ of Zurich or Oslo inhabitants are satisfied, only the $67 \%$ of the population of Palermo, Italy reported to be satisfied.

Qualitative studies investigate in depth the motivations, feelings and reactions of selected social groups towards a given subject or concept. This is accomplished 


\section{BOX 4.4 continued}

by listening and analysing the respondents' way of expressing themselves in discussion groups or non-directed interviews.

The results of a qualitative study on EU citizen opinion was published in 2015. For this report, public opinion on future innovations, sciences, and technology was assessed through focus-group interviews. Participants from 16 EU countries gave their viewpoints in semi-structured discussions. Overall, the results show that all the participants have a positive opinion regarding innovation. Internet and mobile technology were considered the most important innovations by the respondents.

Telephone surveys, also known as CATI, for Computer-Assisted Telephone Interviews, are favoured because they can be carried out quickly. They also provide a degree of flexibility in how the questionnaire is handled depending on answers already obtained. This makes it possible to control the structure of the sample and avoid possible bias caused by the presence of the interviewer. In addition, they can be monitored to ensure their quality.

On the other hand, because telephone surveys have multiplied, a decreasing rate of response is being observed. Therefore, if a list of the entire target population is not obtained beforehand, it is increasingly difficult to be certain of having a truly representative sample.

For example, people with unlisted numbers, people on 'do not call' registers, people having only a cell phone, or people with no telephone at all, will be excluded from the study. Telephone surveys can only be used to answer simple questions. Complex subjects cannot be adequately addressed over the telephone. Telephonic interviews should always be limited in number and last no longer than 10-15 minutes.

If the purpose of the survey is more complex; if the subject matter is delicate, if there are many possible answers or it requires documents to be presented - layout sketches, logos, etc. - then personal interviews will be preferable.

Normally conducted after making an appointment, this type of survey requires time and is expensive. The budget will have to cover the interviewer's travel and provide pay for the duration of the interview. It should also be taken into account that certain segments of the population are difficult to reach - young people, ethnic communities, etc. - and experienced interviewers are required.

Today, postal or correspondence surveys are quite rarely used because of low response rates. However, they are useful when those surveyed have a proximity relationship with the organization commissioning the survey. Such an inquiry would in some way involve the respondents such as a satisfaction survey of employees of an organization, survey of members of an association, etc. 
This form of survey is very economical when the addresses of the target population are known and also of benefit to respondents. They can choose when to complete the survey as well as take the time to provide well-thought-out answers. And, best of all, there is no pressure from the interviewer.

However, with this type of survey, no control is possible because one cannot know who actually completed the questionnaire or whether the respondent completed some unrelated fields. This form of survey can only be used to canvass people who are sufficiently literate and able to independently complete the questionnaire.

Online surveys are very easy to plan and construct and software applications make it easy to prepare online questionnaires. However, online sampling can be quite complex and therefore, more difficult to conduct in a professional manner.

Unless one has a list of people in the target population and can provide advance information by e-mail - with a link to the questionnaire - it is very difficult to obtain representative samples chosen in a truly random manner. Another roadblock to greater reliance on electronic surveys is, for some countries, the fact that a significant part of the population does not have private internet access.

Secondly, putting a questionnaire together is easy. However, it is equally easy to complete one without giving much thought to the questions asked. Clicking on answers without having properly read or understood the questions is always a possibility. In addition, respondents can easily abandon the questionnaire without having answered all questions.

Provided that information about the target population is available, online surveys can certainly replace postal surveys and, in some cases, telephone surveys. This is because, in spite of the difficulties already mentioned, the advantages of the online survey are immense:

- speed of execution,

- instant capture of answers,

- the possibility of presenting a variety of elements to be tested,

- low cost.

All the above make it a form of survey bound to be developed further.

As part of a study on the images of countries in preparation for the 2010 Shanghai World Expo, a survey was conducted in 2006 with a sample of 2,000 Chinese residents. These people were a representative sample of the urban population having a medium to high standard of living. The results in Figure 4.3 were obtained in response to the question on spontaneous associations people made when hearing the names of various countries.

These graphics reveal the Chinese public associates the United States with the economy, recent wars, terrorism, and American presidents. They linked Germany with World War II, the economy, product quality, and German brands. Finally, Switzerland is associated with watchmaking, landscapes, banks, and skiing. 
SWITZERLAND
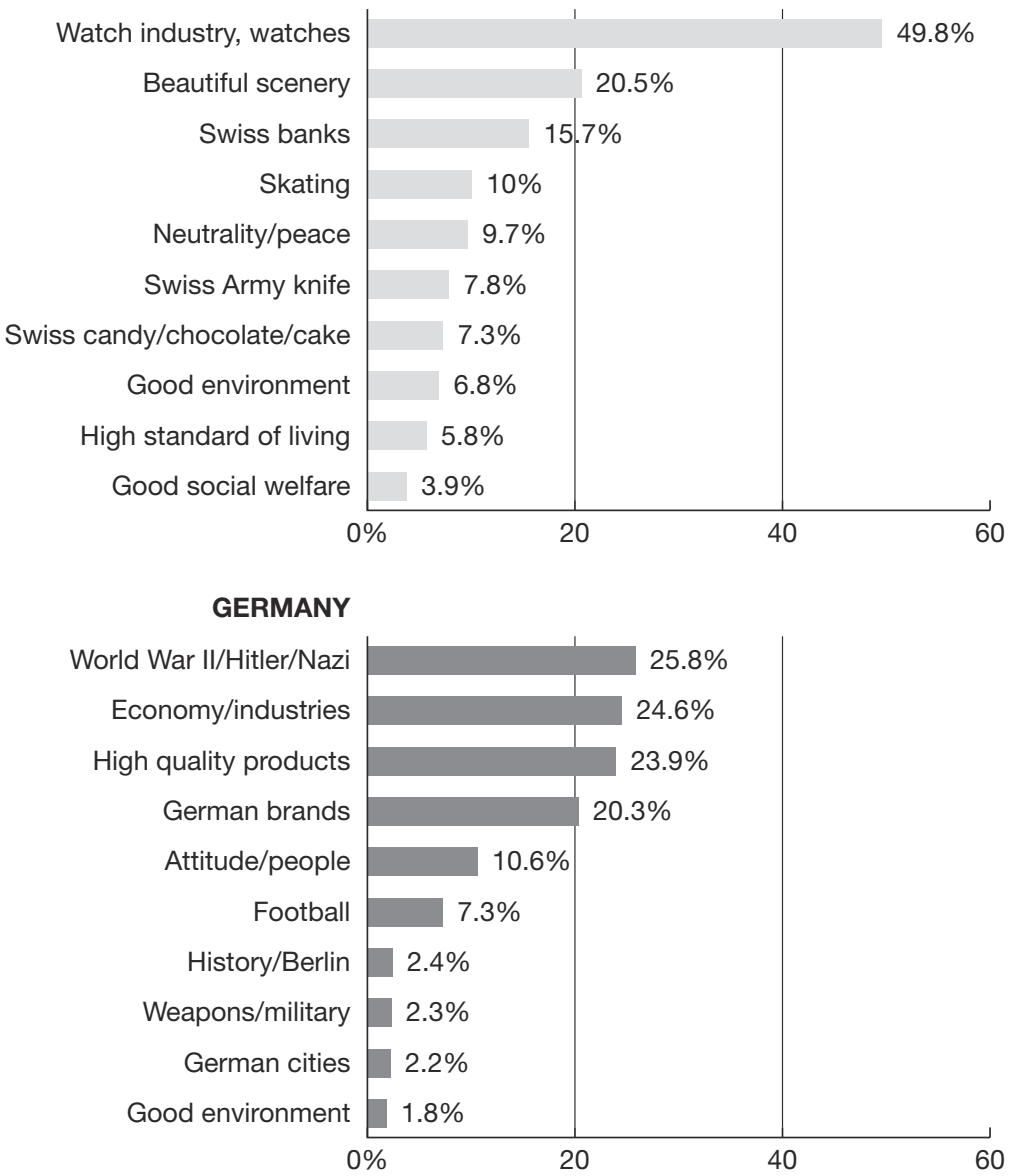

\section{UNITED STATES}

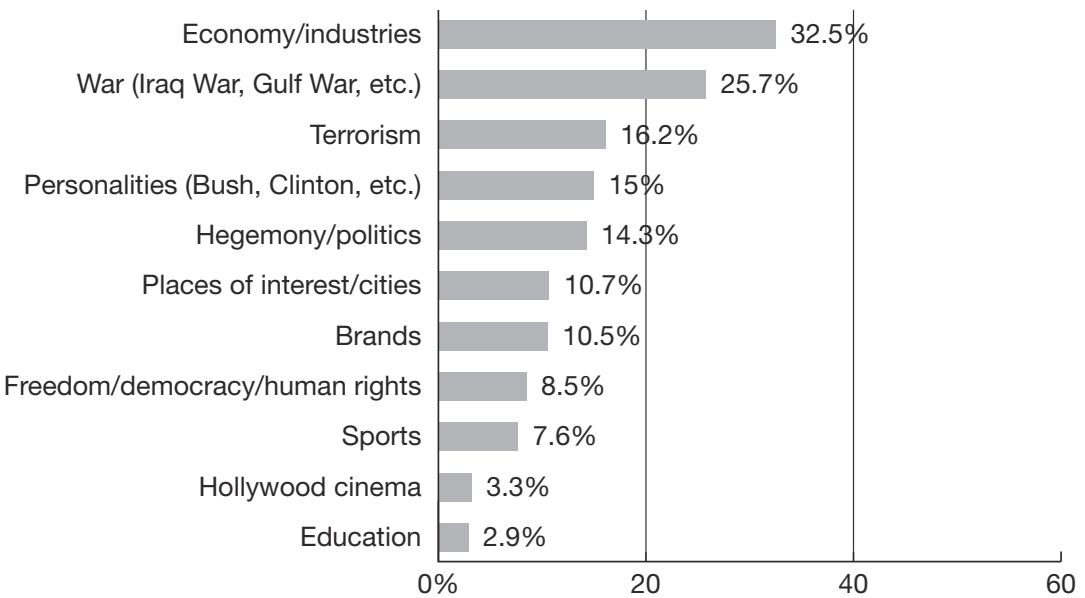

Figure 4.3 The images of Germany, the USA, and Switzerland in China 


\section{Qualitative surveys}

Qualitative surveys generally deal with complex problems requiring a high level of interaction between the respondent and the interviewer who needs to establish trust, adapt questions to the answers already received, etc. These interviews are generally conducted person-to-person.

However, in rare cases, such as when the people surveyed are experts in a field and living in different countries, a telephone quantitative survey can be considered. Finally, there are two forms of qualitative survey: in-depth personal interviews and focus groups.

The basic premise of in-depth personal interviews is that whatever is said in the interview contains or hides deep meaning. By allowing the person surveyed to talk as much as possible, the whole of his or her discourse, both verbal and nonverbal gestures, silences, etc. - provides considerable information. By using specific analysis methods, this form of information gathering allows for better understanding of behaviours, opinions, or intentions.

In the most widespread form (semi-structured/structured) the interviewer uses an interview guide listing the main topics to be addressed. However, he or she will introduce these topics depending on the flow of the discussion, allowing the participant time to respond.

This is done by avoiding direct questions, sidestepping closed questions, or if necessary, reviving the interview by using words previously spoken by the respondent, etc. For reasons of completeness, these interviews are normally recorded with the

\section{BOX 4.5 QUALITATIVE STUDY ON EU CITIZENS AND THE EURO}

This qualitative study was commissioned by the European Commission's Directorate-General for Health and Consumer Protection and conducted in 2002. It was mainly aimed at analysing attitudes to the euro and assessing difficulties encountered by the elderly - those over 70 years of age - as well as those in a vulnerable economic situation. In addition to these two target groups, a control sample was also surveyed.

In each of the three groups, seven people were surveyed in each country, making a total of 263 persons. Each personal interview lasted an average of 60 minutes. This survey highlighted, among other things, the fact the elderly found it difficult to establish a value scale for the euro. They had to convert prices in euros into their former national currency almost systematically in order to be able to establish such a value scale.

Source: Directorate-General for Health and Consumer Protection (2002) 
interviewer rounding out the information by taking notes on non-verbal aspects. Box 4.5 provides an example of this type of survey.

Focus groups or group meetings are based on the principle that interactions among several people on a specific topic will produce results superior to the sum total of information that would be collected from each person individually. The difference lies in the group dynamics developed during the discussion.

Focus groups are normally composed of eight to ten persons and hosted by a trained moderator. They are often recorded so guidance can be given to the moderator and the discussions can be transcribed. Although it is important to have a reasonably homogeneous group, people recruited must not know each other and the amount of information given about the topic to be discussed must be restricted.

The composition of a focus group can affect its results such as when one member exerts a strong influence over other, more passive participants. To circumvent this, it is common for at least two groups to be formed so results can be compared. In addition, depending on the topic and the commissioning body, a small stipend is paid to each participant at the end of the meeting.

\section{Other methods}

An omnibus survey is one conducted on behalf of several organizations, each of which can include a limited number of questions. Organizations can thus benefit from a representative survey even when their need for information is minimal. Perhaps only two or three of their questions will be answered but the information received could possibly be invaluable.

In addition, this type of survey allows costs to be shared by several organizations, each paying on the basis of the number and complexity of the questions asked. This aspect is important, because it allows smaller organizations or those with limited budgets to gain access to this type of survey. Omnibus surveys are frequently designed and conducted by market research firms that announce their intention to conduct a study and give organizations an opportunity to include their questions.

Panels involve questioning and/or observing the same group of people at regular intervals. They gather information on opinions, attitudes, behaviours, etc. The structure and representativity of the panel are very important. Panels of the following types are used:

- Household panel: gathers information on all purchases of consumer goods in a household. In Switzerland, the household panel comprises 5,074 households and 12,031 persons. The EU panel includes 60,000 households (for example 7,000 in France and in Span and 1,000 in Luxembourg.

- Media panel; television or internet: in Germany, 5,000 households agreed to allow a monitoring device to be connected to their television sets. The 'box' then transmits information on channels watched and the characteristics of those watching - their numbers and sociodemographic criteria, etc. The largest television rating panel in the United States, Nielsen, uses some 26,000 households. 
Over time, as people complete several questionnaires, they become more aware of their behaviour patterns. Therefore, there is the risk they will begin to rationalize their behaviour. To avoid some of the constraints involved in this type of survey, those in charge of a panel will ensure panel members are rotated regularly; usually 20-25 per cent each year.

\section{SELECTING A SAMPLE}

For two main reasons, regardless of the method used, it is rare that every member of the target population is surveyed. First, the costs of doing so are extremely high and the benefit is marginal compared with data provided by a sample - such as sufficient approximation for decision taking. Second, the technical and legal difficulties of obtaining a list of every member of the target population would be enormous. For example, nobody has a list of all smokers, or all HIV-positive people, should a study wish to focus on these target groups.

In fact, all members of a population are surveyed in only two cases: during censuses to record population related information and when the population is known and its size is small. A satisfaction survey of all employees in an organization would fall into this category. In all other cases, a representative sample of the target population is taken.

Allowing for a margin of error which is fixed at the outset, the results obtained with a sample can be generalized to encompass the entire population under study. Consequently, depending on the desired accuracy and the complexity of the questions, the size of samples will vary between 50 and 2,000 participants.

It is important to note that the accuracy of results obtained in a survey depends on the size of the sample and not the percentage of the population studied. There is no relationship between the size of the population and the size of the sample. Since methods for selecting a sample are many, only a general overview of these methods is given here. The two most widely used methods - random sampling and quota sampling will be compared later in greater detail. To complete this discussion, information will be given about the size of samples.

\section{Overview of sampling methods}

Generally, sampling methods fall into two categories: probability or random methods and nonprobability or empirical methods.

The principle of probability methods is that the sample is constituted by a random draw from a list of the target population. This means every person theoretically has the same chance of being included in the sample. Realistically, however, there are just three variants (Malhotra, 2009; Vernette, 2002):

- Simple random sampling: members of the sample are drawn at random using computer algorithms, or a table of random numbers if the sample is small. 
- Stratified random sampling: the target population is first divided into strata or groups. For example, people may be categorized by age range or their district of residence. Next, random sampling is applied. This method is very useful when a higher survey rate is wanted for particular groups such as urban populations rather than populations in rural areas.

- Cluster random sampling: the population is divided into clusters - streets, schools, factories, hospitals, etc. Elements from each cluster are then drawn at random and all individuals belonging to the selected elements are surveyed. As an example, let's take a study on the vocational training of young people. One might first draft a list of all existing training establishments or all existing classes. Next, at random, select a number of them, or a number of classes in these establishments. And finally, survey every member of the establishment or class who meets the study criteria.

Nonprobability methods are based on a reasoned selection of individuals for the sample. This is done when complete files are unavailable, when funding is very limited, or when it is relatively difficult to obtain a random sample containing a certain number of individuals who meet various criteria important to the study. However, a number of variants exist:

- Quota sampling: the sample is determined on the basis of characteristics or quotas of the target population. Depending on the survey, these quotas might be professional activity, age, income bracket, social status, and so on. Figure 4.4 illustrates an example of the use of the quota method.

- Convenience sampling: information is gathered from people who are conveniently available - for example, all passengers in a train at a particular time. This solution is very useful for testing hypotheses or carrying out an exploratory study.

Take as an example a study designed to ascertain whether and under what conditions home owners would be prepared to invest in measures designed to reduce their building's energy consumption.

Since we do not have a complete list of all owners and all heating systems, we can proceed by quota to determine the sample. Two quotas could be used. First, the type of residence could be established - a free-standing house or a unit in a multi-occupancy building. Secondly, determine the main type of heating in use - electricity, heating oil, gas, renewable energy sources, etc.

In this instance, 60 per cent of non-owners and 40 per cent of owners are divided into 18 per cent house owners and 22 per cent are owners of strata units in large buildings. If we know the national distribution of the number and type of owners and the main types of heating in these categories, we can initially determine the basic structure of the target population. Thus, if we take owners heating with oil -55 per cent of all owners - then 20 per cent are owners of stand-alone houses while 35 per cent are owners of units in larger buildings. 


\begin{tabular}{|c|c|c|c|c|c|c|}
\hline & \multicolumn{2}{|c|}{$\begin{array}{c}\text { Own an } \\
\text { individual house } \\
18 \%\end{array}$} & \multicolumn{2}{|c|}{$\begin{array}{c}\text { Own a unit } \\
\text { in a building } \\
22 \%\end{array}$} & $\begin{array}{l}\text { Total } \\
\text { owners } \\
40 \%\end{array}$ & $\begin{array}{c}\text { Renters } \\
60 \%\end{array}$ \\
\hline & \multicolumn{2}{|c|}{$45 \%$} & \multicolumn{2}{|c|}{$55 \%$} & $\leftarrow 100 \%$ & \\
\hline Electricity & $10 \%$ & 50 & $10 \%$ & 50 & $20 \%$ & \\
\hline Oil & $20 \%$ & 100 & $35 \%$ & 175 & $55 \%$ & \\
\hline Natural gas & $10 \%$ & 50 & $8 \%$ & 40 & $10 \%$ & \\
\hline $\begin{array}{l}\text { Renewable } \\
\text { energies }\end{array}$ & $5 \%$ & 25 & $2 \%$ & 10 & $7 \%$ & \\
\hline
\end{tabular}

Figure 4.4 Example of quota sampling study

If we chose a sample of 500 people, we could then determine the number of owners to survey for the eight groups arising out of the two defined quotas. In this way, 40 condominium owners who heat with gas should be part of the sample. These people could then be recruited in various ways - by telephone, by ringing doorbells in blocks of flats, etc.

Leaving aside professional surveys conducted by statistics departments making use of multiple forms of sampling methods, the two main methods used to conduct market studies in the public sector are random sampling and quota sampling. Table 4.2 comparatively presents these two methods.

\section{Sample size}

As mentioned above, the size of the sample does not depend on the size of the target population. Instead, it relies on statistical rules, inevitably, and budgetary constraints. Available funds often strongly influence the maximum size of the sample.

Since the objective of a sample is to make it possible to generalize results to the target population, the acceptable risk threshold regarding results needs to be determined. For example, if a 5 per cent risk is tolerated, there will be a 95 per cent chance the result will lay within a defined range.

To be more precise, there is a 95 per cent chance that 51-55 per cent of people who vote in the next referendum will say 'yes'. The numbers support the idea of 'the narrower the level of confidence, the more accurate the survey'. Thus, if the sample is large, accuracy will be good and the results can be generalized without too much risk. Box 4.6 shows how to calculate the sample. 
Table 4.2 Comparison of random sampling and quota sampling

\begin{tabular}{|c|c|c|}
\hline Characteristics & Random sampling & Quota sampling \\
\hline Representation & $\begin{array}{l}\text { Use processes that guarantee } \\
\text { each individual has the same } \\
\text { chances of being drawn at } \\
\text { random }\end{array}$ & $\begin{array}{l}\text { If the characteristics of the } \\
\text { population are available, the } \\
\text { sample representing the } \\
\text { population can be constructed }\end{array}$ \\
\hline \multirow[t]{4}{*}{ Difficulties } & $\begin{array}{l}\text { Databases nonexistent or out } \\
\text { of date }\end{array}$ & \multirow{2}{*}{$\begin{array}{l}\text { Difficult to guarantee good } \\
\text { representation of the population } \\
\text { using quotas }\end{array}$} \\
\hline & \multirow{3}{*}{$\begin{array}{l}\text { Individuals difficult to reach } \\
\text { questionnaire - risk of } \\
\text { certain groups being } \\
\text { underrepresented }\end{array}$} & \\
\hline & & Data regarding certain quotas \\
\hline & & $\begin{array}{l}\text { Risk of easy-to-reach groups } \\
\text { being overrepresented }\end{array}$ \\
\hline $\begin{array}{l}\text { Application } \\
\text { of probability } \\
\text { theory }\end{array}$ & In principle, yes & In principle, no \\
\hline $\begin{array}{l}\text { Choice } \\
\text { influenced by } \\
\text { the interviewer }\end{array}$ & $\begin{array}{l}\text { In principle, no - there is no } \\
\text { choice of people to be } \\
\text { interviewed }\end{array}$ & $\begin{array}{l}\text { Yes, but it is possible to control } \\
\text { the choices made }\end{array}$ \\
\hline Costs & Relatively high & Relatively low \\
\hline
\end{tabular}

Source: adapted from Kühn and Kreuzer (2006).

Take the following example. It is estimated 30 per cent of the people in a town of 20,000 inhabitants are dissatisfied with the services of the roads and highways department. The municipality wishes to verify this information and better understand the reasons for satisfaction and dissatisfaction. Suppose those responsible for the study accept a margin of error of $+/-3$ per cent and a 5 per cent level of risk. The size of the sample is calculated as follows:

$\mathrm{n}=$ sample size

1.96 - or 95 per cent - is the level of confidence

0.3 stands for the 30 per cent of the population who are dissatisfied

0.7 stands for the 70 per cent of the population who are satisfied $(1-0.3)$

0.03 stands for the confidence interval

Thus, for this study, the recommended sample size will be 896 individuals. The size of the sample can be calculated using the formula in Box 4.6. Independently of the possibilities available for determining the sample size and for selecting the individuals making it up, one must bear in mind the risks of error in the representativity of the sample. These risks are of two types: 
- Statistical sampling error: to limit this risk, it is recommended that before analysing the results, various aspects of the sample - such as sociodemographic characteristics - should be compared with those of the population.

- Errors arise from the fact certain groups are overrepresented or underrepresented in the sample. In the example given above, a survey of the roads and highways department in a small town reveals it is possible that all the disgruntled people polled and all those close to people who work in the department will respond to the questionnaire. Conversely, those with no definite opinion will take little interest in the study and not respond. Errors such as these can be identified by using various statistical tests.

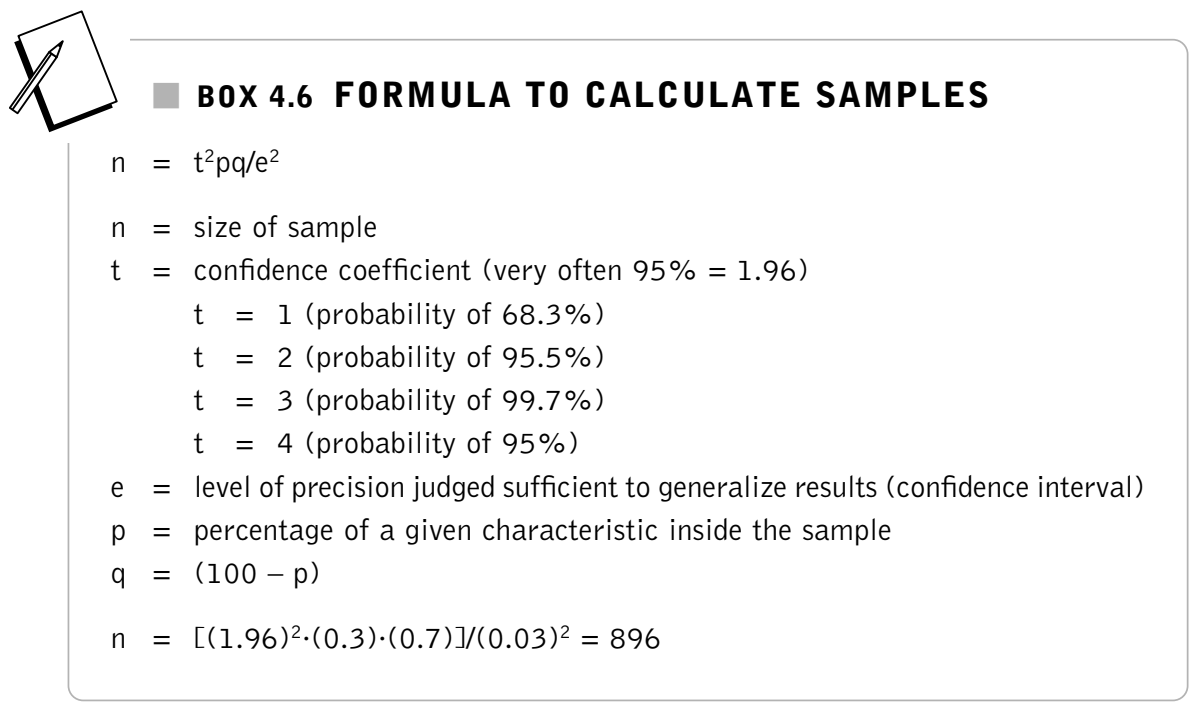

\section{PLANNING A STUDY}

Given the complexity and cost of market research, it is important to plan very carefully. The process can be divided into six phases, set out in summary fashion in Box 4.7.

The first phase is to delimit the problem and decide whether or not to conduct research. This involves defining the purpose of the research and determining corresponding objectives. This phase is very constraining because it necessitates accurately identifying the concrete need for information allowing a decision to be taken.

This will entail finding out whether secondary data are available and evaluating the main research parameters. These would include target populations, possible study techniques, sample sizes, budget, and timetable. On these bases, a decision can be taken on the timeliness and usefulness of conducting primary research.

The second phase is designing the research plan. This involves, first, the design of the study, which must identify the target population and choose the survey technique 


\section{BOX 4.7 PHASES OF A MARKET RESEARCH STUDY}

1. Define the problem and decide whether to conduct the study

- Define the purpose of the research

- Determine the research objectives - the information to be obtained

- Conduct a documentary analysis - secondary study

- Evaluate the main research parameters

- Decide whether or not to carry out the study

2. Study plan

- Research design: population(s) observed, survey techniques, nature, and size of the sample

- Develop data-collection tools - questionnaire, observation system

- Design analysis plan

3. Data collection

- Detailed information on the sample and individuals to be recruited

- Training of interviewers

- Data gathering

4. Data analysis

- Coding of responses

- Data entry and processing

- Statistical data analysis

5. Presentation of results

- Highlight the main results

- Draft study report - with interpretation of results

- Presentation

6. Contribution to the decision taking

Source: adapted from Kühn and Kreuzer (2006)

and nature and size of the sample(s). It is not always easy to identify the appropriate people to be surveyed with precision. For example, in a study of resident's satisfaction at a nursing home, should the survey canvass the residents themselves, their family members, their visitors or outside professionals - physicians, social workers, etc. working on their cases?

Each of the people listed above carries a portion of the information. Therefore, detailed guidelines about those needing to be surveyed will be required. Next, the data-gathering tools - questionnaires, observation system, etc. - must be developed. Box 4.8 sets out the main rules to follow in developing a questionnaire for a quantitative study. 


\section{BOX 4.8 RULES FOR DESIGNING A QUESTIONNAIRE}

\section{Recommendations on the structure of the questionnaire}

- The introduction to the questionnaire must be short, precise, and generally contain the following points: the name of the institution, the purpose of the study, a guarantee of anonymity, and the amount of time required. Depending on the survey's objective, indications of the commissioning body may or may not be disclosed. If the commissioning body's name is likely to influence responses, it could be stated at the outset that the commissioning body will be disclosed at the end of the questionnaire. However, this is not possible if the questionnaire is mailed.

- At the start of the questionnaire, questions must be easy and interesting and must avoid sensitive topics.

- Sensitive topics and more complex questions should, if possible, be placed at the end of the questionnaire.

- Sociodemographic profile questions - age, gender, income, ethnic origin, etc. - are placed at the end of the questionnaire.

- Topical questions must be asked before those referring to the past. It is easier to remember a current or very recent fact than one from the distant past.

- Questions regarding behaviour must be asked before those related to opinions, expectations or motivations.

- Sudden changes of topic must be avoided, as well as long lists of very similar questions. If many questions are monotonous, intervening questions to reawaken participants' interest should be inserted.

- Put one or two open questions at the end of the questionnaire if no questions of this type have yet been asked.

- At the end of the questionnaire, thank the participants for taking part in the survey.

\section{Recommendations regarding the formulation of questions}

- Questions must be concrete, short, and unambiguous. Abstract questions, complicated definitions, and technical jargon must be avoided. If necessary, questions must be adapted in the light of the experience of those polled young people, the elderly, foreigners, etc.

- Questions must be asked in a neutral manner. No suggestive questions or those containing value judgements are allowed.

- Each question must contain only one element requiring an answer. Avoid binary questions dealing with several ideas. 


\section{BOX 4.4 continued}

- Because respondents have a tendency to be positive in order to please the interviewer or they wish to avoid having to justify a negative answer, it is practical to vary the manner in which questions are formulated.

- When the same scale is used throughout a questionnaire, respondents tend to give the same answers and to use the same parts of the scale. For this reason, it is useful to vary the scales.

- In closed questions, it is advisable to add an alternative response category such as 'Other' or 'Don't know'. A 'don't know' answer is preferable to a forced response which does not reflect reality.

Sources: Hague and Jackson (1999); Freudiger and Stihl (1996).

Lastly, this phase must also specify how the results will be analysed. It is important to avoid first collecting the data and only afterwards addressing the issue of how they are to be analysed. At this point, it is still possible to refine the collection tool - the questionnaire - to ensure information needs are covered.

The third phase is data collection. Details regarding the recruitment of individuals and the sample are decided upon, interviewers are trained, and the data is gathered. This phase is followed by data entry and then data analysis. Before entering the collected information into a computer system, all responses must be coded.

For example, if the questionnaire includes a query such as 'What do you spontaneously associate with the Netherlands?' a decision must be made. It must be determined whether the responses 'flowers', 'floristry', 'roses', 'tulips', etc. should be grouped into a single category or should a category be opened for every association. The latter decision would make analysis and interpretation very difficult.

The last two phases involve the presentation of results - formatting of the main findings, study reports, oral presentations to deciders - and, lastly, decision taking.

\section{MANAGING INFORMATION IN AN INFORMATION SYSTEM}

Many studies are conducted in organizations where information is gathered on an ad hoc basis. Often they respond to a one-time need for information in connection with a decision needing to be taken or a particular requirement of an authority. Such a study would seek data relating to particular questions such as: What percentage of smokers are less than 18 years of age? What is the satisfaction level of beneficiaries of a service?

Although these studies can resolve the information problem at a particular moment, the designers and producers of these surveys often fail to consider how the data can be integrated into an information system. As a result, a great deal of information is 
gathered with no possibility of subsequently comparing it with information gathered during other studies with different samples, or variables defined differently, etc.

Because the information is not integrated into the system, in a few years nobody will know the location of the data. In another scenario, the data may be no longer available in electronic format, or they cannot be imported into a compatible system. Therefore, when carrying out a study, it is important to consider and plan for the integration of data to be gathered into an information system. This will prevent wastage of resources and improve the organization's efficiency.

An information system is an organized set of elements which allows the collection, storage, processing, and above all, structured dissemination of information on a given phenomenon. This includes products, customers, competition, the organization's processes, etc. It is principally comprised of:

- a set of resources - data, personnel, equipment, procedures, etc. - that make it possible to acquire, store, structure and communicate information in various forms like texts, tables, images, and so on.

- a computer system enabling all the data to be linked and managed.

Today, business operators realize the importance of relationships in attracting and keeping customers of value. Therefore, the company must devise, manage, and use systems to control mass quantities of customer-related information. Collected data should include customers' names and other personal information, their purchases, purchase frequency, corporate hospitality events, claims, and services rendered, etc. All have become vitally important for business success.

In many sectors, the cost of securing the fidelity of an existing customer is considerably lower than the expense of acquiring a new one. This means it is worth investing in the management of relations with existing customers. This field is generally known as Customer Relationship Management (CRM).

Systems for managing data on users or beneficiaries of services are not limited to the private sector. The public sector also has an interest in developing such systems for the purposes of gaining better knowledge and optimizing the use of services.

Take the example of the school system. In very many countries, every time a pupil or student moves from one level or institution to another, he or she or a parent must complete new forms, provide transcripts or examination results from previous levels, and more.

This involves the use of specific resources such as staff assigned to the task, forms developed by schools, computerized tools, and so forth. This can also lead to possible loss of information and the introduction of errors in the completion of questionnaires or their entry into the computer system.

Consequently, an integrated system able to track the student's progress independently of his or her study level and the institution attended would make it possible to economize on resources. The pitfalls previously mentioned could be 
avoided. Above all, this type of system would deliver not easily obtainable information in a fast and complete manner.

Without a system as described above, information - such as finding the percentage of students who repeat a year during their education; the effect of support and integration; measures on results; or the relationship between marks obtained in early educational levels and the choice of academic or vocational training - could be extremely difficult to locate.

In summary, analysis of existing data and the gathering of new statistics in ad hoc studies must be, as far as possible, carried out using information systems allowing this data to be used over time for monitoring purposes and to make them available to those who may need them for authorized purposes.

\section{EXERCISE 4.1}

1. Define an information research strategy for the following hypothetical situations and identify the possible pitfalls.

- satisfaction of patients in a local hospital

- identification of potential users of a new sport complex

- citizens' perception of an environmental policy regarding traffic lanes to be reserved for cars carrying more than two people.

2. Think about the multiple ways in which a university can collect information about students and how the university administration can use this data.

\section{DISCUSSION QUESTIONS}

This chapter addresses the collection of information by the State.

1. How justified is the State in seeking information, especially for exploratory reasons?

2. Is it not the role of parliamentarians to anticipate the needs of citizens?

3. What is the role of the State? More specifically, what is the role of its administrative and political branches in this situation?

4. In Montreal, a smart card called OPUS provides an easy way to use public transport throughout the city. In order to get the card, it is necessary to provide personal data. Further, the movements of card users is recorded for statistical purposes. Discuss the advantages and disadvantages of this system. What are the limits and considerations of large scale data collection as in this example? 


\section{REFERENCES}

Directorate-General for Health and Consumer Protection (2002) Qualitative Study on EU Citizens and the Euro in the Months Following its Introduction, Brussels, European Commission.

Freudiger, P. and Stihl, S. (1996) Methodische Handlungsregeln zur Gestaltung von Fragebogen und zur Formulierung von Fragen, Bern, Institut für Marketing und Unternehmungsführung der Universität Bern.

Hague, P. and Jackson, P. (1999) Market Research: A Guide to Planning and Evaluation, London, Kogan Page.

Institute for Citizen Centered Services (1998) Citizen First - Common Measurement Tool, Ottawa, Institute for Citizen Centered Services.

Kühn, R. and Kreuzer, M. (2006) Marktforschung: Best Practices für Marketingverantwortliche, Bern, Stuttgart, Vienna, Haupt Verlag.

Malhotra, N. (2009) Marketing Research: An Applied Orientation, New York, Pearson Education.

Pasquier, M. and Weiss Richard, M. (2006) Das Image der Schweiz in China: Ergebnisse der Länderstudie China, Berne, Presence Switzerland.

Schmidt, F. (2000) Sondages sur la Satisfaction des Clients: Guide du Gestionnaire, Centre Canadien de Gestion.

Vernette, E. (2002) Techniques d'études de Marché, Paris, Vuibert. 


\section{Chapter 5}

\section{Marketing strategy}

\section{LEARNING OBJECTIVES}

By the end of this chapter you should be able to:

- Understand the various steps in the strategic planning process.

- Identify and select the appropriate elements and tools of marketing analysis.

- Understand the process leading to the determination of marketing strategy, taking into account implementation dynamics and the inherent limitations of this approach.

\section{KEY POINTS OF THIS CHAPTER}

- The structuring of strategic processes differs significantly between public and private organizations, notably in terms of translating political objectives into managerial action.

- Marking strategy is divided into analytical/information-gathering and decisional phases. The analytical phase may focus on the market, the demand side, the supply side and/or the organization's marketing resources.

- To develop a marketing strategy, the following issues must be addressed:

(a) choice of market and target group priorities

(b) competitive strategy

(c) positioning of the organization

(d) market exploitation strategy. 


\section{KEY TERMS}

Marketing strategy - the frame of reference for the means and objectives used by an organization in its marketing activities.

Translation - the passage from political objectives to managerial action.

Segmentation strategy - when an organization focuses on a specific sub-group, based on specific needs or demographic criteria.

Differentiation strategy - when an organization's strategy is focused on the specificities of its products and services as a competitive advantage versus other organizations.

Price strategy - when an organization's strategy is focused on the lower prices of its products and services as a competitive advantage over other organizations.

\section{STRATEGIC PLANNING PROCESS}

Marketing strategy provides an organization with a framework for carrying out its marketing activities. 'Strategy' is originally a military concept, basically aiming to determine goals and how best to obtain them. More precisely, Mintzberg (1992: 12-19) defines strategy on five different levels or the five Ps:

- Plan: a purposive course of action or guideline to deal with a given situation with actions developed consciously and purposefully.

- Ploy: designed to gain competitive advantage or pose a threat to a competitor.

- Pattern: more than just a plan - the actions needed to accomplish it.

- Position: where an organization wants to be on a given market - characterizing the relationship between the organization and its environment.

- Perspective: the shared vision of how an organization's personnel see the world common values - as shown by their intentions and actions.

Before outlining the process for developing a marketing strategy, we shall first look at how marketing strategy can be applied to a public organization. Primarily, it must be understood the institutional, organizational, and market contexts are very different for a private company than for a traditional public body.

\section{Strategy within a public organization}

Figure 5.1 presents a comparative overview of how strategic processes are structured in private and public organizations. For major organizations, four strategic levels can be identified as: 
Private organizations

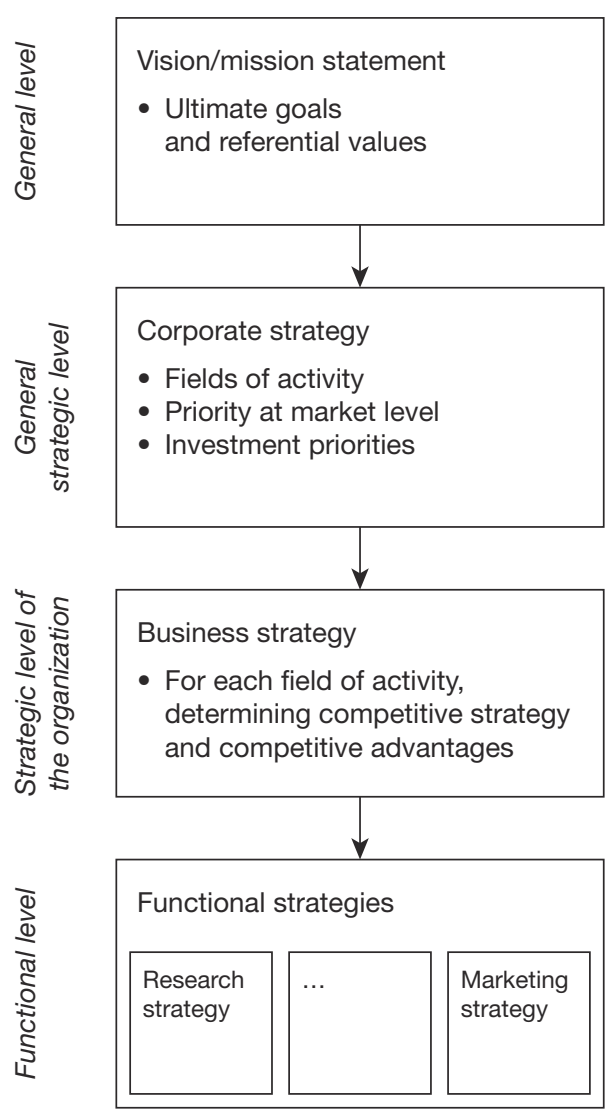

Public organizations

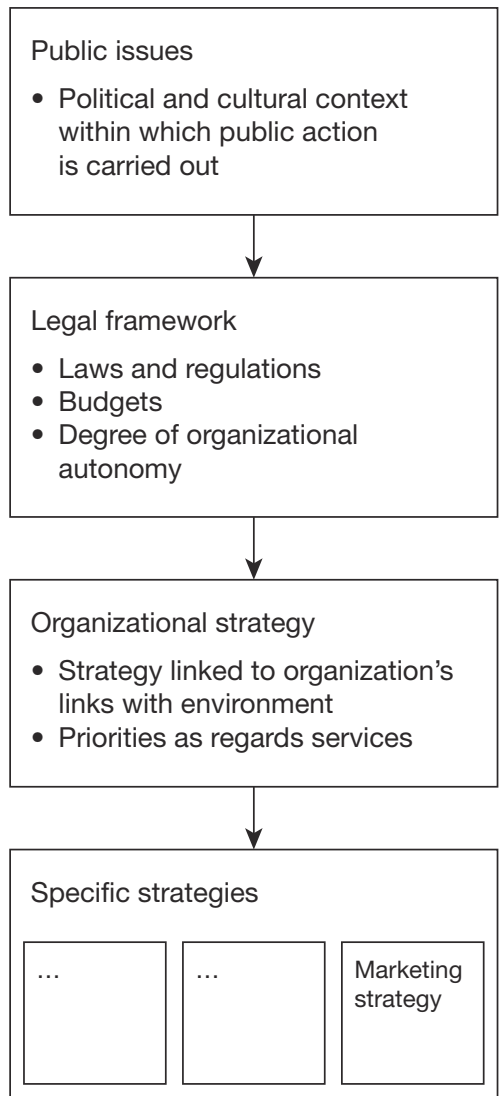

Figure 5.1 Strategic development processes: comparison between private and public organizations

- the general level not linked to any specific time-frame;

- the overall strategic level, defining main priorities;

- the strategic level - within the narrow sense of the term - the organization pursues its development, notably in regard to its competitors;

a and, lastly, the functional level.

In private companies, the general level involves the corporate mission - 'We are a bank involved in international wealth management' or 'We are a security firm involved in protecting goods and people.' This involvement would also include the values its staff should respect in their attitudes, decisions and behaviour. Staff must have 'total confidence', 'respect for the hierarchy', as well as a 'high degree of confidence accorded to staff', etc. 
'Unless a major event occurs' implies significant change such as a merger with another company or investing in a totally new field; these elements are likely to remain for the long term and only evolve gradually (Grünig and Kühn, 2008).

The next level is corporate strategy. For major companies active in a number of fields and/or different markets, these fields need to be defined. Some examples are investment banking, private wealth management, corporate wealth management, retail banking, etc. So, too, must priorities in terms of market and more importantly, investment given that a company may not be able to finance all the developments necessary in every arena.

A business strategy must then be drawn up for each area defined. Generally speaking, as private companies are active in competitive markets, relevant strategic decisions must enable a competitive strategy to be defined (see Porter, 1985). In addition, they must identify the effective competitive advantages which will help clients view the company differently from its competitors.

The time-scale for these two levels naturally depends on the economic context and on which sector the company is active. It is, however, worth noting that corporate strategies are often planned over a five to ten-year period. Conversely, business strategies sometimes need revising or updating every three to five years. For small or medium-sized companies - whose activity is concentrated in a single field - corporate and business strategies tend to be one and the same.

Marketing strategy is one of a company's various functional strategies and includes research strategy, production strategy, etc. This kind of approach must identify priority target groups in a field of activity and/or a specific market. Such a plan, combined with a competitive position resulting from a competitive strategy and the principal measures at the instrumental level, should create a viable marketing mix.

The rationale for establishing strategy for a public organization is very different. Firstly, at the general level, public action takes place in response to public problems. Remember, there can be no public intervention without a 'public' problem to start with. The political and cultural framework within which public action is carried out varies greatly from country to country, and even from region to region.

Let us take the example of police action to maintain road safety. National priorities and preventive/repressive measures vary considerably in nature and scope from country to country. They may evolve over time, but depend largely on political and cultural criteria. Exceeding the speed limit by 20 kilometres per hour is not punished in the same way in the USA as in Italy.

At an overall strategic level, public activity is defined on the one hand by laws and regulations, or aspects of public policy. On the other hand, strategies are governed by arrangements concerning the organizations responsible for carrying out these tasks the degree of organizational and decision-making autonomy.

Matters are affected by whether an organization is a legal entity or not, with its own budget, right to hire personnel, etc. Organizational strategy only occurs at the following level, and must take account of both the context previously mentioned, and the organization's environment. These are both discussed in more detail below. 


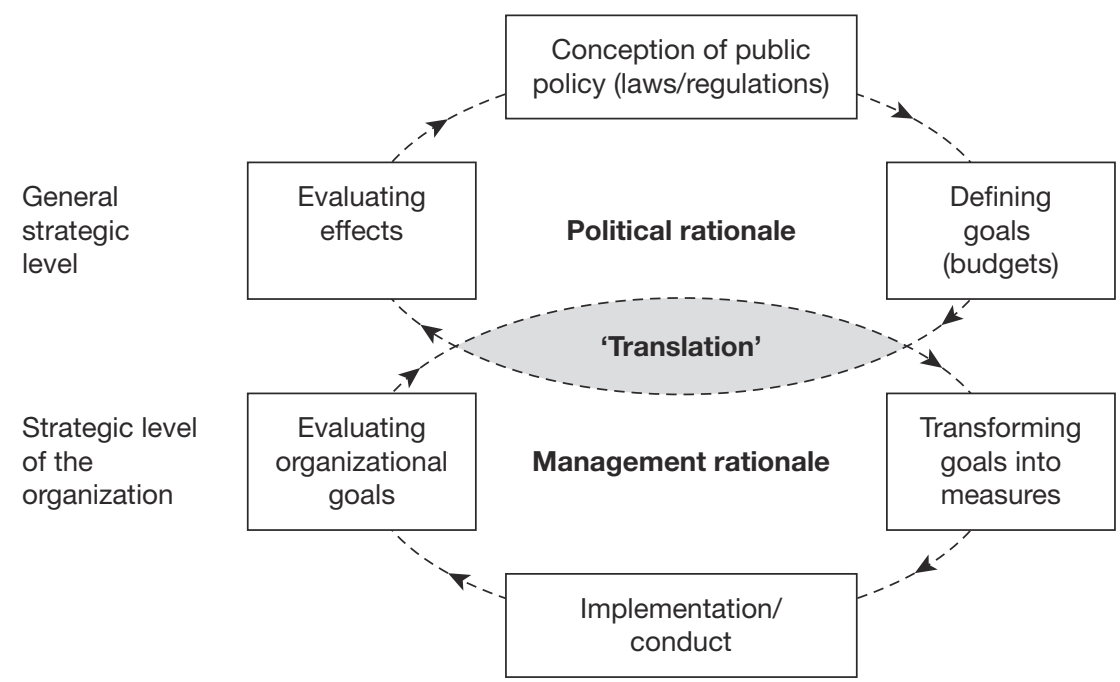

Figure 5.2 Interaction between an organization's political and strategic levels

Source: adapted from Schedler and Proeller (2003).

In private organizations, the passage from corporate to business level is relatively straightforward. But, in the public sector, the relationship between legal framework and organizational strategy is more complex. This occurs because the legal framework has a political base, while organizational strategy depends on an economic and managerial rationale. Figure 5.2 illustrates the interplay between these two levels.

One of the problems for an official in a public organization is to 'translate' decisions resulting from political rationale and debate into objectives and practical measures able to be implemented. In ensuring road safety, laws and regulations voted by parliament require road users to respect the law so fewer accidents occur. No political decisionmaker would dare assert that an annual threshold of, say, 5,000 deaths on the roads is acceptable.

In theory, a politician's approach and activity will target a decrease in the number of deaths, with the objective of attaining zero deaths. The police need to translate political intentions into practical measures - based on budgetary means at their disposal. They must also do the same on more technical criteria like greater presence at 'accident-prone areas' or outside schools; more speed-checks and breathalyser tests, installing new radar detectors, etc.

The police cannot prevent every type of accident or dangerous behaviour since they also have other duties like ensuring the safety of goods and citizens, crime-fighting, emergency services, etc. Therefore, they must choose what to prioritize and ensure measures are implemented in a structured and coordinated fashion. In addition, they must evaluate results not just in terms of public policy goals but also with respect to available resources. 


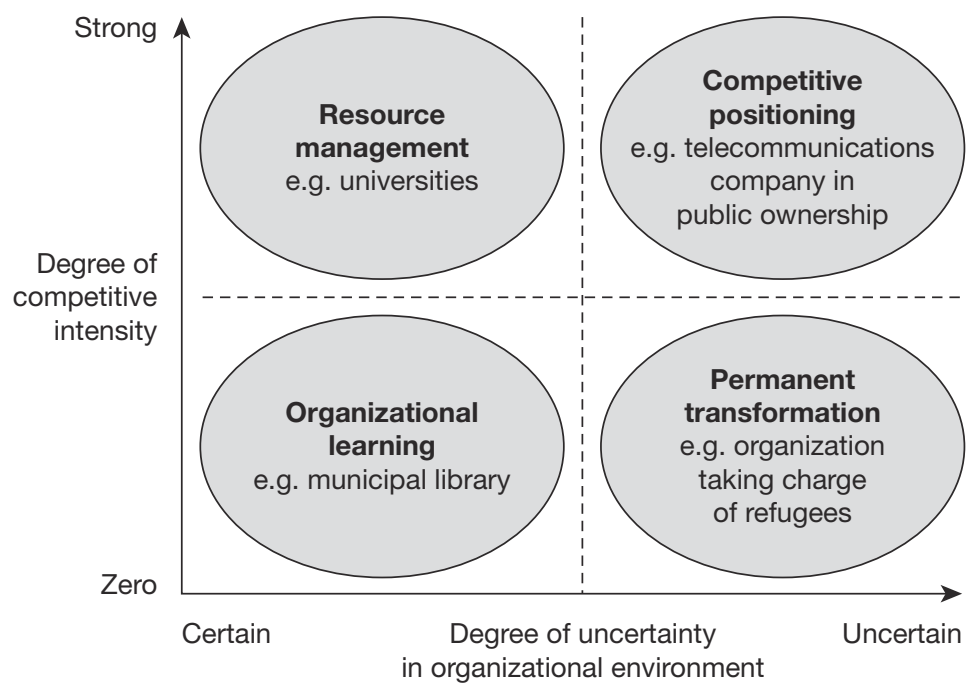

Figure 5.3 Possible public organization strategies

The environmental context also needs to be taken into account when defining an organization's strategy. Unlike private companies, the overwhelming majority of public organizations do not face competition, so they do not need to develop competitive strategies. Another reference framework must therefore be found for public organization strategies. Two criteria help establish a typology of a public organization's possible strategic orientation. These benchmarks are: the degree of competitive intensity and the degree of uncertainty in the organizational environment. Figure 5.3 looks at these two criteria and suggests strategies that result from combining them.

Should an organization find itself without any direct competition, and in a relatively stable environment, with no likely change to its public mission, budgetary stability, etc. strategy will basically consist of achieving constant improvement or organizational learning. These can be achieved through staff training; if possible, establishing a dialogue with consumers; paying attention to outside criticism, and benchmarking - making comparisons with similar organizations in other regions to improve procedures, etc.

The situation is different if, despite a relatively stable environment, there is a high degree of competitive intensity. Direct or indirect competition cannot be ignored. So, rather than seeking to position itself in relation to its competitors, an organization needs to have its own 'preferably unique' resources, which similar organizations cannot offer.

Some universities, facing competition from other learning institutions, have perfected high-level teaching and research capabilities. They do this because they are compelled to focus on and reinforce these specific resources to maintain their preeminent position, reputation and status. 
The third, less frequent scenario concerns a relatively unstable context and an absence of competition. An organization's mission - or some of its major aspects may change rapidly. Accordingly, it must maintain the flexibility needed to respond to unexpected tasks.

For example, an organization whose mission is to house and feed asylum-seekers, and deal with the relevant administrative tasks, should be able to react quickly to a sudden influx of refugees in the wake of political conflict. They must also have the language skills needed to communicate with them, and have staff able to understand the refugees' sociocultural habits.

The final scenario has similarities with the private sector, involving intense competition and an unstable environment involving technological developments, market liberalization, etc. In these circumstances, strategies tend to be the same as those adopted by private companies, as described by Porter (1985). Organizations basically have a choice of three strategy types:

- Segmentation strategy: concentrating on a segment or niche such as a set of clients with specific, identifiable needs distinct from those of other segments.

- Differentiation strategy: the organization wishes to exploit the market as a whole, offering specific competitive advantage other organizations lack. Such pluses could include a high level of service, superior level of quality, products adapted to client's needs, and so on.

- Price strategy: the organization's prices are the most attractive on the market and help it stand out from its competitors.

This final scenario appears infrequently in the public sector and mainly concerns public enterprises active in liberalized markets - telecommunications, postal services, electricity, etc.

\section{MARKETING STRATEGY PLANNING PROCESS}

In the public sector, marketing strategy is a functional approach which must answer the following questions:

- Who does the service offer target? Can the offer be differentiated to target specific groups?

- What is the effective offer being addressed to these persons?

- What is the offer's image and profile?

- What are the quantitative and qualitative objectives?

- How will the offer be proposed on the market - by price; means of communication; where available?

Answering these questions requires a planning process which includes an analysis phase, followed by a decision-making phase. Both phases must then be presented in detail (see Figure 5.4). The analysis phase integrates market analysis and an analysis of 


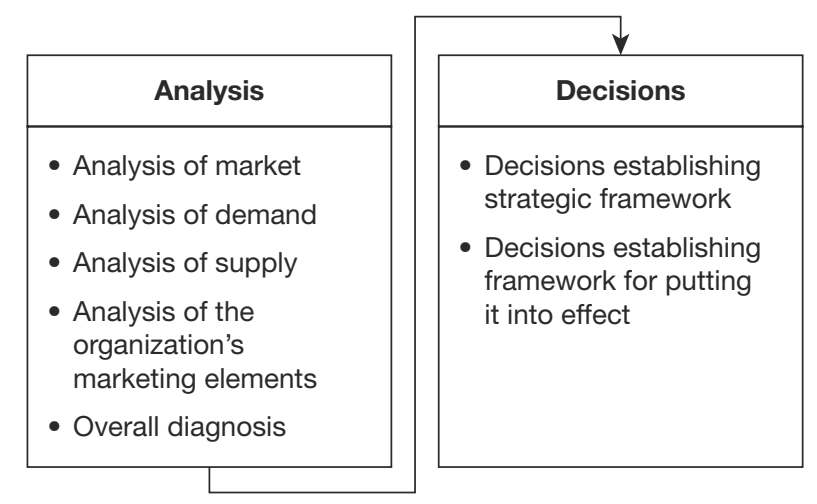

Figure 5.4 Phases of marketing strategy

the demand, the offer, and the organization. The decision-making phase differentiates between decisions fixing the strategic framework and those preparing the framework for setting the strategy into effect. The next two sections deal first with the analysis phase, then the decision-making phase.

\section{ELEMENTS OF ANALYSIS}

A situation analysis helps obtain and structure the information needed for decision taking. It should lead to an overall diagnosis highlighting an organization's strengths and weaknesses and what it has to offer, as well as the risks and opportunities it confronts in the market. Figure 5.5 shows the several analytical phases, comprising (1) a general market analysis; (2, 3) specific analyses of the market's twin components; demand and offer; and (4) an analysis of the organization's own marketing elements. A diagnosis based upon a synthesis of the information obtained (5) completes the analytical stage.

Before looking at these phases in more detail, it should be made clear that the elements mentioned in Figure 5.5 are the subject of more or less detailed studies, depending on the market context and on their relevance. Some points warrant detailed analysis, while the response to others may be obvious or irrelevant. These limitations must therefore be used with flexibility and adapted to the context.

\section{Analysing the market}

The first phase aims to study the 'market' and its principal actors. The tools linked to constructing the market system (see Chapter 4) can be used, as they help identify the leading participants and the links between them. Along with an analysis of all the elements liable to influence market development such as technological changes, modifications to the legal framework, economic situation, etc. The overall development 


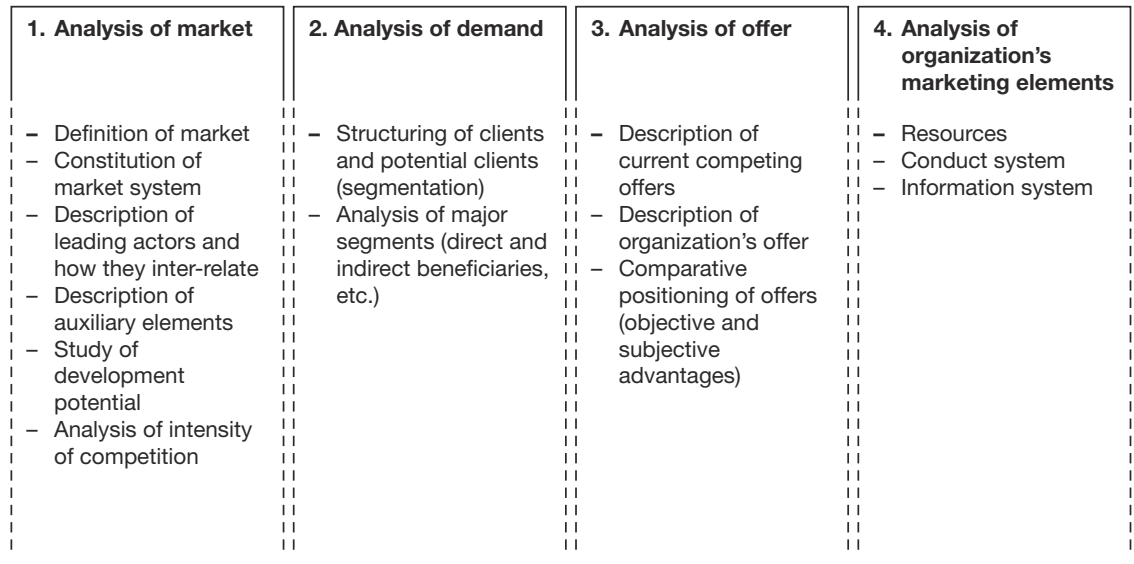

\footnotetext{
5. Overall diagnosis

- Market risks and opportunities

- Strengths and weaknesses of organization's offer
}

Figure 5.5 Stages of marketing analysis

potential should also be assessed to make it easier to reply to demand as and when necessary. Finally, depending on the market context, the intensity of the competition is analysed. Obviously, in the absence of competition, such analysis is unnecessary.

\section{Analysis of the demand}

Structuring and analysing demand - known as market segmentation - is at the heart of the marketing strategy planning process. Most authors agree that segmentation is one of the most important marketing concepts. It first appeared in specialist literature in 1956, in an article published by Smith (1956), who described it as follows: 'Segmentation is based upon the development of the demand side of the market. It is attributable to the desires of consumers or users for more precise satisfaction of their varying wants.'

The basic rationale behind this type of structure is that a competitive relationship among products can be treated directly through consumer characteristics. Different needs and expectations help create homogenous consumer groups/segments likely to behave in similar fashion, and can be targeted by specific measures.

It follows that, for segmentation to be used, demand needs to be heterogeneous; having different purchase criteria. Additionally, these resulting markets must be sufficiently interesting for a company's profitability to be assured.

There are two ways of distinguishing the various segmentation criteria from one another. The first centres on the relationship between the person and product or service desired. But is it a direct and objective relationship, or an indirect relationship? The 
Table 5.1 Typology - segmentation criteria

\begin{tabular}{|c|c|c|c|c|}
\hline & \multicolumn{2}{|c|}{ General consumer properties } & \multicolumn{2}{|c|}{$\begin{array}{l}\text { Product-specific consumer } \\
\text { properties }\end{array}$} \\
\hline $\begin{array}{l}\text { Direct and } \\
\text { objective } \\
\text { relationship }\end{array}$ & \multicolumn{2}{|c|}{$\begin{array}{l}\text { Sociodemographic and } \\
\text { socioeconomic characteristics }\end{array}$} & \multicolumn{2}{|c|}{$\begin{array}{l}\text { Observable criteria of } \\
\text { consumer behaviour }\end{array}$} \\
\hline \multirow{2}{*}{$\begin{array}{l}\text { Indirect } \\
\text { relationship }\end{array}$} & \multicolumn{4}{|c|}{ Psychographic characteristics } \\
\hline & $\begin{array}{l}\text { General } \\
\text { criteria }\end{array}$ & \multicolumn{2}{|c|}{$\begin{array}{l}\text { Mixed } \\
\text { criteria }\end{array}$} & $\begin{array}{l}\text { Product-specific } \\
\text { criteria }\end{array}$ \\
\hline
\end{tabular}

second concerns general consumer properties or product-specific consumer properties (see Table 5.1). Combining these two approaches yields the following groups of criteria:

- Sociodemographic, socioeconomic and sociogeographic criteria: gender, age, size of household, religion, domicile, geographic criteria, revenue, profession, etc. These are the oldest criteria corresponding to the general characteristics of the various parties. They are often used since the information is easy to obtain and understand but their relationship with market purchasing behaviour can be tenuous.

- Behavioural criteria linked to products: choice of product, intensity of purchase or use, price sensitivity, preferences as regards the distribution system, etc. These behaviour-linked criteria may vary and do not concern individuals as such, but rather how they react to a range of marketing activities or stimuli.

- General psychographic criteria: reasons for purchasing, or personality. These criteria are of an introspective nature and cannot be directly obtained. Motivation is a construct, involving both a need and how to satisfy it. Segmentation linking behaviour to personality criteria is open to criticism given that it attempts to explain consumers' behaviour by their traits of personality - obsessions, degree of introversion, etc.

- Mixed psychographic criteria: attitudes, lifestyles. Attitudes have special importance in consumer research. This concept simultaneously integrates a product, person and situation on which a judgement is made. The use of variables describing lifestyle involves measuring the activity of those questioned in terms of interests, basic sociodemographic variables, their opinions, and so on. It derives from the hypothesis that, by better understanding consumers, it is easier to communicate with them.

- Psychographic criteria linked to products: advantages or profits obtained. These criteria are based on the advantages consumers gain when buying and/or using a product. The benefits consumers seek from using a product are supposed to be the fundamental reasons for the existence of market segments. 
In his segmentation case study of high-speed train users in Germany, Perrey (1998) used mainly behavioural criteria linked to the product. Price of the service offered; psychographic criteria linked to products, social utility, ecological aspects, etc. were taken into account. Box 5.1 shows the results of the study, made from a sample of over 5,000 users. In a similar analysis, this time of the Dutch train users, van Hagen (2009) used in addition sociodemographic criteria to identify six types of users: the 'Explorer', the 'Convenience Seeker', the 'Individualist', the 'Functional Planner', the 'Socializer and the 'Cerrtainty Seeker'.

A variety of methods can be used to carry out a segmentation study. The most frequent is the intuitive or empirical method, based on experience and general observation of the market and its actors. An example if this is when one wishes to segment demand for training in the medical field, criteria. Research may include participants' needs - professional improvement or career-guidance, general knowledge, etc. and/or availability - evening classes, full days, weekdays or Saturdays - to structure demand.

The other possible approach involves using statistical methods or hierarchical analysis. Such methods are commonly used in the fields of medicine, biology or archaeology and aim to structure observed data into explicit groups, allowing taxonomies to develop. Technically speaking, such methods rely on separating objects into groups. This is done so that each object in a group is more similar to other objects in the same group than any object in another group. Box 5.1 reflects a hierarchical analysis of personal data.

An alternative to constructing a specific typology for a market involves taking an existing general typology whose lessons can be used with the help of complementary information.

Whether intuitively or ideologically, it soon becomes apparent that market segmentation can create problems in the public sector. This is especially so when results produced are likely to distort principles of fairness and equality. However, for reasons of both economy and efficiency, segmentation may help in identifying bias in the distribution and utilization of public services. In addition, if there are significant differences regarding users' potential access to services, it may help more effective public policies to be introduced.

For instance, segmentation of the population according to the use they make or might make of a municipal library could help to adapt the offer to these various groups. Moreover, it could be used as a mechanism allowing the municipality to pay closer attention to groups who are unaware of, or do not use, these services.

Likewise, bodies responsible for activities of prevention are obliged to structure all the persons liable to be affected by their offer and message. For example, in the area of AIDS prevention, such activities and information will obviously vary, depending on which group is addressed. Some of these groups could include those carrying the virus; members of their family; adolescents; or high-risk groups - prostitutes, prisoners, etc.

Structuring groups in the most homogenous way possible helps the corresponding measures be targeted more efficiently. Once the structures are obtained, it is still 


\section{BOX 5.1 SEGMENTATION OF HIGH-SPEED TRAIN USERS IN GERMANY}

\section{Price-conscious clients}

This market segment accounts for 51 per cent of rail users and is the largest in numerical terms. The main criterion when choosing a means of transport is the price - followed, at some distance, by journey time. Such train users view the study's other criteria - service, facilities and social usefulness - as secondary.

Because of its relative unimportance to users, service offers railway companies little scope to stand out. Compared to the other two segments, price-conscious clients are younger, and include men and women in roughly equal numbers. A large proportion of these users are still in training (24 per cent), and their average disposable income is comparatively modest.

\section{Clients in a hurry}

This market segment concerns users for whom journey time is the main criterion when choosing their means of transport. Price is less important, although not irrelevant; other criteria are not decisive. This segment represents 31 per cent of users. Clients in a hurry are most often age 27-55 and predominantly male. They represent just over two-thirds of users of the service.

They are employed in the private and public sectors, with a monthly income of over 3,000 euros, and describe their journeys as business trips or shuttles. They tend to buy their tickets at sales points other than train stations. Price-conscious clients in a hurry represent over 80 per cent of total demand.

\section{Comfort-lovers}

This is the smallest market segment and represents 18 per cent of users. Journey time and price are of secondary importance to such clients. Instead, they attach overriding importance to service and facilities, with the former outweighing the latter. This segment therefore offers railway companies the opportunity to stand out by providing a better level of service. The scant importance of price shows that customers in this market segment are prepared to pay more for good service and facilities. This naturally suggests there is an unexploited margin potential at a corresponding level of cost. The majority of comfort lovers are 27-59 years of age, male, salaried, or retired with above-average disposable income. 
necessary to analyse and describe the most important segments, notably to ascertain what affects their importance, stability, and relevance in helping target specific offers.

\section{Analysis of the offer}

Structuring the offer involves identifying and grouping together differences among offers considered substitutable. A distinction may be made between structures based on a product's objective characteristics like technical criteria, physical or chemical components, etc. These can be compared to those based on people's perception of a product or service depending on their judgement or preferences.

For an example of how these two types of structure can be applied, see Box 5.2. While the first type of structure is relatively simple to understand and apply, the second - called 'positioning' in marketing terms - is far more complex.

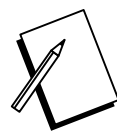

\section{BOX 5.2 EXAMPLE OF STRUCTURATION}

Let us take the offer of a city's museums. Structuring the museum offer on the basis of objective criteria could, for instance, yield the following results:

- art museums - traditional, contemporary, tribal, etc. (Louvre, France)

- art museums devoted to a single artist (Frida Kahlo Museum, Mexico)

- history museums (British Museum, United Kingdom)

- natural history museums (Smithsonian National Museum of Natural History, United States

- special interest museums - dolls, toys, cars, etc. (Swiss Museum of Transport, Switzerland)

The other possibility would involve positioning these museums according to criteria linked to the image we have of them. This would mean creating groups of, say, prestigious museums; museums of a strongly didactic character, perhaps for schools; museums of a conservationist or historical nature; museums staging numerous events, etc. The positioning of each of the museums would no longer depend on what they offer, but how they were perceived.

Structuring the offer in this way derives from psychology (Spiegel, 1961) and advertising (Reeves, 1960). It was made famous by Ries and Trout (1976), who asserted that 'positioning is not attached to what one does with the product, but rather to what the product represents in the head of the prospect'. The result of positioning is therefore what allows one offer to be distinguished from another.

The principal instruments for measuring positioning occur in consumers' minds. Constructs such as impressions and attitudes may be measured in a number of ways: 
- Associations: the most direct approach consists of asking people to evaluate the dimensions associated with an offer; perhaps on a scale of one to ten. The main advantage of this form of operationalization is that many of the offer's objective characteristics can be reduced to a limited number of dimensions associated with the product as subjectively perceived by consumers.

Box 5.3 presents a typical example of association linking economic sectors and countries to measure the potential difference of the countries' images.

- Perceived similarity: this concept, linked to the analysis of similarities, is the most widely used in positioning studies. Perceived similarity between two products is defined as a combination of the number of their mutual and distinct characteristics.

The results obtained make it possible to draw up representative charts of the offers available on the market. This is based on criteria which differentiate the alternatives or offers proposed from a perception point of view.

Perceived similarity prompts a cognitive type of judgement, as those questioned will be judging the offers' attributes.

- Substitutability: with the two previous instruments, the measure of positioning is essentially at a cognitive level. However, perceived substitutability involves evaluating the offer in terms of attitudes or preferences. In marketing terms this concept is defined as the ability of two alternatives to satisfy the same needs within a market.

Substitutability encompasses the concept of preference and results from evaluating an offer's attributes in a consumer context.

- Competition: this is linked to consumer behaviour and can be defined as the relationship between two alternatives in a world of choice. This concept differs from perceived similarity in that two offers identified as similar may not necessarily be in competition. This occurs in the event of strong brand loyalty. Likewise, two brands can be differentiated at a perceptual level while remaining in competition.

This brief description of the instruments used for measuring positioning highlights the fact that the relationship between offers is not measured systematically. So it is fundamental to determine the nature of the positioning issue. Who are the competitors I need to position myself against? How is my offer perceived by consumers compared with other substitutable or competing offers?

These basic questions must be answered before choosing the type of measure and the optimum method for treating the data obtained. The most widely used methods are factorial analysis, multidimensional analysis of similarities, and joint analysis.

The organization's new or existing offer must be compared with others on the market so the organization may develop alternatives to attain the positioning it seeks. 


\section{BOX 5.3 IMAGE DIFFERENTIAL BETWEEN ECONOMIC SECTORS}

Research carried out in six countries in 1997 studied the image of various branches of the economy. Figure 5.6 presents the 'international' image of each branch in the six countries concerned. For instance, if one takes the machine industry, Germany is the country most closely associated with this economic sector, while for tourism it is France with the United States coming in a close second.

Machine industry
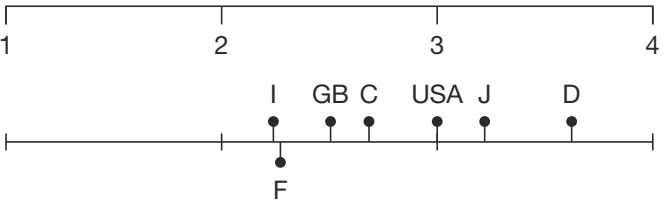

Tourism

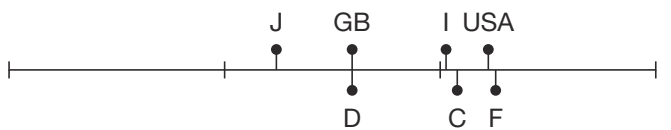

Watchmaking and jewellery

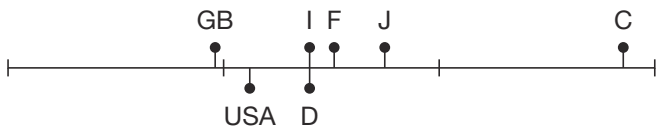

USA D

Banks and financial services

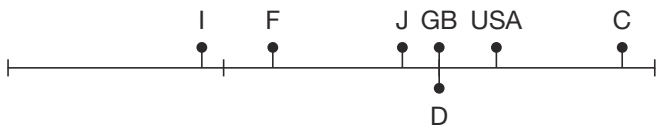

Food-processing industry

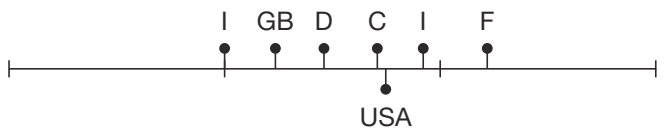

Pharmaceutical industry

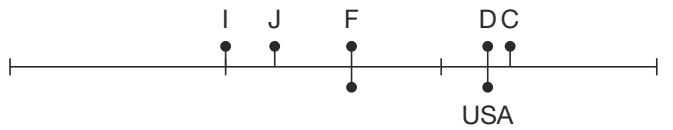

Figure 5.6 Image differential between economic sectors

\section{Analysis of organizations' marketing elements}

Implementing marketing activities requires skills and resources within an organization. Subsequently it is important to be sure of their internal or external availability before taking decisions. There are three main types:

- financial resources in personnel and the specific skills needed for activities to be carried out - number of staff, their knowledge and skills, etc. 
- system for applying marketing instruments: staff's attitude or state of mind regarding marketing tasks, marketing organization, training, pay, etc.

- information system: indicators and information, databases and how to use them, etc.

The analysis phase should not be underestimated. It is crucial that resources and skills available correspond to the goals an organization sets for itself. Otherwise, there is a high risk of failure.

\section{Overall diagnosis}

In theory, market analysis culminates in an overall SWOT-type diagnosis (see Figure 5.7). It aims to provide a synthetic overview of strengths, weaknesses, opportunities and threats. As a result, an external and an internal diagnosis are produced:

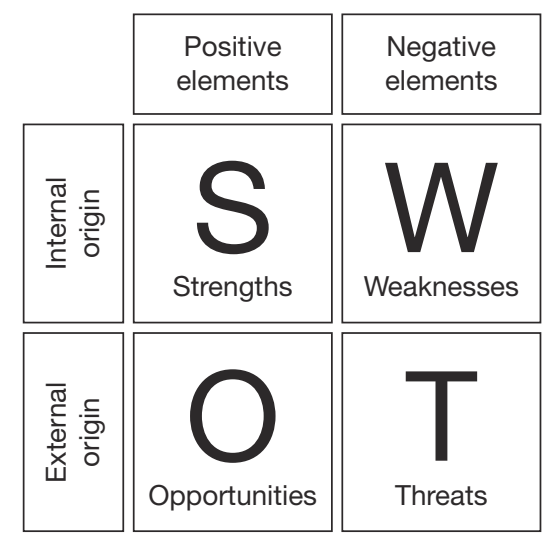

Figure 5.7 SWOT diagnosis

Source: Kühn (1993)

- The external diagnosis looks at opportunities and threats the organization must identify. These would include which elements within its environment - the market system - will have an impact on all the actors concerned. These could include new technology, new intermediaries, new competition, etc. Different scenarios can be used to test the possible consequences of these developments.

- The internal diagnosis concerns the organization's strengths and weaknesses with respect to its environment. Systematic comparison techniques such as benchmarking help to identify and outline the organization's situation.

\section{4}




\section{STRATEGIC DECISIONS AND THEIR IMPLEMENTATION}

Determining a marketing strategy, and the consequent choice of marketing instruments, is often associated with problems of optimization. Solutions require operational research methods but, in practice, such methods can create various problems:

- There are too many strategic choices and instruments available for all of them to be reviewed systematically without entailing excessive financial outlay.

- Information obtained about the consequences of these choices often lacks the quality required to apply these methods.

- The methods proposed are based partly on fictitious conditions, and limited to quantitative aspects of marketing such as size of advertising budget, or price. This often comes with the cost of neglecting qualitative factors of at least equal importance. These would likely include the product's required characteristics, or the content of the advertising message.

The very limited field of application of the quantitative methods proposed in literature leads, in practical terms, to the process of defining strategy being broken down into a series of smaller problems to be resolved one at a time. Similar processes also occur in other fields of management and organization, notably in planning. Such 'heuristic' methods systematically simplify a complex problem to facilitate swifter progress towards an acceptable - if not always ideal - solution. Experiential methods for determining a marketing strategy usually make a distinction between:

- Decision-making problems of a conceptual nature - resolving these problems helps determine and articulate programmes for implementing marketing instruments in the form of a master-plan.

- Operational decisions connected to the use of the marketing instruments, as well as serving to put previously defined strategy into effect in 'everyday corporate routines'.

The listing below presents a synthetic overview of the principal stages and corresponding decisions. It distinguishes between those decisions establishing an organization's strategic framework and those affecting the strategy's implementation - especially regarding marketing instruments.

\section{Decisions regarding the strategic framework}

- Market strategy and market segmentation: what offer for what target groups?

- Competitive strategy: what difference with other offers?

- Positioning of the offer: what image with target groups?

- Elaborating the market strategy: what relations with the partners of the exchange? 


\section{Decisions regarding implementation}

- Defining the instruments of the marketing mix

- Necessary changes and adaptations to the marketing infrastructure

- Establishment of the marketing budget.

\section{Description of decisions}

The first decision concerns market choice and priorities in terms of target groups or segments. The main issue for a public organization, given that its 'market' or scope of action is generally fixed by law, and concerns which target groups to prioritize. Some areas of the public sector cannot or may only with great difficulty prioritize their actions according to target group - emergency services, providing ID cards, etc.

Most, however, retain the possibility of establishing differences but not in regard to the essence of public action such as legal tasks or basic missions. Instead, it takes into account aspects often termed peripheral but considered essential in evaluating the service concerned. For example:

The law differentiates between at least two of the parties ${ }^{1}$ with which it is in contact. They are the parties standing trial - citizens, residents, companies - and their representatives, usually lawyers or specialist bodies. The intensity of the law's relationship with these two groups - and the needs in terms of information and how to communicate, etc. - can, or even must, be adapted to circumstance.

Some countries even hold 'legal information' days for citizens, involving detailed explanations about how the law operates. By using, mock trials, etc., they also develop information management tools for professionals. This often involves electronic data management, access to all jurisprudence, etc.

Without questioning the principle of equality in how cases are treated, priorities can be established in how to treat the law's relationship with its environment, and appropriate marketing activities introduced.

In many countries, car-owners are required to have their vehicle tested regularly. MOT (Ministry of Transport) in England, Department of Motor Vehicles (DMV) in the United States and contrôle technique in France are three examples. In some countries this task is assigned to private operators - officially approved garages - but usually a public organization is responsible. The latter can easily vary its offer according to the target group. Are they targeting private car owners having their vehicle tested every three years? Or is it professionals who come to have their own or their clients' vehicles tested several times a week.

The test itself, of course, needs to be the same whatever the vehicle or person presenting it. However, all other service criteria like opening times, billing methods, etc. can be adapted according to the target group.

In both cases, the organization must decide whether the distinction among target groups is relevant. In addition, the company must ascertain if it is better to establish priorities for handling such groups in order to develop marketing activities. Otherwise, 
Table 5.2 Marketing strategy

\begin{tabular}{llll}
\hline Segments & $\begin{array}{l}\text { Young people } \\
\text { completing their } \\
\text { education }\end{array}$ & $\begin{array}{l}\text { Other young } \\
\text { people }\end{array}$ & Adults \\
\hline Priority & 1 & 2 & 3 \\
\hline $\begin{array}{l}\text { Offers/ } \\
\text { services }\end{array}$ & $\begin{array}{l}\text { Visiting classes at } \\
\text { the beginning of } \\
\text { the year }\end{array}$ & $\begin{array}{l}\text { Visiting classes } \\
\text { during the school } \\
\text { year - timing upon } \\
\text { availability }\end{array}$ & \\
\cline { 2 - 4 } & $\begin{array}{l}\text { Individual meetings } \\
\text { with students }\end{array}$ & $\begin{array}{l}\text { Individual meetings } \\
\text { upon request }-\end{array}$ & $\begin{array}{l}\text { Individual meetings } \\
\text { upon request }-\end{array}$ \\
& (10-15 days delay) & month delay & First session free, \\
\cline { 2 - 4 } & Free & Free & then fee-based
\end{tabular}

it will need to identify which specific offers it wishes to address in each of the defined target groups. Table 5.2 presents a similar situation for career guidance.

The second decision concerns competitive strategy. If there is no competition, this stage is clearly irrelevant. But, if the organization does have competitors, a competitive strategy must be defined. Public organizations involved in postal activities, telecommunications, transport, energy, etc. are increasingly subject to competitive pressure, and can no longer ignore the strategic approach of others.

This competitive strategy stems from the generic strategies outlined in Figure 5.1. There are two main choices: differentiation strategy or price strategy. Generally speaking, the organization must decide whether it wishes to profile its offer in the eyes of clients through an advantage linked to the service offered, or through lower prices. If the service-linked option is chosen, we speak of a differentiation strategy; if the advantage centres on lower prices, we speak of price strategy.

Advantages linked to service vary greatly in nature in the context of a differentiation strategy. One thinks first of differences in quality, or some particularly innovative aspect to the offer. But it must not be forgotten that many differences correspond to differences of image, created by using the instruments of marketing communication. In any case, a differentiation strategy involves a wide range of marketing tools, which all help profile the offer.

Price strategy, on the other hand, clearly stresses the instrument of price. The profile then becomes one-dimensional and far more easily substitutable. All it takes is for another organization to propose a better-value offer to no longer have a veritable profile. So price strategy is only possible if the organization enjoys a long-term advantage in relation to cost structure, so that it can always offer better value than its competitors. The success of such a strategy also implies that buyers are price sensitive and that price elasticity is important. 
Another situation concerns new markets, where no organization is yet in a position to make an actual offer. In this case it is best to contribute to, and benefit from, the market's overall development, rather than concentrate on competitive strategies which may be inopportune in the circumstances.

The third stage is important for all organizations, irrespective of what is decided for the first two stages. It involves consolidating the organization's positioning and offer among selected target groups. Even if the offer is unique and competition totally absent, the image which the organization wishes to bestow upon itself, and its offer to the outside world, must be established not just among beneficiaries, but also among all other actors.

If the organization's offer is specific and clearly distinct from others', it should seek to shore up its positioning through these relatively objective differences. In marketing parlance this is referred to as USP or Unique Selling Proposition.

If, on the contrary, an organization's offer is interchangeable with others with no obvious difference, it then should seek to use means of communication to construct what target groups will perceive as a difference. As an example, what universities have to offer prospective students may scarcely differ from one to the next. Therefore, they attempt to create a different image in other ways such as a special ambiance on campus, international character, close ties with alumni, etc.

At the end of this stage, it is also recommended to establish quantitative and qualitative targeted goals. They could include the number of services aimed among target groups, image and attitude sought among beneficiaries, etc. Box 5.4 shows an example of the overlap between segmentation decisions and defining the service offer.

The final stage of the strategic framework concerns strategy for exploiting the market. Corresponding decisions depend largely on the existing market system. The question is whether the organization should target beneficiaries directly or via intermediaries. When it comes to consumer goods - drinks, washing powder, etc. buyers are hardly ever in direct contact with producers, and buy via intermediaries.

\section{BOX 5.4 MARKETING STRATEGY FOR A PROFESSIONAL CAREER-GUIDANCE SERVICE}

Many countries have professional State career-guidance and information services, with specialists offering help and advice about career choices and professional reorientation. This typically involves skills appraisal, helping women return to work after spending several years at home bringing up children, etc.

Given the reduced resources available, and above all the increased demand, some services - with the backing of political authorities - have segmented service beneficiaries and delimited the corresponding offer. 


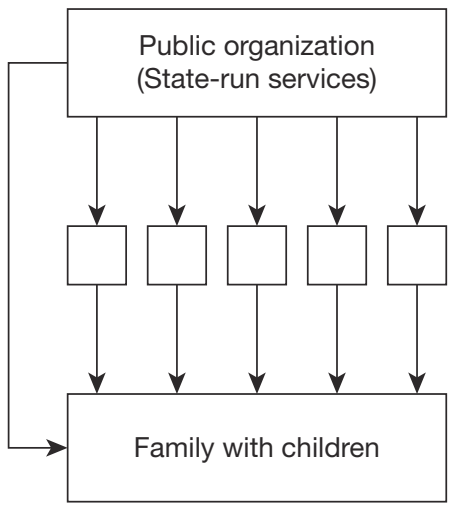

Fixes rules and norms as regards supervision and safety

Defines financial framework according to resoures allocated (budget)

Private-sector (and/or public-sector) actors offering kindergarten places

These families have a commercial relationship with their kindergaten (practical offer, conditions, prices, billing, etc.) but also receive information from the public organization

\section{Figure 5.8 Example of intermediation in a market}

On the other hand, when it comes to services like banks, doctors, hairdressers, etc., these intermediaries are far rarer and the organization provides the service directly.

In the public sector, when it comes to services, it usually occurs with the organization taking charge of supplying the offer to beneficiaries. In addition, it handles relations with them directly and intermediaries tend to be rare. But there are other fields where the public organization has a mere regulatory role, and services are provided by a third party.

This often applies, for example, to places available at kindergarten (see Figure 5.8). Using rules, norms, and financial incentives, public organizations can stimulate the creation of extra kindergarten places without having to provide or make available the corresponding offer themselves.

A private third party proposes and manages the offer within the legal and financial framework. In the context of the overall system, private actors have a vital role as intermediaries. Consequently, public organizations must manage their relationship with both service beneficiaries, families with young children and the private organizations offering places in their kindergartens.

As well as dealing with intermediaries, an organization must also consider the measures it wishes to take regarding other market actors - influencers, suppliers, etc. In the scenario presented above, keeping the media regularly informed may lead to articles in the press. This bonus should be considered a part of the goal of improving the flow of information to the parties concerned.

Ensuing decisions are derived from strategic decisions and establish a framework for putting the strategy into effect. This means determining which marketing instruments to use, and to what extent; defining the necessary adjustments to the marketing infrastructure; and drawing up the necessary budget. Only then can the decisions' overall coherence be assessed, and modified if necessary. The budget could, for instance, prompt a review of target group priorities, or indicate which instruments to use. 
One should first decide which marketing instruments to use in order to put the defined strategy into effect, and to what extent they should be used. It is vital to ensure homogeneity when choosing these instruments, as well as to ensure their use is effective.

For instance, there is a very strong risk of engaging in extensive promotional activity for a service such as kindergartens for which the organization or its partners are unable to satisfy the demand. Sometimes the budget available does not allow a minimum level of effectiveness to be obtained, leading to a waste of resources.

Then, the organization must verify its ability to attain the goals and implement the measures that derive from the decisions taken. This is not just a question of financial wherewithal. It is equally vital that skills and attitude of personnel are kept in line with the organization's ambitions. Likewise, some adjustments to the organization's information and operational systems may well be necessary.

Finally, the decisions and measures taken will need to be put into effect on a financial level by drawing up a budget. It is this last phase that may or may not oblige the marketing's strategic planning to be reviewed. It is better to delay taking budgetary constraints into account during the planning process, so as not to limit creativity or put a brake on innovative ideas.

\section{Problems in implementing strategy}

There are a number of measures likely to play a role in the success of a marketing strategy. There are also a wide range of market elements like competition, environmental factors, product users, intermediaries, etc., which strongly influence marketing strategies. Hence, it is not surprising that setting instruments into effect is a complex task and mastering it can be problematic for many organizations.

One problem comes from the fact that 'markets' or target groups are not compartmentalized. It is easy to forget that measures taken for one target group may impact on other groups. Consequently, it is all the more important to suitably define the market or commercial environment of the service offered.

The need for marketing instruments to be used in the long term should also be taken into account. Borden's call for a balanced dose of externally geared marketing instruments is no longer disputed. Various behavioural studies have confirmed product users and other marketing targets do not record or evaluate each message separately. Instead, all messages are considered as a whole. So a product's quality is not judged individually and 'objectively', but in relation to the price and the advertising message.

Nor can marketing instruments be coordinated harmoniously on an ad hoc basis. Changes over time, especially if too sudden or frequent, can hinder this constructive process. In general one needs to start from the premise that all marketing activity produces impulses that, in the eyes of individual targets, may mutually boost one another or cancel each other out. Hence it is important to keep the same marketing approach in the eyes of product users and other market participants, so images and preferences may be freely formed over time. 
A common error observed in this implementation is the use of insufficient means. Empirical experience, and many studies, have highlighted a link between the degree of commitment to a marketing instrument - as measured in monetary units - and its impact. Each marketing instrument has a sort of inferior effectiveness threshold that must be exceeded to justify use of the instrument concerned.

However, if the means are inadequate or scattered - the sprinkler principle - they are highly unlikely to attain this minimum effectiveness threshold. For budgetary reasons, many communication activities in the public sector are not implemented with sufficient intensity to be properly perceived or have the required effectiveness.

\section{LIMITATIONS}

Developing marketing strategies poses a host of problems to public organizations and services, and the principal limitations involved need to be considered.

First, the process outlined above and the principles of application are difficult to implement given the constraints imposed on public organizations, such as laws, rules, etc. Reduced leeway for decision making, the absence of autonomy, an organizational culture not open to risk taking, or a particular corporate ethos, can be enormous stumbling blocks. In addition, an overall context exists enabling services to be introduced despite the absence of a coherent strategy. However, because of the legal framework and an absence of competition, public organizations can utilize resources to less than full effect without risking sanction.

Another important limitation lies in the difficulty of ensuring continuity in the application of strategic decisions. A private company may set aside reserves, and anticipate long-term investment, to attain its marketing goals. These measures could include investments in the brand or in creating a distribution network. Conversely, a public organization depends on an annual budget voted by politicians.

It is not rare in public organizations for PR campaigns or projects linked to developing or promoting a service, to be halted or seriously scaled down due to a drop in annual funding. It then becomes difficult to ensure a correlation between the objectives targeted and the measures taken.

Finally, one should never forget the scale of values guiding public organizations in their decision making and activity. Principles of equality and fairness should prevail over criteria of efficiency and effectiveness. Although the principle of opportunity is increasingly taken into account, it is not always easy to apply marketing rules and processes. Intelligent adjustment, on a case-by-case basis, is often needed to 'remain within the confines of legality' and ensure public action remains legitimate.

\section{EXERCISE 5.1}

Using the SWOT approach from Figure 5.7, offer a general diagnosis on your organization. 


\section{DISCUSSION QUESTIONS}

1. Is it the role of civil servants and public-sector employees to define an organization's strategy? Shouldn't that be left to politicians?

2. How fundamental is the difference between a public-sector and a private-sector organizational strategy?

3. Define the management strategies of a public hospital as opposed to a private hospital. Consider especially the corporate objectives and related strategies. Compare and identify the key differences.

\section{NOTE}

1. In fact, there are more - the media, political institutions etc. should also be mentioned.

\section{REFERENCES}

Bean, J. and Hussey, L. (2011) Marketing Public Sector Services, Second Edition, Essential Skills for the Public Sector, London: HB Publications.

Grünig, R. and Kühn, R. (2008) Process-based Strategic Planning, Berlin, Springer.

Kühn, R. (1993) Das Image Ausgewählter Bereiche der Schweizer Wirtschaft im Internationalen Vergleich, Die Volkswirtschaft, 3, 14-22.

Mintzberg, H. (1992) Five Ps for Strategy in the Strategy Process, Englewood Cliffs, Prentice Hall International Editions.

Perrey, J. (1998) Nutzenorientierte Marktsegmentierung, Wiesbaden, Gabler.

Porter, M. E. (1985) Competitive Advantage: Creating and Sustaining Superior Performance, New York, Free Press.

Reeves, R. (1960) Reality in Advertising, New York, Knopf.

Ries, A. and Trout, J. (1976) Positioning: The Battle for Your Mind, New York, McGraw-Hill.

Schedler, K. and Proeller, I. (2003) New Public Management, Bern, Stuttgart, P. Haupt.

Smith, W. R. (1956) Product Differentiation and Market Segmentation as Alternative Marketing Strategies, Journal of Marketing, 21, 3-8.

Spiegel, B. (1961) Die Strukturder Meinungsverteilung im Sozialen Feld, Bern, Verlag Hans Huber.

Van Hagen (2009) How to meet the needs of train passengers? A successful customer segmentation model for public transaport, European Transaport Conference, 6-8 October, Noordwiijkerhout, Netherlands. 
Marketing instruments

\section{LEARNING OBJECTIVES}

By the end of this chapter you should be able to:

- Understand the specificities of marketing instruments in the public sector structure of public services, notably by taking into account their intangible nature.

- Differentiate the various approaches to pricing in the public sector.

- Understand the implications of various distribution models in the public sector.

\section{KEY POINTS OF THIS CHAPTER}

- The instruments of marketing, or marketing mix, are the means of action an organization has to attain its marketing objectives.

- Many public services are intangible. This situation has numerous consequences, among them the impossibility of issuing stocks, the central role of human interaction, and the indivisibility of product and production.

- There are three types of approach to pricing in the public sector - free service, taxes, and licence fees. The choice of which to use is based on the concepts of non-rivalry and non-exclusion. Each of these approaches puts the burden of total payment of the service on various actors - be they the user, the government, or a third party.

- The distribution model of public services is based on the legal and structural make-up of a country's specific institutional arrangement. This can consist of both direct delivery with no intermediary between government and user; or indirect, where a third party plays a role in the delivery. 


\section{KEY TERMS}

Four Ps - main instruments of the marketing mix: product, price, promotion, and place.

Services of general interest - concept used by the European Union to identify core functions of the State's service provision.

Distribution channels - ways by which a service is made available to the user.

\section{INTRODUCTION}

Marketing instruments, also known as the marketing mix, represent an organization's means of action to attain its set marketing goals. This involves defining several factors including:

- terms of the exchange: what services and at what cost;

- how and where the exchange can take place - for example, distribution or accessibility of the service, and/or the persons in charge of making the service available;

- means used to promote what the service has to offer such as communication and 'branding'.

As outlined in Chapter 4, Borden (1965) was the first to use the marketing mix concept, while McCarthy (1960) provided a basic structure for all the instruments available by introducing the four Ps - product, price, place, and promotion. Subsequently, new proposals were made for structuring the instruments, including a further three Ps - people, process, and physical facilities. These were coined by Bitner and Booms (1981), linked mainly to the development of services marketing and have since been adopted by many other authors. Figure 6.1 presents the structure of these marketing instruments.

While the first four Ps still remain a marketing reference, especially for the marketing of consumer goods, the last three Ps have become more important. This is because a service is intangible by definition and cannot be produced independently of the persons who are producing it. To illustrate, there is no school without a teacher to transmit knowledge, and no justice without judges to make decisions.

This chapter seeks to present basic elements regarding marketing instruments used in the public sector, and will concentrate on the definition and structuring of public services, their pricing and the possibilities of using them. As the communication of organizations and public services is the subject of several other chapters in this book, it will not be dealt with in this chapter.

\section{4}




\section{PRODUCT/PUBLIC SERVICES}

The definition and analysis of public services is a political, managerial, and marketing issue. At a political level, in a context of mounting public debt, analysing services helps to establish priorities. It also differentiates between basic and complementary services like price differentiation and links the allocation of resources to tangible results.

At the managerial level, analysing services can affect the organization's plans, or oblige it to determine more precisely which form the service should take. Finally, at the marketing level, and in line with principles of New Public Management, a service must be linked to expectations, notably in terms of quality as expected/perceived by beneficiaries.

Even though we often talk about public services, a distinction should be made between services provided by public bodies for external parties, and public policy services such as planning for, putting into effect, and monitoring public policies destined for political institutions. Without neglecting the latter type of service, which is far more complex and difficult to systematize, this section will concentrate mainly on services destined for beneficiaries external to the administration.

\begin{tabular}{|c|c|c|c|}
\hline \multirow{3}{*}{ 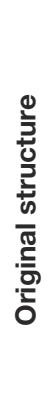 } & $\begin{array}{l}\text { Content } \\
\text { of the offer }\end{array}$ & $\begin{array}{l}\text { Product: } \\
\text { Price: }\end{array}$ & $\begin{array}{l}\text { Goods and services, size of the offer } \\
\text { (depth and breadth), level of quality } \\
\text { Base price, reductions, modes of payment }\end{array}$ \\
\hline & $\begin{array}{l}\text { Diffusion of } \\
\text { information } \\
\text { on the offer }\end{array}$ & Promotion: & $\begin{array}{l}\text { Publicity, promotional activities, } \\
\text { personal relations }\end{array}$ \\
\hline & Accessibility & Place: & $\begin{array}{l}\text { Channels of distribution (points of access), } \\
\text { opening hours }\end{array}$ \\
\hline 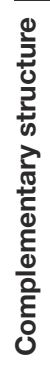 & $\begin{array}{l}\text { Aspects of } \\
\text { quality in the } \\
\text { production } \\
\text { of the service }\end{array}$ & $\begin{array}{l}\text { People: } \\
\text { Process: } \\
\text { Physical } \\
\text { facilities }\end{array}$ & $\begin{array}{l}\text { Abilities, knowledge and capabilities } \\
\text { of staff in delivering the service } \\
\text { Processes leading to the delivery of service } \\
\text { Physical aspects (tangibles) linked to service } \\
\text { delivery (building, waiting room, parking) }\end{array}$ \\
\hline
\end{tabular}

Figure 6.1 Basic structures of marketing instruments

Source: adapted from McCarthy (1960) and Bitner and Booms (1981). 


\section{DEFINITIONS OF A PUBLIC SERVICE}

\section{Politico-legal sense}

Public services are provided by an administrative entity or delegated to a private body. They have a legal basis specifying the nature of the service and the basic ways in which it is provided.

The concept of public services derives from an older concept - service to the public or service of general interest with both judicial and political scope. The notion of public service comes from French law and serves to distinguish administrative law from private law.

There are two distinct types of public service tasks:

- tasks linked to State sovereignty - justice, police, diplomacy, army, currency

- tasks concerning the administrative sector - seeking to fulfil a general or social need which cannot be satisfied by the private sector such as transport, teaching, social services, etc.

Given the general interest of these activities, they are required to be subject to a public authority and the corresponding jurisdiction of administrative law.

The term public service is hardly used by the EU, ${ }^{1}$ which, however, makes a distinction between services of general interest and services of general economic interest (Commission of the European Communities, 2003). Services of general interest are government amenities for citizens subject to the specific requirements of public service. Services of general economic interest form a sub-category of provisions and refer to services of an economic nature. Beneath such an umbrella, EU member states comply with specific public service requirements via the criterion of public interest.

Whereas services of general interest remain under the sway of member states, services of general economic interest - energy, transport, postal services, or telecommunications - come under the remit of the EU. This ensures that the principle of free competition is applied with respect to public service missions. These services are the subject of liberalizing policy, although they remain quite strongly regulated by the principle of separation of the functions of owner and regulator.

Whether the notion of 'public service' or the more neutral idea of 'service of general interest' is used, it is important to specify what actually is involved. Here, it is an authority's decision to define and propose services in a non-exclusive manner to beneficiaries who fulfil predefined conditions. Such services can, however, be provided either by a public body or delegated to a private concern. In some regions of Denmark or the United States, for instance, fire-fighting is ceded to private security firms. 


\section{A more managerial definition of public services}

It is difficult to apply the notions of public service or service of general interest with regard to an organization, for two reasons. First, these ideas have a strong political connotation, and are therefore often subject to intense debate. Secondly, they remain vague, and do not suffice for organizing and establishing services for the population.

For instance, legally stipulating that the State is responsible for maintaining the roads under its authority provides scant indication of the quality and frequency of upkeep. Nor does it include the means to be used or the possibility of delegating the task to a third party. The actual definition of the service to be provided and its organization requires a more managerial approach. Hence, the use of the private-sector term 'service provider'.

Although public-sector activities mainly involve services, it should first be specified these are far from homogenous. There is nothing comparable about teaching and clearing snow from the road. In addition, the tangible part of the service varies considerably from one amenity to the next.

For example, the proportion is high for issuing a passport, when a tangible document is delivered, or for a municipal library lending books and magazines. However, it is very limited when it comes to police checks or medical treatment. Figure 6.2 provides some examples of tangible and intangible areas of public services.

There are several reasons to study the intangible aspect of services. First the number, and above all variety, of services provided by the public sector have considerably increased over the last 50 years. Next, the intangible aspect of these services has also grown, notably because the exchange's relational aspects - welcome, friendliness, empathy, etc. - have assumed greater importance, often serving as elements of reference when evaluating quality of service.

Finally - due to the development of both service activities in society and the principles of New Public Management - relations between a public administration and beneficiaries have become far more individualized. This obliges the administration to clarify the services it can provide and the level of differentiation acceptable within these services.

At a marketing level, services can be defined as follows (see Kotler, 2009; Kühn et al., 2006):

- Intangible: services which cannot be seen, touched or felt, let alone heard, before being bought. The offer is abstract and it is only after 'buying' it that a person can really evaluate it. For instance, it is only after attending a class that one can judge the quality of the teaching. As a result, the offerer's credibility and confidence in their ability to deliver the service are particularly important.

- Indivisible: whereas material goods are produced before being sold, a service is produced at the same time as it is consumed. As the presence of both the persons buying and supplying the service is necessary, their proximity to one another is highly relevant. 


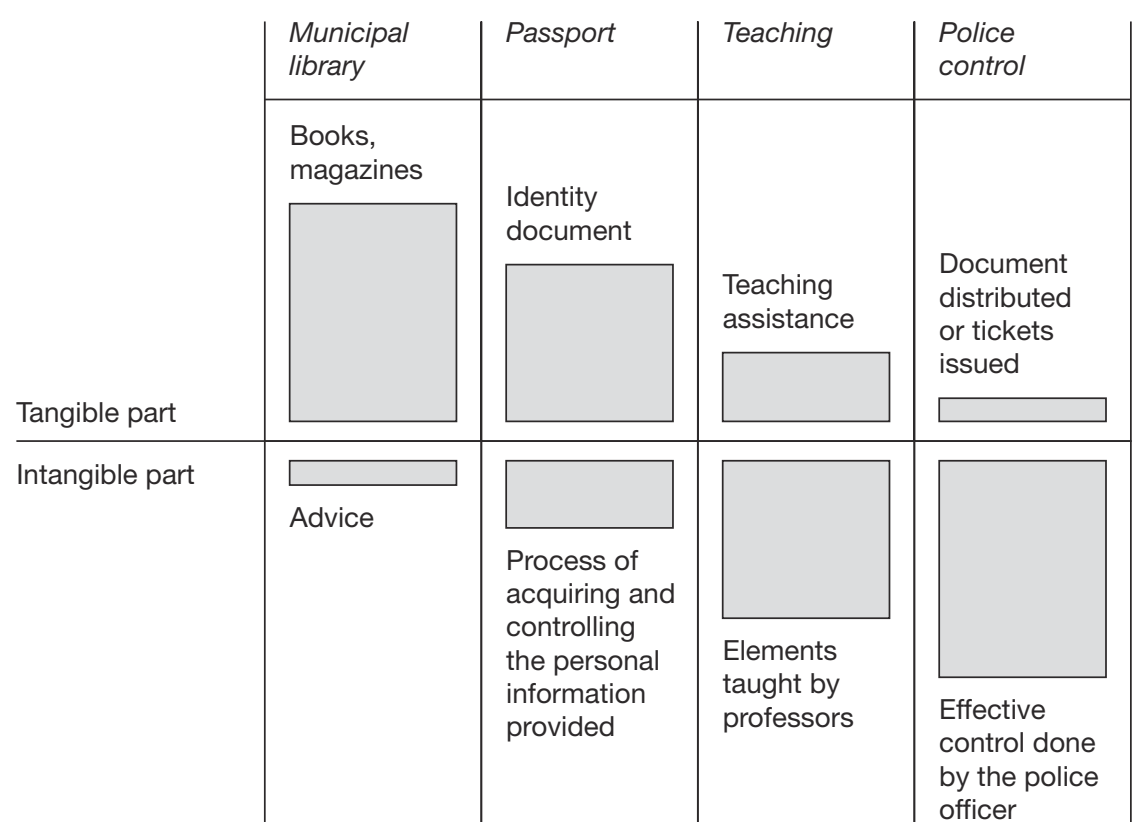

Figure 6.2 Tangible versus intangible proportion of public services

A beneficiary based far away from the service provider needs facilitated access to a certain number of services such as long-distance teaching. Given the administration's territorial scope and despite the development of electronic communication, notably the internet, the problem of service accessibility at the public sector level remains crucial.

- Inability to store services: an empty bus costs as much to run as one full of passengers. If demand for a service is stable and known in advance, the organization's offer the number of buses and drivers - can be adapted to the demand. The problem for many services is that the offer fluctuates and the administration, given the resources at its disposal and the constraints on their use, has great difficulties in flexibly adapting offer to demand.

- Key role of personnel: the quality of a service can vary considerably according to the persons in charge. We've all experienced the occasion when the same lesson has been given by two different teachers - one was exciting and the other tedious.

Three ways of improving service quality are explored:

a the search for qualified personnel

- the codifying processes for conceiving the service

- harmonizing the approach of those involved.

\section{8}


This is done in order to minimize variations in standards. By involving beneficiaries in producing the service as much as possible - like taking note of their criticisms and comments - will help the organization reduce the difference between the level of service expected and the level perceived.

The greater the intangible portion of a public service, the more public bodies need to take account of the above-mentioned characteristics in defining and implementing their services.

\section{Structuring public services}

Although New Public Management has received some severe criticism, the structuring and analysing of public services is rarely questioned, and retained even if other aspects are rejected. Public services are usually structured according to their components or the necessary tasks involved.

\section{Structuring according to components}

A service can be divided into three parts (Kotler, 2009): central, secondary, and peripheral. These elements as shown in Figure 6.3, take the issuance of a passport as

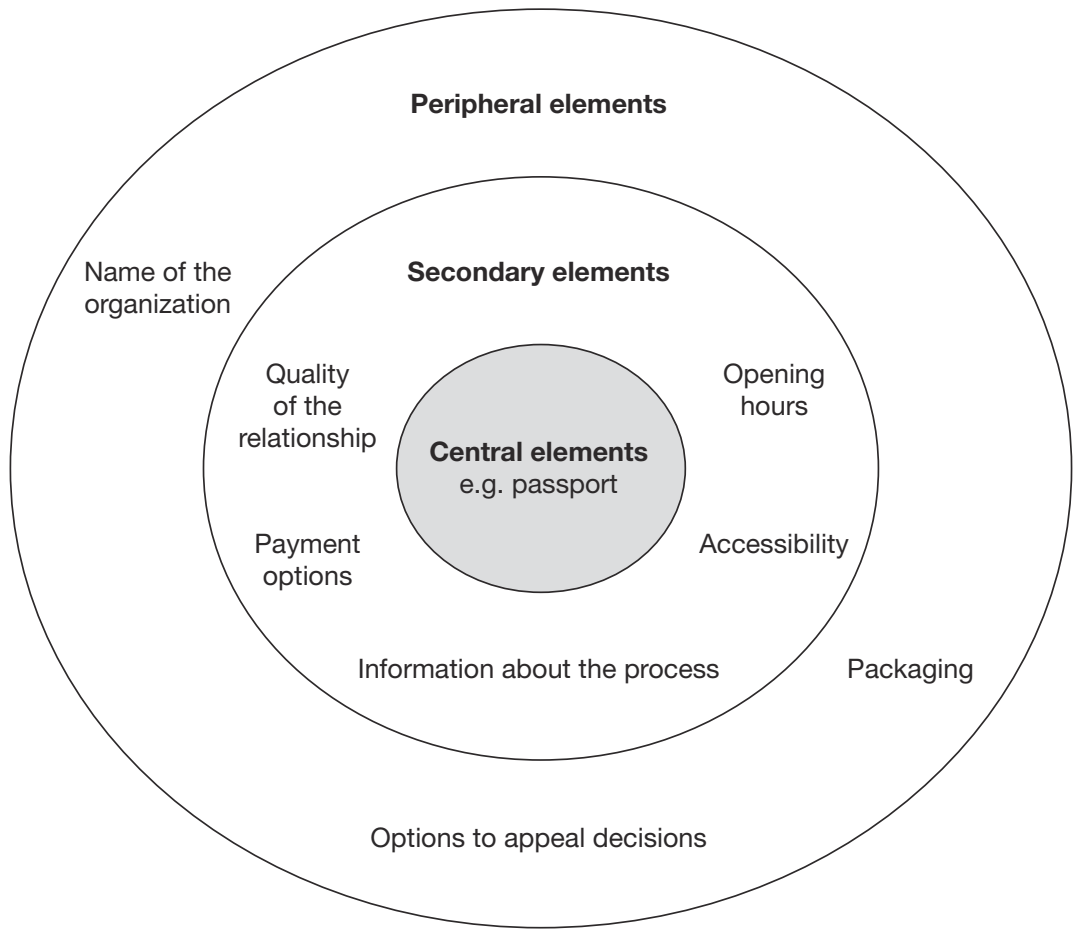

Figure 6.3 Components of a public service (for issuing a passport) 
an example. The central elements of a service concern the principal benefit it provides. In Figure 6.3 the essence of the service is the passport. In the public sector, the essence of a service often concerns elements stipulated by law.

Secondary elements are not usually defined by law, but directly linked to producing the service, and naturally vary according to the service itself. In the case of issuing an identity document, several steps are involved. Prior to the process the applicant must provide support documents and forms in order to qualify. Next, access to the service - physical accessibility, opening times, etc. - must be shared with the applicant as would be methods of payment available - bank transfer, cash, check, debit or credit card. All are elements that can facilitate the service or make it costlier and more complicated.

Although a public service's quality is often assessed according to its peripheral elements, an identity document like a passport is strictly defined. No differentiation in the essence of the service is possible. Obtaining a passport is the same for every citizen, therefore it is the secondary elements which determine if the service is provided diligently and whether or not citizens are satisfied with it.

Finally come the elements peripheral to a service. In theory these have only limited importance to how the service is appreciated, while potentially offering a little plus. In Figure 6.3 a small wallet provided with the passport, and special facilities for contacting the organization in case of problems, count as peripheral elements.

\section{Structuring in groups of services and activities}

The idea of structuring government activities into services, like firms providing and commercializing services, has been little challenged. While it may seem obvious that tasks carried out by a public administration exceed the mere framework of producing and delivering services, such a concept of an administration's activities offers several advantages.

First, the activities are grouped together and defined in the same way, according to service beneficiaries. Then the services can be analysed according to their cost and the income they generate. Finally, these services constitute a reasonably objective unit of analysis to help political authorities make choices linking political priorities to available resources and services delivered - or not.

For example, increasing resources for a public task not only indicates that a number of posts will be created but also infers an increase in the number of services provided or an improvement in their quality such as reduced waiting time to obtain a document.

A service counts as a 'tangible output' of an administrative unit. To recap: an administrative unit is an entity responsible for carrying out a task defined by law or in official documents. Depending on how public communities are organized, these entities may vary greatly in size and autonomy. The main thing is that they can be attributed responsibility for carrying out a task.

If, as we saw at the start of this chapter, administration services are invariably of an intangible nature, one should be able to make a service correspond to quantities. Factors would include the number of controls, classes, pupils, decisions taken, etc.; 
level of quality such as length, success rate, etc.; as well as goals; indicators; and costs. Several services provided by the same administrative body constitute a group of services, Additionally a service can be broken down into sub-services or partial services, depending on its level of complexity.

A service has the following characteristics:

- Its beneficiaries must be external to the administrative unit. They may be external to the administration such as an individual, company, other body, etc. or internal as in other administrative entities. An example would be an IT service supplying services to the other units within the administration. When appropriate, these internal services can be defined - for instance, support services. The same applies for important projects, or mandates needing to respect a deadline.

- It derives from laws and regulations. Sometimes, if these legal bases are too vague, the administrative entity has to issue precise guidelines about the services required in regard to the legally defined goal.

- It may either be free, subject to tax partially covering costs or available only if all the costs are paid.

- It consists of tasks which the administrative unit either supplies or purchases from other units or external bodies - undertakings for which it is possible to specify a time of work or a cost. The process combining all these tasks enables the service to be provided.

The process for structuring services in an administrative unit is outlined in Box 6.1.

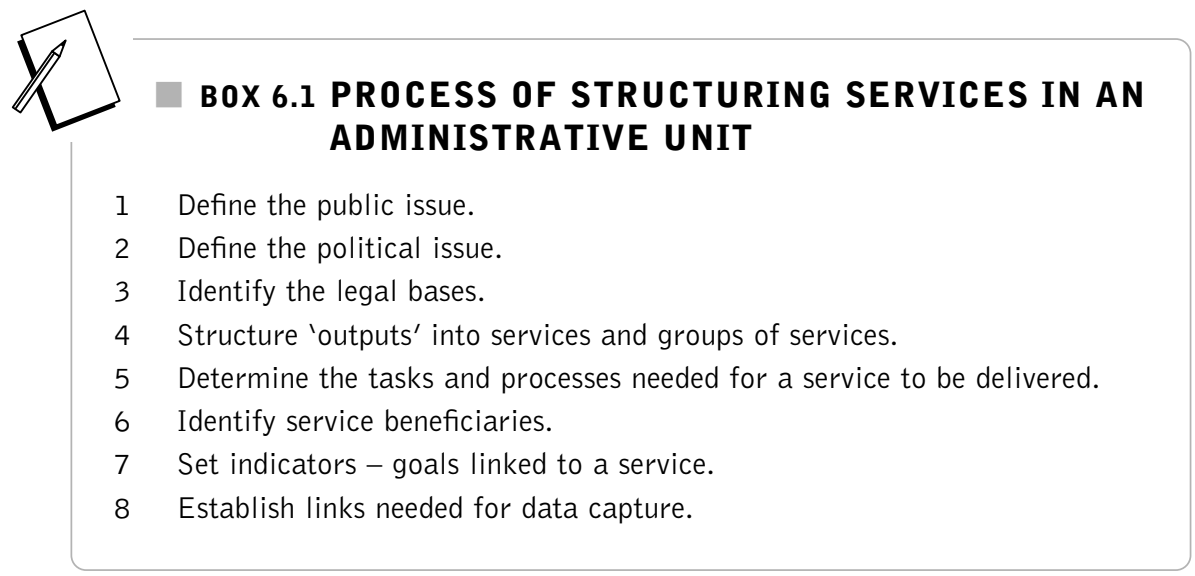

An example of how the process is applied is shown in Box 6.2. 


\section{BOX 6.2 STRUCTURING SERVICES LINKED TO THE PROTECTION OF CULTURAL GOODS}

Buildings of historical significance, whether ancient ruins, castles, churches, old farmhouses, etc. or modern houses or buildings designed by famous architects, are protected in many countries. This is enabled by laws obliging owners to respect rules of upkeep and renovation. However, owners of such properties may receive financial subsidies and other forms of assistance.

Preliminary phase:

To facilitate structuring and establish a link with the time spent in data capture and analytical accountancy, the functional classification of public tasks is often used. ${ }^{a}$

0. General administration

1. Public safety

2. Teaching

3. Culture, sport and leisure

\subsection{Cultural heritage}

\subsubsection{Preservation of historic monuments and protection of nature}

\section{Phase 1: Defining public issues}

Cultural goods are fundamental elements of human culture and civilization. Any reduction of this centuries-old cultural heritage counts as a loss.

\section{Phase 2: Defining political issues}

- Lawmakers wish to protect all cultural goods - whether moveable or immoveable, old or new - which are important to the community as evidence of spiritual activity, artistic creativity, or social life.

\section{Phase 3: Identifying the legal bases}

- Federal law on the protection of nature and landscapes

- Federal law on the protection of cultural goods in case of armed conflicts, etc.

\section{Phase 4: Structuring 'outputs' into services and groups of services}

Group of services for the 'protection of cultural goods':

- inventories

- placing under protection

- protection in the event of conflicts or crises.

Group of services for the 'preservation of cultural goods':

- advance permit applications

- allocating subsidies 


\section{B0X 6.2 continued}

Group of services for 'publications and awareness':

- publications

- actions to promote awareness.

Group of services for 'internal services':

- unit representation in commissions

- unit direction and management.

Phase 5: Determining the tasks and process needed to provide a service such as for 'inventories' service

- Building inventories

- on-site visits

- photographs

- archive research

- data capture.

\section{Phase 6: Identifying service beneficiaries}

- Administrative services

- Tourist promotion services

- Other public communities such as communes

\section{Phase 7: Setting indicators}

Having an exhaustive, up-to-date inventory of cultural goods to be protected, or likely to need protection in future

\section{Phase 8: Establishing the necessary links for data capture}

\begin{tabular}{lll} 
Level & Number & Subject \\
\hline Group of services & 1000 & Protection of cultural goods \\
Service & 1100 & Inventories \\
Tasks & $1100-01$ & On-site visits \\
$1100-02$ & Photographs & \\
$1100-03$ & Archive research & \\
$1100-04$ & Recording data &
\end{tabular}

a The functional classification groups all public tasks into ten categories: 0 General administration; 1 Public safety; 2 Teaching and training; 3 Culture, sport, and leisure; 4 Health; 5 Social contingency planning; 6 Traffic; 7 Environmental protection and territorial development; 8 Public economy; 9 Finance and tax.

Source: Adapted from Davet (2006). 
The first phase involves defining the public issue. In a democratic system, the State is called on to act only if the reason for its intervention has already been collectively defined as a public issue. For instance, environmental protection was not considered a public issue 30-40 years ago, and State intervention in the field remained negligible

As an example, the water supply and water table were protected to guarantee people's health, not with a balanced eco-system in mind. It can take decades for a public issue to be recognized, and the approach can vary considerably from one State to the next. Then, for services to be clearly identified and structured, attention must be paid to the public issue for which political institutions consider it necessary to provide services.

Once the public issue has been identified, political authorities need to decide to act - or not. Lawmakers' intentions regarding public policies, goals, and, above all, the types and methods of state intervention are revealed at this point. So, should the state regulate private activity, mandate bodies to provide services, or provide the services itself? It is especially important to obtain this sort of information if political discussions linked to state intervention took place quite some time earlier, and administrative units have greatly developed in the interim.

Identifying and obtaining the legal bases is the third stage. One should obviously pay attention not just to the law but also to all texts regulating and guiding the action of the administrative units. Many tasks assigned to these units are stipulated by decrees, regulations, directives, etc., rather than the law itself.

The fourth and most important stage regarding the targeted objective involves structuring the activities of the administrative unit into services and groups of services. This means using criteria appearing in the definition of a service and in the service's characteristics. The next phase is to assign all tasks performed by the unit to the various services defined.

The last stages are more technical. Initially, one needs to identify if the service beneficiaries are internal or external to the administration. Next, the indicators must be set - like 'what are its specific goals for the service?' Finally, each task or unit activity must be given a functional classification number, so the amount of hours spent on an activity, and costs involved - such as paying a mandated third party - can be assessed.

\section{Quality of public services}

Studies of the quality of public services are largely based on the principles of New Public Management - especially on the concept of the State as service provider. This is derived from a higher demand for efficiency and on 'client' orientation in supplying services. For private bodies and other marketing sources, analysing service quality has long been a major issue (Parasuraman et al., 1985; Zeithaml et al., 1990. However, public bodies cannot merely limit themselves to commercial criteria - reliability, relational qualities, etc.

Therefore, they must also consider criteria linked to general interest and social justice, such as theories of fairness. In the context of public services, individual 
satisfaction - like a building permit believed to have been fraudulently obtained - can be in contradiction with the general interest or nature preservation.

So it is crucial that the process enables the service to be carried out and to be perceived as fair (Rawls, 1971; Tyler, 1988, 2005). In democratic systems, persons concerned are usually all the more tolerant about services provided and their consequences such as service quality. If they think the way they have been dealt with is fair - equal treatment, fair-minded decision making, etc. - they will be satisfied.

By returning to the various types of relationship that can develop between the administration and service beneficiaries (see Chapter 3), the criteria for assessing quality of service can be identified (see Figure 6.4). The first set of criteria is linked principally to the traditional relationship between administration and citizens as to the decision-making process. These criteria include respect for rules, transparent procedures, and equality of treatment. The more constrained people's relationship with a public body, the more these criteria are fundamental in assessing the service provided.

The second set of criteria concern the relationship between the administration and people as consumers. It is not so much the procedure itself that influences how the

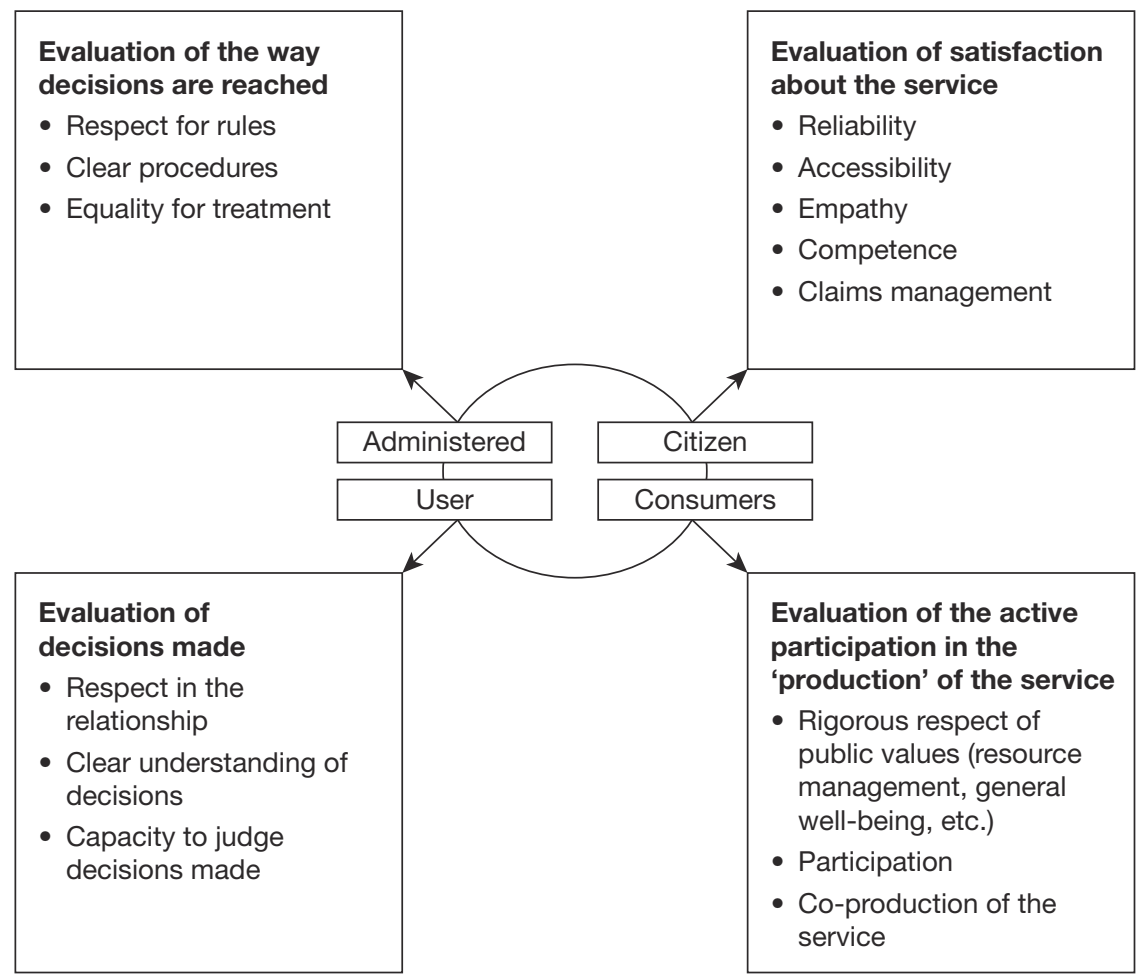

Figure 6.4 Public service quality criteria 
service is appreciated - like the ability to explain decisions, their transparency, etc. but how decisions are taken, and how they are communicated. The traditional assessment of a service within a commercial relationship involves the client's degree of satisfaction and corresponding criteria such as reliability, empathy, accessibility, etc.

The final set of criteria must allow for people taking an active part in providing the service. Within this 'citizen relationship', respect for higher values such as rigorous resource management and direct involvement in producing the service, matter as much as, if not more than, the service itself.

It is important to specify that a public service is not just evaluated according to one set of criteria, but to all of them. Depending on the service, and to what extent it is commercial, certain criteria may have more or less importance.

\section{PRICING OF PUBLIC SERVICES}

In the private sector, price is the compensation paid by the client, with companies aiming to maximize profit. But prices in the public sector play a totally different role, in that many services are free for beneficiaries. Prices charged for some services do not cover their cost and there are even services which the State pays for beneficiaries to use. An example is when the State woos companies by offering them land free of charge.

Three aspects are considered in this section: the notions of free services, taxes and price; pricing and the strategies applicable; and monetary and non-monetary incentives.

\section{Free services, taxes, licence fees, and price}

The public sector inevitably supplies collective goods under the umbrella of public service and the notion of price differs considerably from that in the private sector. In the public sector, there are four specific concepts of price:

- Free services: numerous public services such as schooling, police, roads, etc. are 'free', and financed by taxation.

- Tax: a levy charged to use a public service, with two main features: the sum charged has no connection to the actual cost of the service, nor is it proportional to actual use of the service. Here, the tax must be paid even if the service is not used. In Switzerland, for instance, the State taxes cars to use the highway network. An obligatory voucher costing CHF40, must be displayed on the car windshield. This fee has no link with the actual cost of constructing and maintaining the highway, and is due regardless of how often the citizen's vehicle is used on the road. A modulated variant of this system is also used in Austria.

- Licence fee: the amount is linked directly to how much the service is used, proportionate to the service provided. To take a Swiss example, heavy vehicles - trucks carrying goods - are fitted with a meter, and the vehicle owner must 
pay two to three cents per kilometre. Like the tax, the licence fee does not reflect the actual cost of the service.

- Price: we speak of the price of a public service when the sum demanded takes the actual use of the service into account and when it has to cover at least most of the costs engendered. In this instance, there is a link between price and costs.

Two criteria linked to the differentiation between a public and a private entity explain why public services are not charged to beneficiaries, and why the latter are only liable for some of the costs: non-competition and non-exclusion (Le Gall-Ely, 2003; Urbain and Le Gall-Ely, 2009).

Non-competition means service beneficiaries are not in competition for the use of goods or services. Unless there are traffic jams, car drivers can use the road network without hindering other drivers. Similarly, any individual can breathe in air without preventing other people doing the same.

Non-exclusion means individuals cannot be prevented from having access to a service or product. All members of the community benefit from services like security, control of epidemics, etc. and it is virtually impossible to stop anyone swimming in a lake or walking up a mountain.

Table 6.1 provides an overview of the various combinations between criteria of competition and exclusion. The traditional market mechanisms of supply and demand are inappropriate when public goods display characteristics of non-competition and nonexclusion. The service can be provided free of charge, and still be financed by taxes paid by beneficiaries and non-beneficiaries alike.

Yet many services are of a non-competitive nature, not being able either to identify the beneficiaries, or exclude those not respecting established rules. Examples of this are water treatment, using a road network, visiting a museum, etc. It is then possible to ask beneficiaries to contribute towards the cost of the service through taxation or fees.

Table 6.1 Public goods and types of price

\begin{tabular}{|c|c|c|}
\hline \multirow[t]{2}{*}{ Exclusion } & \multicolumn{2}{|l|}{ Competition } \\
\hline & No & Yes \\
\hline \multirow[t]{2}{*}{ No } & Public goods & Common goods \\
\hline & Free & $\begin{array}{l}\text { (More unusual) rivalry for a } \\
\text { limited renewable resource like } \\
\text { water in certain countries }\end{array}$ \\
\hline \multirow[t]{3}{*}{ Yes } & Club goods & Private goods \\
\hline & $\begin{array}{l}\text { (No rivalry between users } \\
\text { but a contribution to be } \\
\text { paid) }\end{array}$ & $\begin{array}{l}\text { Possible intervention of the } \\
\text { State that plays a tutelary role } \\
\text { (school medicine) }\end{array}$ \\
\hline & $\begin{array}{l}\text { Some public services } \\
\text { (water, garbage collection) }\end{array}$ & \\
\hline
\end{tabular}


Cases where it is not possible to exclude beneficiaries - while observing consumer competition - are less frequent. Among those most often cited are deep-sea fishing and the use of water in some countries. Price here is not usually an instrument for regulating consumption. Instead, other instruments, like the introduction of quotas, are needed.

This evokes private goods - competition and possible exclusion - with the State playing a guardianship role in seeking to encourage consumption. Otherwise, without the State's intervention, the goods would be unaffordable for many people. Education in general, along with more specialized services like medical training, or providing bikes for cheap public hire in cities like Paris, Madrid, or Montreal fall into this category. These are examples of the State exercising a guardianship function regarding what are essentially private goods. See Box 6.3 for more information about the Vélib' system operated by the City of Paris.

\section{BOX 6.3 BICYCLE HIRE IN PARIS}

Vélib' (http://www.velib.paris.fr) is a bike-hire system in Paris, with nearly 20,000 bicycles available for hire at over 1,800 stations across the city. Users need to take out a subscription then pay according to use. As an added incentive, the first half-hour is free. The service is provided by the City of Paris in collaboration with the advertising company Decaux.

Decaux's ten-year contract with the City of Paris (until 2017) obliges them to install and maintain the bicycles and stations, and pay the City of Paris an annual fee of $€ 3.4$ million. In return, Decaux have exclusive access to nearly 1,600 station billboards.

\section{Pricing strategies for public services}

If the price for a public service can be linked to its cost - taxes and licence fees being 'political' prices - it is important to study the function sought by the price (Greffe, 1999) as well as the possible strategies for fixing it (Urbain and Le Gall-Ely, 2009).

Prices can indicate the value of the product or service. As people are ready to pay to acquire a good, its price should correspond to the degree of satisfaction it gives them. Fixing the price is, however, tricky if users have no pricing reference and no market mechanisms or competing proposals exist.

Price can also be a tool for rationing demand. If resources or capacities are limited, and to ensure excessive demand does not beleaguer the organization and prevent it from carrying out its mission, a price may be introduced for the service, providing principles of fairness are respected. One may also talk of 'de-marketing', or rationing demand. This was the case in a previous example (see Box 5.4), when a body offering 
students and adults career advice began to charge adults. This was implemented to reduce demand and be able to continue its mission with students.

The price's main raison d'être may also be to gather the main resources needed for the organization to function. This could occur if the organization encounters a drop in subsidies and has to seek new resources by commercializing services at the going rate. Since the early 1990s, various public meteorology services have been faced with growing needs such as new technologies, models of calculation, etc. As a result, they have introduced a wide range of paying services in response to their public funding being scaled back.

Lastly, price can be used to make public agents manage more responsibly. If these representatives realize some of the organization's revenue depends directly on the sale of services, then it is in their best interest to ensure the quality of those services is reflected in the price.

Fixing prices in the public sector can reflect various strategies. First, the price can be based on marginal costs where users pay all the variable costs without having to contribute towards the fixed costs. Subsequently, a price strategy may have no direct link to the actual cost. This occurs either because this is the simpler alternative, or it is spreading the cost among all service users. For example, the price of sending a letter is fixed irrespective of distance. The final strategy, widespread in the private sector and increasingly so in the public sector, involves differentiating price according to a variety of factors:

- Objective aspects of the service offered: in the public transport or culture sectors, price differences based on the class or category chosen have long been common.

- Time of day: prices are based on when the service is used so as to modify people's behaviour if possible, and discourage use of the service at peak times; such a policy is practised by museums, for certain types of public transport, etc.

- Method of distribution: to encourage people to book on the internet rather than at the ticket office, for instance, booking online can be cheaper or free.

- The person(s) concerned: this is naturally a tricky subject in the public sector. However, price is often used according to:

(a) zone of residence, with separate prices for residents who already pay towards the service via taxes and non-residents who are charged more but tend to be less bothered about the price than residents

(b) demographic criteria, such as age - preferential prices for young people and senior citizens

(c) social criteria, favouring people from under-privileged groups such as the unemployed, those on social benefit, or families; with policies like the third child rides free, etc.

- Specific differentiation - season tickets: setting a fixed price for unlimited use fosters user loyalty and provides greater flexibility. For the organization, this type of differentiation offers the advantage of helping cash-flow and reducing sales structures. 
Any price differentiation should, in theory, take account of equal treatment and a certain fairness in the criteria adopted. Additionally, some differentiations can lead to a loss of income - which the organization must then compensate through a corresponding subsidy.

\section{Monetary and non-monetary incentives}

Prices in the public sector can be used to incite people to act in a desired way, or sanction them for unacceptable or undesirable behaviour. Prices here, whether monetary or non-monetary, are not linked to cost. In this case, the administration, rather than providing a service as such, decides how people should behave. This is the main issue about incentives, which lend themselves to two types of study: monetary or non-monetary incentives; and positive or negative incentives.

Positive monetary incentives seek to reward people for behaving in a certain way. For instance, in some countries, to ensure children attend school and are not employed in economic activity, the government gives parents financial help if their children go to school. In the USA, anyone who agrees to join the army receives a bonus of up to several thousand dollars. Negative monetary incentives, in contrast, include fining individuals or bodies who break the law. Additionally, monetary penalties seek to sanction those responsible for ill-doing and dissuade them from behaving similarly in the future.

Positive and negative incentives may also be non-monetary. Certain types of behaviour are encouraged by granting official recognition, for example to a firm for displaying a responsible ecological approach. Conversely, inappropriate or bad behaviour can be discouraged, with sanctions such as banning single-passenger vehicles from dual carriageways.

\section{ACCESS TO PUBLIC SERVICES (DISTRIBUTION)}

Distribution is the marketing instrument whereby goods or services are delivered from producer to consumer. The distribution system for physical goods like cars is familiar and well-structured - producer/importer/distributor/garage owner/consumer. However, the system used for services, specifically public services, is very different and for two reasons.

On the one hand, and this concerns nearly all services, organizations distribute their services themselves. This is mainly done because it is not possible to separate production from service consumption. For example, banking services are provided mostly when clients visit their branch or log on to the bank's website. In contrast, public services are generally distributed via territorial structures which tend to have evolved historically, according to the State's administrative organization, rather than according to the nature of the service and the needs of beneficiaries.

Study of service distribution used to be neglected, but has now developed considerably given that access to services - proximity, opening times, waiting time, 
etc. - has become important in assessing their quality. An organization's best possible services are of limited impact if people need to take a day off work to be able to use them due to distance, inadequate structures to absorb demand, etc.

\section{Distribution circuits and channels}

A distribution circuit involves all those taking part in transferring goods from production to distribution. Put simply: we can distinguish between a direct and indirect circuit. A direct circuit has no intermediaries between producer and consumer. An indirect circuit has various intermediaries like wholesalers and retailers. In turn, the middlemen take charge of the goods or service, along with other goods or services from other producers, and offer them to beneficiaries. A distribution channel is a delivery path for goods and services whose distribution structures are of the same type and utilize a network of shops or other methods of sale.

At public-sector level, even if direct face-to-face relationships between public sector agents and beneficiaries have become more common, several distribution circuits and channels can be identified, as outlined in Figure 6.5.

As we can see above, the most frequent type of relationship in the context of fixed structures is a personal one - children going to school, filing a complaint with the police, etc. Itinerant or personal structures are rarer but have developed, becoming very important in rural areas; or if a high number of beneficiaries are concerned.

\begin{tabular}{|c|c|c|c|}
\hline \multicolumn{3}{|c|}{ Direct circuit } & \multirow[t]{3}{*}{ Indirect circuit } \\
\hline Persona & elations & \multirow{2}{*}{$\begin{array}{l}\text { Impersonal } \\
\text { relations }\end{array}$} & \\
\hline Fixed & Mobile & & \\
\hline $\begin{array}{c}\text { Traditional } \\
\text { counter }\end{array}$ & $\begin{array}{c}\text { Mobile } \\
\text { structure }\end{array}$ & $\begin{array}{l}\text { Telephone, } \\
\text { internet }\end{array}$ & Collaboration with partners (private) \\
\hline
\end{tabular}

Figure 6.5 Distribution of public services 
Some examples include the following:

- mobile libraries or 'book buses', which, at certain times, travel from district to district

- school road safety programmes where police officers visit schools to teach children basic safety rules

- fiscal administration where, for example, staff visits small municipalities to help people fill in their tax forms.

Whether as part of fixed or itinerant structures, a distinction can still be made between self-service and a face-to-face service. The former is cheaper but rarer, and usually limited to providing free access to available information. As an example, in modern libraries, users enjoy direct access to all the books and are only checked as they leave. However, in older libraries users must fill in a form and hand it in at the front desk, and only receive their book once a staff member has fetched it for them.

Even if direct contact is maintained, the relationship between the administration and beneficiaries may become impersonal. This is the case, for instance, with services ordered by telephone and sent by post. This form of service delivery has developed extensively with the arrival of the internet and, more generally, electronic means and systems of communication - cyber-administration, call-centre, etc. It enables a wide range of services to be offered at all times and at reduced cost.

It is not so frequent for the administration to use indirect circuits, such as calling on intermediaries to deliver services. But this procedure has developed with third parties being contracted to deliver services. This has been done either for economic reasons, or to ensure those in decentralized regions also enjoy the same basic services. In many countries, including the Netherlands, Sweden, Germany, Hong Kong, Japan, people must pay for household waste disposal as per the polluter/payer principle. This is where the householder buys vouchers to affix to their garbage bags.

Without the voucher, the bags are not collected and the person may be fined. Consequently, people must be able to conveniently buy their vouchers, and to this end they are sold at gas stations, department stores, and local shops. To ensure their cooperation, shopkeepers keep a percentage of the fee for the service they provide. This distribution circuit is thus organized with partners who are external to the administration.

\section{Physical aspects of distribution}

For historical reasons linked to the nature of the core public services - schools, hospitals, justice, police, etc. - distribution of these services has mainly been organized on the basis of institutional and political territorial structures. This means each country has a distinct political and administrative structuring of its territory. For several reasons, reorganizing the distribution of these services is often essential. 
First, the spread of electronic communication helps people avoid having to move around. For instance, tax offices have set up call centres to answer taxpayers' questions, avoiding the need for people to make unnecessary trips. Then again, distribution structures are not always adapted to the mobility of the population or its density in certain regions. Currently, more and more post offices are being opened in shopping centres, to the detriment of traditional village post offices.

Another factor is linked to the need for some specific types of services to have a minimal infrastructure size. For example, a medical transplant service must carry out a minimum number of operations each year in order to maintain a high degree of competence. This means that such services - along with the necessary investment can only be offered in a very limited number of hospitals. Finally, the physical structures of service distribution are very costly and, for economic reasons, many public communities are forced to reduce or alter them.

Along with venues such as tribunals, schools, town halls, etc. often having great symbolic importance in the public sector, the material aspects and the service's physical accessibility also needs to be considered.

A first, major factor is opening times. When services are open from 8.30 to 11.30 and $2.00 \mathrm{pm}$ to $4.30 \mathrm{pm}$, users are virtually obliged to take time off work to carry out an administrative formality or obtain a service. So, to bring the service closer to citizens' schedules, some public agencies are now open all day, 8 am to $5 \mathrm{pm}$. Others elect to stay open one evening a week such as Thursdays until $8.00 \mathrm{pm}$. Such options make it much easier for working people to have access to the service.

Another aspect concerns the internal architecture of the buildings concerned. Many administrative offices were not designed to encourage a relationship between exchange partners. Therefore, great efforts must still be made to improve the material conditions for such an exchange.

In Switzerland, a service in charge of personal bankruptcies was formerly housed in an old building with one long counter topped by frosted glass windows. There was invariably tension when personal files were submitted. Everyone could hear what was being discussed. There was no room set aside for depositing personal files which often fell on the floor. Nor were there any chairs for people having to wait, let alone a cafeteria or other amenities.

When the service moved, the management - dismayed at the material conditions of the relationship between their organization and citizens filing for personal bankruptcy - insisted their new premises be designed to reduce such tension to a minimum. They called for an 'open-space' premises with partition walls to help preserve confidentiality; a new, comfortable waiting-room well away from the interview 'desks'; the possibility of sitting during the interview and depositing personal files, as well as one's coat, without a problem, etc.

These changes in how the public were received did greatly reduce tension and potential causes of conflict. Subsequently it is important that, for the comfort of beneficiaries, close attention should be paid to the physical conditions of public service accessibility. 


\section{CYBER-ADMINISTRATION}

Cyber-administration, also known as e-administration or e-government, means using all available information and communication technology to offer services on behalf of the administration, and render public information accessible.

The number of public administration portals continues to grow as do the number of services provided via such technology. This field is currently the subject of extensive research due notably to the internet's vast potential, but continues to be under-used. In addition, the attitude of the public towards this technology varies considerably.

There are many advantages, both for the administration and beneficiaries, in using these new tools. One of the main advantages is undoubtedly that all services are available round the clock, irrespective of where they are ordered. The process is much simplified if you can fill in a form at any time of day or night wherever you are - even abroad.

Next, the cost is usually less - both for the beneficiary and the organization. The beneficiary does not need to travel. And with this type of interaction, the organization can deal with subjects according to its resources and possibilities, without relying on the physical presence of the persons concerned. Finally, if the service lends itself to facilitation and the offer is not limited, then all public services can be accessed via the same portal.

These undeniable advantages should not obviate the limits of internet use in the relationship between administration and beneficiaries. We first need to bear in mind that many people do not have internet access, or know how to use the available services properly. For many, filling in a tax return online, using an electronic signature, and so on, can be daunting.

Although some services can be carried out on the internet, it may still be necessary to visit the administration to complete certain formalities. To obtain a biometric passport, for instance, a person can fill in the forms; book an appointment, make advance payment online and apply to receive their passport by post. However, they still have to come in person to have their fingerprints taken.

And, finally, the internet cannot assume the task of maintaining and reinforcing social links between people. Therefore cyber-administration should be regarded as an additional distribution channel for improving the quality of the services provided, rather than as a substitute for traditional channels.

\section{CHOOSING A PUBLIC SERVICE DISTRIBUTION SYSTEM: DECISION-MAKING CRITERIA}

As indicated above, public service distribution is largely dependent on territorial structures. In addition, there must be legal bases linked to introducing the service. And, a series of other criteria may also be noted as part of a more technical analysis of a public service distribution system:

- Existing infrastructure: the infrastructure in use - hospitals, schools, etc. - is often costly and impossible to move. Still, it cannot be ignored when discussing service 
distribution. But transforming such buildings or assigning them new roles such as turning a hospital into a medico-social establishment, often needs to be contemplated.

- Equal access to services: it is naturally impossible for each inhabitant to live the same distance from all public services. But it is important - particularly for essential public services - to ensure distance does not hinder accessibility, especially for people with reduced mobility such as senior citizens and many others.

If a maximum distance cannot be developed - various criteria must be considered, such as frequency or degree of importance to the beneficiary - large distances can lead to people renouncing their rights and confidence in the administrative system is undermined.

For example, if individuals must attend in person in order to contest something like a parking fine, and the administration's offices are situated over an hour's drive away, it is highly probable most people, even with right on their side, will prefer to pay the fine rather than waste a day in travelling and waiting.

- Service quality: this does not necessarily depend on proximity, insofar as certain services require infrastructures and skills not possible to develop in many places. In certain instances - hospitals, police, and so on - physical proximity to the service but without access to adequate resources may actually reduce the quality of service. As well, when it comes to service quality, the possibility of hiring personnel able to offer advice and deal with users' needs has an impact on the distribution structure.

- Free services: paying services can generate different expectations compared to free ones.

- Versatility: this is very important. Many administrative services have introduced the concept of the 'one-stop' centre where most procedures linked to a particular issue can be handled, preferably by one and the same employee. An example is: a company service is created to process all the formalities required to create a new company. The development of 'one-stop' centres tends to mean beneficiaries face greater travelling, as a large number of multi-skilled staff must be concentrated in one location.

- Personal involvement of beneficiaries: if this is extensive such as in launching a business, undergoing a major operation, visiting a leading museum, etc., people will be more prepared to travel long distances. On the other hand, for services where personal involvement is less important or non-existent, they will be loath to make a special effort. In this case greater proximity is a requirement, with services available more simply and readily.

- Public transport: a structure may be geographically close at hand, yet considered far away if it is not readily accessible by conveniently organized public transport. Often, this relates to scheduled times, frequency, connections, etc.

- Economic aspects: these can be decisive, given the high cost of administrative structures or economic structures dependent on public bodies. 


\section{CONCLUSION}

The marketing mix will be putting all these elements - product, price, promotion, place, people, process, and physical facilities - into a coherent and well-adapted concept. There are not one size-fits-all solutions but, rather, mixes more or less adapted to the service being marketed by a specific type of organization.

\section{EXERCISE 6.1}

Analyse two of your organization's services on the basis of the four Ps approach. Next, compare the results with colleagues in other organizations. Is the weight of each element the same? What makes the mix of these elements different? Is it the nature of the service, the type of organization, etc.?

\section{DISCUSSION QUESTIONS}

1. Is the definition of the price of a public service really a marketing decision? Isn't it a public policy decision? How would you differentiate the two?

2. Aside from the four Ps and the three additional elements presented - people, process, and physical facilities - do you believe your organization's particularities would require an additional category?

3. Outsourcing services to private operators is a logical consequence of New Public Management reforms. Discuss examples from your country and identify advantages and disadvantages of outsourcing public services.

4. Based on the information in this chapter (Boxes 6.1 and 6.2), develop a strategy for the management of a retirement home. According to you, what will be the most problematic phases? And what will be the most politicized phases?

5. Motorways can be administered in different ways. In some countries like Luxembourg, using the highway is free of charge. Conversely, Austria requires drivers to purchase a windshield-sticker allowing them use the infrastructure for a specific period of time (ten days, two months, or one year). France, finally operates on a road toll system, requiring drivers to pay a fee each time the motorway is used. Discuss: which advantages or disadvantages can you identify for each systems?

\section{NOTE}

1. The phrase 'public service' is mentioned just once in the EC Treaty, Article 73, which states: 'Aids shall be compatible with this Treaty if they meet the needs of coordination of transport of if they represent reimbursement for the discharge of certain obligations inherent in the concept of a public service.' 


\section{REFERENCES}

Bitner, J. and Booms, B. (1981) Marketing Strategies and Organizational Structures for Service Firms, in Donnelly, J. and George, W. (eds) Marketing of Services, Chicago, American Marketing Association.

Bloom, N., Propper, C., Seiler, S., and Van Reenen, J. (2014) The Impact of Competition on Management Quality: Evidence from Public Hospitals, Review of Economic Studies, 1-33.

Borden, N. H. (1965) The Concept of the Marketing Mix, in Schnertz, G. Science in Marketing, Chichester, John Wiley \& Sons.

Carter, L., Weerakkody, V., Phillips, B., and Dwivedi, Y.K. (2016) Citizen Adoption of E-Government Services : Exploring Citizen Perceptions of Online Services in the United States and United Kingdom, Informations Systems Management, 33, 124-40.

Cats, 0., Reimal, T., and Susilo, Y. (2014) Public Transport Pricing Theory, Empirical Evidence from a Fare-Free Scheme in Tallinn, Estonia, Journal of the Transportation Research Board, 2415, 89-96.

Chatzoglou, P., Chatzoudes, D., and Vraimaki, E. (2013) Service Quality in the Public Sector: The Case of the Citizen's Service Centers (CSCs) of Greece, International Journal of Productivity and Performance Management, 62, 583-605.

Chen, L., Dai, Y., Zhang, Y., Wu, O., Rudan, D., Saftić, V., van Velthoven, M., Su, Y., Tan, Z., and Scherpbier, R.W. (2013) A Comparison between Antenatal Care Quality in Public and Private Sector in Rural Hebei, China, Croatian Medical Journal 54 (2), 146-56.

Commission of the European Communities (2003) Green Paper on Services of General Interest, Brussels, Commission of the European Communities.

Cooper, Z., Craig, S. V., Gaynor, M., and Van Reenen, J. (2015) The Price Ain't Right? Hospital Prices and Health Spending on the Privately Insured, National Bureau of Economic Research.

Davet, P. (2006) Gestion par Prestation au Niveau Cantonal: Développement d'un Concept pour la Définition des Prestations dans une Logique de Pilotage Politique et Opérationnel, Lausanne, Institut de Hautes Études en Administration Publique.

Greffe, X. (1999) Gestion Publique, Paris, Dalloz.

Haynes, P. (2015) Managing Complexity in the Public Services, Second Edition, Routledge.

Kotler, P. K. (2009) Marketing Management, New York, Prentice Hall.

Kühn, R., Reimer, A. and Fasnacht, R. (2006) Marketing: System, Strategie und Instrumente, Bern, Haupt Verlag Ag.

Le Gall-Ely, M. (2003) Le Marketing Public, E-theque (www.numilog.com).

McCarthy, E. J. (1960) Basic Marketing: A Managerial Approach, Illinois, Irwin.

Osborne, S. P., Radnor, Z., and Nasi, G. (2012) A New Theory for Public Service Management? Toward a (Public) Service-Dominant Approach, American Review of Public Administration, 43, 135-58.

Parasuraman, A., Zeithaml, V. A., and Berry, L. L. (1985) A Conceptual Model of Service Quality and Its Implications for Future Research, Journal of Marketing, 49, 41-50.

Pierce, G. and Shoup, D. (2013) Getting the Prices Right, An Evaluation of Pricing Parking by Demand in San Francisco, Journal of the American Planning Association, $79,67-81$. 
Rana, N. P., Dwivedi, Y. K., and Williams, M.D. (2015) A Meta-analysis of Existing Research on Citizen Adoption of E-government, Information Systems Frontiers, 17, 547-63.

Rawls, J. (1971) Theory of Justice, Cambridge, Belknap Press of Harvard University Press.

Reddick, C. G. and Turner, M. (2012) Channel Choice and Public Service Delivery in Canada : Comparing E-government to Traditional Service Delivery, Government Information Quarterly, 29, 1-11.

Scholl, H. J. (2015) E-government, Information, Technology, and Transformation, Advances in Management Informations Systems, London, Routledge.

Treasury Board of Canada (1994) Quality and Affordable Service for Canadians: Establishing Service Standards in the Federal Government: An Overview, Ottawa, Government of Canada.

Tyler, T. R. (1988) What Is Procedural Justice? Criteria Used by Citizens to Assess the Fairness of Legal Procedures, Law \& Society Review, 22, 103-35.

Tyler, T. R. (2005) Readings in Procedural Justice, Burlington, Ashgate.

Urbain, C. and Le Gall-Ely, M. (2009) Prix et Stratégie Marketing, Paris, Dunod.

Van Dooren, W., Bouckaert, G., and Halligan, J. (2015) Performance Management in the Public Sector, Second Edition, London, Routledge.

Verbeeten, F. H. M. and Speklé, R. F. (2015) Management Control, Results-Oriented Culture and Public Sector Performance: Empirical Evidence on New Public Management, Organization Studies, 37, 953-78.

Weerakkody, V., Irani, Z., Lee, H., et al. (2015) E-government Implementation: A Bird's Eye View of Issues Relating to Costs, Opportunities, Benefits and Risks, Informations Systems Frontiers, 17, 889-915.

Zeithaml, V., Parasuraman, A., and Berry, L. L. (1990) Delivering Quality Service: Balancing Customer Perceptions and Expectations, New York, Free Press. 


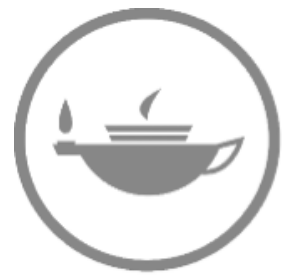

Taylor \& Francis Taylor \& Francis Group http://taylorandfrancis.com 


\section{Public communications - an introduction}

\section{LEARNING OBJECTIVES}

By the end of this chapter you should be able to:

- Identify the underpinnings of modern communications in the public sector.

- Distinguish between the various levels of communications from government communications to crisis communications.

- Understand the issues and challenges involved in government transparency.

\section{KEY POINTS OF THIS CHAPTER}

- Public communications is taking an increasingly important place in advanced democratic societies. It serves a number of functions: to inform, to influence, to promote value, and to be accountable.

- Public communications has developed in response to changes in society, changes in the roles of public-sector organizations, and changes in the media sector.

- There are a number of differences between public and private communications. Among them are the importance of the organization's legal bases and the obligation of neutrality.

- There are various levels of public communications each with its own specific attributes. The emphasis - or lack thereof - on political aspects is one of the most significant factors in determining the level of a communication.

- Transparency, implemented among other things through access-to-information legislation, is now an essential element in a modern democratic state. This is linked to the increased need for information from citizens as well as the goals of increased accountability, greater participation, and better relations with citizens.

- Despite the legal obligation imposed by transparency focused legislations; organizations have developed numerous strategies to counter the move towards greater transparency and openness. 


\section{KEY TERMS}

Public communications - communications used in a public-sector setting that take into account the corresponding specificities, notably the importance of neutrality and specific legal framework.

Active communications - voluntary, planned communications strategy by a public organization.

Passive communications - information provided by an organization in response to requests from various parties.

Access to information - the legal right of citizens to have access to information held by their government.

\section{INTRODUCTION}

Communication is a fundamental component of our society, the basis of social relationships among people. The field of communications assumes enormous importance in complex, democratic societies. It takes very varied forms - written, oral, visual, virtual, etc. - and is carried by varied media used in combination with each other.

A particular feature of democratic societies is that the common good is debated in the public sphere in view of and with the involvement of citizens. Public communications cannot therefore be dissociated from democratic societies. It must make information available to those participating in the debate and must take into account the growing complexity of relations between individuals and organizations making up society.

There are many possible fields for the analysis of communications, but this chapter and the following deal solely with communications of public organizations. By this is meant the transmission of information or elements of meaning for the purpose of influencing the knowledge, attitudes, opinions, expectations, and/or behaviour of recipients. Consequently, nonverbal communications and personal communication will not be addressed.

\section{FUNCTIONS, DEVELOPMENT AND PRINCIPLES OF PUBLIC COMMUNICATIONS}

One of the main characteristics of public communications is its diversity. By this we mean diversity in senders and receivers, their interactions and the roles they play, the possible forms and objectives of communication, etc. Box 7.1 provides a few examples of public communications to illustrate this diversity. 


\section{BOX 7.1 EXAMPLES OF FORMS OF PUBLIC COMMUNICATIONS}

- Participation by managers of public organizations in public debates

- Press conferences to present and explain decisions

- Communicating information through press releases

- Responses to questions and criticisms from the media and other actors in public life including political parties, civil-society organizations, citizens, and so on

- Distribution of information brochures to parents

- Paid advertisements in the press or other media for prevention campaigns

- Mailing of letters and e-mail messages as part of normal public-sector activity

- Management and hosting of websites

- Participation in fairs

- Open days

- Publication of periodicals and books.

A closer look at this diversity reveals the main aspects of public communications (Figure 7.1.).

The first element to consider is the originators of acts of communication - the 'senders'. Here, a distinction must be drawn between the State, the civil service, and all administrative and public bodies. All have a degree of autonomy and often use it to develop communications activities of their own.

At the other end of the communications spectrum we have the receivers. Here, a distinction must be drawn between individuals with the various roles they may play citizens, customers, employees, and groups of individuals. The latter includes political parties and associations, businesses, institutions, public communities, and government bodies.

Communication between senders and receivers can be intentional or unintentional, declared or undeclared, personal or impersonal, active or passive, etc. To this must be added types of communications and their functions and objectives. The last two points are covered in the following sections.

\section{The functions of public communications}

Even though functions of private organizations do go beyond simply buying and selling, functions of public organizations are much more varied and complex. The first function is to inform. The government must not only inform the public of all decisions taken by political authorities and government departments, but must also explain these decisions as well as how and why they were taken. 


\section{Functions and objectives of communication}

- Inform (e.g. decisions, information useful to daily life)

- Influence (e.g. prevention)

- Confirm, prove (e.g. give an account of activities)

- Position (e.g. give a profile to the organization)

- Support values, motivate (e.g. citizen participation in political life)

\section{Forms of communication}

- Insititutional and non-institutional communications

- Declared and non-declared communications

- Personal and non-personal communications

- Verbal and non-verbal communications

\section{Actors and levels}

- The State

- Administration

- Autonomous entities

- Public enterprises

- National, regional and local levels

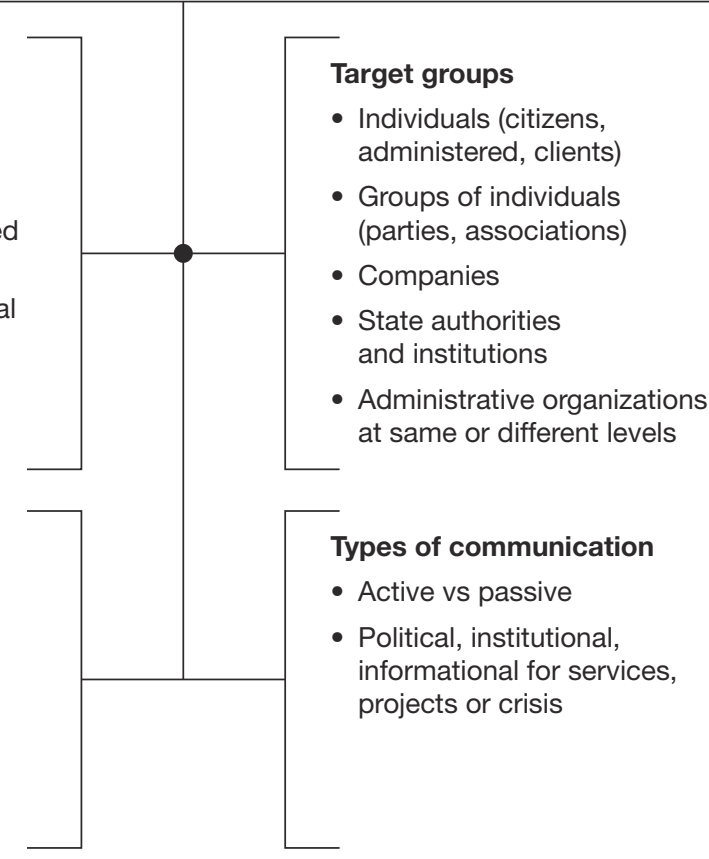

Figure 7.1 Elements of public communications

With the expansion of public services, this function has become especially important because everyone concerned by the government's decisions and services must be kept informed, or at least must be able to have easy access to clear, accurate information. A lack of information about a public action can have serious consequences.

For example, on 27 April 2009 a Boeing 747 belonging to the American Presidency, escorted by a fighter plane, flew over Manhattan at low altitude to take photographs. Fearing a new terrorist attack, thousands of people panicked and came out of their offices. Regardless of the wisdom of flying over the city of New York at low altitudes with such a plane, information distributed widely in advance to the entire population could have prevented inhabitants from reliving a moment of horror (Sulzberger and Matthew, 2009).

Influencing or attempting to change the behaviour of people is another function of communications - one in which large sums of money are invested. Through many 
communications campaigns and activities, the government or organizations mandated by it endeavour to warn against behaviours posing a risk to individuals and to society in general.

Such preventative measures are becoming more and more widespread, aimed in particular at reducing risk behaviour. These include drinking and smoking, driving behaviour, protection during sexual acts in order to prevent the spread of AIDS and other STDs, the fight against illegal drugs and other addictions, as well as the promotion of a healthy diet.

Another function of public communications is to explain, confirm, and attest to tasks and initiatives that have been carried out. Public organizations must be accountable, which means they must report their actions, attest to the fact they are well founded, and reply to enquiries about them. Communications activities such as these will consume an increasing share of time for managers of public organizations.

Because certain public bodies have been made more autonomous or have been given specific, clearly delimited tasks, they have developed communications activities aimed at giving themselves a profile and an image distinct from those of the government as a whole. In doing so, they establish their own visual identity, their own set of values, and their own communications agenda. The National Aeronautics and Space Agency (NASA) in the United States is a prime example. The aim is to allow the agency to position itself relative to other organizations

Lastly, public organizations are also charged with promoting the main values of the socio-political system in which they operate. In a democratic environment, public organizations must - through their actions and behaviour and actively in their communications - stand for and promote values such as equity, integrity, transparency, and the respect for law.

\section{Reasons for the development of communications in public organizations}

A number of reasons explain the growing importance of communications for public organizations and they fall into three groups:

- those having to do with changes in society and its expectations of the politicaladministrative system;

- those having to do with the roles and functioning of administrations;

- and those having to do with the evolution of the media.

In our society, information has become a vitally important public resource. Without information, citizens, political parties, associations, and journalists cannot participate in the political debate and contribute to the workings of democracy. The government has a great deal of information at its disposal and an increasing disparity is being observed between the quantity of information it collects and the quantity it disseminates. 
Consequently, political authorities are seeking to enshrine in laws a broad obligation to provide information to citizens and to individuals or organizations concerned by its actions and decisions. This opening up of the government, its activities, its decisions, and its functioning to citizens aims at strengthening their confidence in a system that gathers a great deal of data. Communications thus become a public task which government departments must perform actively.

Other reasons are also to be found in the place and role of government departments in the political system. Until relatively recently, civil service was a closed Weberian system accountable only to political authorities. This included parliamentary control, monitoring of finances and management, and legal authorities - legal redress, complaints, etc. (see Chapter 1).

Outside these clearly defined and quite constraining avenues, government departments had little need to open up and expose themselves to the scrutiny of other actors in society. The advent of New Public Management principles, particularly the development of a more customer-oriented relationship with the beneficiaries of public action, brought about core changes such as administrative bodies being granted partial autonomy. However, along with this increased autonomy came demands for results.

Now, public bodies have very actively developed measures to communicate with beneficiaries, persuade them of the merits of services, either proposed or imposed, and more generally work towards increasing their satisfaction.

As criticism began to be levelled at New Public Management, principles of democratic governance - accountability, transparency, citizens' involvement - were brought forward. Following this, it was expected organizations would cut back on their communications activities. Instead, they simply shifted their endeavours to adapt to the new requirements.

This means that regardless of the reference model for administrative conduct, organization-specific communications tasks have increased. There are also other reasons, again with reference to the conception of the administrative system, why public organizations extend their communications activities. They do this in response to pressure on their budgets and to ensure public policies, for which they are responsible, positively remain on the political agenda.

Lastly, the evolution of the media is another factor underlying the trend for organizations to communicate more. As the number of media has increased, their liberalization and the role they play in society in general have enlivened political debate. Public organizations are solicited by the media because the areas for which they are responsible are of general interest. Because they involve education, police, social protection, unemployment, and so on, they are also of interest to the public.

Added to this is the fact that the multiplication and diversification of communications media reduce the effectiveness of every communications activity taken in isolation. As a result, to attain the same communications objective, communications activities must be stepped up appreciably in comparison with the past. This trend seems set to continue well into the future. 


\section{Basic principles of public communications}

Unlike private organizations, which have great freedom in communications, public bodies must abide by a number of principles in their communications. These include:

- being based on provisions of the law

- non-partisan and independent of political circumstances

- transparent with regard to the issuing body and its funding

- carried out in timely fashion and usually continuously

- as objective and complete as possible

- adapted to the needs of target groups and the media

- proportionate to objectives and the target groups.

Public communications must be developed and implemented on the basis of legal provisions. In most political systems, there are laws or rules to authorize or even oblige the administration to develop and implement communications activities. These rules may be general and valid for all administrative units (see Box 7.2) or specific, and connected with tasks such as promoting prevention campaigns, defence of common values, etc.

A more difficult requirement, but one vitally important for gaining credibility over time, is the necessity for public communications to be non-partisan and as far as possible, to avoid playing political games. Reality frequently reminds us that the communications activities of government departments are taken over by ministers as elections loom or in particular political circumstances.

Although this kind of takeover is very difficult to avoid, government departments must ensure that as far as possible their communications remain independent of

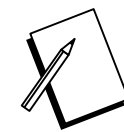

\section{BOX 7.2 LEGAL FOUNDATIONS OF COMMUNICATIONS ACTIVITIES}

In Switzerland, government communications are regulated by a specific article of the constitution (art. 180 Cst) which stipulates the Federal Council - the executive - must inform the public about its activities in a timely and detailed manner provided there is no preponderant public or private interest to the contrary.

In France, government communications are based on decree no. 2000-1027 dated 18 October 2000 in respect of the government information department (SIG).

In Germany, government communications are based on the general principles of the constitution. Articles 5 and 20 set out the right to freedom of opinion, freedom of the press, and the foundations of democratic order. 
partisan considerations. Communications succeeding in doing so are bound to enjoy increased credibility with target audiences.

The publisher and the source of funding of any public communication must be easy to identify. A message's origin is as important as its content, and must be obvious to its receiver. The same goes for funding. Often an organization that finances communications activities may also have clear intentions and objectives of their own.

If public communications are financed directly or indirectly other than with public funds, it must be clearly indicated. This allows the receiver to interpret the message in the light of the relationship between the publisher and whoever is paying for the message.

The value of information depends on the use that can be made of it at different times. The dissemination of information must therefore take into account times when the probability of its being received by target groups is highest. Outside these times, there is a significant risk of its going unnoticed.

In addition, information must, generally speaking, be repeated and continuously available. If a message is to be noticed and understood, it cannot be communicated only once. Messages must be repeated and made accessible whenever those concerned need them. In this respect, the internet allows complete information to be made available continuously.

Total objectivity may be impossible, but public information must strive towards objectivity. Furthermore, it must also be as complete as is necessary for the message to be noticed and understood. This principle underlines a clear distinction between private and public communications. Private organizations deliver only the information they wish to disclose. Most often, it is not objective information.

The objectivity of a communication will naturally be perceived through the message itself. Nevertheless, it will also be identified on the basis of the media chosen to convey the message as well as the frequency of dissemination. With regard to completeness, a communication must contain sufficient information for the message to be understood. However, loading the communication with too much additional information could hinder the full understanding the message.

Public organizations must take particular care to adapt messages to target groups and the media. This is because public information must be comprehensible to all recipients regardless of their intellectual, linguistic, and social abilities. For example, letters sent by public bodies may sometimes contain expressions or technical terms that make them difficult to understand. Messages should also be comprehensible to people with insufficient language skills. Naturally, this concerns foreigners who are not fluent in the national language(s), but also those who are illiterate or have poor reading skills.

The use of foreign languages or other forms of communication such as sign language, specific visual aids, etc. must be considered where necessary to ensure the message reaches everyone in the target audience. When informing the media, several aspects need to be addressed apart from the need to use an understandable vocabulary. Press releases should be expressly documented with a glossary, lexicon, and so on.

\section{8}


Publications' cycles, deadlines, and needs such as photographs, data for computer graphics, interviews, additional information, and the like, must be taken into account.

Lastly, public communications must be proportionate to target groups and objectives. Too often, communications in the public sector are deployed with insufficient intensity and over too short a period for them to be able to produce appreciable effect. The goal of achieving sufficiently intense communications can be achieved, for example, by using several distinct media in order to reach the target groups in various ways.

Conversely, although this is relatively rare, public communications must not incur disproportionate costs that may subsequently be criticized by financial auditors, or even directly by citizens. Generally speaking, largely due to the increase in the number of organizations communicating and the diversity of communications media, public organizations are obliged to increase and diversify their communications activities in order to attain their objectives.

\section{TYPES AND LEVELS OF PUBLIC COMMUNICATIONS}

\section{Types of public communications}

A distinction must be drawn between two main types of public communications - active and passive. Active communication covers all information provided spontaneously and generally in an organized manner by the authorities and by government departments. Such communications may focus on the general public or to defined target groups. Most communications activities by public organizations are active, since they are planned, organized and financed by organizations themselves (see Box 7.3).

Conversely, passive communications refers to information transmitted by public bodies in response to requests based on access-to-information legislation existing in most countries. Generally, the sole obligation of public bodies is to make available registers of documents available so citizens can identify and request those of interest to them, as well as dealing diligently with requests received.

The following paragraphs are essentially devoted to active communications. However, a presentation of the bases and implications of passive communications is set out in the next section of this chapter.

\section{Levels of communication}

Table 7.1 contains an overview of types of public communications along with a few examples. Although it is important to distinguish between political communications and public communications, the latter necessarily contains information of a political nature.

Although it is difficult to generalize about the strength of the political component of a type of communication, information favourably presenting government activity is considered to have the strongest political nature. The same is true of crisis 


\section{BOX 7.3 THE GOTTHARD TUNNEL}

As part of its transport policy, Switzerland decided to build two new tunnels under the Alps: the Lötschberg base tunnel, which came into service in 2007 and the Gotthard base tunnel, that came into service in 2016 . The Gotthard base tunnel specifically received not only national but international attention: with the breakthrough of the 57 kilometre tunnel in October 2010, it became the world's longest and deepest tunnel. Unsurprisingly, the construction and inauguration of service were accompanied by various communication operations:

- The piercing of the last few metres was broadcast live on public television.

- European transport ministers, meeting in Luxembourg, watched the proceedings live. The Swiss delegation presented each minister with a gift of a fragment of Gotthard rock on which was mounted a clock.

- For the inauguration several heads of State, including those of France, Germany, and Italy were in attendance.

- Special programmes were broadcast during the days leading up to and following the breakthrough as well as during the full ceremonies of the official opening.

- Invitations were sent to journalists all over the world.

communications, in that virtually any crisis or conflict in the public sector leads to intervention by all political and public actors and very frequently generates political debate.

Communications related to citizens' rights and obligations and communications as an instrument of public policy are not free of political considerations but are less strongly connected to immediate political issues. Lastly, other types of communications such as those dealing with government services and internal communications are almost completely free of political considerations.

\section{Government communications}

In democratic countries, to ensure institutions function properly, governments are required by the constitution, laws passed by the parliament or by common law, to inform the public, encourage dialogue and account for their activities. This means they must communicate and in many countries the departments set up to perform this task have substantial human and financial resources at their disposal. Generally speaking, government communications perform four tasks. However, the importance of these tasks may vary considerably from one country to another: 
Table 7.1 Levels of public communications

\begin{tabular}{|c|c|c|}
\hline Types & Examples & Political nature of public information \\
\hline & & High \\
\hline $\begin{array}{l}\text { Government } \\
\text { communications }\end{array}$ & $\begin{array}{l}\text { Information and } \\
\text { explanations of } \\
\text { government decisions } \\
\text { and actions }\end{array}$ & \\
\hline $\begin{array}{l}\text { Communications } \\
\text { related to citizens' } \\
\text { rights and } \\
\text { obligations }\end{array}$ & $\begin{array}{l}\text { Making available } \\
\text { information on laws; } \\
\text { promotion of civic } \\
\text { rights; making } \\
\text { available information } \\
\text { on political issues } \\
\text { (e.g. on official } \\
\text { statistics) }\end{array}$ & \\
\hline $\begin{array}{l}\text { Communications } \\
\text { as an instrument } \\
\text { of public policy }\end{array}$ & $\begin{array}{l}\text { Prevention and } \\
\text { awareness } \\
\text { campaigns }\end{array}$ & \\
\hline $\begin{array}{l}\text { Institutional } \\
\text { communications }\end{array}$ & $\begin{array}{l}\text { Publications aimed } \\
\text { at promoting the } \\
\text { organization }\end{array}$ & \\
\hline $\begin{array}{l}\text { Communications } \\
\text { related to public } \\
\text { services }\end{array}$ & $\begin{array}{l}\text { Information brochures, } \\
\text { detailed explanations, } \\
\text { etc. }\end{array}$ & \\
\hline $\begin{array}{l}\text { Communications } \\
\text { regarding projects }\end{array}$ & $\begin{array}{l}\text { Communications on } \\
\text { major projects (bridges, } \\
\text { tunnels, metro systems, } \\
\text { etc.) }\end{array}$ & \\
\hline $\begin{array}{l}\text { Internal } \\
\text { communications }\end{array}$ & $\begin{array}{l}\text { Communications for } \\
\text { staff }\end{array}$ & \\
\hline $\begin{array}{l}\text { Crisis } \\
\text { communications }\end{array}$ & $\begin{array}{l}\text { Any communications } \\
\text { activity in a crisis } \\
\text { situation }\end{array}$ & \\
\hline
\end{tabular}

- Providing information on the government's actions: Governments must provide all necessary information to elected representatives, the media and the general public on their intentions, decisions, and actions. The way this obligation is understood gives rise to very different practices. In some countries, government departments concerned focus upon transmitting important information about government decisions and activities. This is usually expedited through press releases and press conferences and by making this information available on internet sites or in official 
documents as well as newspapers, magazines, etc. They are also responsible for official portals of the government and the country. In other countries, these departments also have the responsibility for conducting communications campaigns which include events, paid advertising, and a wide range of communications tools.

- Being responsive to the public: The second task falling to government information departments is to inform the government about the needs, expectations, and concerns of the population and about the opinion of various groups that may influence policy such as foreign media. Governments are making increasing use of such tools as press reviews by the country's media as well as major foreign media, opinion polls, and, sometimes, quantitative surveys.

- Coordinating communications activities: These departments are also charged with coordinating the communications activities of the entire administrative apparatus. This is a task made necessary by the constant growth in the amount of information being issued by all administrative entities. Coordination can be of three types. The first is thematic coordination. For reasons of its political agenda, or depending on its activities, a government may wish the topics addressed to be actively coordinated to guarantee consistency in communications across departments.

Next, temporal coordination is designed to prevent potentially damaging short-term overlapping of communications activities of different administrative entities. When several government departments wish to communicate on various subjects at the same time, it is important that one of them should arrange the timing of messages. In particular, accredited journalists are able to cover all press conferences without putting departments or administrative bodies into competition with each other.

Third, financial coordination of communications budgets of the various departments allow prices to be negotiated, particularly when purchasing advertising space from communications agencies and the media. For example, in Australia, all government departments and agencies are required to work with a specific agency for campaign advertising and for non-campaign advertising - for example, recruitment advertisements (Australian Government, n.d.).

- Advising government departments: Less frequently, and depending on their skills and resources, government communications departments may provide advice to all departments of the administration, as communications agencies might do. In the United Kingdom, the Central Office of Information is a true agency. Its services are offered to government bodies, including strategic consulting, production of campaigns, hiring, and training of communications specialists, etc.

Government information departments are characterized by three elements.

1. They are directly subject to the authority of the head of the government or the government as a whole. In France, the SIG is subject to the prime minister; in Germany the chancellor; and in Taiwan, Nauru and many other countries, the department is located within the Office of the President.

\section{2}


2. The source of information is clearly identifiable as being governmental. This is explicitly announced in writing and by the display of the appropriate logos.

3. The communications of these departments are not concentrated on a single field of public policy such as health or safety, but on all the government's activities or their promotion.

\section{Communications in connection with citizens' rights and obligations}

This is one of the foundations of public communications and covers, on the one hand, the obligation to make information available to the media and to the public adhering to the principle of openness. On the other hand, it reminds citizens of their civic rights and duties, inviting them to participate in political life. In some countries, these tasks are carried out by the government's own information department and in others by specialized departments.

As we have seen, democratic life is particularly dependent on citizens' capacity to have access to information they need to exercise their rights. For a long time this obligation upon the government was limited to legislative and legal decisions and on the opening of debates to the public.

Currently, the principle of openness applies more broadly to all information held by the government, except in cases where there are preponderant public or private interests. Conversely, the state must ensure that information is indexed and archived in such a way that citizens can readily find the information they want. Likewise, the state must deliver information proactively - 'proactive disclosure' - in order to enable political debate.

A second tier of activities involves disseminating civic information. This is information reminding citizens of their rights and duties, as well as the fundamental values of the democratic state. It explains how institutions work in order to increase their accessibility and legitimacy. In short, it encourages participation in political life. This is particularly important during elections and votes at all levels of government.

These tasks are becoming increasingly important since 'incivility' is increasing. Criticisms of the legitimacy of institutions are now more frequent, and voter participation in elections often falls below 50 per cent. ${ }^{1}$

\section{Communications as an instrument of public policy}

While communications accompany almost all the government's decisions and actions as a tool, it has also become a fully fledged instrument of public policy, used in the same way as incentive, disincentive, or regulatory measures. Objectives may include discouraging certain behaviours such as not driving under the influence of alcohol; raising awareness of various attitudes - sorting household waste for recycling; and inviting people to take concrete action like getting vaccinated. 
For these purposes websites are created, newsletters are distributed to households and businesses, publicity campaigns are disseminated via the main media such as television and billboards, personalized letters are sent, etc. The government therefore uses communications tools to attain its various policy objectives. Communications campaigns in some fields, such as health and economic promotion, date back decades, while others such as the environment, education, and safety have appeared only more recently.

\section{Institutional communications}

An increasing share of communications activities is devoted to promoting public institutions and organizations. This is not a matter of highlighting the work of these bodies so much as the organizations themselves. Three main reasons explain this trend.

1. New entities, be they the Department of Homeland Security created in 2002 in the United States, or the Efficiency Unit of Hong Kong need to make themselves known to the public in order to properly fulfil their missions.

2. To facilitate access to their services or reinforce their legitimacy, public organizations are developing a range of measures, from open days and the production of brochures to invitations to journalists to produce special reports.

3. Organizations need to position themselves and build a positive image to facilitate attainment of their objectives. Examples of these would be when recruiting new staff, marketing their services, attracting more businesses, residents, or tourists.

This type of communication also encompasses all information concerning the life of the organization, such as appointments, organizational changes, and, particularly, reports on activities. In the classical view of bureaucracy, the civil service has no legal personality and must limit itself to implementing rules and procedures set out in legislation. Today, it is clearly becoming increasingly important for public organizations to be known to the general public, enjoy a high level of trust and account for their activities regularly.

\section{Communications regarding services}

Communications regarding services is not a public policy measure but is aimed at providing information on services offered by the government. Clear information should be provided for the following:

1. services and eligibility for these services,

2. procedures to follow,

3. documents required,

4. the time it will take to obtain a reply or a decision,

\section{4}


5. possible recourse,

6. prices and methods of payment,

7. opening hours, etc. greatly facilitates the lives of citizens.

These aspects are all the more important because in the public sector, the perceived quality of a service is judged not so much on the service itself but upon peripheral elements. Information and the attitude of personnel are vital elements in this perception of quality.

\section{Project communications}

The public sector undertakes projects that require specific communications activities for a number of reasons. Major projects such as the Millau Viaduct in France, the Confederation Bridge in Canada, Boston's 'Big Dig', the Channel Tunnel linking France and the United Kingdom, and the construction of the Hong Kong International airport all involve numerous public and private actors. All need to be kept informed of progress on the project, and of the technical and financial difficulties encountered.

Projects have a defined temporal framework, with a beginning and an end, and important stages which are traditionally highlighted. This may consist of the placing of the first stone, tunnel breakthrough, etc. They serve as milestones for communications purposes. Lastly, projects such as these also constitute the achievements of a generation, national, or territorial symbols valuable not only because they bring a community together but also because they serve as flagships for the outside world (see Box 7.3).

Today, no major project goes without a communications concept and a substantial communications budget is built into the cost of the project.

\section{Internal communications}

In addition to communications aimed at external actors, consideration must be given to communications aimed at staff. While this may appear obvious, there is an unfortunate tendency to overlook the fact that staff is the civil service's main resource. They are frequently the first vectors of an organization's communications.

If they receive information at the same time or even after the general public or certain specific actors, they will be unable to act as facilitators in the transmission of messages. For example, in one crisis affecting a public-sector organization, many staff members openly complained. They had not been provided necessary information with which to respond to remarks and criticisms made by their families, friends, neighbours, and acquaintances (Pasquier and Fivat, 2009).

Internal communications activities have also increased considerably with intranet sites, internal newspapers, newsletters, the organization of events, and so on. 


\section{Crisis communications}

The final type of communications governments need to consider is crisis communications. What is unusual about crisis communications is that it can affect any field of government activity. It may be a problem involving relations with political institutions; a crisis of confidence at the organizational level; a serious problem in a major project; a defective service; or an internal crisis.

In addition, a crisis will concern an entire organization because the general public is usually not able to draw a clear distinction between the service provided by an organization and its global image. Crisis communications will also go beyond government agencies to involve political authorities and parties. This is because, depending on the type of crisis, it is highly probable that these actors will contribute to communications through their questions and the positions they adopt.

For this reason, conflict and crises affecting the public sector frequently take on a political dimension. This occurs either through the intervention of political actors or via a political discussion of the problems which are the basis of the crisis.

\section{PASSIVE COMMUNICATION, ACCESS TO INFORMATION OR THE CONCEPT OF TRANSPARENCY}

The concept of transparency has taken root over the past decades as a necessity to counter both organizational and individual lapses such as corruption, fraud, and financial scandals. Additionally, transparency is believed to improve the governance of organizations in both the public and private sectors (Kosack and Fung, 2014).

Laws regarding free access to information held by government departments and agencies, and laws concerning the opening of all proceedings of parliament, commissions, and agencies, are essentially designed to increase the transparency of government activities. Yet, although organizations are obliged to demonstrate transparency, it is clear they are very often reluctant to spontaneously disclose information.

\section{Definition and origin}

In spite of numerous references to transparency in both official discourse and scientific literature, it is difficult to find a set definition. Literally, transparency is what allows us to see through something (Blomgren and Sahlin, 2007), or to see what is happening inside something (Naurin, 2006). In the context of public institutions, transparency means the opening up of an organization's processes and internal decisions to third parties, regardless of whether or not they are involved in the organization (Florini, 1998).

Transparency is the 'availability of information about an actor that allows other actors to monitor the workings and performances of the first actor. This definition consists of an institutional relation in which an information exchange takes place that relates to the workings or performance of an actor' (Meijer 2013). 
The origins of the concept of transparency and its application to public organizations can be found in philosophical, epistemological, economic, and political reflections (Popper, 1949; Mill, 1961; Habermas, 2003). As early as 1859, John Stuart Mill considered that putting arguments into the public sphere was an unconditional benefit. He wholeheartedly believed transparency made it possible to discriminate between good and bad arguments.

Globally, transparency is directly linked to the construction of modern democratic states (Stiglitz, 1999). It challenges traditional bureaucratic models in which the relationship between the administration and citizens was/is a one-sided dependency (Chevallier, 1988; Hood, 1991; Cottier, 2001). Table 7.2 presents the dates when access to an information regime was established in various countries.

Table 7.2 The legal bases of access-to-information rights (selection)

\begin{tabular}{|c|c|c|}
\hline Country & Year & Law \\
\hline Australia & 1982 & Freedom of Information Act \\
\hline Canada & 1983 & Access to Information Act \\
\hline China & 2008 & $\begin{array}{l}\text { Open Government Information Regulations } \\
\text { (Zhengfu xinxi gongkai tiaoli) }\end{array}$ \\
\hline European Union & 2001 & FOI Regulation \\
\hline France & 1978 & $\begin{array}{l}\text { Law on Freedom of Access to administrative } \\
\text { documents ( Loi de la liberté d'accès aux documents } \\
\text { administratifs) }\end{array}$ \\
\hline Germany & 2006 & $\begin{array}{l}\text { Federal act governing access to information } \\
\text { (Informationfreiheitsgesetz) }\end{array}$ \\
\hline India & 2005 & RTI: Right to Information Act \\
\hline Malta & 2012 & Freedom of Information Act \\
\hline Paraguay & 2014 & $\begin{array}{l}\text { The Freedom of Information and Government } \\
\text { Transparency Law }\end{array}$ \\
\hline Sweden & 1766 & Freedom of the press act (Tryckfrihetsförordningen) \\
\hline Switzerland & 2006 & $\begin{array}{l}\text { Federal law on the principle of administrative } \\
\text { transparency (Loi sur la transparencel } \\
\text { Öffentlichkeitsgesetz) }\end{array}$ \\
\hline Tunisia & 2016 & $\begin{array}{l}\text { Law on Access to Information (Loi organique sur } \\
\text { l'accès à I'information) }\end{array}$ \\
\hline United Kingdom & 2005 & Freedom of Information Act \\
\hline United States & 1966 & Freedom of Information Act \\
\hline
\end{tabular}




\section{Reasons underlying the development of transparency}

Four main reasons explain the development of the concept of transparency and related practices.

First, transparency must be understood as an exchange of information. In order to accomplish its various tasks, the State requests ever more information from citizens surveys, forms, etc. This must be understood against the background of an increasing value of information. In the context of the information society and with the revolution in means of communication, information is being transformed. From being a resource essential to the sound administration of citizens, it has become an indispensable public resource (Juillet and Paquet, 2001). This being said, a strong imbalance can be observed between information held by governments, growing in both quantity and value, and information in the hands of citizens (Sanchez, 2002).

Increasingly, legislative frameworks allow citizens to either request governmentheld information concerning themselves (information privacy laws) or information concerning the processes and decisions of public institutions (access to information laws). Such laws aim to address the balance of information between citizens and governments.

Besides information balance and possibly as a result of it, the goal of transparency is to improve relations between governing bodies and citizens. In a context marked by the thorny problem of public deficits, loss of confidence in administrations demands greater accountability on the part of elected officials. Moreover, in the fight against corruption, access to information makes it possible to reverse some of these trends and potentially re-establish a relationship of trust between government and citizens (Grimmelikhuijsen, 2012). The aim is, therefore, to improve the management of government departments and agencies through an external pressure mechanism to make internal operations public (Juillet and Paquet, 2001; Reid, 2004).

Transparency is also a tool that fosters the involvement of citizens in the development and implementation of public policies. A growing propensity of citizens to participate in decision making and the political processes of the State is being observed (Lunde, 1996; Rowe and Shepherd, 2002; Juillet and Paquet, 2001; OECD, 2005; Lahtrop and Ruma, 2010; Worthy, Meijer, and Hart, 2015). More active participation of citizens in the governance of the State requires greater quantities of information, and the information must be of higher quality. In this context, transparency of the State's activities becomes a prerequisite for good governance and active involvement of citizens in political processes.

Lastly, transparency must be understood as a method of management, which improves organizations' efficiency and effectiveness (Caron and Hunt, 2006). While bureaucratic culture is characterized by secrecy (Reid, 2004); transparency forces public organizations to provide information about their internal processes. For example, expense accounts or internal guidelines must be made public and, together with greater accountability of public actors, must explain and justify actions taken (Roberts, 2004; Sanchez, 2002). In this way, it compels organizations to more efficiently manage the resources made available. 


\section{Different forms of transparency}

When applied to public organizations, transparency can take a number of forms (Pasquier and Villeneuve, 2005; Audria, 2004). These can be referred to collectively as a 'transparency framework' (Caron and Hunt, 2006):

- Documentary transparency: this is access to information held by or collated by the administration. Active information, spontaneously made available to the public, via the internet for example, must be distinct from passive information delivered in response to a request from a citizen. Although transparency laws and access to information sometimes contain clauses on the proactive release of information, they are largely aimed at regulating passive information. This is the most widespread and most highly codified form of transparency in administration.

- Organizational transparency: this means access to knowledge of the organization and its functioning - processes, rules, and decisional criteria. The goal is to show not only what is produced but above all, how it is produced. This type of transparency also applies to electoral processes managed by the government and the opening to public observation of the proceedings of various commissions internal to the government.

In the United States, for example, the 'Sunshine Act' applies to government agencies headed by a collegial body composed of two or more appointed members. They are required, among other things to open their sessions to the public.

- Accounting and budgetary transparency: here the purpose is to link the origin of funds with their use in public action. This may be done either administratively, through the production and official reporting of financial information to the political authorities, or through external auditing mechanisms.

- Transparency of action and administrative responsibilities: here the onus is on the government to make known and explain the meaning of its decisions and actions. It must also ensure that civil servants and the civil service as a whole comply with their obligations.

These forms of transparency are applied - albeit in very diverse ways - in processes of parliamentary control and are very broadly documented. However, free access to all information held by the government including documentary transparency is more recent. It developed in response to the multiplication of access-to-information laws during the $1980 \mathrm{~s}$.

Historically, the Swedes, with the introduction of their Freedom of the Press Act in 1766, laid the foundations of the principle of access to government information. In recent history, Finland was the first country, in 1951, to build citizens' access-to-information rights into its laws. Since then, many countries have framed laws of this kind, including the United States in 1966, France in 1978, and Canada in 1983 (see Table 7.2).

More recently, similar laws came into effect in Tunisia (2016), Paraguay (2014), Malta (2012), Germany and Switzerland (2006) or the United Kingdom (2005). 
To date, over 100 countries have adopted laws facilitating citizens' access to government information (Esquivel, OGP).

Although access-to-information laws essentially concern national governments, it is worth mentioning that international institutions and organizations such as the United Nations and the European Union have made some advances in the field of access to information. For example, in 2001 the European Parliament and the Council of Europe adopted regulation 1049/2001 dealing with access to documents of the European Parliament, the Council of Europe, and the European Commission (Maiani et al., 2010).

\section{Analytical framework for transparency laws}

The principles underlying the various laws on transparency are fairly similar from one country to another, although they vary principally in their scope and application. For the purposes of comparative analysis, two levels of study are possible. First, the text of the law can be examined to identify the ways in which information can be accessed and from there the extent of the prescribed field of transparency. Second, we must look at the manner in which the law is applied in practice by the organization concerned and how it is used by citizens (e.g. see Worthy, 2013).

The first level consists of analysing the law's characteristics. These are principally based on the content of various legislative documents - laws, orders, implementing regulations, and other guidelines. In particular, the following elements require study:

- Accessible information: the basis of any access-to-information law lies in the opportunity given to the citizen to request information, or a document containing the desired information, without having to justify the request. The document in question may take very wide-range of forms: reports, notes, minutes of meetings, letters, e-mail messages, and even unwritten documents such as telephone conversations. Access-to-information laws must therefore explicitly specify what information is accessible and what is not.

- Exceptions: generally, such laws apply to all governmental and administrative entities. However, provision will be made for exceptions related to the defence of national interest (international relations, security services) or the higher interests of citizens (courts, privacy).

- Assistance provided by the State in the search for information: given the complexity of government operations, it is unreasonable to expect citizens to be aware of all documents prepared and therefore accessible to them. Depending on the country or institution, instruments or information counters are set up to inform citizens of the type of documents produced by the government.

- Time required for delivery of information: laws or regulations generally specify a period of time during which the government or entity concerned must respond to the access-to-information request. The government cannot therefore make citizens wait unduly. This is vital because information often loses its value over time; the subject is no longer topical; an important vote has been held, etc. 
- Research costs and charges: the costs of a request are set out in the law. If research costs, which are frequently quite high - photocopies, research time, etc. - exceed a certain threshold, the possibility of invoicing for such costs is provided. However, these amounts must remain reasonable; otherwise some citizens will be deprived of their rights.

- Appeals procedures: a distinction is made between procedures for appeal within the government (mediation procedures, ombudsman, legal recourse, etc.) and the possibility of asserting access-to-information rights directly in judicial courts in response to refusals (failure to respond, delays beyond the legal mandate, etc.).

These parameters may vary from one law to another, thereby affecting the scope of the transparency model. In Canada, for example, access rights are limited to Canadian citizens and permanent residents. However, in most other countries having a similar law, access is open to anybody and requests may remain anonymous.

Practically all transparency laws provide exemption for certain organizations, and in some countries the list of exempt organizations is extensive. In the US, many federal government entities are not subject to the FOIA because they do not fit the law's definition of an agency. Equally, not all entities that receive federal funds are covered by the FOIA; for instance, the Corporation for Public Broadcasting and the American Red Cross. However, such entities might voluntarily adopt disclosure policies very similar to FOIA (RCFP, 2009).

The type of information accessible may also take various forms: reports, notes, minutes of meetings, mail (Sweden), e-mail (United States, Canada, Great Britain) and even unread documents such as telephone conversations (Denmark). Exceptions provided for in the law and the margin of interpretation allowed to government bodies in applying the law also vary from one law to another.

Finally, the time allowed for an organization to respond to a request, rules for the charging of fees, and possibilities for redress provided for in the law must also be taken into account when determining the degree of openness of a law.

The second level of analysis concerns the concrete application of the law and its effects. These depend on the infrastructure and resources made available, but may also vary considerably depending on the administration's behaviour regarding making information available and the use citizens make of the law.

\section{Resistance to transparency}

While documentary transparency is firmly established in the legal framework, resistance to this transparency and the development of avoidance strategies by organizations can be seen, obstructing the right of inspection legally granted to civil society (Pasquier and Villeneuve, 2007):

- Non-transparency is characterized by the fact that an organization or part of its activities are legally exempt from the obligation to disclose information. 


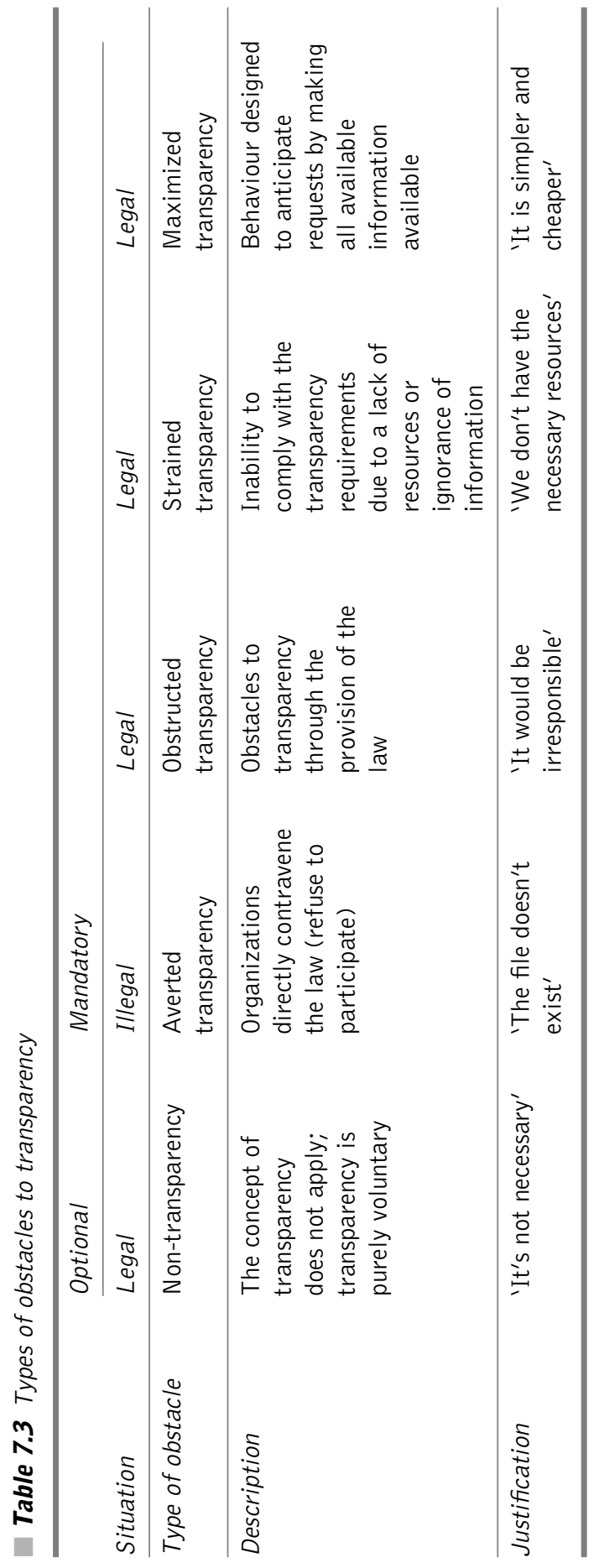


- Averted transparency refers to the behaviour of an organization that is subject to the law but actively and illegally prevents access to information.

- Obstructed transparency means the use of all legal processes to limit access to information. This could include redaction, misclassification of documents, restrictions in the transparency of the request handling process, and so on.

- Strained transparency designates behaviours of the administration which, consciously or unconsciously, limit access to information, either through the absence of resources to deal with requests, ignorance about documents, and more.

- Maximized transparency might appear to be a panacea, because it refers to the behaviour of an organization that makes available all the information it holds. Citizens then no longer need to make requests.

However, it can also provide a hindrance if people do not have indexes or familiarity with record filing systems, etc. Therefore, they may not be able to access information of interest to them or at best, they may have great difficulty locating it. In other words, too much transparency may kill transparency. These various dynamics are classified according to their optional or mandatory nature and their legal natures in Table 7.3.

Communication, whether active or passive, is now a mandatory activity for public organizations. The following chapters detail the specifics of communicating in a publicsector environment.

\section{DISCUSSION QUESTIONS}

1. In times of economic crisis, are public communications an unaffordable luxury for the State?

2. Can/should governments be transparent? Is access to information a force for good or simply an administrative fad?

\section{NOTES}

1. In Switzerland, voter participation in votation (elections and referendums) in the past decade has stood at between 40 per cent and 50 per cent. In France, voter turnout at the 2014 European elections was 58.6 per cent and in the second round of the 2014 municipal elections, 38.9 per cent (http://www.france-politique.fr/participationabstention.htm). In the US presidential election of 2012, turnout was at 54.87 per cent (http://www.statista.com/statistics/262915/voter-turnout-in-the-us-presidentialelections/, or http://www.presidency.ucsb.edu/data/turnout.php). In India, in the 2014 election the turnout voter was at 66.40 per cent (http://www.idea.int/db/field view.cfm?field=221\&region=34). 


\section{REFERENCES}

Audria, R. (2004) New Public Management et Transparence: Essai de Déconstruction d'un Mythe Actuel, Geneva, doctoral thesis, University of Geneva.

Australian Government (n.d.) Central Advertising System. Online at http://www.finance. gov.au/advertising/cas.html (accessed 11 June 2016).

Australian Government (2004) The freedominfo.org Global Survey: Freedom of Information and Access to Government Record Laws around the World, Privacy International.

Blomgren, M. and Sahlin, K. (2007) Quests for Transparency: Signs of a New Institutional Era in the Health Care Field, Transcending New Public Management: The Transformation of Public Sector Reform, Aldershot, Ashgate.

Caron, D. J. and Hunt, T. D. (2006) Accountability and Disclosure: The Proper Use of Transparency Instruments and their Implications for Canadian Public Administration, in I. I. 0. A. Sciences (ed.) Third Regional International Conference: Transparency for Better Governance, Monterrey.

Chevallier, J. (1988) Le Mythe de la Transparence Administrative, in Curapp (ed.) Information et Transparence Administrative, Paris, Presses Universitaire de France.

Cottier, B. (2001) De l'administration Secrète à I'administration Transparente ou les Enjeux d'un Prochain Renversement de Paradigme, Lugano, Commissione ticinese per la formazione permanente dei giuristi.

Esquivel, Luis (2014) 'One Hundred ATI Laws, Now What?', Open Government Partnership, http://www.opengovpartnership.org/blog/luis-esquivel/2014/09/10/onehundred-ati-laws-world-now-what (visited 11 June 2016).

Florini, A. (1998) The End of Secrecy, Foreign Policy, 111, 50-63.

Grimmelikhuijsen, S. G. (2012) Linking Transparency, Knowledge and Citizen Trust in Government: An Experiment. International Review of Administrative Sciences, 78 (1), 50-73.

Habermas, J. (2003) The Structural Transformation of the Public Sphere, Cambridge, Polity Press.

Hood, C. (1991) A Public Management for All Seasons, Public Administration, 69, 3-19.

Hood, C. (2001) Transparency, in Clarke, P. B. and Foweraker, J. (eds), Encyclopaedia of Democratic Thought, London, Routledge.

Juillet, L. and Paquet, G. (2001) Politique D'information et Gouvernance, Ottawa, Gouvernement du Canada.

Kosack, S. and Fung, A. (2014) Does Transparency Improve Governance?, Annual Review of Political Science, 17, 65-87.

Lahtrop, D. and Ruma, L (2010) Open Government: Collaboration, Transparency and Participation in Practice, California: O'Reilly Media.

Lunde, T. (1996) Client Consultation and Participation: Consumers and Public Services, in OECD (ed.), Responsive Government: Service Quality Initiatives, Paris, OECD.

Maiani, F., Villeneuve, J. P., and Pasquier, M. (2010) Less is More? The Commission Proposal on Access to EU Documents and the Proper Limits of Transparency, Lausanne, Institut de hautes études en administration publique.

Meijer, A. (2013) Understanding the Complex Dynamics of Transparency, Public Administration Review, 73 (3), 429-39.

\section{4}


Mill, J. S. (1961) On Liberty, in Cohen, M. (ed.) The Philosophy of John Stuart Mill, New York, Modern Library.

Naurin, D. (2006) Transparency, Publicity, Accountability - The Missing Links, Schweizerische Zeitschrift für Politkwissenschaften, 12, 90-8.

Organisation for Economic Co-operation and Development (OECD) (2005) Engaging Citizens in Policymaking, Paris, OECD.

Organisation for Economic Co-operation and Development (2013) Governance at a Glance 2013, Paris, OECD.

Pasquier, M. and Fivat, E. (2009) Crise à I'Université de Genève: Une Étude de Cas, Cahier de I'IDHEAP, 2009.

Pasquier, M. and Villeneuve, J.-P. (2005) Typologie des Comportements Organisationnels des Administrations Publiques Visant à Limiter I'accès à l'information, Working Paper, IDHEAP.

Pasquier, M. and Villeneuve, J.-P. (2007) Organizational Barriers to Transparency: A Typology and Analysis of Organizational Behaviour Tending to Prevent or Restrict Access to Information, International Review of Administrative Sciences, 73, 147-62.

Popper, K. (1949) The Open Society and Its Enemies, London, Routledge \& Sons.

Reid, J. M. (2004) Discours Sur l'Accès à l'information, Toronto, Groupe Ginger.

The Reporters Committee for Freedom of the Press (RCFP) (2009) Federal Open Government Guide, online at http://www.rcfp.org/rcfp/orders/docs/FOGG.pdf (accessed 15 August 2016).

Roberts, A. (2004) Orcon Creep: Information Sharing and the Threat to Government Accountability, Government Information Quarterly, 21, 249-67.

Rowe, R. and Shepherd, M. (2002) Public Participation in the New NHS: No Closer to Citizen Control? Social Policy \& Administration, 36, 275-90.

Sanchez, A. C. (2002) The Right of Access to Information and Public Scrutiny: Transparency as a Democratic Control Instrument, in OECD (ed.), Public Sector Transparency and Accountability: Making It Happen, Paris, OECD.

Stiglitz, J. E. (1999) On Liberty, the Right to Know, and Public Discourse: The Role of Transparency in Public Life, Oxford Amnesty Lecture, Oxford.

Sulzberger, A. G. and Matthew, L. (2009) White House Apologizes for Air Force Flyover, New York Times, 27 April, New York.

Worthy, B. (2013) Some Are More Open than Others. Comparing the Impact of the Freedom of Information Act 2000 on Local and Central Government in the UK, Journal of Comparative Policy Analysis : Research and Practice, 15 (5), 395-414.

Worthy, B., Meijer, A., and Hart, P (2015) Assessing Government Transparency. An Interpretive Framework, Administration \& Society, 0095399715598341.

Zémor, P. (1999) La communication publique, Paris, Presses Universitaires de France. 


\section{Communications models and strategies}

\section{LEARNING OBJECTIVES}

By the end of this chapter you should be able to:

- Clearly identify the various elements making up a communications model.

- Construct and analyse a communications campaign.

- Define a coherent, integrated communications strategy.

- Identify the objectives of a communications initiative.

\section{KEY POINTS OF THIS CHAPTER}

- Communication is a process that can be intentional or unintentional, simple or complex.

- A communications model includes a sender, a message, and a receiver, all linked together in a relationship framed by a common code and occurring in a given context.

- A communications strategy has four main steps: (1) defining the general framework, (2) identifying the target audience, (3) designing the message and identifying the medium to be used, and (4) finally launching the communications campaign.

- A modern communications strategy must, as far as possible, be integrated, achieving consistency of form, content, and timing.

\section{KEY TERMS}

Communications model - schematic construct of the various elements allowing the establishment of communication. 


\section{KEY TERMS continued...}

Communications strategy - an iterative process involving a series of key decisions regarding the consistency between objectives and the concrete measures to be developed.

Integrated communications - logical, self-reinforcing coordination of the various elements of a communications campaign.

\section{INTRODUCTION}

Constructing a communication process is a complex task requiring an understanding of how communication is established and following the steps involved in conceiving a message and then conveying it. The first part of this chapter presents the main components of the communications model. The second part describes the steps involved in developing a communications strategy. The third, shorter, presents the concept of integrated communications, which stresses the need to ensure communication activities are consistent in form, content and timing.

\section{COMMUNICATIONS MODEL}

Communication is a process of transmitting elements of information to someone. While this extremely simple definition does not convey all conceptions of communication, it at least highlights the main characteristics.

The process of communication can be intentional or unintentional, simple or complex. A newspaper advertisement is of course an intentional form of communication. However, style of dress, body language, remarks made in a corridor or in the cafeteria may all be elements of unintentional, or at least unplanned, communication.

Communication can be relatively simple such as asking for information about a museum's opening hours. Or it can be highly complex such as a study of the entire set of interpersonal relationships in a group of individuals will develop.

Communication establishes a relationship with another person in order to transmit information, generally with the intention of producing an effect upon the intended recipient(s). The result could be an increase in their knowledge, a change in their attitude, their behaviour, etc. Many methods and techniques - from very simple to very sophisticated - can be used for this purpose and may include work sessions, newsletters, websites, systematic blogging, and so on.

The communication process has been modelled in various ways depending on the reference discipline: Weaver and Shannon (1963) took a technical, mathematical approach, Lasswell $(1927,1948)$ formulated a persuasive political conception, Jakobson 


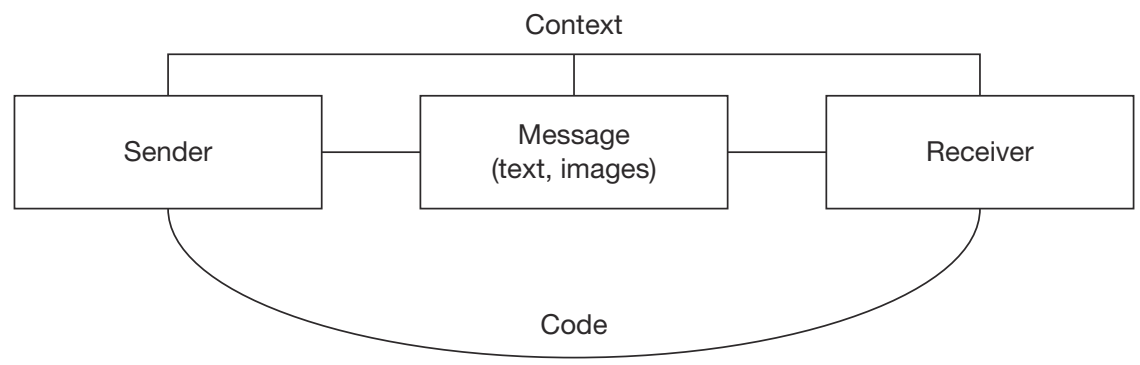

Figure 8.1 Schematic model of communication

(1963) used linguistics as a reference, while Gerbner (1955) adopted a sociological approach.

The basic elements of a communications model are shown in Figure 8.1.

Communication requires a sender who emits the communication and one or more recipients of the communication. The message is a set of information such as text, images, sounds, etc. and conveyed by a medium - the spoken word, newspapers, documents, advertising spots, and the like.

Communication occurs in a defined context, at a given moment, in a given place and in relation to a given situation. This context is not part of the communication but accompanies it and can be the source of interference or, to use a specialized term, 'noise'. All may influence the desired effect in one direction or another. For example, if police announce that members of an organized gang have been arrested, the news may not produce the same effect in a region where crime rates are low as in a locality recently experiencing a series of violent attacks.

Lastly, communication requires a code allowing the sender and receiver to understand one another. This requires a common perception of signs and their usage. Numerous classic examples of the absence of a common code can be observed in intercultural relations.

For example, a Japanese person is invited to a friend's home in New Orleans. He offers a chrysanthemum as a gift since it is considered to be one of the most beautiful
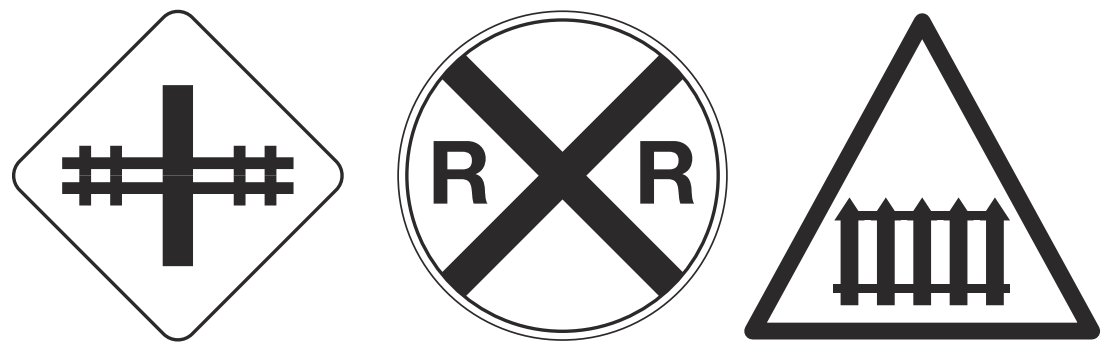

Figure 8.2 Road sign indicating a level crossing

\section{8}




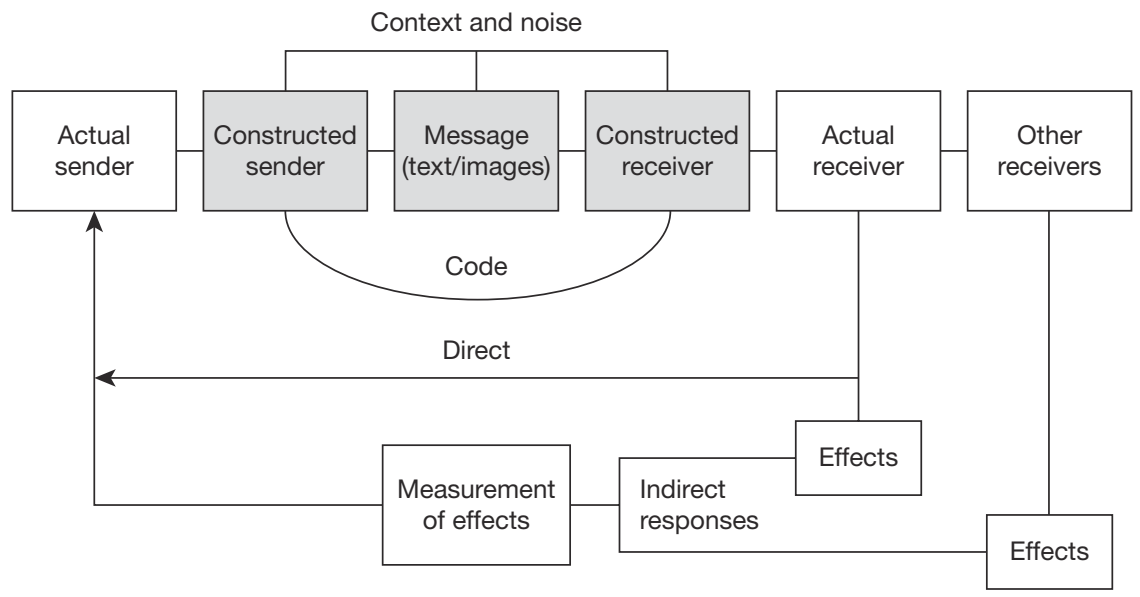

Figure 8.3 Integrated communications model

flowers in Japan. But for people of New Orleans (as well as France and other countries) this flower symbolizes bereavement; therefore the offering may not have the desired effect. Another example of differentiated code can be found in road signs (see Figure 8.2).

Although the simplified schematic diagram in Figure 8.1 shows the main elements in a communications process, it is inadequate to describe the increasing complexity of communication. Figure 8.3 shows an integrated communications model which is more complete and better reflects the effective dynamics of a communication process.

The first distinction to be made is in the nature of the sender and receiver; meaning actual versus constructed sender/receiver. It is not so much an organization that issues a communication as it is the organization's representation of itself and the perception that receivers have of it.

Depending on the message the organization wants to convey, as well as the image it has of itself or produces in others; it will make choices regarding the coding of the message. This would include choice of text, image, sounds, and so on. The message will be conveyed through a medium whose neutrality can vary considerably. A message in a serious newspaper regarded as reliable would most certainly not be perceived in the same manner as if it was placed in a popular tabloid.

With regard to reception, we must also distinguish receivers' ability to decode the message. This involves reconstruction of the message on the basis of what they see and hear. Additionally, the potential effects upon these same persons given their knowledge, experience and environment must be taken into consideration.

As well, we must also take into account other receivers who were not originally targeted but who may be reached by the communication relayed by a receiver. This could include discussions in the family or among friends, word of mouth, etc. 
The last major element to bear in mind is feedback, which is the message sent back to the sender by the receiver. Direct feedback can be confirmation the message has been received, a request for additional information, etc. Indirect feedback occurs when response to the communication is measured - someone stops smoking in reaction to prevention messages. After taking these responses into consideration, the sender will develop, refine, or suspend the communication. This is known as a feedback loop.

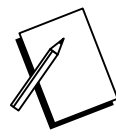

\section{BOX 8.1 THE EUROPEAN UNION 5OTH ANNIVERSARY LOGO}

To mark its 50th anniversary in 2007, the European Union launched a contest for the design of an anniversary logo. Out of more than 1,700 entries the competition was won by a Polish graphic designer named Szymon Skrzypczak see Figure 8.4. At the ceremony, the EU vice president, Margot Wallström, stated: 'The winning logo represents the diversity and vigour of Europe and at the same time it underlines the desired unity and solidarity of our continent' (European Union, 2006).

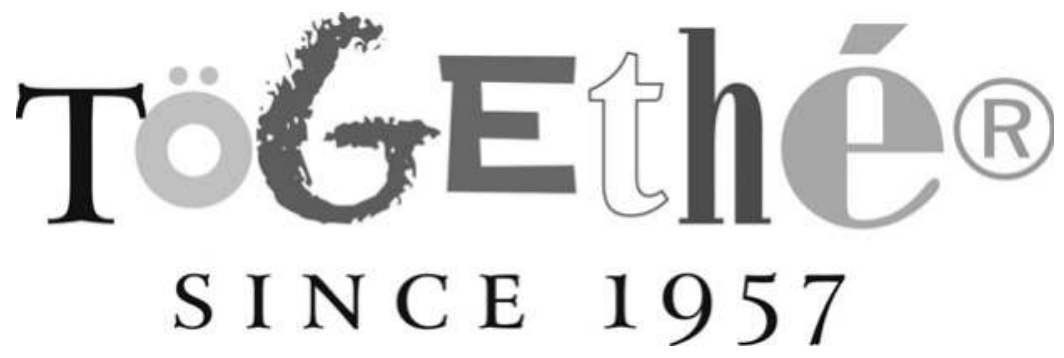

Figure 8.4 The European Union 50th anniversary logo

Source: European Union.

A brief study of this logo reveals that identifying the sender is difficult since it does not carry the European Union's 'signature'. The coding of the message unity in diversity - is made relatively clear through the use of characters from several different typefaces for the word 'together'. However, it is reasonable to wonder whether those who see the logo are able to decode it and successfully identify the original message.

Use of the $\AA$ symbol for the letter $R$ came in for criticism, since in American law this would indicate that a trademark has been registered. 


\section{BOX 8.2 CAMPAIGN TO PROMOTE BORROWING BY THE FRENCH GOVERNMENT}

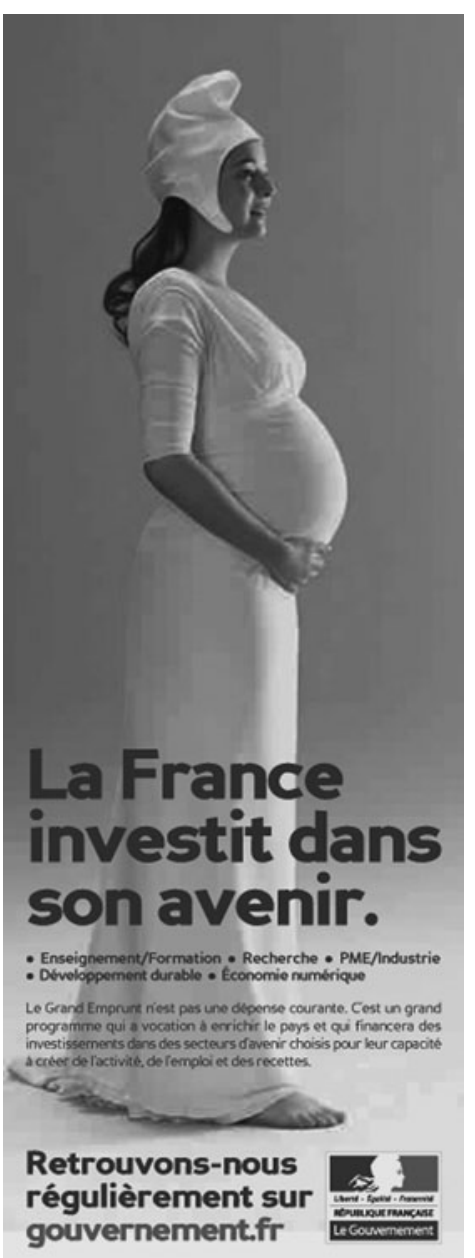

\section{Figure 8.5}

Campaign to promote borrowing

Source: Government of France.
The advertising campaign shown in Figure 8.5 cost approximately $€ 1$ million. This money was spent on advertising space in the press and on the web. It was developed by the French government to promote $a € 35$ billion governmental loan for investment aimed at increasing France's competitiveness.

The sender, the French government, is easily identifiable thanks to the logo and the information it contains. The message is very clear, despite its coding being somewhat unusual for communication with the public. Allegory, a rhetorical device, is used to reinforce the message contained in the text. The figure of Marianne represents France and the symbol of maternity represents the future.

It is highly probable those at whom the message was aimed - the French public - were easily able to decode the message. But because private individuals could not benefit from the loan, we can assume the campaign's main aim was to inform citizens about the decision to borrow and foster their support for this decision and the policy behind it. 
The communications model highlights all major elements making up a communication and allows us to analyse it:

- Who is the sender?

- What is the message?

- What instrument or medium will be used?

- To whom is the message addressed?

- What are the planned and actual effects?

Boxes 8.1 and 8.2 illustrate the analyses that can be performed on the elements of communication.

\section{COMMUNICATIONS STRATEGY}

Communications strategy is an iterative process that involves making a series of decisions aimed at achieving consistency between objectives and concrete measures. Very often measures taken are not in line with objectives. This is either because the latter are too ambitious in relation to available resources or because the means of communication chosen are not suited to the messages intended to be conveyed. This is why it is necessary to take a series of steps, systematically checking each is consistent with the others.

Figure 8.6 provides a schematic presentation of the main steps in a communications strategy.

The eight steps of this process can be grouped into four major parts or decision groups. The first step consists of drawing up a list of framework conditions to restrict the decision-making margin when formulating the strategy.

The second group of decisions concerns target groups and the objectives to attain with these groups (steps 2 and 3). This is the heart of the process because decisions taken here will have an impact on all subsequent steps.

The third part includes the conception of the message and the choice of means, or instruments, of communication (steps 4 and 5). These two elements must be considered at the same time because they are closely linked. The choice of instrument used will depend upon the message to be conveyed and vice versa.

The fourth and last group of steps is more operational in nature. They include checking the communications plan and its concrete execution as well as gauging its effectiveness - steps 6, 7, and 8 .

The following paragraphs describe in detail the various stages of this process.

\section{The general framework}

Before developing a new communications campaign or any new measures, key information must be gathered. This is necessary so the framework within the communications activities to be carried out can be established. Three types of items need to be taken into account. 


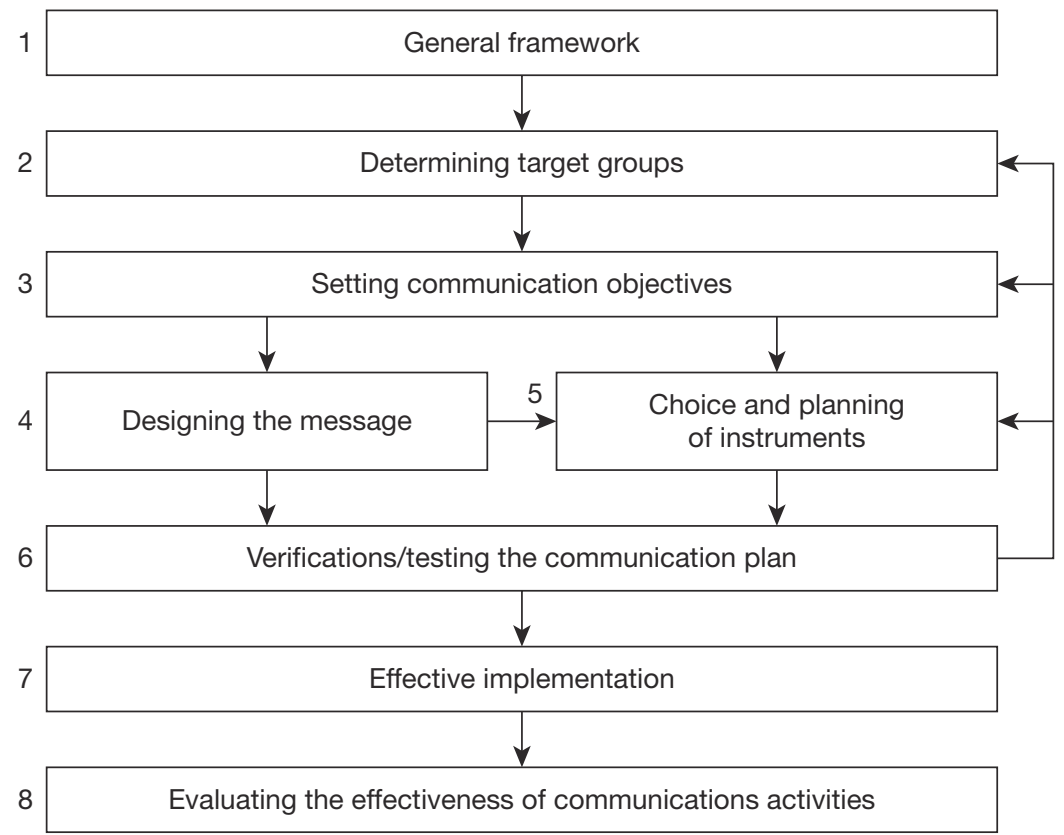

Figure 8.6 Steps in a communications strategy

The first concerns the environment and the general context of the communication - including the political and social environment. Consideration must also be given to other organizations currently communicating on the same subject or may do so later, together with their objectives and their concrete measures.

Although in principle public organizations have no direct competitors to interfere in their communications, they must still check whether similar communications activities are being planned by other organizations or at a different level of government; for example regional as opposed to national government. Or the situation may be organizations at the same level, such as another government department or nongovernmental organizations (NGOs) are working on closely related subjects, whether mandated by the government or not.

Different messages from several organizations risk creating confusion in the minds of recipients rather than mutual reinforcement and synergy. The State, and frequently the public sector in its entirety, is seen by some as a single interlocutor. No distinction is made between the various organizations and missions.

The second element to influence development of communications activities are items of information specific to the organization. First among these are the organization's policy and its past and present communications activities. These must be taken into account in order to avoid contradictions in the message and to ensure a degree of continuity. The organization's public profile and its credibility in the minds of the main recipients must be analysed. 
Many organizations tend to overestimate their own profile and hence their ability to persuade the public with communications messages. Lastly, formal elements of the communication must be identified and respected. This includes visual elements such as logos and other elements of the graphic charter, organizational elements such as coordination rules, and predefined or contractual elements such as the choice of certain media or certain instruments, etc.

The final element framing the development of communications activities is budget. In principle, the budget should result from decisions taken at the various stages. However, because the costs of communications are high and greatly dependent on the instruments chosen, it is recommended that a budget framework be set to serve as a reference for decisions made during the process.

Obviously, this budget framework should not be so restrictive as to hobble creativity during development of the message and the choice of instruments. Although optimization models for defining the budget framework exist, very often it is based on set objectives. More often still, it depends on the experience of previous years or on the means available in a budget determined by political authorities.

\section{Determining target groups}

In the public sector, determining specific target groups can be difficult where the communication concerns all citizens and residents of the territory in question. Therefore, the message could comprise of general information for the public in a municipality, information on a vaccination campaign, etc. However, in many situations, aiming at a very large population group is the best way to reach no one. Moreover, communications activities are increasingly aimed at defined target groups. Such demographic units could include professionals such as doctors or teachers, as well as regular citizens - parents of schoolchildren, residents of a district, the elderly, and so on.

In many cases, describing the people to whom the organization wishes to send a message presents no great obstacle. The real difficulty lies in the choice of media instruments to reach them. Since all these people will not necessarily have homogeneous behaviour regarding the media they consult, target groups need to be defined. This may be delineated on the foundation of their characteristics but also on the basis of their attitudes and behaviour regarding all communications instruments and media.

Let us take as an example a municipality wishing to regularly provide information on the city's services and activities. Describing the target audience is easy enough all residents. However, what they read, where they go and so on need to be taken into account. The municipality could use public notice-boards or electronic panels in various places. But there is no guarantee the movements of parts of the population will take them past these displays or that they will be disposed to stop and look at them (see Box 8.3). On the other hand, people outside the municipality may regularly see this information and it will have no relevance to them at all. 


\section{BOX 8.3 GENERAL INFORMATION FOR THE PUBLIC}

During the summer of 2004, in response to high summer temperatures and ozone air pollution, a prefectural decision was taken to reduce the speed limits on roads and highways in the Côte $d^{\prime}$ Azur Provence in the south of France. A number of municipalities in the region chose to inform the public of this decision by posting a copy of the administrative decree on the door of the town hall.

While the municipality cannot be accused of having failed to communicate the decision, it is a safe bet that almost nobody took the time to stop in front of the town hall and read the entire text. Luckily, the media relayed the decision to some extent and people passing through the region were informed by electronic signs on the highways.

For all subsequent heat waves, notably that of 2015, numerous other communication channels and stronger coordinated communication strategies were put in place by the local, regional, and national authorities. These measures were all based on the problems identified in 2004.

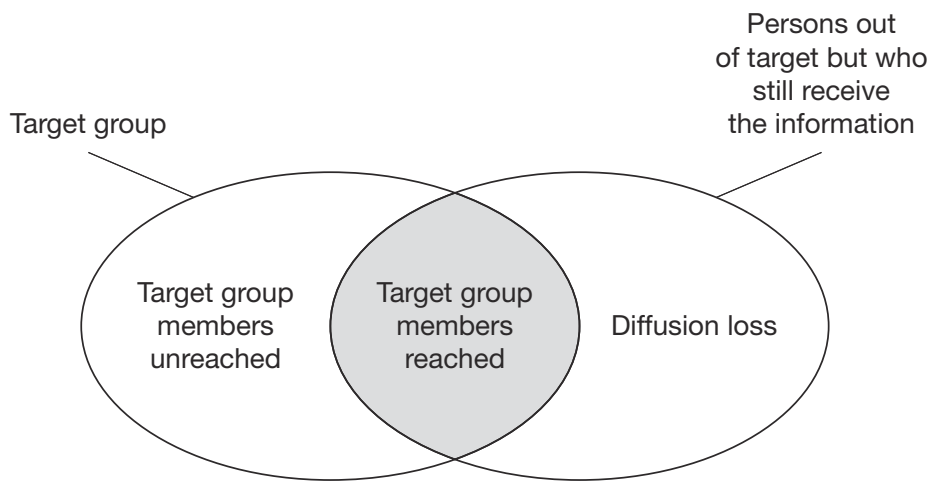

Figure 8.7 Target group reached and dispersion loss

This means it is important to define target groups in such a way that they can be reached by communication activities while minimizing diffusion loss. That is, the number of people reached who do not belong to the target group. Figure 8.7 illustrates the problem. 


\section{Setting communications objectives}

Once communications targets have been defined, the next step is to set communications objectives. These are derived from the model developed by Elias St-Elmo Lewis in 1898 (Barry, 1987) and summed up by the formula AIDA (Attention - Interest - Desire - Action). In other words, a communication must first attract attention or be visible, then elicit interest in its content before provoking desire.

Finally, action, or the behavioural aspect, is the ultimate objective. Many models for achieving communications effectiveness have been developed, including the DAGMAR model (Colley, 1961) and the AIDA model (Strong 1925).

Although the basis of these models is valid for the public sector, it needs to be adapted for two main reasons. First, the ultimate objective is not to induce a person to make a purchase, which is the main goal of business communications.

Second, these models have been designed as a series of steps to be taken, whereas public communications may be perfectly content with 'only' attaining the first level simply transmitting information without any further objective. Table 8.1 sets out the various types of objectives of public communications together with the main levels to be considered.

Knowledge, or basic information, is the first type of objective to consider. Organizations need to provide basic information on activities, events or actions such as the appointment of a new manager, report on activities, etc. With regard to services, the same type of objective will be aimed at providing information on the content of the service, its accessibility and so on.

Very often, public organizations can restrict themselves to conveying very basic information so that recipients have the required information when needed. But it is vitally important for an organization to provide at least this minimum amount of information. This will provide it and its services a degree of visibility and simplify matters for beneficiaries.

The second type of objective goes further than simple dissemination of information and is aimed at legitimizing public action. This might involve explaining and justifying the reasons for a decision, setting out the pros and cons of a project as well as justifying the temporary inconvenience for nearby residents. Or, it may present the main characteristics of a new service, such as explaining to foreign investors the fiscal benefits of setting up in business in the region.

In many countries, the introduction of biometric passports has stirred up a lively civil-society debate. Political and administrative authorities have been obliged to explain in the media and in a variety of documents exactly what data are gathered. They must also explain why it is no longer possible in many cases to supply one's own photographs or what the State intends to do with the information gathered, who is entitled to consult this information and so on. It is clear in cases like this that the organization must go beyond simply making information available. Instead, the public must be educated with frequent repetition of easily understood messages. Finally, the organization must be responsive to inquiries. 
The third type of communications objective is more complex because it is aimed at helping to create or modify attitudes towards an organization or a project, or at creating a climate of trust. Suppose asbestos is discovered in a school building. Even though the risks to children may be nil, the public organization cannot limit itself to providing information and explaining the situation. It must in addition ensure that a climate of trust is created in order to ensure the attitude of students, parents, and organizations concerned remains constructive.

For example, every week it could inform the public of readings taken by a recognized company even if specialists consider this measure to be completely unnecessary. In the same way, it could provide regular updates on progress in the renovation project via public information sessions, press briefings, newsletter sent to parents, etc. Again, this should be standard procedure, even if very little new information is available.

All these communications measures will be mainly designed to reassure people and to prevent them from developing an overly critical attitude towards the organization. As far as collaborators are concerned, these communications objectives will consist of creating a sense of belonging, developing their pride in working for the organization and thus adopting values specific to the culture of the organization.

The case of the 2006 soccer World Cup in Germany provides an interesting example. The country seized the opportunity of hosting a large-scale sporting event to act on its brand image through the vision the Germans have of themselves. An internal campaign involving numerous government economic and social institutions succeeded in substantially revamping the serious straight-laced image that much of the world still had of Germany. In many ways, both the Beijing summer Olympics of 2008 and the Sochi Winter Olympics of 2014, also had clear communication aims.

The final type of objective to be aimed at in communications terms is a change in behaviour or, at least, the establishment of stated preferences. This is, obviously, the main goal of marketing businesses. For public organizations, this objective comes into play particularly in social marketing type prevention campaigns aimed at changing people's behaviour. Such public service campaigns may promote wearing seat belts, stopping smoking, using condoms to prevent transmission of the AIDS virus, urging people to get out and vote, and so on.

In addition, a campaign could aim at provoking an active behavioural changes: urging parents to provide better support for their children's schooling. Another campaign aimed at all residents could be to 'keep an eye on' elderly neighbours or friends during heatwaves.

Because of the large number of active collaborators in the public sector - teachers, police officers, and other civil servants - it is important they should contribute freely to explaining any activities and changes in the organization. Thus they become, in a sense, promoters of the organization. Of course, they must be correctly informed in advance and convinced of the worth of the organization's activities and values.

Although each communications objective can be considered on its own, they very often overlap. That is, in order to attain emotional and behavioural objectives, a good basic knowledge of the organization or its services is vital. 


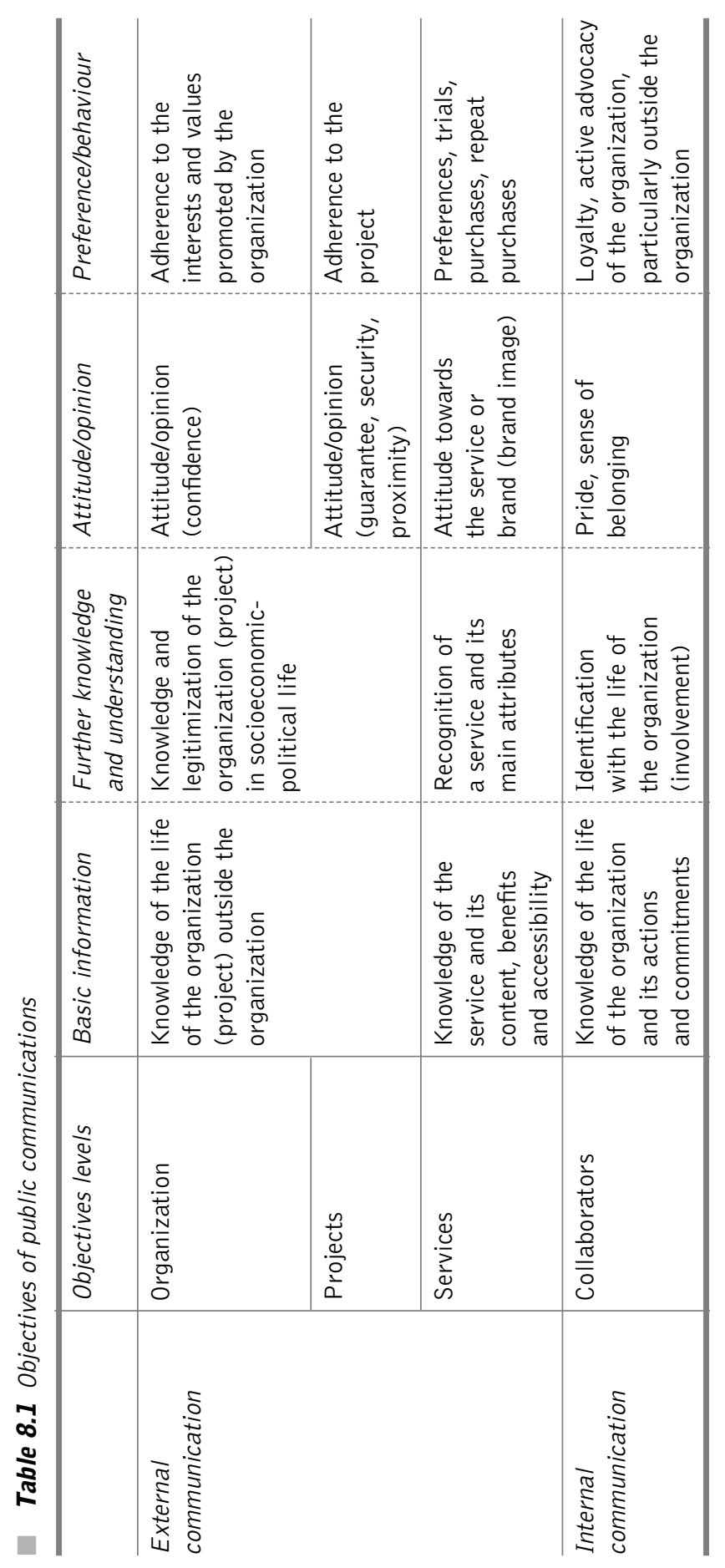




\section{Designing the message}

Designing a communications message often demands both creativity and precision. This is particularly so if the message is complex and must be conveyed through advertising media - newspaper advertisements, posters in the street, etc. Without downplaying their importance, the creative aspects can be accompanied and guided by considering the objectives of the message and its content in relation to the motivation of the target groups.

Three main questions must be asked about the message:

- What will receivers get from the communication? In other words, what benefits will be derived from understanding the message?

- What will make recipients change their perception, opinion or behaviour?

- What is the tone or general impression conveyed by the communication? Is it highly official, austere in its choice of words and visuals? Or, is it more playful, with drawings, pictograms, and a message that is easy and enjoyable to read?

Let us take as an example a municipality adopting a new policy for waste collection and management. Under the new policy, household waste must be sorted into categories, each having a specific collection system. Moreover, residents are to be charged by weight for waste that cannot be recycled and must be incinerated, etc.

The municipality will certainly have to develop a communications campaign to inform the public of its new policy and, above all, the consequences for residents.

\section{BOX 8.4 SMOKING BAN IN CALIFORNIA}

The negative consequences of smoking for individual and public health have been known for a considerable time. Addressing the problem, the state of California launched a large-scale campaign running from 1990 to 2009 seeking to reduce the rate of smokers. Besides regulatory measures, such as introducing a smoking ban in bars, restaurants, and airplanes, the campaign relied on awareness raising through a number of communication channels. The efforts turned out to be a major success: the smoking rate among California adults declined by 42 per cent, from 22.7 to 13.1. per cent.

In 2009, the state provided for another three-year campaigning, this time addressing specific target groups that were more resistant in giving up smoking. Also, they adapted the campaign message to more recent issues that evolved around smoking, such as second-hand smoking, which was identified as one of the key problems by citizens. Finally, the new campaign also reminded citizens that while major successes were achieved, people still died from smoking - thus reiterating the core policy message. 
Such information could be circulated in the media, in public information sessions, in a detailed brochure for residents, in flyers giving an overview of the most important information, plus posters at collection sites, etc.

Depending on the region, some of these communications measures may have to be translated into other languages to make sure that all those concerned are correctly informed. In certain American states communication in Spanish is essential just as English is in some districts of highly cosmopolitan cities (London, Toronto, etc.).

Recipients of these messages should understand the municipality's main reasons for adopting this policy such as benefits to all residents. And, these communications should especially have all the information needed to minimize any inconvenience that sorting of refuse will bring.

Those who take in the various messages must then take on board the elements encouraging them or obliging them to change their behaviour (Box 8.4). At the outset, the organization will have to make a decision as to the form the message will take. Will they opt for a mainly technical presentation of information with all the necessary details, or use a more playful form, possibly with pictograms allowing everybody to understand the new principles for sorting and collection of waste. Various local and national public organizations include cartoons in their documentation explaining to individuals how to fill in their tax returns, obtain a construction permit, or get access to different subsidies. Such strategies are frequent in areas where citizens have low literacy skills.

Other elements will also help in the design of the message and shape the attitude of its recipients. Two criteria should be taken into consideration (Rossiter and Percy, 1987): people's interest in the subject - involvement - and their motivation with regard to the organization or its services.

If the degree of involvement or interest is low, communication must be very simple, straight to the point and avoid any kind of rhetorical language removed from the needs of people. Conversely, if the degree of involvement is high and people are ready for and interested in the information, the organization can develop it further, providing all the necessary information even when this is quite technical.

The second criterion is motivation which, simply put, can be either negative or positive. Negative motivation involves a situation in which a person is interested in information or a service in order to resolve a problem. Perhaps it is because they have no choice such as buying pest-control products, or being required to purchase vehicle insurance. Conversely, positive motivation arises in situations where people freely buy a service to satisfy a pleasurable desire - like going on vacation.

In the public sector, situations are most frequently linked with negative motivation - requesting authorization, paying taxes, calling an emergency service, etc. However, situations involving more positive motivations do arise such as children's education, developing the tourism sector, setting up businesses, etc.

In negative situations, the recommended approach is to communicate in a rational manner while also highlighting the benefits - for example, explaining the purpose of 
taxation. Where the motivation is positive, a more emotive style of communication making use of figures of speech can be envisaged (see the example in Box 8.2).

\section{Choice and planning of instruments}

The choice of instruments is closely bound with the message. A highly complex message will normally require the use of instruments involving prolonged contact with the recipient such as information sessions, or a brochure that can be read several times, etc. More basic messages can be conveyed on media where the contact time is shorter - posters, flyers, letters to the household, etc.

Whether one or several communications instruments and media are chosen depends on a number of criteria, the most important of which are set out here:

- Audience, or capacity to reach target groups: this is the percentage of people in the target group having at least one chance of contact with the medium in a defined period. For example, if an organization has the names and addresses of all those it wishes to reach, it is relatively simple to send a brochure to those people and secure an audience of close to 100 per cent. On the other hand, obtaining the addresses of all young people to whom an organization might wish to send an AIDS prevention message is impossible. This means other instruments and media must be chosen and attempts must be made to minimize the risk of dispersion loss.

- Frequency: this means the average number of contacts a person will have with a medium during a defined period. Some messages are very easy to understand and a single reading or viewing will suffice. A message that is - like most - more complex needs to be repeated frequently in order to be understood and assimilated.

- Period and duration: the timing of the message and continuity in its dissemination are also important. During the weeks that followed the attacks of 11 September 2001, many messages from public organizations went unnoticed because people were mainly focused on discussions about security policies and the human and geopolitical consequences of these attacks. In order to gain more notice of lighter subjects such as maintenance of forests and natural spaces as well as special initiatives, these communications benefit from 'quiet' periods of the year such as summer holidays and school holidays, when current affairs take up less space in the media.

- Credibility of the medium: in communications, the medium or channel of transmission is often as important as the meaning or content of the message itself (see McLuhan, 1964's assertion that 'the medium is the message'). The importance of the medium and its credibility in the eyes of target groups can therefore determine whether the message is received. For example, a report on environmental protection broadcast on a television channel recognized as being serious may have greater effect than flyers deposited in residents' letterboxes.

- Control over content: organizations can choose between developing and hence paying for their own medium or purchasing advertising space in a medium. Otherwise, 
they can organize communications in such a way that the medium itself relays the information in its editorial sections. In the latter scenario, the organization can control the information made available to the media, but not the media's treatment of it. In the other two situations mentioned (own medium, advertising), the organization retains complete control over form and content.

The main instruments are presented in Chapter 11.

\section{Testing the communications plan and evaluating the effectiveness of communications activities}

A clear distinction must be drawn between two steps: testing the communications plan, and gauging the effectiveness of the communication.

When any communications plan is developed - even when it is limited to presenting a public policy measure in a press conference or a press release - a check of the concept and a test of this communication with recipients are recommended. Testing the concept consists mainly of ensuring consistency in all the decisions taken in the previous steps.

Is the message well-suited to the communications objective? Does the choice of instruments comply with internal rules regarding communications? Will the available budget and the choice of instruments allow the desired continuity in the dissemination of the message? These and other questions are designed to prevent gross errors being made and effectiveness compromised by lack of consistency.

It is also essential to test the message on target groups before going into production with the campaign's documents and materials. Certainly, for budgetary and/or time constraints, it is often impossible to arrange a pre-test involving a representative sample of the target audience.

However, it is always possible to have a press release read by two or three people who are unfamiliar with the topic discussed or to organize a focus group to make comparison judgements of various draft advertisements or circulars. This type of summary check will not reveal every possible problematic detail. However, it will very often prevent errors with more serious consequences such as placing too much importance on secondary information; the message is too complex or too abstract; and so on. If the budget set aside for the communication is large enough, then carrying out a professional pre-test of communications measures is strongly recommended.

Effectiveness testing is very often given very little credit in the whole communications process. One reason often advanced to explain the lack of resources devoted to this task is the difficulty of assessing the effectiveness of communications activities.

It is surprising to note the ease with which millions may be paid to secure spots on television or radio or to take part in a major event such as country pavilions at universal exhibitions. Yet there is great difficulty for small budgets to be granted to assess a few basic effects of communication. A simple survey would investigate - the number of 
people reached, comprehension of the message, suitability of the medium for the message, and so on.

Small amounts invested into gauging the effectiveness of prior communications are most often brushed aside, citing lack of interest in a past event. Researchers are then urged to 'look towards the future'. Resistance to such studies involves fear of being faced with unsatisfactory results; the need to be accountable and accept criticism; and finally, the need to interpret these results and consequently devote precious time to doing so.

However, when carried out regularly, these measures could be quite simple. They would produce very useful lessons and make it possible to continually improve communications measures taken by public organizations (see Chapter 12).

\section{INTEGRATED COMMUNICATIONS}

As a result of increasing numbers of communications media, there is growing difficulty and greater cost in reaching target audiences. The concept of integrated communications - originating with Integrated Marketing Communications (IMC) - is progressively and systematically being applied by private companies. Additionally, it is gradually being adopted by public organizations. The aim is to achieve consistency in all communications activities for the purpose of improving their effectiveness (Percy, 2013, Belch and Belch, 2006; Bruhn, 2006).

More and more organizations are communicating on the same subject at the same time, for example, prevention initiatives, using increasingly varied media. To guarantee highly effective use of the means at their disposal, organizations must, in developing a communications strategy, ensure consistency and coherence in all communications activities (Bruhn, 2006):

- Consistency of form: this is often the most basic type of consistency, achieved through the integrated use of all formal elements of a communication independently of the medium used. These would include logos, typeface, font size, colours, images used, etc. The principal objective is quick, clear identification of the issuer of the message and easy reading of the content.

- Consistency of content: this involves making the various messages consistent by coordinating the objectives, using similar logical arguments and repeating the same message for the duration so it is understood. Typically, this is used for communications aimed at prevention or at modifying people's behaviour encouraging cyclists to wear helmets, and drivers to take regular breaks on long journeys, etc. The same message with clear arguments must be stated consistently and in a coordinated fashion by organizations devoted to prevention and companies that manage highway infrastructures.

- Consistency of timing: if several media and instruments are used in the same period, close coordination is very important in order to allow mutual reinforcement of communications activities. Unfortunately, examples of bad timing abound, with 
campaigns failing not as a result of the objectives or the message but of poor coordination. For example, an item in the media sends people to a website to order a brochure or service, but the site is not yet ready or the link is broken. Or, an advertising campaign designed to reinforce the message of television spots with a simplified repetition of the basic message is inserted a month after the spots have ended, etc.

The integration of communications activities must form part of the whole communications process. This entails defining the general framework or setting formal rules through to checking the effectiveness of measures taken. The analysis of mutual reinforcement of measures is a useful example.

\section{EXERCISE 8.1}

Take three recent communications initiatives made by a single public organization. For each, try to evaluate the various communications objectives based on the elements presented in Table 8.1. Having selected one specific issue, look at the variation across campaigns in the other aspects presented in Figure 8.1 - the message, the receiver, the code, and the context. Do these elements vary according to the objectives identified?

\section{DISCUSSION QUESTIONS}

1. Consider a public communications campaign you are familiar with. Can you identify: (a) the sender; (b) the message; (c) the intended target audience; and (d) the expected effects?

2. A communications strategy implies a degree of coordination of communications efforts across government agencies. What might be some of the difficulties in developing such an approach?

\section{REFERENCES}

Barry, T. (1987) The Development of the Hierarchy of Effects: An Historical Perspective, Current Issues \& Research in Advertising, 10, 251-95.

Belch, G. E. and Belch, M. A. (2006) Advertising and Promotion: An Integrated Marketing Communications Perspective, Boston, McGraw-Hill.

Bruhn, M. (2006) Integrierte Unternehmens-und Markenkommunikation, SchäfferPoeschel.

Colley, R. H. (1961) Defining Advertising Goals for Measured Advertising Results, New York, Association of National Advertisers.

Dinnie, K. (2008) Nation Branding: Concepts, Issues, Practice, Burlington, Butterworth Heinemann.

\section{4}


Elliott, S. (2011) California Revamps Its Campaign Against Smoking, New York Times. http://www.nytimes.com/2011/01/18/business/media/18adnewsletterl.html?_ $r=0$ (accessed 26 July 2016)

European Union (2006) EU 50th Birthday Logo Selected. Online at http:// europa.eu/rapid/pressReleasesAction.do?reference $=I P / 06 / 1415$ (accessed 26 July 2011).

Gerbner, G. (1955) Toward a Theory of Communication, Los Angeles, University of Southern California.

Jakobson, R. (1963) Essais de Linguistique Générale, Paris, Editions de Minuit.

Lasswell, H. D. (1927) Propaganda Techniques in the World War, Cambridge, Massachussets, MIT Press.

Lasswell, H. D. (1948) Power and Personality, New York, W.W. Norton.

McLuhan, M. (1964) Understanding Media: The Extensions of Man, New York, McGraw-Hill.

Percy, L. (2013) Strategic Integrated Marketing Communication, London, Routledge.

Rossiter, J. R. and Percy, L. (1987) Advertising and Promotion Management, New York, McGraw-Hill.

Strong, E. K. (1925) The Psychology of Selling, New York, McGraw-Hill.

Weaver, W. and Shannon, C. E. (1963) The Mathematical Theory of Communication, Illinois, University of Illinois Press. 


\section{Chapter 9}

\section{Communications instruments}

\section{LEARNING OBJECTIVES}

By the end of this chapter you should be able to:

- Understand the characteristics and uses of various communications instruments.

- Evaluate communications instruments according to their nature - direct or mediated; and target audience.

- Identify the key points of media relations for public-sector organizations.

- Classify the internet-based communications instruments of your organization.

\section{KEY POINTS OF THIS CHAPTER}

- Organizations use different communications instruments, both direct and mediated, depending on the target audience - internal, prescribers, general public; and the resources available - financial, human resources, etc.

- Advertising has long been used by administrations. Careful coordination of the actors involved, due consideration of budgetary matters, and proper integration of the various media are essential.

- Media relations are essential for organizations aiming at reaching a large and diverse audience. They can be developed using various tools including press releases, press conferences, and press briefings.

- E-government initiatives need to be well planned and coordinated to achieve their full potential. Considerations specific to public-sector organizations mean internet-based communications can only supplement, not replace, other communications instruments. 


\section{KEY TERMS}

Classical advertising - the traditional tool of communications using one or more media such as radio, print, television, or the internet to convey a message. This approach allows direct targeting of the general public or a subgroup of citizens.

Media relations - the goal of media relations is to ensure that the media relay information on behalf of an organization. This involves targeting the media as key interlocutors.

E-government - the use of information technology by governments to enhance the quality and accessibility of their services. E-government splits into several categories, chiefly e-administration and e-democracy.

\section{INTRODUCTION}

Communications activities involve the use of various instruments. As in marketing, the instruments used are well known. However, their choice, the way they are combined, the timing and the intensity of their use, as well as the degree of professionalism employed, differ from one organization to another.

Because such a wide range of instruments is available, we begin this chapter by presenting an overview before exploring a smaller number of instruments in greater detail: classical advertising, media relations, and internet communications.

\section{AN OVERVIEW OF PUBLIC-COMMUNICATIONS INSTRUMENTS}

A number of ways of classifying communications instruments have been proposed, using a variety of criteria (Zikmund and D'Amico, 1993; Rossiter and Percy, 1987; Hartley and Pickton, 1999; Pickton and Broderick, 2005; Bruhn, 2009). The most widely used criterion is the distinction between direct, or personal, communications instruments and indirect, or mediated, instruments - those requiring a medium.

Direct communications instruments are those where information is transmitted directly through personal contact such as bilateral or group discussions, lectures, seminars, presentations, etc. This may be accomplished with or without the use of a medium - paper document, electronic medium, etc.

Indirect communications, on the other hand, use a medium to convey information - newspapers, press releases, websites, etc.; hence the descriptor is 'mediated'. In this case there is no direct personal contact between the emitter of the message and the receiver.

The second criterion classification is target audience(s). In public communications, three target groups are differentiated. These are: members of the organization - 
internal communications; deciders and prescribers - persons and organizations having a direct impact on the public policy at issue; and, lastly, the general public.

Other criteria have also been proposed in the literature. For example, a distinction can be made between individualized and mass communications. Individualized communication occurs where the content and even the form is adapted to each recipient. Mass communications happens when a single message per medium is addressed globally to all recipients.

A further distinction can be made between unilateral and bilateral or multilateral communications. With unilateral communication, there is no possibility of observing a direct reaction from the receivers. Conversely, with bilateral or multilateral communications the issuer can, through the questions or reactions of those present, respond to and interact with the recipients of the message(s).

Table 9.1 combines two main criteria (direct/personal communications and indirect or mediated communication) to classify the main communications instruments relevant to the public sector.

Personal communications addressed to members of the organization essentially consist of individual or group interviews, work sessions, and conferences. These classical tools allow every organization to convey accurate, detailed, interactive information.

Under the pressure of time, managers frequently fail to construct messages properly; to coordinate the timing of messages intended for staff and external messages. Ideally, messages to staff should be released earlier and essential information should be repeated.

Sometimes, when particular items of information are highly complex and difficult to communicate, seminars conducted by people from outside and/or inside the institution can be organized. This may be carried out when a major change in the organization is envisaged. For example, this can occur when the status of the organization is modified in such a way that an administrative body is transformed into a more independent agency.

Communications for staff is completed by other instruments based on written or electronic media. Chief among these are letters and e-mails, memos, in-house journals, noticeboards, and the intranet. Added to these instruments may be documents intended for new members of staff. A brochure on the organization, summary of current rules, and the like would be good examples.

Communications aimed at deciders and the organization's important partners are one of the distinctive features of the public sector. The taking and implementation of decisions in the public sector are governed by rules that are very different from those of the private sector. These include the length of the decision-making process; the need to achieve consensus; legal procedures; the number and diversity of partners; tradeoffs between policy rationale and economic rationale, etc.

As a result, public organizations must identify partners who are important for their actions and ensure that many of their communications activities are targeted. For example, a department in charge of regional policy on forests must take regional factors into consideration. In mountainous areas, forests serve a protective function and a high

\section{8}


Table 9.1 The main public communications instruments

\begin{tabular}{|c|c|c|}
\hline & $\begin{array}{l}\text { Direct, personal } \\
\text { communications }\end{array}$ & $\begin{array}{l}\text { Indirect or mediated } \\
\text { communications }\end{array}$ \\
\hline \multirow{6}{*}{$\begin{array}{l}\text { Staff or members of } \\
\text { the organization }\end{array}$} & Speeches, oral messages & Letters and e-mails \\
\hline & Personal interviews & Memos \\
\hline & Work sessions & Bulletin boards \\
\hline & Training seminars & In-house journal \\
\hline & & Intranet \\
\hline & & $\begin{array}{l}\text { Documents about the } \\
\text { organization }\end{array}$ \\
\hline \multirow{5}{*}{$\begin{array}{l}\text { Deciders/prescribers } \\
\text { and important partners }\end{array}$} & Personal interview & Letters and e-mails \\
\hline & Testimony before a & Presentation kit \\
\hline & commission & Annual report, historical \\
\hline & Personal relations & works \\
\hline & & $\begin{array}{l}\text { Information letter and } \\
\text { technical notes }\end{array}$ \\
\hline \multirow[t]{8}{*}{ General public } & Trade fairs and shows & Advertisements \\
\hline & $\begin{array}{l}\text { Events (open days, } \\
\text { anniversaries, etc.) }\end{array}$ & $\begin{array}{l}\text { Information letters, } \\
\text { corporate journals, historical } \\
\text { works }\end{array}$ \\
\hline & & Sponsoring \\
\hline & & $\begin{array}{l}\text { Media relations (press } \\
\text { release, conference, press } \\
\text { briefings, interviews, } \\
\text { participation in debates) }\end{array}$ \\
\hline & & Internet communications \\
\hline & & $\begin{array}{l}\text { Documents on the } \\
\text { organization, multimedia } \\
\text { presentations }\end{array}$ \\
\hline & & Promotions \\
\hline & & Social networks \\
\hline
\end{tabular}

forest density will contribute to fulfilling this purpose, whereas in drier, fire-prone regions, scrub growth must be cleared to prevent the spread of fires and protect dwellings.

This department will thus have to work closely with owners of forests - both private owners and local communities - and municipalities in order to raise the awareness of political deciders so resources are assigned to these tasks.

For this purpose, regular discussions, presentations, and sessions to inform partners are important, as is maintaining personal contacts in formal and informal settings. 
For instance, in the case of a difficult or complex situation, relationships of trust with main partners can facilitate the implementation of a policy.

However, personal contacts take up a good deal of time as well as many resources. Subsequently, indirect instruments are widely used because they allow large quantities of more technical information to be provided in a permanent, structured manner. In addition to the instruments mentioned earlier, newsletters in paper or electronic form can be highly useful. Over time, they provide effective back-up, provided they bring true added value information and are published regularly.

The general public comes last. Over the years, activities and tasks handed over to the public sector have grown considerably. This comes along with greater demands from all citizens as well as escalating accountability requirements. Today public-sector organizations are devoting ever-increasing amounts of resources to communications activities aimed at the entire population.

Because of the numbers of people targeted in these activities and their cost, indirect communications instruments using external media are greatly preferred. Among these, media relations, advertisements, and the internet constitute the virtually indispensable foundations of public communications.

Yet, particularly because the media are free to choose what topics they wish to cover and how, and because these instruments do not allow direct contact with the target audience, there has been a revival of interest in personal communications instruments. Among these, participation in trade fairs, shows, and the holding of open days are widely used by public-sector organizations (see Box 9.1).

\section{BOX 9.1 OPEN DAY FOR JUSTICE}

As part of the European Day of Civil Justice in 2015, the Superior Council of Magistracy of Romania invited citizens, representatives of the media and organized groups of students and school children at the venue of the courts and the Superior Council of Magistracy. The main objective of the day is to help the public realize Justice is a service available to citizens for settling disputes and asserting their rights. Activities included:

- Round tables with the stakeholders

- Meetings and presentations for students, justice auditors, and clerks

- Launching of a practical guide to help citizen understand the judicial system

\section{CLASSICAL ADVERTISING}

Advertising is a non-personal form of communication using media generally designed for conveying news in order to disseminate messages declared to be advertisements. The use of these media requires payment and the advertiser retains control over the content disseminated. 
Advertising in the modern sense of the term appeared in 1836 when Émile de Girardin first inserted into his newspaper commercial announcements in order to bring down the price and expand his readership (Thérenty and Vaillant, 2001). Billboards in the early twentieth century, followed by radio, cinema, and television, subsequently generalized the use of information media for conveying advertising.

More recently, advertising has strongly marked the development of new electronic media such as the internet. Today, virtually all media derive a substantial portion of their income from advertising.

Until quite recently, governments limited their use of advertising for both budgetary and political reasons. Previously, advertising was considered to be manipulative. But in recent decades, advertising has been increasingly used by governments; particularly for prevention and awareness activities (see Box 9.2). Additionally, it is used for diverse purposes such as informing citizens of their rights and duties, promoting certain behaviours like energy saving, integration of immigrants, the promotion of government services, or reputation development (see examples in Box 9.3).

There are several facts to be aware of before conducting a classical advertising campaign. First, advertising involves a number of actors whose interactions should be controlled. These would include, at the very least, a communications agency tasked with designing the campaign and producing advertisements - ads, film clips, posters,

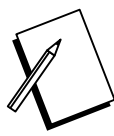

\section{BOX 9.2 GOVERNMENT ADVERTISING IN SINGAPORE}

The government of Singapore is the country's biggest advertiser and develops communications campaigns with a strong advertising component for subjects as diverse as:

- speaking more Mandarin

- speaking better English (http://www.goodenglish.org.sg/)

- being more polite

- not gambling

- being punctual.

One of the communications campaigns of the Ministry of Community Development, Youth and Sports was at boosting the rates of marriage and birth in the country. This follows the finding that many young women and men aged between 20 and 35 are not looking for lasting relationships in a highly competitive professional world. This initiative, which began with a series of television commercials, followed other recent campaigns. 'Romancing Singapore' celebrated love while 'Superbly Imperfect' presented and reinforced the message that searching for an absolutely perfect partner is illusory.

Source: Singapore Ministry of Community Development, Youth and Sport (n.d.). 


\section{BOX 9.3 COMMUNICATIONS CAMPAIGNS IN CANADA}

'In fiscal year 2014-15, the Government of Canada spent CAD68.7 million to inform the public, through advertising, of key programs, services, and health and safety issues. A variety of traditional, digital and social media channels were used to reach out to newcomers, veterans, business owners, parents, youth, students, workers, and the general public.

'Many of the campaigns were a continuation of ongoing government priorities to celebrate Canada's men and women in uniform - past and present; to recruit new generations for careers in the Canadian Forces and the Royal Canadian Mounted Police; to encourage taxpayers to take advantage of tax relief measures; to increase awareness of various job training and skills development programs; to promote services to newcomers; and to foster healthy, safe behaviours.'

Source: Public Works and Service Canada (n.d.).

banners, etc. Additionally, the communications agency would select the advertising media used to disseminate the message - newspapers, television, radio, websites, etc.

Depending on the size of the budget and the complexity of the campaign, other actors will also intervene. They could include a media agency, specialized agencies, communications consultants, and so on. Coordinating all these actors, as called for by the objectives of integrated communications, is imperative.

A second important element is the cost of campaigns. In 2014-15, the Australian federal government spent some AUD 107.1 million through its central Advertising System. For 2013, the American government spent some USD 892.5 million (Australian Government, 2015; Kosar, 2014). Unless advertisements are limited to a small number of regional media with a very restricted number of broadcasts, classical advertising campaigns can often cost several million euros or dollars.

For example, in 2016 a full-page ad in Le Monde cost $€ 104,000$, and in The New York Times USD 157,000. This means campaigns must be managed professionally in order to achieve their objectives. Unfortunately, all too often there is insufficient preparation such as overly general briefing, as well as failure to take into account previous campaigns and their results. Another major pitfall is failure to coordinate the dissemination of information on the various media. Failing to do this leads to disappointing results. In addition, since large sums of money are at issue, public organizations must comply with the rules for the awarding of public contracts.

There are complex choices to be made regarding media exposure. The number of possibilities for placing an advertisement, a commercial or a poster is extremely high, and all media actively seek to acquire business. At the same time, not all media can reach certain target groups or attain certain specific communications objectives.

Table 9.2 compares the main advertising media in terms of criteria such as availability, ability to reach specific target groups, and cost. Because the media context 


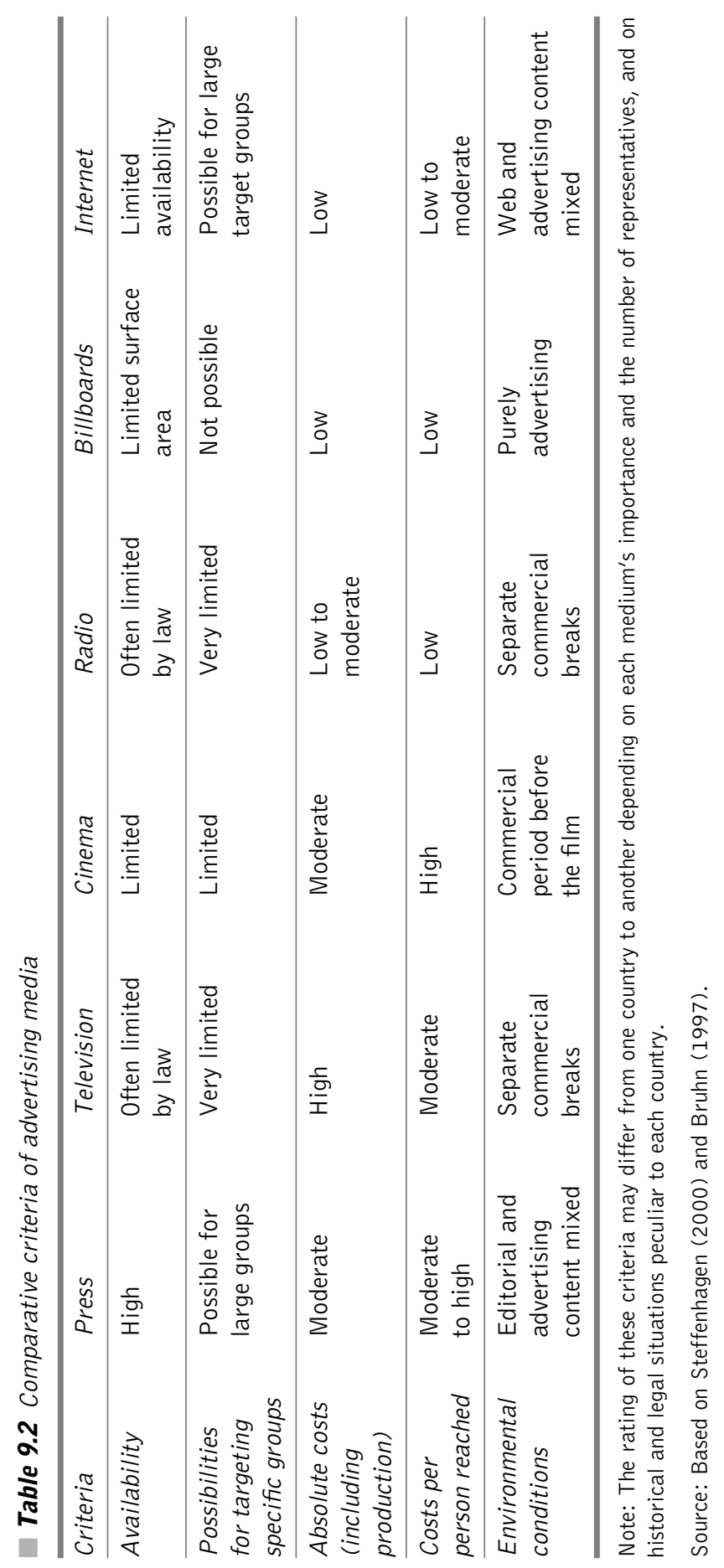


varies greatly from one country to another, the importance of individual media for placing advertising can vary considerably.

For example, the costs of advertising on classical media for 2015 totalled close to $€ 24$ billion in Germany. In Germany, spending on television advertising represents 47 per cent of total advertising expenditure or 53 per cent of advertisement spending on traditional media (Goldbach, 2016), compared to France where TV advertisement made up 27 of the total media ad spending in 2014. In addition, with the continuing development of the internet and mobile media, the distribution of advertising budgets among various media is bound to continue changing in the coming years.

Online advertising revenue in the US reached a record of $\$ 59.6$ billion in 2015 , a 20 per cent increase compared to 2014. 64 per cent of that revenue is claimed by Google ( $\$ 30$ billion) and Facebook (\$8 billion) (Bloomberg Technology, 2016). The PWC Global Entertainment and Media Outlook predicts that e-advertising would rise to $\$ 93.5$ billion by 2020 , thus overtaking TV, which is expected to be at $\$ 81.7$ billion in 2020 (PriceWaterhouseCoopers 2015).

Generally, a combination of media is chosen, with one main medium and one or two complementary media. For example, depending on the advertising objectives, television can be chosen to convey a basic message. But, such an investment can represent up to 60-70 per cent of the budget. Billboards and internet could be the complementary media acting as simple reminders and repetitions of the message in the following weeks. This would account for about 10-15 per cent of the budget for each medium.

\section{MEDIA RELATIONS}

Advertising uses the media by purchasing a portion of their space in order to place an advertisement or a commercial. Therefore, the purpose of media relations is to inform the media so they will convey all or a portion of a message as part of their normal business.

Economically, politically, and socially, the media play a crucial role in our societies. Naturally they carry considerable economic weight and competition among them is increasingly intense. They constitute what de Tocqueville as early as 1835 called the 'fourth estate' (de Tocqueville, 1992 [1835]) in our democracies, alongside the legislative, executive, and judiciary powers. This refers to their capacity to exert control over political and public activities and influence opinion by virtue of the fact that they are the public's main source of information. The vast majority of the information at our disposal has been conveyed by the media and does not come from direct contact with the persons or organizations concerned.

With the liberalization of the media and the partial or complete privatization of radio and television, in most countries the media are completely autonomous of public institutions, and work independently. Consequently, it is important to know the rules governing media relations before making use of the main tools available - press releases, press conferences, and press briefings.

\section{4}




\section{Rules for communication with the media}

The media are businesses, mostly private, whose goal is to provide information and entertainment services to broad audiences. The cost of media production and broadcasting are so high that they must address a wide audience to be profitable or to fulfil the public-service mission assigned to them.

One of the first elements to take into consideration is that the media have their own business model - objectives, priorities, specific target groups, etc. They also have their own method of producing news and technical considerations which place large constraints on the treatment of information.

In the written media, journalists will be given a maximum number of lines in which to cover the chosen article. On television, it is rare for stories on TV news broadcasts to exceed two or three minutes. On radio, information bulletins during the day are no longer than a few minutes. These constraints therefore force journalists to select a limited number of subjects and to focus on the essential points of each.

With globalization, the number and diversity of the media have grown to incorporate new information technologies that were quite inconsequential a little over a decade ago. These newer options have made it possible to communicate in real time from any point on the globe. As a result, media competition has intensely increased and finding exclusive information enabling organizations to set themselves apart from the competition has become increasingly difficult.

At the same time, the number of organizations striving to communicate through the media is also growing constantly. Today, most organizations - whether private, public or nonprofit - are seeking to gain media visibility to raise their profile and improve their reputation. As an example, Associated Press (AP), the largest and oldest international press agency, supplies news information to its customers. These consumers are, of course, the media that use the gathered information for publishing or broadcasting. In addition, AP produces dispatches in several languages, producing more than 2,000 stories a day (2014).

It is therefore hardly surprising that a very large number of press releases and press conferences organized by governments are not relayed by the media. It is simply impossible for the news service to deal with the entire glut of information made available to them every day.

Similarly, they must satisfy readers, listeners, viewers or internet users who are ever more demanding and have a wide choice of news outlets. Therefore, the media look for new subjects, exclusive information, different angles, and sometimes 'juicy' information about people or organizations for their front pages. The adage 'nobody writes about trains that run on time' is very relevant here. This explains why many people attempting to communicate on certain topics are disappointed to find they are ignored by the media.

These general characteristics mean it is essential to be aware of a few principles or rules governing media relations. First, the independence of the media has to be accepted. The media are free to choose what information they cover and how. This 
independence is necessary both from a political and democratic viewpoint as well as from an economic viewpoint. Media too directly tied to a government may struggle to survive in the long run.

It is also necessary to know and anticipate the needs of the media. Each medium has its own rhythm and its own structure. Peak times for audiovisual media are midday and evening, while newspapers are generally distributed in the morning. Therefore the time when a news item is released will dictate that certain media will cover it in depth while others will lose interest or will publish it as just a brief item because it has already been covered elsewhere.

In addition, the media frequently need complementary elements such as pictures, video footage, eyewitness accounts, interviews, and so on. This is because raw news is insufficient to guarantee editorial coverage. The availability of such complementary elements often determines whether or not the message is followed up, or obtains sufficient visibility in relation to other competing topics.

Organizations seeking to have a message conveyed by the media must be ready to face controversy and unpleasantness. Critical questions and scrutiny are to be expected. This kind of interaction may prove trying, but to reject it will almost certainly encourage the media to focus on problem areas - or to lose interest in the subject completely.

Information must be active and clear. In the world of politics and in the public sector, it is very difficult to keep information confidential. Demands for accountability, the interest of the public and the media in public affairs, political machinations and influence mean much information, when not released officially, comes to the notice of the media via leaks.

As a result it is very often wise to arrange for proactive disclosure of information, since failing to do so lays one open to criticism for attempting to hide information or events. In addition, the information must be clearly understandable to non-specialists. Technical data and jargon risk causing the media to deal with the subject in a highly limited fashion at best. At worst, it may present misleading or enormously incomplete information.

It is vital to maintain regular direct contacts with the media. Managers of public organizations may sometimes view media relations with great reluctance, consenting to make contact only when necessary. But, without necessarily developing relationships of involvement, regular meetings with media representatives in informal settings can allow them to acquire basic knowledge of the organization and its activities. Covering a complex subject will be much easier if the basic elements are known and if some grounding in the subject has been given.

Lastly, keeping some distance from information conveyed by the media may be a wise course of action. Information is often transient, and most people who hear or read it have usually forgotten about it within a few days. As a result, it is better to avoid arguing detailed points of editorial coverage, and to concentrate instead on the heart of the message.

\section{6}


Public communications through the media, although difficult given the above nonexhaustive list of rules, is indispensable for reasons of speed, cost and the fulfilment of governments' basic mission. Speed of dispersing information is essential and the media can process possibly complex information almost instantaneously. Both the internet and the radio can broadcast an important news item in just moments.

Cost is another prime consideration because frequently it would be impossible to communicate general information to the entire population using government media. Respect for the basic mission is fundamental because only the media are able to reach a very broad segment of the population in all regions. Thereby the media keeps citizens informed of public and legal affairs while fuelling democratic debate.

\section{Tools for media relations}

We have seen that informal contacts are an integral part of media relations. But four main tools are used in more formal, systematic relations: press releases, press conferences, reports, and briefings.

Press releases are a very widely used tool in public communications because they enable the quick release of summary information on a specific subject. The topic might be an official appointment, a decision of an authority, a particular event, etc. These announcements usually consist of a short, easily accessible text sent to all the media organizations concerned. Based on the press release, the media can then relay the

\section{BOX 9.4 RULES FOR THE DRAFTING OF A PRESS RELEASE}

- The headline is the main teaser, designed to convince reporters to read the release and write a story.

- The lead of a release is similar to a newspaper lead; most releases should use a summary lead, condensing the most important information.

- Restrict the length to about 200 words.

- Refer to additional information through links in the releases.

- Provide first names, last names, and titles.

- Avoid abbreviations or acronyms that may be unfamiliar to some readers.

- Contact information should include a phone number and email address.

- Include a release date and dateline and, if necessary, embargo details (information not to be divulged until a particular time).

- Have the press release read by a third party to check for errors and to make sure the message is understandable.

- Answer the five Ws and one $\mathrm{H}$ (who, what, where, when, why and how).

Source: Rüttimann (2006) and Fitch (2012) 
information without special coverage and without going into the topic in greater depth. Hence, there is no need to search for further information or question other actors concerned. Box 9.4 sets out some rules to follow in drafting a press release.

Press conferences are events to which journalists are invited. They generally consist of a presentation and an opportunity for journalists to ask questions. They are useful for releasing news on an important subject or where the information requires explanations difficult to put across in a press release. This might include disclosure of a highly sensitive subject; a message with strong political impact, or complex data needing to be interpreted.

Because many press releases are not taken up by the media, an alternative trend is being observed. Organizations are increasing the number of press conferences in a bid to guarantee a degree of visibility for the event or the news. An abundance of press conferences attracting only sparse attendances is tending to dampen media interest. Box 9.5 provides an overview of some important rules for organizing press conferences.

\section{BOX 9.5 RULES FOR ORGANIZING A PRESS CONFERENCE}

- Time and place: the timing of a press conference must take into account the availability of the media as well as the publishing or broadcasting rhythm. A press conference given at the end of the day will often not give the media time to explore the subject. Professional press conferences require an orderly setting and backdrop in place. The conference venue can also take on a symbolic importance that should not be neglected.

- Invitation: except for emergency conferences, invitations should be sent two to three days in advance to allow the media to organize themselves and be represented. The media may be very eager to cover the words and deeds of the main actors in the government, but the same does not apply for events and information concerning the civil service and its implementation of public policy. Ideally, media representatives will sign in and provide contact details.

- Press kit: this must contain the documents to be presented at the press conference (text of speeches, images, etc.). Sound or video recording should be produced for reference and might be published on the website.

- Duration: the presentation should not exceed 30 minutes. While the opportunity for questions and answers is provided, the conference should drag out unnecessarily.

- Availability: those giving the conference should allow time after the press conference to respond to specific requests from each media organization represented. Allow time afterwards, if necessary, for separate interviews.

Source: Rüttimann (2006), Brown, Gaudin, and Moran (2013). 
The idea behind organizing a special feature report lies in the fact that some subjects need to be illustrated to be understandable and interesting. However, some of these may be insufficiently topical to be covered by the media in an ordinary way.

For instance, the function of a feature report could be to explain the issues involved in various public policies such as environmental protection. As well, feature reports could give people insight into the difficulties of various public-service vocations such as police officers, firefighters or teachers working in difficult areas. Unfortunately, these subjects are not - barring a particular event - of great interest to the news media.

One can therefore invite one or a small number of newspapers or television channels to create a feature report. This gives them a degree of exclusiveness that may lead them to cover the subject from a different angle. The organization must therefore arouse the interest of an editor or a journalist, provide documentation to help prepare the report, and finally ensure the people who need to be consulted during the report's creation are readily available.

Last are press briefings. Press briefings are useful in major projects, when the implementation of a public policy is long and complex, or when the government or an organization deals with varied, sensitive files. They provide an opportunity, without expecting the media to relay any information. They report on the progress of a project or a case; to furnish off-the-record explanations; to speak critically about the way certain subjects have been covered, and so on.

Briefing meetings with journalists - by invitation, or sometimes around a dining table - must be infrequent. However, they must make it possible, as their name suggests, to brief journalists about a situation and thereby facilitate media relations at the time of subsequent official communications.

\section{INTERNET COMMUNICATIONS}

\section{Definitions, advantages, and limitations}

The internet has revolutionized not only the way people communicate but also the interaction between individuals as well as between political and public institutions and citizens. E-government addresses 'the use of information and technology to support and improve policies and government operations, engage citizens and provide comprehensive and timely government services' (Scholl, 2008).

Online administration can reduce costs and facilitate transactions between governments and citizens. It also contributes to making the public sector more open and transparent. A number of fields of application fall under the overall concept of e-government (see Figure 9.1), and particularly take note of:

- E-administration: 'covers the deployment of modern ICT in the public sector administration in order to make the performance and management of business operations more efficient and effective' (E-Government Glossary). 
- E-democracy describes the technical and organisational modernization and support of political and democratic processes with innovative information and communication technology (ICT). E-democracy evolves around three main pillars: e-public (internet facilitated exchange of politically relevant information); eparticipation (online engagement around public issues through government institutions or NGOs) and finally e-voting (Lindner et al., 2016).

E-government provides the opportunity to simplify and improve governance processes through the use of new technology. Besides service delivery, e-government efforts tie in with public sectors' strive for increased transparency insofar as large quantities of information can be made available online (open data), ready to be used by citizens, NGOs and private sector entities. Finally, e-government facilitates the goal of increased citizen participation in governance processes through the provisions of online platforms.

With regard to e-democracy, digital technology allows to cast and count votes electronically, as well as opening new channels for information exchange prior to elections. But above all, it can supply information enabling political actors - citizens, political parties, interest groups, etc. - to exchange views and take part in debates.

The advantages of the internet as an information medium and new technologies are many. First of all, it must be said that means of digital communication are a factor that has appreciably contributed to changing the relationship between the government and citizens (OECD, 2014), towards more collaborative and participatory interactions. Concretely, governments tailor communication around specific groups of citizens, while in turn citizens can directly communicate concerns and thus actively shape partnerships with the government.

In accordance with the principles of New Public Management, without calling into question the criteria of equality and equity, the internet facilitates the individualization of the relations between all actors. Another advantage lies in the multimedia possibilities offered by the internet: text, sound, images, and video can be combined to create a dynamic and compelling message.

A successful adaptation of governments to the digital environment and integration of communication technologies can help to foster citizen information, participation, and service delivery. Government can provide information immediately and continuously; beneficiaries can access up-to-date information at a time of their convenience and select information based on their own needs. Further, participation is facilitated by opening new channels of communication and creating means for a bilateral relationship. Finally, service delivery - e.g. change of address notifications, online completion and filing of tax return - can be conducted regardless of business hours. For instance, Georgian citizens living abroad can apply for a new passport online, confirming his/her identity through a verification call on Skype. Such services can help to reduce the distance between government and citizens.

Besides improved communication, the use of digital tools also promises to enhance speed of service delivery and communication while reducing the costs. After all, 


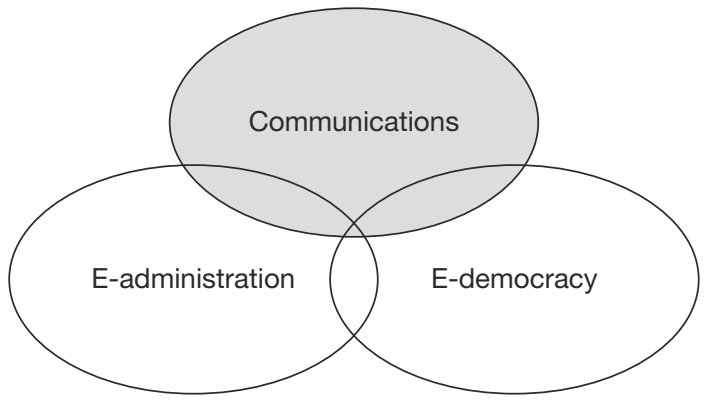

Figure 9.1 E-government and communications

automating processes, reducing hours at service counters, employing fewer office personnel, and so on have to be appreciable money savers; or are they? The UK 'Digital by Default Strategy' estimated in 2013 that online transactions can be 20 times cheaper than those done by phone, 30 times cheaper than through the post and 50 times cheaper than face-to-face service delivery (Government UK, 2013). It is indeed true, savings are possible in some areas. However, the design and management of websites, together with the hardware and skills necessary to develop platforms and keep systems operational, are primarily a cost factor and consume many resources.

Effective savings are further limited by the fact that government agencies cannot turn their backs on classical methods of communicating or service delivery (service counters, telephone information, letters, etc.). As part of its function of creating and maintaining social bonds with people, the government cannot reduce its presence to electronic exchanges. Government must ensure it maintains a visible 'physical' presence with the general public. In addition to that, governments are obliged to guarantee access to services and information to everybody. This includes people having no internet access, those lacking the necessary skills to use the internet, as well as people with disabilities. The danger of turning the 'digital divide' into an administrative divide caused by limited access to government portals must above all, be guarded against. Conversely, a private business is entirely free to impose constraints on its customers such as online ordering only.

Lastly, the internet must be considered not as a medium to replace all other media but as an additional medium that facilitates the transmission of information and the distribution of services.

\section{E-GOVERNMENT SUCCESS FACTORS}

Although certain general principles for using the internet are valid for both private and public organizations, particular features of the public sector mean specific success factors must be taken into account (OECD, 2014). 
First, it is widely recommended that a common portal be set up for all government services. This is what the United Kingdom has done with gov.uk, France with www.service-public.fr and the United States with usa.gov. Because of the diversity of public-service organizations and missions, the temptation is strong to develop a website for each. This would thereby allocate the services or departments concerned with better visibility and, sometimes, better individualization of relations with beneficiaries.

Still, three aspects need to be borne in mind when creating citizen-oriented web services: First, starting from the beneficiaries' point of view, it must be assumed they do not have detailed knowledge of administrative structures. A further assumption might be they will not immediately be able to locate the organization or website where the information or service they are seeking is to be found. A common portal will assist most beneficiaries in their search for relevant web pages. Thus, the architecture and navigation model must be common to all departments and all online content. It is important that users can be directed to the desired department without difficulty or uncertainty. In every case, it is recommended not to give portals a structure reflecting administrative structures. Instead, it should be one that mirrors user groups or services provided (taxes, schools, identity documents etc.) and thus provide a customeroriented approach. This is the approach taken by the Australian and the Canadian governments' websites. They identify the various types of users and then guides them according to their specific situations and needs.

Second, a number of parallel sites generally mean different designs, constructions and approaches. Legitimate public action requires clear identification of the issuing body, but this is not always the case with websites. On the internet, one is in a virtual bubble so there is always reason to be unsure about the issuer. Is it a public organization or a private organization to which powers have been delegated? Or, is it a completely private organization having no connection with the public sector whatsoever?

The financial aspect is by no means least important. A multiplicity of sites increases the need for consistency and coordination often leading to higher development and management costs. After all, the benefits of the internet only become reality if the management of the various platforms and their content is continuous and professional.

For all these reasons, a common portal for the government as a whole is recommended. However, deviations from this policy can be allowed as long as there are clear rules that are strictly applied. This is particularly so for major projects or for government departments that have been made autonomous and whose activities go beyond the classical relations of a government department. Such an agency could offer both public services and business services.

A success factor to be kept in mind is the need to identify the portal strongly and clearly as well as to promote it actively. Changing people's usage or consumption habits is difficult, and the mere existence of a portal will not suffice to modify them. If a government really wishes to benefit from the advantages of the internet, and to pass these benefits on to citizens, it must encourage the use of the portal through active promotion. For example, the Canadian government did set up an across-medium 
campaign to promote its website Canada.ca. The EU launched a 12-week online consultation in 2015 regarding their forthcoming E-government Action Plan, identifying citizens' and businesses' needs and expectations from EU digital public services.

Governments must make sure they protect the confidentiality of citizens' private data; meaning they cannot be intercepted or seen by unauthorized third parties. Improper use of such data can not only have consequences for the people involved but can also lead to considerable loss of credibility for the organization in the performance of its tasks (Carey, 2015).

\section{Website design}

Many books and articles (see for instance Leavitt and Sneiderman (2003); Barnum (2011) or Krug (2014)) discuss principles and rules to follow in designing a website. Some specifically discuss the design of government or public institution websites or web solutions (Downey et al., 2011; Gil-Garcia, 2012; Yannacopoulos, 2014; Manoharan, 2015). Granted, some rules are valid for all communications tools, for example those calling for clear identification of user needs. However, others are specific to this new tool. An example is the 'three click' rule according to which a webpage or an item of information sought should not require more than three mouse clicks to display. Otherwise users may either lose patience or get sidetracked by other content.

Box 9.6 sets out important, specifically communications-related elements to bear in mind when creating a website. Although all the rules are important, updating information and links is vital. As a result, it is better to progressively develop a relatively simple but always kept up to date rather than a site offering every possibility and all information. Such websites can quickly become obsolete because it is not kept current. The rate of updating depends on the organization operating the site and the supplier of content.

Although the rules set out in Box 9.6 are valid for any website, public organizations need to take various elements into account in setting the content of webpages:

Quantity of information put online. Two extreme trends can be observed. At one end of the spectrum, some organizations are very parsimonious, placing a minimum of information online. Such organizations have to deal with many telephone or e-mail queries from people seeking information. At the other end, some organizations use websites to put a maximum amount of information online, posting everything imaginable - reports, opinions, files, etc. By using copious amounts of information, there is the danger of 'drowning' information important to citizens. Sometimes, information overload is deliberate, intended to discourage the public from searching for data they might need. 'Infobesity' is a recently coined word sometimes used to describe websites with overabundant information.

Homogenization of rules for putting information online. The public sector is not homogeneous in the nature of tasks performed or to the type of organization performing these tasks. Therefore, the degree of autonomy allowed to each administrative entity, in the design and content of its own webpages, should be determined. 


\section{BOX 9.6 IMPORTANT ELEMENTS IN WEBSITE CREATION}

\section{Content-related aspects:}

- Define the objectives of the website.

- Provide useful content based on users' needs.

- Take into account the various possible users - user categories, types of computer, types of connection, etc.

- Update content very regularly.

- Ensure the site is properly referenced.

- Monitor and track usage - how many visitors, what pages, when, from what site, from what page users leave the site, etc.

- Ensure that practical information - addresses, business hours, telephone number, etc. - are easily and quickly accessible.

\section{Formal and technical aspects:}

- Ensure that a clear domain name is used.

- Coordinate graphic elements, harmonizing them with all communications tools - integrated communications.

- Devise a navigation system to suit users' needs and skills.

- Pay attention to ergonomics.

- Organize information in a clear and logical manner.

- Facilitate quick reading with short titles, sentences, and paragraphs, etc.

- Minimize the number of clicks necessary to reach information.

- Establish links between subject and information.

- Use a Responsive Design Format ensuring adaptability of the site to various devices.

\section{Financial and organizational aspects:}

- Determine content and structure before design.

- Determine rules for making decisions and competences in adapting and updating content.

- Organize resources such as trained staff for development and especially for updating of the site.

- Determine the budget.

Sources: Leavitt and Sneiderman (2003); Emond and Steins (2011); Krug (2014). 
Coordination of the internet tool with other communications tools. While this aspect is not limited to public organizations, it takes on a particular character in this sector. In order to achieve equality of treatment, people who cannot access or will have difficulties accessing information via the internet must not be given second-class treatment.

This makes it very important to consider the complementarity aspects shared by the various communications tools, and it must be done in a systematic manner. To save costs, some private organizations do not show a telephone number or address on their websites. Thereby users are forced to navigate through the site, searching for the information they need.

In principle, a public organization cannot proceed in this manner. It must allow several access points, even if some may be limited - such as reduced opening hours for departments whose services are easy to access online.

\section{E-democracy}

E-democracy is a complement of e-government and refers to the use of ICT by institutions for the purpose of conducting their relations with citizens in the exercise of their democratic rights. There are three types of use:

- Engagement and distribution of information (e-participation): in order to facilitate citizens' participation in political debates and decisions, information must be readily available. This could be information on civic rights, budgets, accounts, minutes of meetings, expert opinions, and so on. Besides facilitating engagement, availability of information also strengthens their citizen's confidence in institutions.

- Moderation of the political debate and participation in interactive exchanges (e-public): calls for ideas, surveys, forums, chat rooms, etc. Such exchanges are marked by a low degree of formality and tend to be comprehensive in scope.

- Exercising voting rights over the internet (e-voting): This is a form of electronic voting that has been tried in recent years. It provides easy access to voting for certain groups; for example citizens living abroad. As well, it stimulates participation in elections for other groups such as young people. E-voting is arguably a form of participation, but had received separate attention due to specific procedures and rationales.

Although the general rules for the design and maintenance of e-democracy webpages and platforms are the same as for other pages on government sites, they must strive to adopt an even more unambiguous, and objective stance. There can be no informational bias, partisan comments, favoured target groups, etc. 


\section{EXERCISE 9.1}

Analyse a press release in the light of the criteria presented in Box 9.4. Analyse your organization's website taking into consideration the criteria presented in Box 9.6. Compare the results obtained for both the press release and the website. Are the evaluations similar or dissimilar?

\section{DISCUSSION QUESTIONS}

1. What should be the role of the internet in an organization's communications strategy? Do you see major problems in centring your approach on this new medium?

2. The harmonization of various communication instruments across an entire government, is a challenge. Why do you believe it is so problematic to get organizations onto a specific common approach? What does this say about the dynamics between organizations?

\section{REFERENCES}

American Press (2014) AP by numbers, On-line at: http://www.ap.org/annualreport/2014/ap-by-the-numbers.html (accessed 6.071).

Australian Government (2015) Campaign Advertising by the Australian Government, Departments and Agencies, 2014-15, Canberra, Australian Government.

Barnum, Carol (2011) Usability Testing Essentials. Ready, Set\{.\} Test!, Burlington: Morgan Kaufman.

Bloomberg Technology (2016) Google and Facebook Lead the Digital Ad Industry to Revenue Record, online at http://www.bloomberg.com/news/articles/2016-04-22/ google-and-facebook-lead-digital-ad-industry-to-revenue-record (accessed, 9 August 2016).

Brown, J., Gaudin, P., and Moran, W. (2013) PR and Communication in Local Government and Public Services (PR in Practice), London, Kogan Page.

Bruhn, M. (1997) Kommunikationspolitik, München, Vahlen.

Bruhn, M. (2009) Intergrierte Unternehmens-und Markenkommunikation, Stuttgart, Schäffer-Poeschel-Verlag.

Carey P. (2015) Data Protection, Oxford, Oxford University Press.

Downey, E., Ekstrom, C., and Jones, M. (2011) E-Government Website Development: Future Trends and Strategic Models: Future Trends and Strategic Models, Hershey: IGI Global.

Eggers, W. D. and Bellmann, J. (2015) The Journey to Government's Digital Transformation, online at http://dupress.com/articles/digital-transformation-ingovernment/ (accessed 10 August 2016).

E-Government Glossary, online at http://www.egov-conference.org/glossary (accessed 5 August 2016). 
Emond, J. and Steins, C. (2011) Pro Web Project Management, Apress.

European Commission for the Efficiency of Justice. Online at http://www.coe.int/t/dghl/ cooperation/cepej/events/EDCJ/default_en.asp (accessed 22 July 2016).

Fitch, B. (2012), Media Relations Handbook for Government, Associations, Nonprofits, and Elected Officials, The Capitol Net Inc, pp. 23-8.

Gil-Garcia, J. R. (2012) Enacting Electronic Government Success. An Integrative Study of Government-wide Websites, Organizational Capabilities, and Institutions, New York, Springer.

Glassey, D. (2003) Le Plus Petit Nombre de Clics, Working Paper of IDHEAP, $\mathrm{M} / 2003$.

Goldbach Group (2016) Goldbach Annual Report, Goldbach Media Publications. Online at http://www.goldbachgroup.com/en-us/investor-relations/financial-reports/annualreport-2015 (accessed 9 August 2016).

Government UK (2013) Government Digital Strategy: December 2013. Online at https://www.gov.uk/government/publications/government-digital-strategy/ government-digital-strategy (accessed 10 August 2016).

Hartley, B. and Pickton, D. (1999) Integrated Marketing Communications Requires a New Way of Thinking, Journal of Marketing Communications, 5, 97-106.

Kosar, K. (2014) Advertising by the Federal Government: An Overview, Congressional Research Service. Online at: https://www.fas.org/sgp/crs/misc/R41681.pdf (accessed 22 July 2016).

Krug, S. (2014) Don't Make me Think Revisited. A Common Sense Approach to Web and Mobile Usability, San Francisco, CA, New Riders.

Leavitt, M. and Sneiderman, B. (2003) Research-Based Web Design and Usability Guidelines, online at https://www.usability.gov/sites/default/files/documents/guidelines_ book.pdf (accessed 10 August 2016).

Lindner, R., Aichholzer, G., and Hennen, L. (2016) Electronic Democracy in Europe: Prospects and Challenges of E-Publics, E-Participation, and E-Voting, New York, Springer.

Manoharan, A. (eds) (2015) E-Government and Websites. A Public Solutions Handbook, New York: Routledge.

Organisation for Economic Co-operation and Development (OECD) (2005) E-government for Better Government, Paris, OECD.

Organisation for Economic Co-operation and Development (OECD) (2014) Recommendation on Digital Government Strategies, Paris, OECD.

Pickton, D. and Broderick, A. (2005) Integrated Marketing Communications, Essex, Pearson Education.

PriceWaterhouseCoopers (2015) Global Entertainment and Media Outlook 2016-2020, PriceWaterhouseCoopers.

Public Works and Service Canada (n.d.) Annual Report on the Govenrment of Canada Advertising Activities. Online at: http://www.tpsgc-pwgsc.gc.ca/pub-adv/rapportsreports/documents/rapport-report-2014-2015-eng.pdf (accessed 22 July 2016).

Rossiter, J. R. and Percy, L. (1987) Advertising and Promotion Management, New York, McGraw-Hill International.

Rüttimann, J. P. (2006) Travailler Avec les Médias, Fribourg, Département des sciences de la société de I'Université de Fribourg.

Saint-Amant, G. (2005) E-Gouvernement: Cadre d'évolution de I'administration Électronique, Revue Système d'information et Management (SIM), 5. 
Scholl, H. J. (2008) Discipline or Interdisciplinary Study Domain? Challenges and promises in Electronic Government Research, in: H. Chen et al. (eds), Digital Government. Integrated Series in Information Systems, New York, Springer.

Singapore Ministry of Community Development, Youth and Sport (n.d.). Website. Online at http://appl.mcys.gov.sg (accessed 1 April 2011).

Steffenhagen, H. (2000) Wirkung der Werbung. Konzepte, Erklärung, Befunde, Stuttgart, Wissenschaftsverlag Mainz.

Thérenty, M. E. and Vaillant, A. (2001) 1836, L'an I de l'ère Médiatique. Analyse Littéraire et Historique de La Presse de Girardin, Paris, Nouveau Monde Éditions.

Tocqueville, A. de (1992 [1835]) De la Démocratie en Amérique I, Paris, Gallimard. Yannacopoulos, D. (2014) Evaluating Websites and Web Services. Interdisciplinary Perspectives on User Satisfaction, Hershey: IGI Global.

Zikmund, W. G. and D'Amico, M. (1993) Marketing, New York, John Wiley \& Sons. 


\section{Chapter 10}

\section{Communication control}

\section{LEARNING OBJECTIVES}

By the end of this chapter you should be able to:

- Identify the various control mechanisms for communication.

- Select the approach best suited to a specific communication campaign.

- Activate the evaluation of your communication initiatives.

\section{KEY POINTS OF THIS CHAPTER}

- Communication activities are rarely evaluated - due both to cost and the difficulty in confronting failures as well as the desire to go forward. Result: an inability to improve communication initiatives.

- Evaluating communication in the public sector is especially difficult since many bodies and initiatives present the same message and try to reach the same policy objectives.

- Three levels of evaluation can be made, measuring: output - the number of contacts; outcome - modification of knowledge; and impact - changes in behaviour.

\section{KEY TERMS}

Communication control - monitoring of an organization's communication activities to gauge the validity of the concept as well as the outputs, outcomes, and impacts. 


\section{KEY TERMS continued...}

Effectiveness Analysis - the most common form of assessment of a communication campaign. It helps ascertain whether the objectives have been attained in terms of a specific target group to be reached.

Longitudinal Study - evaluating a communication campaign over time.

Benchmark Study - evaluating a communication campaign as compared to similar endeavours by other organizations.

\section{INTRODUCTION}

Controlling communication activities and, above all, assessing their effectiveness, are tasks which are often neglected by both private and public bodies. Although these are complex undertakings, they are vital for ensuring goals are attained and the measures taken are re-assessed as necessary.

Along with a lack of desire to deal with these tasks and a reluctance to admit mistakes, two factors make this a complicated issue. First, it is quite challenging to isolate the effect of one communication measure with regard to other measures in the same campaign. Secondly, in terms of communication, the effects on target groups do not simply depend on activities made by an organization. It is also contingent upon all the activities and events of a great many organizations.

Many non-profit organizations, for instance, raised huge sums through fund-raising campaigns after $9 / 11$. The main reason was not that their campaigns were more effective than those they had staged before. These campaigns were highly successful because of the heightened climate of insecurity caused by the attack. Communication control is even more complex in the public sector. Many organizations act on the same public policies through their own measures. Moreover, their public nature means that the way in which the organization can direct and control its communication - discussion in public and in the media - is restricted. What is more, the details of these public policies are often deliberately left vague to ensure the greatest possible support from political decision-makers in voting on the appropriate laws.

A good illustration of this situation can be found in measures taken to promote a country's image. In the context of World Expos, like the one held in Milan in 2015, countries spend large sums of money to be present with their own pavilion. This is accompanied by various promotional measures, as outlined in Figure 10.1.

A country's presence at a World Expo results from a political mandate assigned to an organization in charge of preparing and carrying out the project. Such organizations are usually regulated by the Foreign Ministry. The flagship measure is the creation of a pavilion to host exhibitions, welcome visitors, and showcase various 


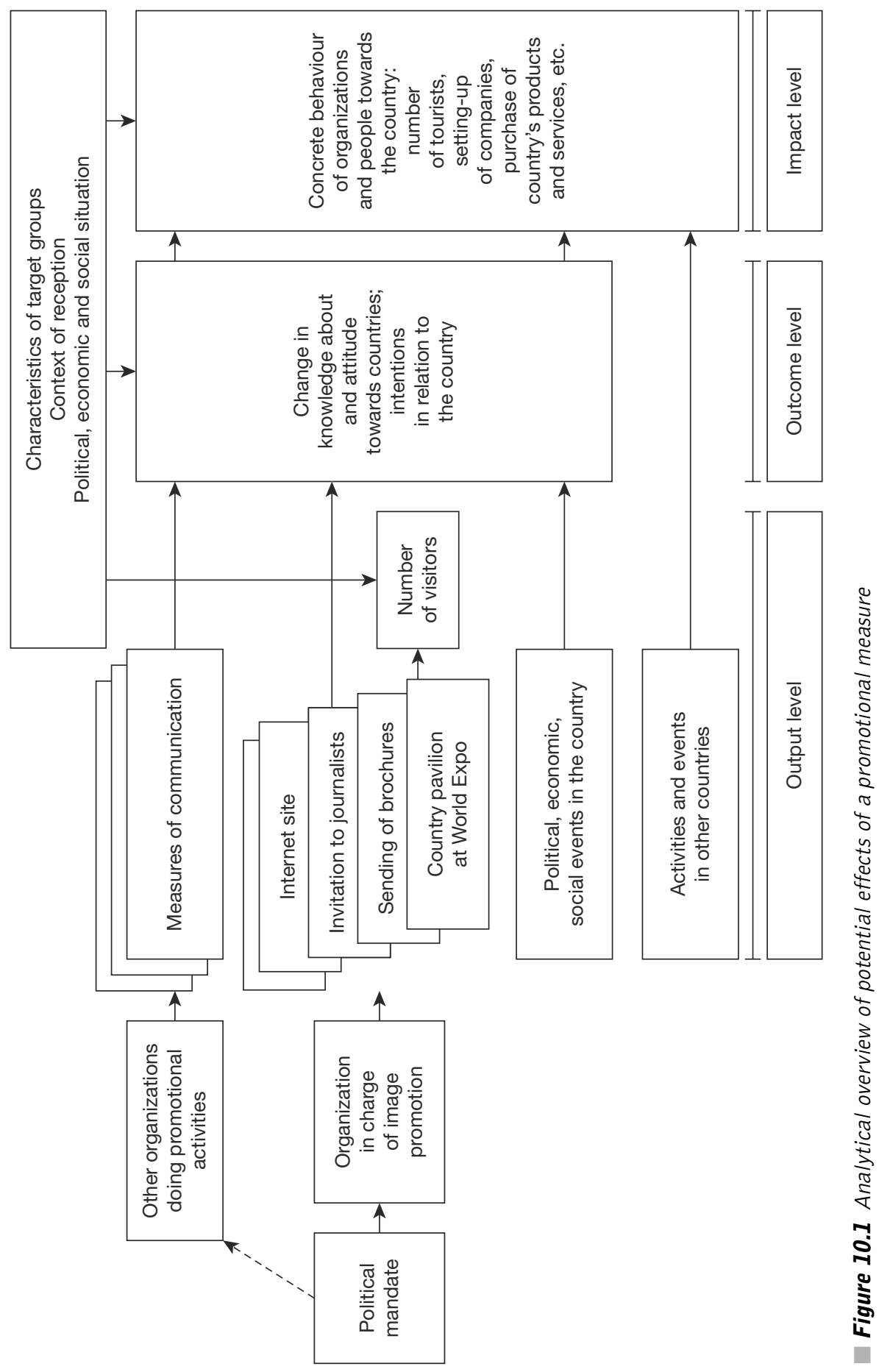


aspects of the country. It is usually accompanied by support measures such as a website, information documents, press conferences, invitations to journalists to visit the country, etc.

Analysing the impact of these measures must take into account how they are received by their target groups. Socioeconomic characteristics of the people concerned include basic knowledge, level of education, and so on. Also to be considered is the situation in which they find themselves when in contact with these measures - economic situation, political context, logistical and technical aspects, etc. Each one will influence their ability to understand the message. All these elements are moderating variables that amplify or reduce the potential impact of the organization's message.

There are three distinct levels of impact:

1. It is relatively easy to determine the number of visitors, evaluate the frequency or length of their visits and, after questioning them, learn how much they appreciated their visit. Points queried will include the pavilion's quality and appeal, what they learned, etc.

2. Analysis of changes pertaining to how a country is perceived will be complex. It will involve filtering information to glean data directly relating to any revised intentions regarding goods and services produced or companies located in the country. However, this can only be achieved by keeping in mind all measures taken by the other organizations involved in promoting the country.

These other organizations will include tourist offices, bodies in charge of attracting companies, embassies, and so forth. Depending on the messages conveyed, and how well they are coordinated, these measures may strengthen or undermine the Pavilion's impact. It is, in any case, difficult to specify how a visitor's opinion of a country might be altered by visiting a national pavilion.

3. The impact sought by political authorities within the framework of a given mandate becomes even more difficult to assess, as one cannot ignore promotional events and activities staged by other countries. This is because analysts must take into account the increasing number of tourists, attracting more firms, helping companies with export activities, etc.

After describing the types and conditions required to monitor communication activities, the next section presents and explains the levels and basic variables to be considered when studying the effectiveness of communication measures.

\section{TYPES AND CONDITIONS OF CONTROL}

The act of monitoring communication activities can take on four different, complementary forms:

The first is the 'monitoring the concept', also known as 'pre-test' control. As outlined in Chapter 9, it is vital to verify the concept before conceiving and carrying out communication measures. The following tasks can be identified: 
- Assessing the concept's coherence: Particular attention must be paid to ensuring the framework of conditions for communication activities is respected, and that the decisions taken during the process fit in with one another. This would be in regard to budget and goals, or budget and choice of means, etc.

- Ascertaining that the concept can be put into effect: It is important to make sure the required instruments are available - such as the possibility of placing an advertisement in a newspaper or obtaining a stand at a fair. But most importantly, coordinating technical and time-related aspects must be at the forefront of conducting the campaign. For example, it may be necessary to cancel, postpone, or bring forward communication activities according to the timing of events.

- Controlling the message: Checking that the message for the target groups, goals, and chosen support is fully understood, achieved ideally by testing a representative sample. But, for both reasons of time and means, such studies are hardly possible. Nonetheless, it is recommended to carry out such tests using whatever samples are readily available.

These samples could include office colleagues, acquaintances or friends, who are consulted individually or within the framework of a group discussion. Either approach is likely to yield critical comment: Is there enough time to read all the information? Do we have enough basic knowledge to understand the message? Does the principal message come across clearly? What effects does the message produce?

The second, and often most important type of monitoring is the 'control of goalachievement', generally called 'effectiveness' control or 'post-test' control. This involves verifying whether the goals with regard to the defined target groups have been attained. The following section is devoted to this type of control.

The two other types of monitoring - longitudinal (tracking) and comparative (benchmark) studies - are slightly less frequent, but often useful, especially in the public sector, and when it is difficult to isolate the specific effect of individual measures.

Third, 'tracking' is used to evaluate the impact of a set of measures over time. One can obviously measure how the fame or reputation of an organization or country evolves. ${ }^{1}$ However, more subtle measures are also worth considering, especially when communication activities are carried out over time, on subjects for which extensive studies are not possible (see Box 10.1).

Fourth and last, is the 'benchmark' study aimed at measuring the effectiveness of communication campaigns not in absolute terms, but relative to campaigns of other, similar organizations. For instance, when it comes to prevention, one can compare the budgets devoted to communication activities and the results obtained among target groups in different countries providing such information is available.

If a State agency sponsors a cycling team, for instance, it could compare how its own image has evolved compared to that of the sponsors of other teams. As well, it could analyse the effectiveness of the sponsorship compared to the goals originally fixed.

Opportunities to monitor communication activities depend upon various factors. The first, and most obvious, is the budget available. Professional and systematic 
monitoring of these activities can be costly and absorb extensive time resources. It is clear many public - and private - organizations struggle to devote the necessary means to this.

A second condition is linked to the existence of goals and with their clarity. Goals are often quite vague such as: 'improving the image of the law', 'encouraging cyclists to wear helmets', and so on. Therefore, measuring the effects serves little purpose.

So, when the mandate is defined, the objectives with regard to precise target groups must be sufficiently explicit for the effect to be subsequently measured. Otherwise, there will always be both positive and less positive effects, making any clear interpretation difficult.

Other factors to be considered are more technical, including the possibility of questioning target groups or obtaining reliable data. Take, for instance, communication measures to prevent obesity among children and teenagers. In many countries surveys of persons under age 16 are not allowed. Consequently, it is not possible to obtain results among the target groups concerned. Only data obtained from indirect target groups - parents, doctors, teachers, etc. - can be envisaged.

Furthermore, data obtained from surveys of children, senior citizens or the underprivileged must be interpreted with caution. However, if the gathering procedures ensure a degree of data reliability such as special qualifications of pollsters, specific data

\section{BOX 10.1 MONITORING INFORMATION OVER TIME}

Much of the information communicated by public agencies is through e-mail and websites. Often, websites are specially created for a given occasion. So, in 10 or 20 years' time, if people seek to understand why a decision was taken, it is far from certain such data will still be available. Nevertheless, it is important to alert all public-sector actors - ministries, municipalities, State agencies, etc. - to this possibility. Anything not archived today will not necessarily be available tomorrow.

In most countries archiving such data is the task of the relevant services, but it is only of marginal interest to political decision makers and typically, budgets for these tasks tend to be inadequate. In order to place this subject on the political agenda, however occasionally, attention raising communication activities may be undertaken.

This could take the form of a seminar on the subject, talking to journalists to ensure they do write about it, lobbying political decision makers, and so on. It is hardly feasible to assess the effect of each individual measure; but it would be interesting to monitor how the subject is treated in the media over time. Data accrued could/should include recording the number and length of articles, the type of newspaper and websites covering the subject, nature of articles, etc. (Caron and Hunt, 2006). 
control procedures, limiting possible third-party influence, etc., then the gathered statistics can be deemed valid.

\section{ANALYSING THE EFFECTIVENESS MODEL}

\section{Bases of the model}

Analysing the effectiveness of communication campaigns and measures is the most frequent type of control, and usually the most important one for public bodies. It involves verifying whether the defined objectives among the target groups have been attained. Figure 10.2 presents a synthetic overview.

The model concerns a basic communication approach and, among other things, differentiates between the party communicating, the support, and the persons targeted. Such distinctions are important because, for communication to have an effect on those targeted, the latter need to be in contact with the support. Therefore, communicators must keep track of how the target group received the information. Did they read it in a newspaper or a prospectus? Did they consult the website; see a poster, or some other form of media?

With reference to the support, a distinction is usually made between the relationship with the support as such, and the relationship with the message. Take a press release whose basic contents are relayed by a newspaper article. A local inhabitant may subscribe to the newspaper and read it every day. This is an excellent example of contact with support. However, this particular subscriber may not see the article in question due to lack of time, interest or some other reason. Thus, he/she has had no contact with message.

Impact on the parties targeted can be described in psychological terms, such as remembering a message or a change of attitude towards the organization or issue concerned. Then there are the behavioural aspects or end results which are typically sought - like taking part in an activity, exhibiting altered behaviour, paying for a service, etc.

Theories of consumer behaviour are often split into cognitive, emotional, and conative aspects, partly overlapping with the phases in the communications approach. The cognitive aspect corresponds to mental functions and the ability to perceive, read, hear, memorize, and reason. Simply put, it is the consumer's ability to understand and interpret.

The emotional aspect covers motivations and the ability to establish preferences. The conative aspect concerns conscious actions from intentions to actual behaviour (Pasquier, 1997).

In many situations, studying the impact of communication follows the three aspects in a linear fashion. The consumer becomes aware of information, forms an opinion and preferences, and then proceeds with actual behaviour. But research into consumer psychology has shown this order can often be reversed.

In the event of spontaneous behaviour or being motivated in a particular way such as giving pleasure to someone else, or satisfying some special wish, people may take 


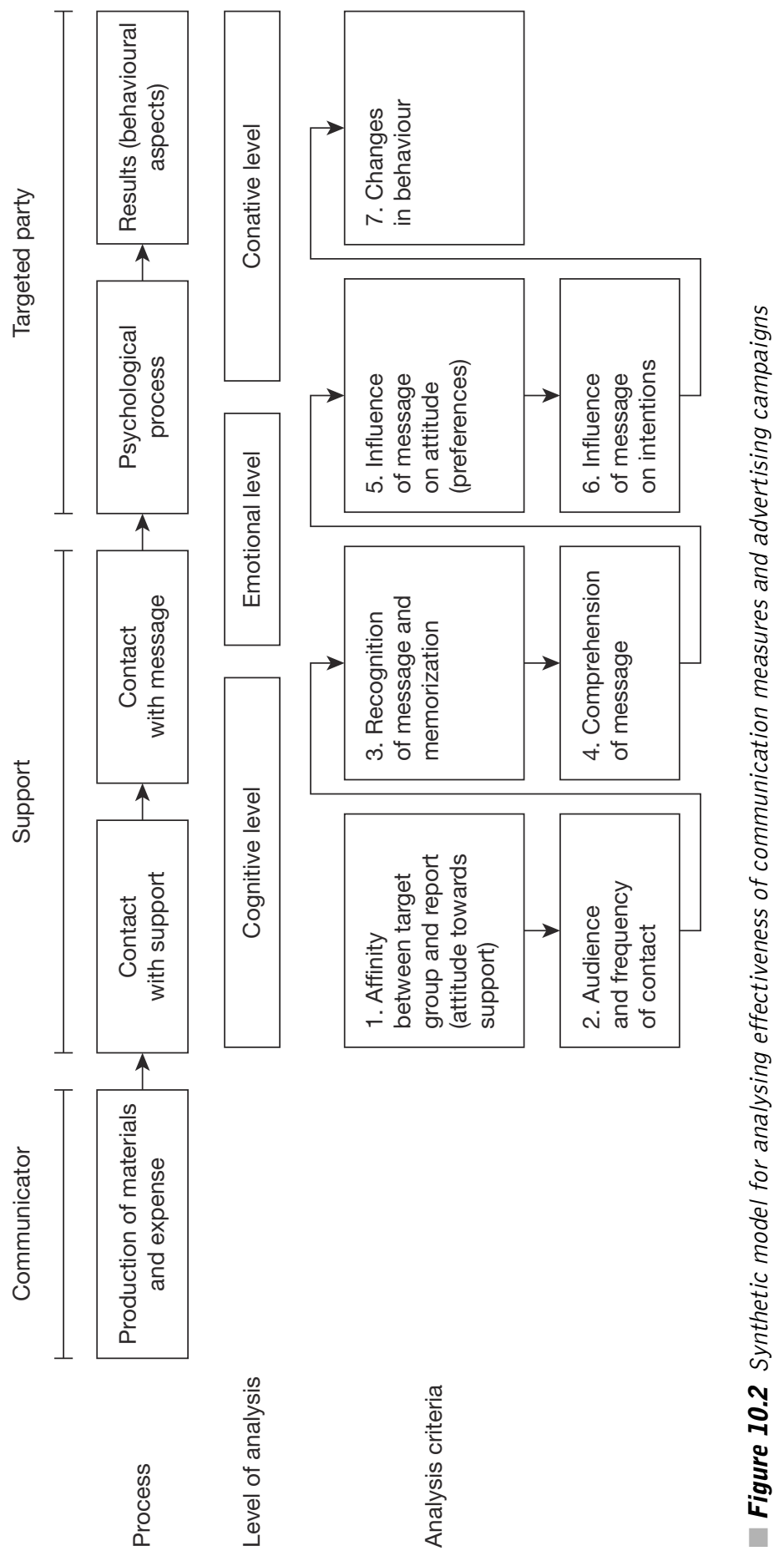


decisions not in keeping with their knowledge or usual attitudes. For example, someone who is environmentally conscious may choose to fly on a trip they would normally make by train. To minimize this apparent inconsistency, people may perceive, or even seek, information that rationalizes their decision. In this way, people's behaviour may affect how they view the service.

\section{Analysis criteria}

Based on the communication approach and the aspects outlined above, we can draw a list of criteria needed to assess the communication's effectiveness.

The first criterion concerns 'physical' contact with the support and the frequency of such contact. For communication to be effective, it is first essential to ensure the persons targeted have been in contact with the support, preferably more than once. Studies show that more frequent contact increases people's memory of an advertising campaign (Pasquier, 1997). Furthermore, the effectiveness of certain supports, like posters, depends almost entirely on repeated contact.

The second criterion is connected to the affinity between the target group and the support. Attitudes towards the support - regular or occasional reading, time spent reading, etc.; its credibility and the value accorded to the information are all moderating variables. These broaden or reduce the communication's potential impact. The same information presented in different supports will not have the same effect. This is because of two factors - the quality of contact is not the same, or because the support does not have the same credibility.

Third, there is recognizing the message and remembering it. Some people may see a message several times, be able to describe it, yet remain incapable of identifying its principal theme, or the brand/body behind it. So we have recognition of the message - but mistaken attribution.

Fourth, if we study the degree of understanding of the message, we can ascertain whether or not its main thrust and arguments have been correctly decoded.

Once the message has been seen and understood, the effects produced at an emotional and pre-behavioural level need to be assessed. Will there be a change in attitude towards the theme being dealt with among the people affected? Will they alter their choices? Are they prepared to change their behaviour? Criteria five and six try to answer such questions.

In the field of prevention, in particular, a number of messages are seen and understood, but do not suffice to make people change their behaviour, no matter what the campaign. If not properly motivated, intelligent people will continue not sorting household waste, continue smoking, will drink and drive, not follow a balanced diet, nor take regular exercise, etc. Reasons for this behaviour vary, but communication alone is often not enough to prompt the desired change.

The final criterion concerns the action taken by those affected. Both economic and non-economic effects can be evoked, especially in the public sector. Economic effects mean the likely consequences of behavioural change can be measured in monetary 
terms. For instance, increasing fiscal receipts may be achieved through a campaign prompting people to declare their earnings and fortune. Non-economic effects can be measured only through observing behaviour - people actually stopping smoking, or sorting household waste, etc.

Although these criteria have been presented one after the other, according to the pre-defined levels, the actual choice depends on the defined goals. If the goal is to

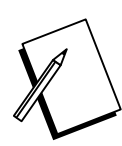

\section{BOX 10.2 BASIC CONTROL OF EFFECTIVENESS OF COMMUNICATION CAMPAIGN AGAINST 'UNDER THE TABLE' EMPLOYMENT}

After introducing a new, much tougher law against illegal employment, the Swiss government adopted various measures, including a public communication campaign. One of the posters reads: Cherche femme de ménage sachant tout faire sauf des accidents. (Seeking cleaning help. Must be able to do everything except generating mishaps) (Figure 10.3).

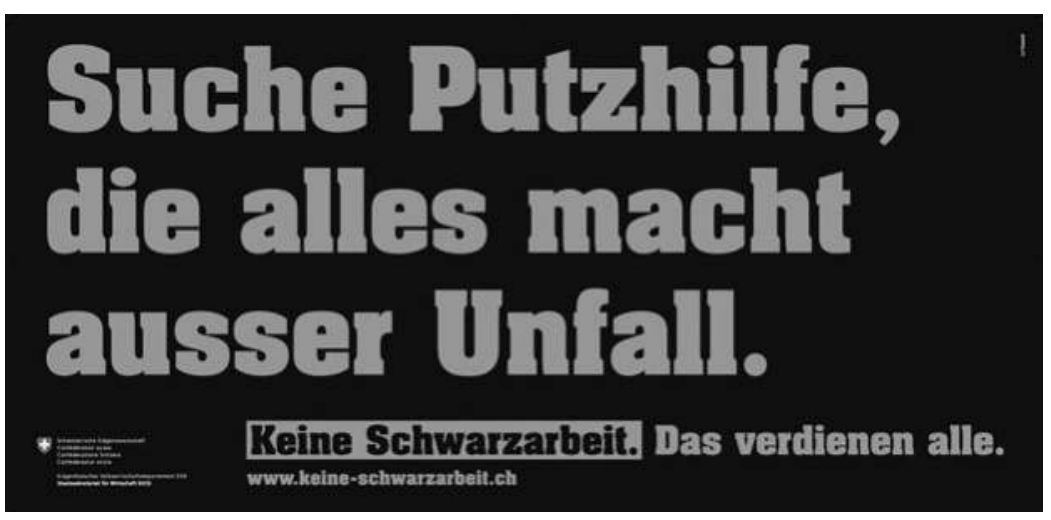

Figure 10.3 Ad of a communication campaign against 'under the table' employment

In Lausanne and Bern, Switzerland, a survey following a campaign involving a representative 15-44 age group sample showed that:

- 92 per cent passed in front of a campaign poster.

- 32 per cent went past a campaign poster at least twelve times.

- 54 per cent recognized the subject of the posters.

- 57 per cent were able to identify the organization behind the poster.

Source: Confédération Helvétique (2008). 


\section{BOX 10.3 VERIFYING THE IMPACT OF PUBLIC RELATIONS (PR)}

PR aims to foster a good relationship with parties who are important to the organization. Two things are vital when assessing the impact of PR measures:

- PR aims less to change the behaviour of those targeted than to spread information and build a positive attitude towards the organization.

- Given the wide range of parties involved, potential types of relationship and large number of possible communication measures, it is not easy for effectiveness to be gauged precisely.

The effectiveness of PR measures can be assessed at three main levels.

- PR outputs - immediate results of an activity or programme:

\begin{tabular}{|c|c|c|}
\hline Traditional media & Internet & Events \\
\hline $\begin{array}{l}\text { - Which media } \\
\text { relayed the } \\
\text { information } \\
\text { and when? }\end{array}$ & $\begin{aligned} \text { - Website traffic } \\
\text { - References to } \\
\text { website or article }\end{aligned}$ & $\begin{array}{l}\text { - Number and type } \\
\text { of participants } \\
\text { - Amount of material } \\
\text { or information } \\
\text { provided }\end{array}$ \\
\hline $\begin{array}{l}\text { - What information } \\
\text { was conveyed? }\end{array}$ & $\begin{array}{l}\text { - Information relayed } \\
\text { by other sites; } \\
\text { number and nature }\end{array}$ & $\begin{array}{l}\text { - Number of person } \\
\text { contacts }\end{array}$ \\
\hline $\begin{array}{l}\text { - Format and } \\
\text { placing of articles }\end{array}$ & & $\begin{array}{l}\text { - Evaluation of } \\
\text { information conveyed } \\
\text { in media }\end{array}$ \\
\hline $\begin{array}{l}\text { - Context in which } \\
\text { information } \\
\text { conveyed }\end{array}$ & & \\
\hline $\begin{array}{l}\text { - Over impression } \\
\text { or 'mood' of article }\end{array}$ & & \\
\hline
\end{tabular}

- PR out-takes - measures related to the message:

- $\quad$ attention paid to the message

- understanding of message as linked to goals

- memorizing the message over short and medium term.

- Measures at an emotional level of the targeted party:

- analysis of people's attitudes and opinions

- analysis of potential impact on behaviour. 
encourage people to frequent their local library more often, then the main criteria will be linked to a change in behaviour. Therefore, the number of actual new readers should increase, as well as the number of people intending to go to the library, etc.

If the goals are not attained, the reasons for falling short must be identified. These could be traced down to the support - the wrong choice, not enough readers, message not repeated often enough, etc. Was the message easy to comprehend? Was there difficulty for certain foreign communities to understand it? Was it too abstract? Did it lack precise information?

In addition, what was the attitude of those targeted? Did they have any desire to change their habits? Were they afraid of trying something that seemed too posh? Or perhaps it was for behavioural reasons such as lack of time, unsuitable hours, difficult access, etc.

Investigating why goals have not been attained should take into account all the indicators or criteria ahead of the goal targeted.

Boxes 11.2 and 11.3 provide examples of communication control.

\section{CONCLUSION}

The evaluation of communication initiatives is essential to ascertain their effectiveness, and, if needed, to modify the approach taken. Difficulties in evaluating are numerous and stem from both practical and political considerations.

On the practical side, are budget and methodological considerations such as difficulty in isolating one's campaign from other environmental factors. Political considerations tend to be more self-serving like not wanting to underline failures. That said, the various analytical criteria available, and the wide range of evaluation options, make it possible to get a sense of the pertinence and general impact of one's own initiatives. Even at an aggregated level, this information will be useful.

\section{EXERCISE 10.1}

Using Figure 10.2 and, based on one of your organization's recent communication campaigns, try to identify the various analytical criteria that were used. Next, evaluate their pertinence in view of the level of analysis and the process.

\section{DISCUSSION QUESTIONS}

1 How far can public bodies justify the costly exercise of communication testing? Is this over-managing communication?

2 With reference to Figure 10.1, what are the potential difficulties about applying such an approach to traditional public services like education or justice? 


\section{NOTE}

1. The GfK Institute, in collaboration with Simon Anholt, publishes an annual study of countries' images worldwide (Anholt-GfK Roper Nation Brands Index); results can be compared year on year, and the evolution of a country's image tracked over time.

\section{REFERENCES}

Caron, D. J. and Hunt, T. D. (2006) Accountability and Disclosure: The Proper Use of Transparency Instruments and their Implications for Canadian Public Administration, in International Institute of Administrative Sciences (ed.), Third Regional International Conference: Transparency for Better Governance, Monterrey.

Confédération Helvétique (2008) PPI Poster Performance Index 2008, Berne, SEC0 and APG Affichage.

Pasquier, M. (1997) The Effectiveness of Outdoor Advertising, The European Research Experience, Federation of Outdoor Advertising, Special Issue. 


\section{Crisis communication}

\section{LEARNING OBJECTIVES}

By the end of this chapter you should be able to:

- Identify a crisis situation.

- Analyse the type of crisis being faced, and outline possible responses.

- Understand and avoid the main pitfalls in crisis communication.

\section{KEY POINTS OF THIS CHAPTER}

- A crisis is a change in all the parameters of an organization's human and physical environment; making all points of reference effectively disappear.

- There are two types of crises:

1. crises linked to accidents and emergencies, and

2. crises linked to information-management problems or tensions internal to the organization.

Each type will involve different dynamics, sequences and solutions.

- One can identify key communication mistakes in a crisis. These include underestimating the risks entailed, refusing to communicate, denying or playing down facts, neglecting internal communication and attacking the media.

- Proper management of a crisis will involve:

1. steps taken before the crisis hits - risk analysis

2. during the crisis - activation of various measures

3. following the crisis - officially declaring the end of the crisis and the beginning of analysing it. 


\section{KEY TERMS}

Organizational crisis - situation in which all the parameters of an organization's human and physical environmental change, making all points of reference effectively disappear.

Crisis communication - a specific sub-field of communication studies dealing with the dynamics involved in a crisis.

Communication strategy - approach used to counter, mitigate or limit the negative impacts of a crisis.

\section{INTRODUCTION}

For any organization, a crisis is a major event that may threaten the jobs of its executives and even jeopardize the organization's survival. Consequently, a crisis must be managed in a specific way distinct from the organization's normal processes. Political crises such as the 1962 Cuban missile crisis and health crises like the Spanish flu, of 1918, have occurred throughout history but fall into a separate category of calamities.

However, since World War II, crises affecting organizations directly have assumed greater importance, especially in the past few decades. A number of reasons account for this development, including:

1. the growing place of organizations in society;

2. the importance given to impacts on persons and the subsequent judicial effects of such events;

3. the speed at which society is evolving;

4. the evolution of the media;

5. technological developments.

First, organizations have taken on considerable importance in our societies, in terms of their numbers and of their diversity. Through their products and services, they affect broad sections of the population. A major event in any organization is therefore highly likely to affect a large number of people directly or indirectly.

People may suffer impacts on their health or their physical integrity such as injuries or poisonings. They may be restricted in their movements due to strikes or outages. Or, they may be outraged by corruption, lies, etc. as well as the contempt shown for their intelligence and values.

The growing importance placed on the individual and his legal rights has also helped strengthen the potential impact of crises. In the same way, the courts play an increasing role in determining liability. 
Moreover, the legal system may have the time and resources to bring serious events into the public eye or prevent such events from being forgotten. This means the dangers of crises for organizations are increasing, and that crises may be prolonged by the involvement of the courts and other institutions such as non-profit associations.

Next, systemic changes and changes within organizations have accelerated, increasing the risks of dysfunction or errors. One serious problem is opportunistic behaviour such as people taking advantage of loopholes within the system. Consequently, since organizations have become highly complex and frequently operate internationally, it is increasingly difficult for managers to have full knowledge of, and control over, their organization's processes and actions.

Another reason for the growth in crisis communication stems from the evolution of mass media. The number and diversity of media mean competition among them has become ever more fierce. This is particularly true when they are engaged in the search of original, exclusive information or 'scoops'. They will strive to discover information and angles for which organizations are not prepared.

Into the bargain, through the liberalization and partial privatization of broadcast media, political control over information in democratic countries has become much weaker. The result is events that might have been covered up half a century ago are today laid out for all to see.

A final aspect has to do with technological upheavals occurring in the telecommunications sector in particular. With mobile phones and the internet, information can be broadcast immediately and continuously. As a result, news that formerly would have made the rounds several hours or even days after an event may be known to the media and broadcasted even before those in charge of the organization have learned of it. In many cases, organizations no longer have any margin of time for anticipating and managing a crisis.

\section{CRISES AND CRISIS COMMUNICATION}

\section{Characteristics of a crisis}

A crisis is defined by Crozier (1991) as 'a change in all the parameters of the physical and human environment with the result that reference points no longer exist and people do not know how to behave'. Lerbringer (1997) defines it as 'an unexpected event jeopardizing the organization's reputation and stability'. A crisis, therefore, marks a break with normal functioning and raises major uncertainties to which it is difficult to respond.

From a more analytical point of view, a crisis for organizations is characterized by the following elements (Coombs, 2014; Coombs and Holladay, 2012; Zaremba, 2015):

- A crisis affects an entire organization; not merely the sectors or departments responsible for the event triggering the crisis.

\section{4}


- Crises disrupt normal operations. Processes and internal rules are abandoned or cannot be applied, thus paralysing the system.

- Causes of a crisis may be known but generally they are unforeseeable, and primarily they take the organization by surprise. Generally, organizations do not have time to implement structures to respond to the crisis in a way they would have preferred.

- Consequences are unpredictable and are likely to jeopardize the organization's survival.

- Inside and outside the organization, perceptions become more important than facts. Emotional reactions dominate and frequently it is impossible, at least initially, to discuss the causes and consequences of the crisis in a rational manner. Elements potentially leading to a crisis situation are outlined in Box 11.1.

\section{BOX 11.1 CRISIS FACTORS THAT BRING MAJOR RISKS}

- Those affected are vulnerable - children, the elderly, pregnant women, etc.

- Recurrence of failures or technical or human errors - successive breakdowns, repeated financial scandals even when of lesser importance, etc.

- Sensitive subjects having health impacts are generally seized on by the media - nuclear, flu, dioxin, asbestos, foods, etc.

- Symbolic places or very well-known organizations are involved

- Information previously denied is subsequently proven to be true

- Absence of answers as to the causes, risks, duration, and solutions

- Situations in which the organization had ignored facts or risks of which it was aware

- Institutional void - resignations, departure of personnel, etc.

- The event is geographically or culturally close

- Persistent rumours

\section{The importance of crisis communication}

A crisis per se calls for professional management in order to find appropriate technical solutions. To begin, this should provide relief for victims, assisting people in difficulty, locating and resolving the breakdown, etc. It should also restore normal operations and communication about the crisis.

This takes on enormous importance, going beyond the framework of the crisis itself in terms both of time and of the people concerned. According to Schwartz et al. (2016), there can be no good management of a crisis without good communication. 
For Revéret and Moreau (1997) and Libaert (2001a), a number of elements explain the importance of effective communication in a crisis:

- Organizations can be imperilled by a crisis. Therefore, it is vital they demonstrate not only their ability to manage the technical aspects of the crisis but also their capacity to show understanding, compassion, empathy, patience, and education if necessary. Generally, the effects of a crisis can only be contained if the organization's main leaders become closely involved.

- As mentioned previously, large numbers of people may feel involved because they may be close to those directly affected. They might feel they could be in the shoes of those affected. Or, they may believe values or basic rules have been flouted. Such people feel entitled to be kept informed and to readily obtain answers. In a globalized world, the likelihood of large circles of people feeling affected by a crisis is increasingly higher. There is no 'falling under the radar' in an era with international social and cultural exchanges, world trade, and instantaneous communications.

- Numerous actors intervene with their own reading of the facts and their own vision of solutions that should be applied. For professional or political reasons, many who would not normally express their views on the organization may seize the opportunity presented by the crisis to step into the media limelight.

They may do this as experts, to defend their values or to put forward general solutions, to raise their own profile or that of their organization. Consequently, organizations themselves must communicate or risk losing all credibility by allowing others to take centre stage.

As a rule, requests for information and explanations come from outside the circle of those directly affected and this pressure exerted on the organization is important. Approaches may come from media or persons who are only remotely - if at all - familiar with the organization.

The organization must therefore understand and deal with the intentions of actors representing 'unknown quantities'. These requests will very quickly swamp the organization's normal communication capacity, especially if the crisis lasts for several days.

Organizations must be able to implement communication strategies and structures to respond to the crisis. Basic actions should include setting up hotlines and ensuring spokespersons are available to respond to media requests including evenings and weekends. Without such structures, the organization risks having to deal with a second crisis caused by its inability to react.

If it doesn't make itself available, the organization will face criticism over the lack of information. Worse yet, rumours may begin to spread because the organization is struggling to respond to all requests.

A characteristic of crisis communication is control of the crisis shifts outside the organization. Depending upon the circumstances of the incident - providing relief to 
victims, restoring basic operations, etc. - technical management of the crisis is normally conducted by the organization, following company procedures. However, what happens to the remainder of the organization is dictated by external actors - the media, government authorities, employees, and other concerned actors.

For as long as the crisis continues, the requests, revelations, questions raised, and rumours will force the organization to react by explaining, informing and refuting. This means it will not be in control of the agenda and will constantly be obliged to adapt to a highly stressful pace - nights, weekends, vacation time - dictated by others. A major stage in a crisis is reached when the media no longer covers the 'event' spontaneously but only when the organization communicates on matters related to the crisis or other subjects.

\section{CRISIS TYPES AND PHASES}

Publications dealing with crisis problems frequently use prior examples such as the Cuban missile crisis in 1962; or oil tanker wrecks - the Amoco Cadiz in Brittany in 1978, the Exxon Valdez in Alaska in 1989. Other examples include health crises such as BSE, or Bovine Spongiform Encephalopathy, commonly known as 'mad cow disease' occurring in the 1980s or Severe Acute Respiratory Syndrome (SARS), in the early 2000s.

These familiar examples provide illustrations of statements about crises everyone can relate to. But they are not very representative of the crises public-sector organizations must confront. The catastrophes they face have real and potential consequences that are closer to home and less far-reaching.

Public organizations are often unprepared to manage crises such as pollution of the water table, embezzlement of public funds by an insider, or the discovery of sexual abuse of children by a teacher or youth leader. These are situations the authorities and administration must deal with at the local level and with staff on hand due to very limited resources. This lack of funding occurs because such crises are fortunately quite infrequent.

\section{Types of crisis}

There are many crisis typologies (Coombs, 2014; Sartre, 2003a, Schwartz et al., 2016) based on criteria such as causes, the nature and degree of risk, internal or external nature, or consequences of crises. Because this chapter is confined to aspects of crisis communication in public-sector organizations, the distinctive features of their activities and the context of their operations need to be taken into account.

From this point of view, two main crisis types can be distinguished: (1) crises resulting from accidents, incidents, and emergency situations, and (2) crises arising from problems of information management or internal operation (see Table 11.1). Two main criteria explain the differences between these two types of crisis: 
- Crises resulting from an accident or serious incident will necessitate the deployment of emergency services or crews dispatched to bring the situation back to normal. Management of the crisis itself can usually be separated from management of crisis communication. Even if both are linked, they can be dealt with by separate teams and will very probably be conducted at different paces and dynamic ranges.

Power outages lasting several days, perhaps following violent storms or unusual weather conditions such as the 1998 ice storm in Québec or forest fires in Fort McMurray in Alberta in 2016 are true crisis situations. However, the experience of the crisis will be very different for those whose job is to restore the situation in the field compared to those tasked with responding to requests from consumers, citizens, and the media. While dealing with queries and complaints, they are also managing problems arising from the intervention of multiple actors.

- The situation is different where the crisis is the result of problems connected to information management and internal operation in the organization. Fraudulent use of public funds is a good example. Very often, the same people will have to manage both the arisen problem as well as provide communication about the situation. So, on one hand, they are searching for information, solving internal problems, informing the political authority, initiating legal action, responding to the media, and so on. On the other, they are also spokespersons for the organization.

Although crises of this type generally have lesser human consequences, they are especially problematic because of the trust issues they may generate. The public nature of organizations and the environment in which they operate - legal framework, obligation of diligence, etc. - makes this distinction important.

Private organizations are not obliged to report internal problems. For example, a bank will try to prevent news of embezzlement by an employee from coming to public notice. However, public organizations are less and less able to avoid doing such a thing as a result of their legal framework and the current media environment.

Crises arising from an accident, a serious incident, or an emergency situation such as a pandemic or any other imminent major health risk - all have several elements in common. First, they affect people's physical integrity. They also cause people considerable inconvenience in their daily lives - for instance, the breakdown of public transport, a prolonged strike, power outages, etc. A detailed example is presented in Box 11.2.

Although exact causes may not be immediately identifiable, generally they are relatively easy to understand. The organization must activate structures bringing relief to people, protect them from danger, and help them to cope with the problems arising out of obstacles to maintaining everyday life.

If these tasks are neglected, a crisis of a second type may well arise because the organization's capacity to respond to and manage the crisis will be thrown into the 
Table 11.1 Types of crisis

\begin{tabular}{|c|c|c|}
\hline & $\begin{array}{l}\text { Crises resulting from } \\
\text { accidents incidents and } \\
\text { emergency situations - } \\
\text { mainly exogenous causes }\end{array}$ & $\begin{array}{l}\text { Crises resulting from information- } \\
\text { management or internal problems } \\
\text { - mainly endogenous causes }\end{array}$ \\
\hline Origins & $\begin{array}{l}\text { Accident, natural disaster, } \\
\text { epidemic, sabotage, major } \\
\text { outage, etc. }\end{array}$ & $\begin{array}{l}\text { Shortcomings in the management } \\
\text { of a programme or an } \\
\text { organization, failures in the } \\
\text { management of an emergency } \\
\text { situation, errors of judgement } \\
\text { information cover-ups }\end{array}$ \\
\hline Characteristics & $\begin{array}{l}\text { Large numbers of people } \\
\text { are harmed - death, injury, } \\
\text { sickness - or hampered in } \\
\text { their daily life - restricted } \\
\text { mobility, restricted } \\
\text { communications, home } \\
\text { comforts, etc., or major } \\
\text { environmental damage is } \\
\text { caused }\end{array}$ & $\begin{array}{l}\text { People are affected because the } \\
\text { organization or persons inside } \\
\text { the organization failed to comply } \\
\text { with rules, procedures or more } \\
\text { generally, key values - human } \\
\text { consequences usually much less } \\
\text { extensive }\end{array}$ \\
\hline Main objective & $\begin{array}{l}\text { Limit harm to persons, } \\
\text { property and environment }\end{array}$ & $\begin{array}{l}\text { Limit the loss of trust in } \\
\text { institutions }\end{array}$ \\
\hline Examples & $\begin{array}{l}\text { For McMurray fires in } \\
\text { Canada in 2016, major } \\
\text { power outage in the USA } \\
\text { and Canada of 2003, } \\
\text { Deep Water Horizon spill } \\
\text { in the Gulf of Mexico in } \\
2010 \\
\text { See also Box } 11.2\end{array}$ & $\begin{array}{l}\text { Kids Wish Network was found to } \\
\text { spend less than } 3 \% \text { of money } \\
\text { raised on kids. The revelation of } \\
\text { such misdeeds led to a fall in } \\
\text { donations not only to this but also } \\
\text { to other organizations. } \\
\text { See also Box } 11.3\end{array}$ \\
\hline
\end{tabular}

spotlight. Management of an emergency situation can normally be separated from management of the accompanying communication. Normally, the crisis itself and crisis communication are managed by different people. This allows emergency personnel to concentrate on their job without having to shoulder the burden of responding to requests from outside.

These requests can be dealt with by specialists who will as far as possible adapt to the pace of external actors such as political authorities, the media and associations. Obviously, exceptional coordination between crisis management and communication management must be established. This is necessary in order to prevent any information problems as well as to allow for the creation and release of appropriate, proactive communications. 
Although communication is very important in a crisis, the priority must remain the relief of victims and limitation of harm to people, property and environment. Communications can never be successful unless proportionate and appropriate relief and assistance are provided to people involved.

Communications may even rely on the work of emergency crews to highlight the organization's capacity to manage the crisis. Conversely, communications can never compensate for deficiencies in intervention. Insufficient relief efforts by an organization, delivery of unsuitable equipment or delay in the implementation of response will be immediately noticed by the public and the media. Then, only one thing is certain; no amount of 'spin-doctoring' will fix it.

In crises arising out of information-management or internal-operation problems, the causes are both much more difficult to identify and more complex to explain and justify. See the example in Box 11.3.

For instance, in the case of abuse of trust or allegations of harassment, only an administrative or judicial enquiry will be able to establish the facts and rule on the guilt or innocence of those concerned. Enquiries of this kind require considerable time and the various actors will not wait for the final results of the enquiry before bringing matters into the public sphere for debate.

As a result, the organization is obliged to provide communication while the facts and causes still remain largely unclear. Moreover, communication is a delicate task when key values have been flouted by members of an organization; especially when all precautions required to prevent such occurrences have not been taken.

This type of crisis is therefore clearly distinct from the crises linked to accidents or natural events, because management of the crisis and crisis communication are closely linked. Since no harm has been caused to persons, property, or the environment, and

\section{BOX 11.2 A CRISIS CAUSED BY A SERIOUS INCIDENT}

\section{Prestige: The shipwreck of an oil tanker}

On 14 November, 2002, the oil tanker Prestige, carrying 77,000 tonnes of heavy fuel, began to break up off the Galician coast and sank five days later. More than 50,000 tonnes of oil leaked from the wreck, polluting the northwest coast of Spain and parts of the French coast. It was one of Spain's worst ecological disasters.

But on 26 November 2002, the Spanish government had yet to acknowledge the presence of an oil slick, preferring to acknowledge isolated contaminated spots. Afterwards, the authorities refused to bring judicial proceedings against the principal actors of the disaster and the government failed to establish a factfinding commission.

Sources: Le Temps newspaper 15 November 2002, 27 November 2002, 22 January 2003, 14 November 2003; Journal du Net (2005). 


\section{BOX 11.3 A CRISIS CAUSED BY AN INFORMATION- MANAGEMENT PROBLEM}

On 9 April 2006, a Sunday newspaper published an article entitled 'Scandale à I'Uni: des profs menaient la grande vie aux frais de I'Etat' - Professors are leading a posh lifestyle on the back of the State.

The article revealed information based on an audit report from the University of Geneva. It underlined frauds on expense accounts involving nearly the entire institution. Of a total of CHFlO million, some 25 per cent of expense accounts did not meet official requirements. Additionally, it was discovered authorities of the institution had prior knowledge of earlier expense account abuses by the same individuals but failed to do anything about it.

Financial and accounting problems were revealed to be based on recurring problems of management and governance of the University. These issues, and the absence of a clear communication strategy, generated interest among journalists and fuelled internal tensions. Rumours, as well as the University's errors and the gap in management of this crisis combined with the inability of some political authorities, greatly diminished the credibility of the institution.

This process was reinforced by a lack of confidence of citizens towards the institution following a series of similar scandals in the Canton of Geneva. After a number of inquiries, the sums presented at the height of the crisis were found to be inflated and had no common measure with reality.

At the organizational level, this crisis led to the resignation of the rectorat or executive of the University. At the institutional level, it pushed political authorities to reform the University; a reform approved by popular vote in November 2008.

Source: Pasquier and Fivat (2009).

because the organization's credibility is at issue, the same people will often be called upon to resolve the problems brought to light as well as communicate about them.

Although this facilitates coordination of crisis management and related communications, it places a heavy burden on a specific group of people. Additionally, individuals' part of the response team must not allow their various roles to become confused. They might be at the same time the investigator, party to a procedure, manager, and communicator.

\section{The phases of a crisis}

Because every crisis follows its own pattern and has its own duration, and in most cases are impossible to predict, defining a generalized list of the phases of a crisis is difficult. Nevertheless, main phases based on the two types of crisis described above can be 
defined (Coombs and Holladay, 2012; Libaert, 2001a; Zaremba, 2015). Crises resulting from an accident, an incident, or an emergency situation generally fall into four phases (Lagadec, 1991):

- The preliminary phase is when the first alert signals occur. It can begin with information suggesting the gravity of an event such as information about the disappearance of an airplane or a ship wreck. Or perhaps it is information difficult to interpret or appears to be banal. However, this can lead to yet another crisis fuelled by allegations, rumours, etc. Organizations must be able to identify such potentially problematic information through strategic watch of their sector of operation.

- The acute phase is when the effects of the events - the announcement of the plane crash, arrival of oil slicks on the beaches - and harm caused to persons, property, or the environment begin to emerge. For example, the wreck of the Erika on 12 December 1999 was only perceived as a serious crisis 14 days after the disaster, when oil washed up over a 400-kilometre stretch of the Brittany coast (Libaert, 2001a, 2001b). See Figure 11.1 for a complete evaluation of this particular crisis.

- The chronic phase ensues after a crisis has peaked. Media interest fades gradually either because there is no new information or because other topics have cropped up to garner media attention. Interest persists, however, and the organization continues to be approached. Still, it might not yet have control over the rhythm of communication.

- The healing phase begins from the time the crisis is no longer topical and the media are no longer actively covering the situation. The only times the event is covered afresh are anniversary dates or when the organization communicates. Questions asked at press conferences, is a good example.

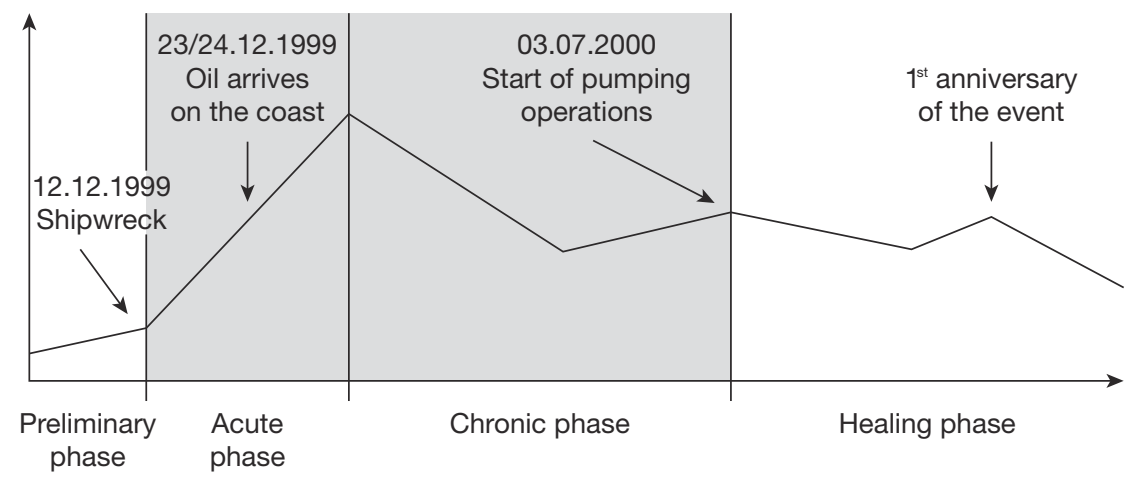

Figure 11.1 Phases of a crisis resulting from a serious accident or incident

Source: adapted from Libaert (2001a). 
The crisis surrounding the oil tanker Erika can be divided into four phases:

- Preliminary phase: During a storm on 12 December 1999, the tanker Erika, carrying 31,000 tonnes of heavy fuel oil, broke in half off the coast of Brittany. Despite leakage of between 2,000 and 8,000 litres of oil on the first day following the accident, the Centre for Documentation, Research and Experimentation on Accidental Water Pollution (Cedre) stated there was no risk of oil slicks along the coasts.

- Acute phase: On 14 December 1999, the press reported Cedre now believed the oil would reach the coast. From then on, the press tracked the development of the oil slick along the Brittany and Vendée coasts every day. Other issues raised in the press were the silence of Total-Fina, the company which had chartered the Erika. The question of its accountability was quickly raised. The crisis worsened on 23 and 24 December 1999, when the first slicks of heavy oil arrived on the coasts. In the subsequent days, the situation intensified along with the oil slick.

- Chronic phase: Although new oil slicks were still arriving on the coast by February 2000, media interest in the crisis had diminished. The press did not mention the fuel arriving on the coast however, but did report preparations for pumping procedures.

- Healing phase: With the start of pumping on 3 July 2000, the crisis entered into its last phase. The oil slick was no longer an item in the press. Only important events such as the completion of pumping at the beginning of September 2000, or the anniversary of the shipwreck were still reported.

The structure of a crisis caused by information-management or internal-operation problems is often different for two reasons:

1. the onset of the crisis is much more difficult to identify, meaning that crossing from one place to another is not always perceptible; and

2. the crisis often dissipates when the problem is resolved or at least recognized, and a commitment to implement solutions is made (see Box 11.4).

Three phases can then be distinguished:

- development phase

- acute phase

- restoration phase.

The development phase involves, as in the crises related to accidents and natural disasters, the disclosure of facts about the organization. Reactions from the various actors concerned and above all, the reactions of the organization are crucial at this stage. This, combined with the general context in which the information is brought to public awareness is essential.

The organization's capacity to assess the risk following the disclosure of information is of the utmost importance as are the answers it provides to questions asked. 


\section{BOX 11.4 TAX EVASION SCANDAL OF BRITISH PREMIER CAMERON}

In 2016, the release of the so-called 'Panama Papers' - files leaked from the database of the world's fourth biggest offshore firm - caused a global scandal by illustrating how wealthy individuals invest their assets in secret offshore tax regimes, thus providing opportunities for tax evasion, fraud, or corruption. Amongst disclosures about Russia's President Putin and Pakistan's Prime Minister Sharif, it also became known that the late father of Britain's Prime Minister Cameron had used such offshore havens and it was suspected that Cameron - who several weeks prior to the incident had condemned tax reduction schemes - had benefited from the investments.

In response to journalist questions, Cameron initially considered the matter as being of a private nature and refused to comment. This stance fuelled suspicions that there was something to hide, creating further media pressure on the Prime Minister. In an eventual statement, Cameron remained rather general, denying that he had any benefits from his father's offshore havens. A more concrete, second statement in response to remaining suspicions he stated more specifically that there was no offshore trust that he or his family will benefit from in the future - grist to the media mill! Ultimately, he had to admit that he indeed benefited from his father's investment, defending however that everything was done in a lawful manner, triggering journalists to examine his past tax records for irregularities to make further headlines news.

At the end of a media-intense week the Prime Minister apologized, 'I know that I should have handled it better, I could have handled it better. I know there are lessons to learn and I will learn them. Don't blame No 10 Downing street or nameless advisers, blame me.' Observers echoed this assessment: they described Cameron's reaction to Panama papers as 'slow, unimaginative and chippy'. In losing control of a news story, he has turned a simple story about his personal finances into an outright scandal that seriously endangered his political standing.

Sources: Economist, 2016 and Telegraph, 2016.

Subsequently, its credibility in its relations with the authorities and the media might allow it to succeed in not arousing increased attention or, on the contrary, may arouse keen interest.

On top of this comes the context in which the information is communicated. If similar facts have come to light in other organizations or if the organization in question is known for its somewhat lax management of problems, then the greater probability is that the issue will turn into a controversy (Box 11.5). 
The acute phase is characterized by intense media coverage of the topic and is essentially determined by the capacity of the media to unearth information. In this situation, the organization must supply clarification and proposals for solutions to prevent similar occurrences in future.

Escalation is frequently observed in proportion to proven fact. If the organization failed to show transparency from the outset and if trust is absent or has been lost, a rocky road will lie ahead. It is highly likely the acute phase will last as long as those seen as responsible for the incriminating acts remain in their jobs. Since pressure generally ramps up, organizations must often release all information available and those in charge must step down.

If all the facts become known and those responsible are no longer in office, the crisis will rapidly move into a restoration phase. The media have no further reason to pursue their quest for information. Other procedures such as administrative enquiry, prosecution, etc. then may be undertaken and will likely not be covered again until the reports are published.

This means the action in the crisis is no longer dictated by the media but solely by normal events further to the crisis. Rebuilding would begin with the appointment of new managers, the publication of a report of enquiry, the introduction of new standards or new equipment, an anniversary date, etc.

As shown in Box 11.3, the crisis at the University of Geneva was essentially the result of internal dysfunction and an information-management problem. An analysis of the number of articles in the media reveals three main phases as shown in Figure 11.2.

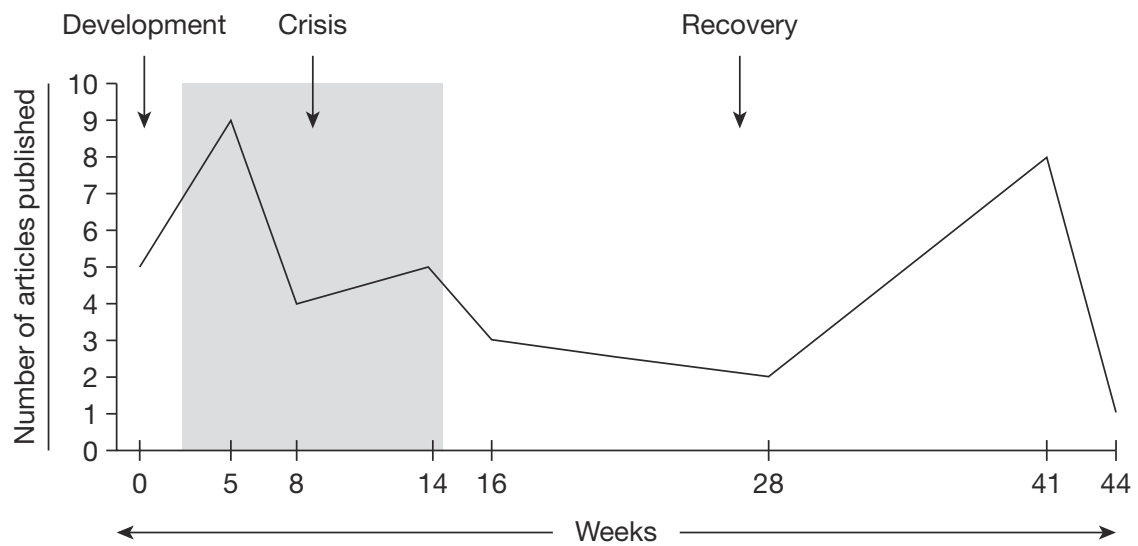

Figure 11.2 Three main phases of the crisis at the University of Geneva

Source: Pasquier and Fivat (2009). 
The vertical axis corresponds to the number of articles published in major Swiss newspapers:

- The development of the crisis: The crisis began with revelations in the press of financial irregularities inside the University. It gathered momentum when, following intervention from politicians, legal sanctions were sought.

- The acute crisis: In subsequent weeks came successive revelations of new events, interpreted as increasingly serious. The University no longer had any control over the information. The press imposed its own agenda. This phase ended when the crisis peaked. Practically all the constituents creating the scandal were unveiled, with the consequence that the University's executive - the rectorat - resigned en bloc.

- The restoration phase: Media interest eventually waned and the University regained control of the communications agenda. The phase ended with the conclusions of the general investigation into the University, which shed light upon all the events. The matter was now closed.

\section{ERRORS AND STRATEGIES IN CRISIS COMMUNICATION}

Although in most cases, a crisis cannot be prevented from emerging, it is possible to attempt to contain the crisis and primarily limit negative effects on the organization in the long term. Such damaging consequences would include internal conflicts, loss of trust, etc. This involves not making the various - and regrettably classic errors - in developing a strategy in line with the organizational context as well as the likely expectations of all actors concerned.

\section{Classic errors}

It cannot be over-emphasized that, since every crisis is different, a search for general characteristics, particularly with regard to errors, is difficult. However, analysis of numerous crises highlights common mistakes that exacerbate the crisis (Zaremba, 2015; Ulmer et al., 2009; Fearn-Banks, 2007; Coombs, 2014; Anthonissen, 2008):

- underestimating the risks involved

- refusing to communicate or waiting too long before doing so

- making pronouncements about the causes and consequences without being aware of the details

- denying facts and attempting to cover up information

- minimizing the significance of facts

- entrusting communications to too many spokespersons

- giving responsibility for communications to someone with insufficient authority in the organization 
- picking up on terms used by the media and giving free rein to exaggerated accounts

- attacking the media or other actors

- neglecting internal communication.

A very common error, particularly in crises related to the disclosure of facts, is to underestimate the risks involved. The cause of such behaviour is legion. Heads of the organization may be absent - on vacation or business travel - when the facts are disclosed. Or, the organization may be incapable of reacting or may lack experience of risk assessment and, various people may attempt to hide information, etc.

Risk assessment may be hazardous, but underestimation is deadly. Should a crisis eventually develop, considerable time will have been lost for gathering information and getting communiqués prepared. Moreover, underestimating the dangers is likely to be noticed by the media during their first contact with the organization. Delayed responses, incomplete information, etc. are media attention magnates most often prompting news investigators to accelerate pressure on the organization.

The expression 'nature abhors a vacuum' is particularly relevant in a crisis and organizations must not fail to communicate or wait too long before doing so. Absence of communication or undue delays can have two consequences. Other actors may step forward to speak, and confidence in the organization may be lost. In a crisis, silence from the main actor concerned is almost always compensated for by utterances from other actors or simply from the media.

Assuming that the media will lose interest in the subject in the absence of explanation is a serious mistake because such an absence can/will encourage the development of assumptions. The spread of rumours tend to increase pressure on the media, which need to be supplied with information. Additionally, this may be viewed as a serious problem by citizens who expect a public organization to adhere to the accountability principle and provide a full explanation.

It is essential to communicate rapidly and continually during a crisis, since special caution is necessary. However, it is unwise to make pronouncements on the causes and possible consequences of the crisis while these remain unknown. It is very risky to begin formulating hypotheses, developing scenarios and so on until the facts have been established. This is especially dangerous because establishing the facts may actually take a great deal of time.

The media and the general public will tend to accept such hypotheses as the true causes of the event. Once all the facts are available, persuading the populace to subsequently change their minds will prove very difficult. This is because many people will not keep up with later news and traces of these erroneous 'causes' will linger especially on the internet.

Denying facts or deliberately hiding known, verified information is highly risky behaviour that can threaten the organization's survival. This is especially so in crises arising from information-management or internal problems. The temptation to deny 


\section{BOX 11.5 EXAMPLES OF ERRORS IN CRISIS COMMUNICATION}

\section{Making pronouncements without having gauged the nature and the causes of the crisis}

Berlin Brandenburg Airport is a prestige construction for the German capital that was to be opened in 2011. That the date could not be met was only announced shortly before the official opening date, putting the blame on the recent drop-out of one of the involved companies. A new date was set to 2012; the mayor stayed in office without any political damage. Only successive investigations over the last years revealed that there were severe construction mistakes heavily impeding safety of the premises; mismanagement and corruption were the reason for the unfinished project. While those facts brought to light the scope of the disaster, the opening date had to be constantly pushed back. The airport is now to be opened in 2018.

\section{Communicating without knowing the facts}

The disappearance of the Airbus from Río to Paris on 1 June 2009 was another case in which hypotheses were made and later disproved. For example, Air France's director of communications stated a few hours after the disaster that the most likely cause was the aircraft was struck by lightning.

Although no definitive conclusions have yet been drawn as to the causes of this accident, the lightning hypothesis was discarded in the days following the accident. Despite being invalidated, this alleged cause remains present in the world of information. In a Google search on 'Airbuses Río Paris', one of the first results is an article in Le Parisien with the headline 'Río-Paris Airbus hit by lightning' (Le Parisien, 2009).

\section{Lying}

Turkish authorities claimed that the cloud of radioactive particles produced by the Chernobyl nuclear accident (1986) had not crossed into their country. Like Ukraine, Turkey borders the Black Sea and the main tea plantations are located along its shores. Turkish authorities persistently downplayed the consequences, denying any scientific study to be conducted. Political leaders from the President and Prime Minister down were pictured drinking tea alongside headlines such as 'A little radiation does you good'. Ultimately, dissident scientists leaked the devastating consequences of the radiation that is haunting the region up until today (Independent, 1993). 


\section{BOX 11.5 continued}

\section{Playing down facts that have come to light}

In 2015, the FIFA corruption scandal hit the news: officials and associates of FIFA were found to be involved in several incidents of bribery, collusion, and money-laundering. The association's president Sepp Blatter refused to admit any responsibility, downplaying accusations saying that 'neither he nor the organization could "monitor everyone all the time"." His re-election as head of FIFA only shortly after the scandal was heavily criticized by the public as well as FIFA sponsors, eventually forcing him to step down (Wall Street Journal, 2015).

the existence of facts or to cover up information in the hope that the media and other actors would lose interest in the problem is enormous.

However, this is very unlikely to happen in democratic and other countries where the media play a significant role. The media are likely to step up the pressure, seek out and publish contradictory information. In this scenario, the organization runs the risk of being caught lying. If this happens, the organization will lose all its credibility in the present moment as well as in its future operations and communications.

Rather than denying the facts, some organizations will minimize them or play down their importance. This can prove counter-productive because this attitude may strengthen the feeling that the organization is far removed from the concerns and worries of citizens. Because the event is unusual and falls outside the organization's normal activities, such as an abusive interpretation of the rules regarding expense accounts, managers may attempt to play down the facts.

They may claim, for example, that their effect is minimal in comparison with the organization's operations or budget. Yet the media and the public will focus not on the rarity of the behaviour but on the fact of its existence and on the flouting of values.

Crises create uncertainty both inside the organization and in the minds of the actors concerned. It is therefore important to provide credible reassurance to all those affected. For this reason, it is wise to avoid making frequent changes in spokespersons appearing before the media.

The presence of a person who is already known or will make themselves known by acting as spokesperson will have a reassuring effect. It conveys the idea of a degree of control over the crisis situation. It also prevents contradictory messages from being conveyed outside the organization, which would only fuel negative analyses.

Similarly, the spokesperson must be kept completely and immediately informed of all events and information coming to the organization's knowledge. If the spokesperson is not involved in the process and does not have the authority required to be kept informed, he or she risks being confronted during a press conference or in an interview. 
A journalist with information the spokesperson is unaware of is dangerous for the organization because there would be no time to formulate a credible response.

With regard to the media, and knowing that emotions tend to take precedence over rationality, organizations must avoid the sometimes metaphorical terms used in the media. They must not be drawn into making the corresponding exaggerations and must above all reiterate the facts as established and show caution when speaking of causes and consequences.

If such care is not taken, ownership of these metaphorical terms and exaggerations would transfer from the media to the organization and the media will legitimately be able to use them for the duration of the crisis. It is also essential not to criticize the media for their interest in the crisis. The same applies to their persistence in obtaining information by questionable means such as late calls, repeated questions seeming to have little relevance, etc. First, it is not the place of the organization in crisis to judge the media, and second, such an attitude is likely to act as an incentive for the media to continue their search for information more aggressively.

Lastly, since the organization may find a very significant proportion of its managerial capacities tied up by the crisis, it may forget its personnel. In a crisis situation, employees often must deal with requests for information from their family, friends, and neighbours who all wish to be kept informed.

Without necessarily making them spokespersons for the organization, staff should be given clear information about what is known; what the organization is doing; and what hypothesis can be refuted. Armed with this kind of information, they can respond to questions and contribute to conveying a consistent message in their inner circles. This aspect is all the more important at the local or regional level where large numbers of employees work and where fewer media are able to relay information.

\section{Strategies and rules to follow}

A number of communication strategies for crisis situations can be found in the literature (Sartre, 2003b; Schwartz et al., 2016):

- Total acknowledgement strategies: The organization acknowledges the facts and where applicable the corresponding responsibilities, in order to quickly regain a degree of credibility. Propose and set into motion solutions or rules to prevent their recurrence. In doing so, it hopes to be pardoned by public opinion. Naturally, this strategy only works well if the organization voluntarily acknowledges its errors, without being forced to do so.

- Partial acknowledgement strategies: These strategies carry a greater degree of risk, consisting of acknowledging the main facts while absolving oneself of responsibility. This involves attempting to dissociate the organization's responsibilities and those of persons taken individually. This attempt here is to link the situation with other similar crises and allows for statements like: 'we're not the only ones'; or accepting only a limited degree of liability - 'we had no choice'. 
- Avoidance strategies: Facts are neither acknowledged nor denied. The organization attempts to create a diversion - for example, by attributing the problem to the absence of guidelines or confusing guidelines or by portraying itself as the victim of the crisis.

- Denial strategies: These strategies are very risky and consist of systematically keeping silent or categorically denying the facts. This can be considered when the facts or accusations have little credibility or when a very important, or very serious offence occurs at the same time. Such distracting events might include terrorist attacks, a global event such as the football World Cup, etc. In this scenario, the organization is wagering the focus of attention currently upon the main actors will be short-lived.

Although all these strategies may be considered by private companies or nonprofit organizations, avoidance and refusal strategies should be rejected by public organizations. A public organization has a much greater obligation to provide information than a private company.

In addition, non-judicial methods of uncovering the truth are many - parliamentary commissions, access to information rights, etc. And, the affairs of public organizations are frequently of greater interest to the media than matters in private companies.

Generally speaking, a public organization must show the greatest transparency, at least as far as allegations are concerned. They must actively contribute to determine responsibilities and put in place measures to prevent similar occurrences in the future. Any other strategy is very risky and should receive explicit prior approval from the political authority.

With this in mind, and also for the purpose of avoiding making crisis limitation errors, basic rules or principles should be followed (Coombs, 2014) (see Box 11.6).

Information must be provided actively and continuously. To prevent the organization from having to communicate in response to external pressure, a proactive attitude needs to be adopted, consisting of revealing the facts as they become known. Subsequently information must be provided regularly, repeating known facts and stating new facts, together with information about next steps. This will provide a degree of control over crisis limitation.

It is also important to check information conveyed and to reveal only established facts. Conveying erroneous or inaccurate information can have serious consequences and the organization will be criticized for it. For this reason, the organization and its managers must stick to the facts and avoid offering up theories or developing possible scenarios that in many cases will be subsequently disproved.

Discussion of where responsibility lies can be undertaken in due course when all information is known. Ideally, this will occur after the crisis when debate can be dispassionate.

Great attention must be paid to the emotional aspects of a crisis. This can be conveyed by showing empathy, or offering a listening ear. When people have been injured or killed, compassion, discussion of responsibilities and consequences must be 


\section{BOX 11.6 RULES TO FOLLOW IN CRISIS LIMITATION}

Inform actively - don't wait for pressure from outside.

- Inform continually.

- Check information before releasing it and speak the truth.

- Correct false information or unfounded rumours.

- Avoid speculating.

- Take the emotional aspect into consideration.

- Do not blame causes or persons for the crisis unless you are absolutely certain.

- Express yourself clearly and repeat information as needed.

- Avoid inconsistencies between words and deeds.

- Deal with all media in the same way and consider their priorities in terms of information.

- Ensure the content of information remains consistent.

- Be open to dialogue and accept disagreement/allow yourself to be contradicted.

- Pay attention to internal communication.

rational and reasoned. Lessons will have to be drawn from the crisis; a process in which it is unwise to be hasty.

Since many people may be affected, most of whom are not specialists in the topic at hand, managers of the organization must ensure they express themselves very clearly. If necessary they must repeat information in as helpful a manner as possible. Knowledge should be passed on avoiding technical jargon. Additionally, people need to be reminded of the order of when events occurred, etc.

For the same reason, managers must take care to show consistency between words and behaviour. For example, in a crisis involving misappropriation of funds or financial abuses, members of the organization must avoid holding a seminar in an expensive hotel with a festive programme.

This applies even if the event had been planned long in advance of the financial crisis. The appearance of frugality is paramount. Otherwise, credibility of the organization's statements will be called into question by behaviour which, while it may be explainable, appears inappropriate in the context of the crisis.

Because of the important role played by the media, organizations must attempt as far as possible to treat them equally. All should receive the same information and at the same time, while taking into account their needs - photos, diagrams, interviews, etc. Moreover, media priorities - broadcast time, time zone differences, editorial lead time, etc. - must be taken into account.

Ideally, the same person should always be in charge of relations with the media and other players outside the organization. This will provide consistency in information 
conveyed. If a number of people speak on behalf of the organization, close coordination will be required to avoid risk of any inconsistency.

The media and the other players will ask questions which may seem irritating or hostile. They may attempt to 'bully' the organization; pass off hypotheses as fact; make connections between unrelated facts, and so on. Throughout, spokespersons must remain calm, be responsive to all requests, repeat the same answers several times if necessary, and accept disagreement. Fielding questions successfully is a vital part of re-establishing the organization's credibility.

Lastly, the organization must not forget its employees who will also have questions. It is very likely at some point, they will be approached by outside players and sometimes, personnel will state their opinion rather than facts. Keeping staff informed as quickly and completely as possible will enable them to correct misinformation, dispel rumours; set out the essential facts and thus contribute to increasing credibility. Most important of all, their confidence in the organization will be bolstered; a fact that will prove particularly important once the crisis is over.

\section{The media and the crisis}

The media will play a central role in any special event leading to the crisis because they serve as a 'resonating chamber' for relaying information. Sometimes the media are informed before the organization and may ask managers questions about an event they are unaware of. Without going into the function and operation of the media in our society, certain characteristics affecting the development of a crisis need to be understood. See Box 11.7 for further examples.

Information is a structured market. It is a market because it has become a consumer product. The media compete fiercely with each other to obtain original and exclusive information. It is not surprising, therefore, that when an incident does occur, the media will be hungry for information and will actively seek it out in order to be quicker or different from the others.

This market is structured because each medium has its own format and a specific relationship with its readers, listeners, or viewers. Radio has the greatest reach in the morning, newspapers thereafter, television in the evening; internet throughout the day and late into the night - with a great deal of information and analysis available.

The quantity of information and the form in which it is provided therefore varies considerably from one medium to another - headlines, pictures, etc. This means it is very important to understand the specific needs of the various media and, to the fullest extent possible, attempt to meet these needs.

The role of the media intensified still further with the advent and development of the internet. First, the internet has increased the competitive intensity among media and has changed the relationship between the media and their uses. All classic media now also use the internet to convey information in addition to portals developed specifically for and on the internet. 


\section{BOX 11.7 SPEED AND INTRUSIVENESS OF MODERN MEDIA}

The speed of the media: After the Concorde crash in Paris in July 2000, the media were already broadcasting eyewitness accounts of the accident and questioning former Concorde pilots before airport management, the airline, or emergency services had a chance to express themselves.

The intrusiveness of the media: Following the San Bernardino shooting (2016), journalists looking for information arrived at the home of the shooter before the police and trampled on a number of pieces of evidence.

Information transmitted over the internet is, at least for the moment, limited, reductionist, and often raw. It contains little analysis, heightening the importance of the accuracy of information for establishing the facts. It is vital to avoid spreading hypotheses or possible scenarios that could rapidly create rumours. As shown previously, disinformation can linger long after the crisis. And since information on the internet is almost permanent, false information can circulate almost indefinitely.

During and after the crisis, an analysis of reports will provide valuable information about the way the media evaluate facts. It will also provide insights about how well they correct erroneous information; how they deal with aspects to be highlighted and others that should be left alone.

\section{TOOLS TO MANAGE CRISES}

Because organizations are taken by surprise and are unprepared for crises, it is useful to have checklists of tasks or elements to take into consideration. Although most of the points set out in Table 11.2 speak for themselves, some require additional explanation:

- before the crisis: risk analysis

- during the crisis: activation of the crisis communication cell

after the crisis: declare the end of the crisis.

When a major event occurs, risk analysis is crucial. It will allow the organization to decide whether it should implement its crisis plans and set up the structures required, particularly the crisis cell. As there is no one criterion that can alone be used to decide the question, a number of factors must be utilized. They include all that emerges from a media watch:

- Innocent victims have been, or are in danger of being, killed or injured.

- The number of people affected or potentially affected is high.

\section{4}


Table 11.2 Crisis checklists

\begin{tabular}{ll} 
Before the crisis & Risk analysis: probability of recurrence, level of risk incurred, \\
& extent to which the subject is understood. \\
& Simulation of consequences: awareness of impacts, \\
understanding of information. & $\begin{array}{l}\text { Setting up a crisis cell: acknowledgement of the gravity of the } \\
\text { situation. }\end{array}$ \\
\hline During the crisis & Analysis and assessment of the situation. \\
& Implementation of operational and communications plans. \\
& Take the initiative, provide information actively. Do not wait for \\
& outside pressure to build up. \\
\hline After the crisis & Declare the end of the crisis and resume normal activities. \\
& Maintain communications with all partners and with the media. \\
& Provide support to everyone who was involved and thank them \\
& for their assistance. \\
& Debriefing and post-mortem. \\
& Produce a full report of experience and adapt operational and \\
& preparation plans - lessons learned.
\end{tabular}

Sources: Adapted from Coombs (2014) and Gabay (2001).

- The subject will affect a wide segment of the public and falls into a category able to attract widespread media exposure such as health, morals, sex, etc.

- The organization in question is well known.

- The event is not isolated but is part of a series of similar events.

- Rumours, doubts, or contradictory information are circulating.

If one or more of these elements are present, the organization must, even if the managers are absent, analyse the situation in detail. Then, whoever is in charge will have to decide whether or not to implement crisis plans or at least monitor the situation closely.

In the event of a crisis, the setting up of a crisis communication cell is very important for two main reasons. First, the organization will be bombarded with requests for several days or weeks, or even months, by outside agencies - media, authorities, etc. Moreover, the organization's usual procedural and hierarchical rules will have to be modified very quickly. Personnel will need to be assigned to handle a hotline, the involvement of outside consultants will need to be arranged, etc.

Only a cell dedicated to the crisis and equipped with personnel and material resources will be able to face up to this avalanche of varied, continual requests. Second, the message issued by the organization must be absolutely consistent and coordinated within the cell tasked with managing the crisis itself. 
In contrast with general rules for communication under which a number of spokespersons may be called upon to speak, it is wise to limit the number of people authorized to do so in this case. In addition, it is essential to make sure there is excellent coordination among those managing the crisis. Only close coordination within a specific cell can guarantee these basic rules will be observed.

The end of the crisis is generally marked by the organization's retaking control after litigation and by a considerable reduction in pressure from the media. Then, the organization must be able, internally at least, to declare the end of the crisis and embark on a process of returning to normal, while maintaining an active communication strategy.

This is also a useful time to learn the lessons of the crisis - through debriefings, and postmortems - and to thank those who were involved. All too often, the belief that the crisis is over leads organizations to want to forget a painful episode instead of preparing for a similar event, even though everyone hopes it will never happen again.

It is only by drawing a complete picture of the crisis and by adapting planned measures that the organization can absorb the lessons learned. This will improve its maturity as well as its capacity to react in the face of the next crisis.

\section{EXERCISE 1.1}

Take the organization you currently for work for and try to identify a crisis situation. Once you have identified it, you should:

1. Determine which type the crisis was.

2. Identify the various phases of the crisis.

3. Pinpoint the event that signalled the end of the crisis.

4. Identify the main mistakes that were made.

\section{DISCUSSION QUESTIONS}

1. What type of crisis do you think is most dangerous for your organization and why? What criteria allow you to arrive at this answer?

2. What is the most easily avoidable communication mistake in a crisis situation? Does the answer vary according to the 'industry' the organization is involved in or is it a matter of the people in place?

3. How can an organization prepare to best mitigate the consequences of an eventual crisis? Is the best approach to be well prepared or is this a waste of resources given that crises are by definition unpredictable?

\section{6}




\section{REFERENCES}

Anthonissen, P. F. (2008) Crisis Communication: Practical PR Strategies for Reputation Management and Company Survival, London, Kogan Page.

Coombs, T. W. (2014) Ongoing Crisis Communication: Planning, Managing, and Responding, Thousand Oaks, Sage Publications.

Coombs, T. W. and Holladay, S. J. (2012) The Handbook of Crisis Communication, Singapore, Blackwell Publishing Ltd.

Crozier, M. (1991) La Gestion de Crise, Les Cahiers de la Sécurité Intérieure, 6, 24.

Fearn-Banks, K. (2007) Crisis Communication: A Casebook Approach, Mahwah, New Jersey, Lawrence Erlbaum Associates.

Economist (2016) What the Panama Papers Really Reveal about David Cameron, online at http://www.economist.com/blogs/bagehot/2016/04/david-cameron-s-taxes (accessed 10 August 2016).

Gabay, M. (2001) La Nouvelle Communication de Crise: Concepts et Outils, Issy-lesMoulineaux, Editions Stratégies.

Independent (1993) Children of Turkey Caught in the Shadow of Chernobyl. Online at http://www.independent.co.uk/news/world/children-of-turkey-caught-in-the-shadowof-chernobyl-1477564.html (accessed 10 August 2016).

Information Office of the Canton of Bern (2001) Communiquer Correctement en Situation Difficile. Un Guide pour la Communication en cas de Crise et de Situation Extraordinaire à l'échelon de la Commune et du District, Berne.

Journal du Net (2005) Communication de Crise: Vingt Crises qui ont Marqué les Esprits. Online at http://www.journaldunet.com/management/dossiers/050167crise/tablo. shtml (accessed 15 Febuary 2011).

Lagadec, P. (1991) La Gestion des Crises: Outils de Réflexion à L'usage des Décideurs, Paris, Ediscience International.

Le Parisien (2009) Vol Rio-Paris: Découverte de Nouveaux Debris, 1 June. Online at http://www.leparisien.fr/.../l-airbus-rio-paris-aurait-ete-foudroye-01-06-2009533641.php (accessed 1 March 2011).

Lerbringer, L. 0. (1997) The Crisis Manager: Facing Risk and Responsibility, Mahway, New Jersey, Erlbaum.

Libaert, T. (2001a) La Communication de Crise, Paris, Dunod.

Libaert, T. (2001b) La Communication de Proximité, Paris, Rueil-Malmaison.

Pasquier, M. and Fivat, E. (2009) Crise à I'Université de Genève: une étude de cas, Cahier de I'IDHEAP, Lausanne, Swiss Graduate School of Public Administration.

Revéret, R. and Moreau, J.-N. (1997) Les Médias et la Communication de Crise, Paris, Economica.

Sartre, V. (2003a) La Communication de Crise, Paris, Les Éditions Demos.

Sartre, V. (2003b) La Communication de Crise: Anticiper et Communiquer en Situation de Crise, Paris, Les Éditions Demos.

Schwartz, A., M. W. Seeger and C. Auer (2016) The Handbook of Crisis Communication Research, Wiley Blackwell: Oxford.

Telegraph (2016) Panama Papers: David Cameron's Worst Week as Prime Minister, online at http://www.telegraph.co.uk/news/2016/04/07/panama-papers-davidcamerons-worst-week-as-prime-minister/ (accessed 10 August 2016). 
Ulmer, R. R., Sellnow, T. L. and Seeger, M. W. (2009) Post Crisis Communication and Renewal: Understanding the Potential for Positive Outcomes in Crisis Communication, New York, Routledge.

Wall Street Journal (2015) Crisis of the Week: FIFA Responds to a Scandal, online at http://blogs.wsj.com/riskandcompliance/2015/06/08/crisis-of-the-week-fifaresponds-to-a-scandal/ (accessed 10 August 2016).

Zaremba, A. J. (2015) Crisis Communication Theory and Practice, New York, M. E. Sharpe. 


\section{Appendix}

\section{A case study}

\section{OF MONEY, MARKETING AND COMMUNICATION}

As is clear from the reading of the preceding chapters, marketing and communication cannot and should not be used indiscriminately in the public sector. The following case study is the application of some of the concepts presented in the previous chapters, in a sector that seems, at first, far removed from matters of marketing and communication: the printing and circulating of money.

Like other central public tasks such as justice or foreign affairs, money is at the core of the State's historical regalian functions. Nevertheless, the development, creation, circulation, regulation, and general management of tangible money, in coin or paper format, are all aspects of the general delivery of a service and/or product to citizens: that of a convenient way of exchanging value.

But can we truly talk about marketing and communication as to regards money? The following examples present various projects at marketing the introduction of new coins and new bills in the United States. They raise fundamental questions as to the use and limits of marketing and communication in the public sector.

In each case, some of the most salient features of the project are presented. A series of questions is then presented to further the discussion.

\section{FROM PAPER TO METAL: THE INTRODUCTION OF THE SACAGAWEA}

Paper bills of $\$ 1$ are the norm in the USA. The American one dollar bill is one of the lowest value paper denominations in the developed world. Over the past decades, a number of attempts have been made at replacing some of them by coins. This desire to introduce coins to replace paper is based mostly on a financial calculation from the Government Accounting Office (GAO) estimating the potential savings at 500 million USD per year over the next 30 years (GAO, 2002: 1). This estimate has since been lower to 146 million USD (McGinty, 2015).

It is with that in mind that the United States 1 \$ Coin Act of 1997 mandated the US Federal Government to introduce a new \$1 coin. It was named the Sacagawea in 
Table A.1 Number of $\$ 1$ coins produced

\begin{tabular}{lll}
\hline Coin design & Number produced & Production years \\
\hline Susan B. Anthony & 932 million & $1979-82$ and 1999-2000 \\
Sacagawea & 1.467 million & $2000-9$ \\
Presidential series & 1513 million & $2007-16$ \\
Native American series & 102.9 million & $2009-0$ ngoing \\
\hline
\end{tabular}

Total: 2,549.367 million

Source: Adapted from US MINT website (2016) and GAO (2011).

honour of the Shoshone guide and translator to the Lewis and Clark expedition that explored the western United States in the early nineteenth century.

This was part of a long list of attempts at convincing Americans to use a $1 \$$ coin. Table A.1 presents the various coins, their production years and the number produced. There had been the early silver dollars (eighteenth century), but of more recent memory one can name the Eisenhower dollar (1970s) and the Suzanne B. Anthony (late 1970s and late 1990s), named in honour of a civil rights leader and a leader of the nineteenth-century women's right movement. None had much success in supplanting the dollar bill. Later attempts, the Presidential and Native American series did not succeed either. The Presidential series will be completed in 2016 with the production of a Ronald Reagan bill, as all other former president are still alive.

In order to raise awareness for the Sacagawea, and to encourage American citizens to use it, the US Mint (charged with the manufacturing of coins in the United States) spent, from 1998 to 2001, some 67.1 million USD in marketing and communication. This programme came at the back of the relatively unsuccessful launch of the Suzanne B. Anthony coin in 1979. It had never caught on with the population. For the Sacagawea, a more active campaign was envisaged.

As part of the bill was the provision that the coin should be golden in colour and have various tactile elements clearly differentiating it from the quarter (25 cents) - a problem that arose with previous dollar coins. To ensure its widest possible use, it was to have the same size and electromagnetic signature as the Suzanne B. Anthony, thus ensuring it being accepted in all vending machines. The communication and marketing aspects were also directly enshrined in the act.

The Mint's programme had three different aspects: (1) research and identification of market opportunities; (2) national public awareness and education programme; and (3) a business marketing programme. The sums allocated were earmarked for elements such as: 'marketing and advertising program, public relations and publicity programmes; 23 partnerships with banking, entertainment, retail, grocery, and restaurant chains; and promotional events with transit agencies' (GAO, 2002: 2-3). The main campaign, using the reassuring image of George Washington, took 40.5 million USD of the total budget. 
For the research aspect of the campaign, a private marketing research company was hired. The initial analysis focused on the Suzanne B. Anthony's use in various economic sectors. Analyses were made of the size of each sectors and the potential 'market' they represented for the new coin. Out of that analysis, a number of high-potential industries were identified (food and beverage, transit systems, postal machines, etc.). Several marketing efforts were made targeting these industries, including personal sale visits, discussions with industry leaders, participation in conferences and symposiums. Opinion polls were also conducted prior to the launch of the coin. The goal was to assess people's opinions and then to use these results to tailor the campaign accordingly. The primary target was 18- to 49-year-old adults in urban and suburban areas.

There followed 11 weeks of intensive advertising on various media (television, print, radio and internet). According to the GAO, 'The television ads reached an estimated 92 percent of the target audience an average of 15 times' (GAO, 2002: 11). For a number of legal and political reasons, in these ads the Mint decided not to point out the benefits of using the coin and thus showing the down sides of using dollar bills.

Many popular venues were used to market the new coin. A Macy's Thanksgiving Day parade float was commissioned, coin-operated machines were installed in supermarkets, a branding agreement was made with Cheerios cereal from General Mills and the coin was featured on the popular television show The Wheel of Fortune. A specific partnership was struck with Wal-Mart to distribute dollar coins as change in its 3,000 outlets. Other such agreements were made with various organizations, including the baseball team the LA Dodgers.

The Mint also marketed the dollar coin to other local, state and federal authorities. The transit systems of large cities were targeted (New York, Chicago, Philadelphia, and San Diego) with free distribution of a dollar with the purchase of a transit card. A new dollar event was also organized at the Pentagon.

\section{Barriers}

To the Mint, of the biggest barrier to the use of the dollar coin is the continuing existence of the one dollar bill. In many countries (France, Canada, UK) the introduction of coins for lower currency denominations was successful only with the withdrawal of the equivalent bank note. But, at least in part due to the rise of a 'save the bank note' lobbying campaign, the US government decided to have both paper and coin dollars in circulation at the same time. That situation implied that the Mint did not have a fixed goal in terms of circulation for the new dollar. It also explains its reluctance to show the benefits of coins to the detriment of the notes.

In its analysis of the campaign, the GAO underlines a number of elements limiting the wider use: (1) negative image from the public following previous failed attempts at introducing it; (2) the lack of knowledge on the population's part of the benefits and savings flowing from the use of dollar coins; (3) the comparative advantages of using coins; and (4) the fact that some consider it easier to use dollar bills rather than coins. 
Distribution issues were also raised by a number of actors: (1) unavailability of coins at all banking institutions; (2) co-ordering of coins with the Suzanne B. Anthony; (3) packaging concerns (coins not available in rolls); and (4) higher fees for the delivery than with dollar bills. Departing from its usual procedures (recirculating 'used' coins before shipping out new ones), the Mint decided to ship the Sacagawea in priority. Unfortunately, the coin being so similar to the Suzanne B. Anthony, no bank or carrier had the necessary equipment to separate them. They were thus delivered commingled to the banks.

One of the goals of the introduction was saving money as well as generating revenues. Costs of money are more than simply the costs of production and of replacement. One has to account for the storage and handling as well as the seignorage, or profit, the government makes from putting currency into circulation.

When a note or currency is produced, the American Mint 'makes' the difference between the cost of producing it and its face-value (GAO, 2013). The Mint evaluates that the new dollar coin has generated about 1.1 billion USD in revenues and 968 million in seignorage. The cost of producing the coin is estimated at $\$ 0.12$ with the government receiving $\$ 1.00$ for each, so a margin of $\$ 0.88$ per coin. The cost of replacement of bank notes is higher, but the rate of replacement is gradually being lowered (Lambert, 2013). In the early 2000s, a \$1 note lasted about 18 months while coins lasted 30 years.

\section{Results}

In a 2000 survey 57 per cent of those questioned said they would be using the coin more readily as it becomes more widely used. The problem for those marketing the dollar is circular. People will use it only when others are seen using it. In a 2001 survey, 66 per cent of the public mentioned that they were saving the coins rather than using them actively. In a 2002 report the Mint estimates that the dollar coin is used in 4 per cent of dollar transactions (GAO, 2011).

Other events were to punctuate the life of the Sacagawea, but the elements presented above suffice for our understanding of the marketing of money. Like its predecessor, and its successor, the Sacagawea failed to achieve widespread use.

In recent years Congress tried to increase the circulation and use of dollar coins. Notably it mandated

the use of $\$ 1$ coins by federal agencies, the United States Postal Service, all transit agencies receiving federal funds, and all entities operating businesses, including vending machines, on U.S. government premises; (2) required the Mint to promote $\$ 1$ coins to the public; and (3) required the Secretary of the Treasury, in consultation with the Federal Reserve, to review the co-circulation of the different $\$ 1$ coin designs and make recommendations to Congress on improving the circulation of $\$ 1$ coins.

(GAO, 2011:6) 
But, despite these efforts, circulation did not increase and is still not increasing. While the GAO's 2011 report proposed a full replacement of the dollar bill for a dollar coin, this did not happen. At the time, and according to the GAO's own analysis, 'replacing the $\$ 1$ note with a $\$ 1$ coin could save the government approximately $\$ 5.5$ billion over 30 years' (GAO, 2011: 2). These numbers have been lowered since then to $\$ 4.4$ billion.

Among the reasons for these lowering of expectations has been the increasing life span of dollar bills. In 2015, 'a circulating one-dollar bill lasts an average of 5.9 years and costs about 4.9 cents to produce. A coin still lasts five or six times as long as a note, but it costs about four times as much to produce' (McGinty, 2015).

In addition, with the low use of coins by citizens, the government has now to stockpile the unused coins. The cost of storage has been estimated at 1.36 billion USD. In a 2012 survey some 70 per cent of Americans opposed removing the dollar bill and 77 per cent felt the dollar coin was 'unwanted'. For all these reasons, the US government is pulling away from producing dollar coins and is scaling back all projects related to it.

\section{MODERNIZING BANK NOTES}

The replacement of bills by coins is not the only dynamic occurring in the financial sector. New bank notes are also introduced, and with it marketing needs arise. In the United States the Bureau of Engraving and Printing is in charge of the creation of bank notes.

Despite some minor modifications in 1990, American paper currencies had not experienced important modifications since 1929. The desire to modify them in a series of modernizations starting in 1996, and redone in 2013, resulted from two central facts:

- US currency is one of the most widely used in the world.

- It is, almost logically, the most counterfeited currency in the world.

With counterfeiting techniques always evolving, it became necessary to introduce the latest technological countermeasures: at the time, micro-impressions and more elaborate watermarks have been developed. The technical requirements seemed reasonable and a technical solution had been found for the modernization of the currency. This could have been the end of the story were it not for the communication and marketing efforts.

One key element is the international importance of the US currency. Due to the international circulation of American currency, the Federal Reserve had to plan ahead to counter any possible reaction of panic that might follow the introduction of a new $\$ 100$ bill. One can refer to the reaction of the many foreigners (Russians, Salvadorians, Nigerians, etc.) who keep in reserve a large number of US $\$ 100$ bills. Would their old bill still be valid? Are their lifetime economies in peril? How to recognize the new bills? Won't they get swindled with fakes? 
These questions were addressed in the introduction of the '1996 series'. The newer model was not a radical departure from the original note. This was deplored by, among other groups, the visually impaired. American bills are all the same colour and the same size. The goal of the project was guided by two main principles: (1) imposing as little a disturbance as possible on individuals and businesses and (2) achieving an expeditious substitution of pre-1996 notes. Several steps were taken with these two aspects in mind. It was estimated that some 60 per cent of all notes in circulation at the end of 1995 were held outside the United States (Federal Reserve note). This was seen as a consequence of the large dollarization of various economies in the 1990s. American dollars are also used as a store of value in high inflation countries.

After more than a decade of development and planning, the Federal Reserve issued some 3.5 billion new 100 dollar bills in late 2013. These featured modern anticounterfeiting elements - a three-dimensional blue strip and a holographic bell - which took more than a decade in development. Due to its large circulation abroad, the $\$ 100$ bill is the most commonly counterfeited note outside the US. Bearing in mind the experience of 1996, when especially Eastern European countries - where the newest bills might be seen as the only acceptable form of payment - were concerned that there might be not enough supply of dollar bills, the Federal Reserve made sure to communicate internationally and meet the immediate demand abroad upon introduction.

Within the realm of making US currency safer, the Federal Reserve also approached a re-design of the dollar bills, representing a greater diversity of American history. In 2016, it was announced that the next wave of 20 dollar bills will carry the face of Harriet Tubman, the former slave and abolitionist. While conservative voices where rather sceptical of the changes, the Treasury said that the decision to make Tubman the new face of the 20 dollar bill was effected after hearing from the American people through roundtables, town halls, and in online discussions.

As for validity the Federal Reserve has only one credo: value is guaranteed ad eternam.

It is important to note that this is not the case in every country. For example, the introduction of a new $£ 50$ note by the British Central Bank gave people only two years to exchange them for the newer model. Despite this perpetual value of notes, the US government nevertheless instigated a conversion programme to ensure the widest possible dissemination of the newer, safer notes (Allison and Pianalto, 1997).

The introduction of the 2003 new $\$ 20$ bill as a case study in public sector communication and marketing in many ways travels the same route as the Sacagawea dollar. The campaign had a budget of some $\$ 32$ million. The channels selected were numerous (print, TV, radio, internet), but to that was added product placement, just as with regular products being marketed. The campaign was termed 'the new colour of money' in reference to the new colour to be shown on $\$ 20$ bills (peach and blue). This was the first time since 1905 that colours beside green and black were used on bills.

As with the other bills a marketing firm was hired, but this time it used the resources of a talent agency to secure the prominence of the 'product' in television 
shows and movies. 'We knew we couldn't rely on public service announcements and the news media alone to get the depth of information out about the bill's new design and security features,' said Thomas A. Ferguson, the bureau's director. 'We needed to look at different avenues. And we knew from our research that people get a lot of their information from entertainment and television' (Streisand, 2003). The campaign was to be focused on the United States with a part of the budget being allocated for overseas activities. A special emphasis was put on the people that handled cash as part of their daily job (cashiers) so that they would be aware of the new security measures.

According to representatives of the marketing company, the overall goal of the operation was quite straightforward: 'We want to build awareness - then we can begin to change behavior,' he said. The behaviour that he wanted to change included stuffing the $\$ 20$ bill, the most frequently counterfeited in the United States, into a pocket or cash register before checking its authenticity by, say, holding it up to a light or feeling for the security thread (Streisand, 2003). The strategy reflected in large part the failure of the campaign associated with the $1996 \$ 100$ series.

Tens of thousands of vending machines in post offices and train and subway stations hadn't been set up to accept the revised version, Mr. Lake said, and cashiers and other money handlers didn't always know what to make of the new money. Overseas, some consumers panicked, thinking that their old dollars would be worthless. Such confusion not only hurts sales for retailers, but can also give counterfeiters a wider berth to exploit the chaos.

(Streisand, 2003)

Numerous communication activities were planned, including the rolling out of a new website. The bill was featured on the David Letterman show as a prop for jokes, it made 'appearances' on Wheel of Fortune, Who Wants to Be a Millionaire?, Jeopardy and others. Joint marketing deals were made with Wal-Mart and with Pepperidge Farm that adorned the packaging of one of its products with the bill. Movies and TV placement was also ensured via CSI:Miami, The West Wing and others.

The results: 82 per cent awareness level. But problems were also identified, notably in terms of distribution. The new $\$ 20$ bill received numerous prizes including one from the Public Relation Society of America, and the Best Product of 2003 award from Business Week.

\section{EXERCISE A.1}

Based on the preceding examples, and using some of the key resources identified, try to answer the following questions:

1. From a wider social point of view, what are the pros and cons of spending public monies on the marketing of currency? 
2. Referring to Table 2.2, what are some of the main characteristics of currency 'product' that limit the use of marketing and communication tools?

3. What are the main 'alternatives' to using a coin?

4. Based on the distinction presented in Figure 3.4 between product and client orientation, can you identify the approach used by the US government in the marketing of its currencies (both coin and paper)?

5. For the Sacagawea and the new $\$ 20$ bill, can you identify the various elements of the marketing mix (see Figure 3.6)?

6. Can you identify the various stakeholders in the marketing of both new coins and new bills? Do they differ? If so how, and what is the likely impact on the development of a marketing and communication campaign?

7. Following Figure 4.2, how would you classify the US government's attempt at gathering information on the potential users of the new denominations?

8. In your own country, what would be the main questions to be taken into account in the marketing analysis for a new bank note? (See Figure 5.5.)

9. Can you define the central and peripheral elements of the product that is a new bank note or dollar coin following the example of Figure 6.3?

10. Can you identify some of the elements of communication as presented in Figure 7.1 and define an integrated communication model based on Figure 8.3?

11. Based on the various communication instruments presented in Table 9.1, can you imagine other initiatives that might have been developed for the communication of these new 'products'?

12. One of the main worries in introducing these new currencies was the possible panic, notably abroad, of seeing one's savings vanish. In such a situation, where holders of American currency believe it to be losing its value, which elements of crisis communication would you use (see Chapter 11)?

\section{REFERENCES}

Allison, T. E. and Pianalto, R. S. (1997) The Issuance of Series-1996 \$100 Federal Reserve Notes: Goals, Strategy, and Likely Results, Federal Reserve Bulletin, July, 557-64.

General Accounting Office (2002) New Dollar Coin: Marketing Campaign Raised Public Awareness But Not Widespread Use, report of the Subcommittee on Treasury and General Government, Committee on Appropriation, US Senate, GA0-02-896.

General Accounting Office (2011) Replacing the \$1 Note with a \$1 Coin Would Provide a Financial Benefit to the Government, report to Congressional Requesters, GAO11-281.

General Accounting Office (2013) US. Currency. Coin Inventory Management Needs Better Performance Information, report to Congressional Requesters, GA0-14110.

Lambert, M. (2013) Staff Working Paper Division of Reserve Bank Operations and Payment Systems Federal Reserve board, Washington, DC. 
McGinty, J. C. (2015) Dollar Coin Loses Currency on Savings, Wall Street Journal, online at: http://www.wsj.com/articles/dollar-coin-loses-currency-on-savings-142808 0583 (viewed on 26.07.16).

Streisand, B. (2003) Business; Need Change for a $\$ 20$ Bill? Call Hollywood, New York Times, 28 September.

United States Mint (n.d.) Online at: www.usmint.gov (viewed on 29.07.16). 


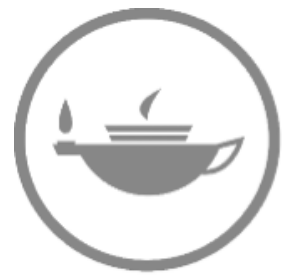

Taylor \& Francis Taylor \& Francis Group http://taylorandfrancis.com 


\section{Index}

Note: Pages referring to figures are in bold; pages referring to tables are in italics.

accessibility 133

access to information 142

access to information rights 157

accountability 9 ; transparency 9 ; vertical vs

horizontal 6, 9

accounting and budgetary transparency 158

active communications 142

actors: as the administered 54-5; as citizen-

partners 57-8; as consumers 56-7; in crisis

communications 156; external 155, 227,

229; political 156; private 109, 155; public

150, 155; in public communications 144;

typology of 54; as users 55-6

the administered 53-7

administrative law 4,5

advertising 16, 20, 52, 53, 101, 105, 110, 143, 152, 167, 168, 179, 181, 182, 184, 186, 190-3, 217; in Australia 192; in Canada 192; for dollar coins 250-1; online 193; in Singapore 191; Swiss campaign against illegal employment 218; see also classical advertising

advertising media, comparative criteria 194 AIDA (attention, interest, desire, action) formula 176

American Marketing Association (AMA) 16

analysis: of demand 97-9, 97, 101; of the market 96-7, 97; of offer 97, 101-2; of organization's marketing elements $\mathbf{9 7}$, 103-4; as phase of marketing strategy $\mathbf{9 6}$; stages of 96-7, 97; SWOT analysis (Strength, Weaknesses, Opportunities, and Threats) 104

Arnstein, S. R. 58

associations 102
Australia, government advertising 192

autonomy $4,8,9,10,12,28,30,54-8,111$, 120, 143, 203; false 56; management 5, 31, 33; partial 146

averted transparency 163

behavioural criteria 98

behaviour and process systems 50

benchmark studies 210, 213

beneficiaries of services 5 ; as consumers 31 ; as customers 63 ; identification of 123,127 ; involvement of 10, 119; management of data on 86; pressure from 47; relationships with $11,12,31,32,109$; relationships with service providers 24-8; see also consumers; users

bicycle hire in Paris 128

brand development 17, 18, 177, 217

budgetary transparency 158

bureaucracy 154; managerial 9; public 56

Cameron, David 234

Canada: access to information rights 159; government advertising 192

case study, Sacajawea coin 249-55

Chevallier, J. 56

China, images of Germany, USA, and Switzerland $\mathbf{7 5}$

citizens: relationship with public organizations 53 ; rights of 31,153 ; typology of $\mathbf{5 4}$

Civil Code (France, 1804) 55

classical advertising 187, 190-1; in Germany 193; government advertising in Australia 192; government advertising in Singapore 191; government advertising in United States 192, 250-1; government 
communications campaigns in Canada 192; see also advertising

Classical model 4; see also Weberian model client orientation 46-7, 124, 256; symptoms of 48

common good 142

communication: active 142; institutional 154; integrated 167, 183-4; internal 155; Internet 199; legal foundations of 147; personal 188; project 155; see also communication control; communications strategies; crisis communications; passive communications; public communications communication control: analysing the effectiveness model 215, 216, 217; analysis criteria 217-18, 220; effectiveness of campaign against illegal employment 218; introduction 209-10, 212; levels of impact 212; post-test control 213; pre-test control 212-13; types and conditions of control 212-15

communications instruments: direct vs. indirect 187; main instruments $\mathbf{1 8 9}$; overview 186-90; target audience 187-8 communications media 146; see also media communications models 166-72; integrated

169; of road signs 168; schematic 168 communications strategies 167; choice and planning of instruments 181-2; consistency and coherence in 183-4; for crisis communication 223; designing the message 179-81; determining target groups 174-5; general framework 172-4; general information for the public 175; objectives of public communication 178; setting communications objectives 176-7; steps in 173; testing the plan and evaluating effectiveness $182-3$

competition 5, 17, 20, 22, 23, 30, 31, 45, 47, 49, 86, 94-5, 97, 102, 104, 107, 116, 127-8, 152; media 195, 224; between public and private funds 23

complex exchange 19

Computer-Assisted Telephone Interviews (CATI) 73

consumer behavior 49, 102, 215

consumers: typology of 56-7; see also

beneficiaries of services; users

corporate mission 91

costs, of producing a service $\mathbf{6 5}$

crises: arising from problems of information

management or internal operations 227-8, 229, 231; characteristics of 224-5; importance of communication during
225-7; phases of 231-6, 232, 233-4; resulting from accidents, incidents, or emergency situations 227-8, 229, 230, 232, 233; tools for managing 244-6; types of 227-31

crisis checklists 245

crisis communications 156; crisis checklists 245; crisis factors that bring major risks 225; and crisis management 244-6; crisis types and phases 227-36; importance of 225-7; introduction 222-3; and the media 243-4; see also crisis communications errors; crisis communications strategies

crisis communications errors 236-7, 239-40; communicating without knowing the facts 238; examples of 238-9; lying 238; major pronouncements without having gauged the nature and causes of the crisis 238; playing down facts that have come to light 239

crisis communications strategies 240-3; avoidance 241; denial 241; partial acknowledgement 240; total acknowledgement 240

crisis limitation 242

customer orientation 63

Customer Relationship Management (CRM) 86

customer satisfaction 26, 63

cyber-administration 134

\section{DAGMAR model 176}

data analysis systems $85-7$

decisions, as phase of marketing strategy 96 demand: adapting offer to 118 ; analysis of 97-9; political 24; rationing of 128-9

democratic control 9

Democratic Governance 4, 6, 9-10, 11, 57-8

differentiation of services 25-6

differentiation strategy 90, 95

Digital by Default Strategy (UK) 201

digital divide 201

distribution: choosing a system for 134-5; circuits and channels 114, 130-1; cyberadministration 134; examples of 132; physical aspects of 132-3; of public services 131 ; study of 130-1

documentary transparency 158

dollar coins produced 250

e-administration 134, 199

economic sectors, image differential between 102

e-democracy 200, 205-6 
effectiveness analysis 210

e-government 134, 187, 199-201; and communications 201; success factors 201-3; website design 203-5

e-participation 205

e-public 205

Eurobarometer surveys 72-3

European Day of Civil Justice 190

European Union: 50th anniversary logo 170; access to information rights 160

e-voting 205

exchange: conditions required for 23-4; defined 16; three types of 19

exclusion $127-8$

feedback loop 170

financial resources 50

Finland, access to information rights 159

focus groups 77

four ps 50, 51, 114, 136

France: access to information rights 159 ; bicycle hire in Paris 128; campaign to promote borrowing by French government 171; government communications in 147

Freedom of the Press Act (Sweden) 159

From Red Tape to Results (Gore) 56

geo-tracking 70

generalized exchange 19

Germany: access to information rights 159;

Gotthard tunnel 150; government

advertising 193; government

communications 147; perception of in China

75; segmentation of high-speed train users 99-100

globalization 17; and the media 195

Gore, Al 56

Gotthard Tunnel 150

governance, networked 9-10

government advertising: in Australia 192; in

Canada 192; in Singapore 191; Swiss

campaign against illegal employment 218;

in the U.S. 192, 250-1

government communications 150-3; see also public communications

health insurance: American 45; comparison of American with Swiss 44; Swiss 45

household panels 77

human resources 50

image differential, between economic sectors 102

information, monitoring over time 214 information systems 85-7; as marketing element 103

institutional communications 154

insurance systems: American 45; comparison of

American with Swiss 44; Swiss 45

integrated communications 167, 183-4

intermediaries 20, 39, 42, 104, 108-10, 113,

131-2

intermediation, in market exploitation 109

internal communications 155

internal resources 50

Internet, as information medium 199-201

Internet communications 199

IT resources 50

longitudinal studies 210, 213

Malta, access to information rights 159

management models 6, 11; Democratic

Governance 6, 9-10, 11, 12; hybrid 21-2,

31; New Public Management 6, 8-9, 10,

11, 12; Weberian model 6, 7, 8, 10, 11,

12; see also marketing management; public

management

managerial bureaucracy 9; see also bureaucracy market, principal criteria for defining 42

market components, viewed as a system 43

market exploitation 108-9; intermediation in 109

marketing: basic concepts of 16-17, 39-40,

41; conceptualization of the field 17;

content of the concept (basic paradigm)

18-20; defined 16; development of the concept of exchange 17; development of the concept 17-18, 17; development of the concept of relationship 17; goals of 50; most important developments in 18; place 29; in the public sector 20-1, 21; relational 20, 22, 25

marketing elements: financial resources 102-3; information systems 103; system for applying marketing instrument 103

marketing information: descriptive 64-5; explanatory 65 ; objective 65 ; in the public sector 63-4; situation necessitating gathering of 64; see also marketing information research

marketing information research 62-3; data collection 85 ; delimiting the problem 82 ; designing a study $82-5$; designing the research plan 82-3; formatting findings and results 85 ; increased use of $63-4$; information-gathering methods 66-70; observation 68-9, 70; phases of 83; primary 
studies 66; secondary or documentary sources 68; secondary studies 66; summary of methods 67; surveys 67-8, 70-4, 76-82; tests 69-70; using an information system 85-7

marketing instruments 40, 50-1, 113-14; basic structures of 115; combined use of 52-3; distribution 52; four ps 50, 51, 114, 136; people 52; physical facilities 52; price 51; processes 52; product 51; promotion 52; see also marketing mix

marketing management 40; tasks of 49-50, 49 marketing mix 18, 39, 40, 50, 51, 92, 106, 113-14, 136; see also marketing instruments marketing of services 18, 28

marketing orientation: client orientation 46-7; comparison of product and client orientations 46; production orientation 45-6; symptoms of 47, 48; types of 45-7 marketing strategies 89-90; competitive strategy 107; decisions regarding implementation 105; decisions regarding strategic framework 105; description of decisions 105-7; differentiation strategy 95; elements of analysis 96-104; five p's 90; limitations 111; phases of 96; planning process 95-6; possible strategies for public organizations 94; price strategy 95; problems in implementing 110-11; for a professional career-guidance service 108; in a public organization 90-5; segmentation strategy 95; strategic decisions and their implementation 105-11

market orientation 40

market planning 50

maximized transparency 163

media: advertising 194; communications 146; and crisis communications 240, 243-4; speed and intrusiveness of 244

media panels $77-8$

media relations 187,193 ; rules for communication with media 195-6; tools for 197-9

Mill, John Stuart 157

Mintzberg, H. 90

mystery shopping 70

neo-liberalism 7

networked governance 9-10

New Public Management 4, 5, 6, 8-9, 10, 11, 22, 30, 56, 57, 63, 115

New York, tourism in 29

non-competition 127

non-exclusion 113, 127 non-profit organizations (NPOs) 28

non-transparency 161-2

observational information-gathering 63, 68, 70; electronic 69

objective information 148

obstructed transparency 163

omnibus surveys 77

online advertising, in the United States 193

opening times 133

organizational crisis 223

organizational transparency 158

panel surveys $77-8$

Paraguay, access to information rights 159

parties to the exchange 16, 46; relationships between 19-20

passive communications 142; analytical framework for transparency laws 160-1; definition and origin 156-7; and the development of transparency 158 ; different forms of transparency 158-9; and resistance to transparency $161,162,163$

perceived similarity 102

personal communications 188

place marketing 29

political mandates, potential effects of $\mathbf{2 1 1}$

political pressure 32

Porter, M. E. 95

postal surveys 73-4

press briefings 199

press conferences 198

press release 198; rules for drafting 197

pricing strategies 90, 95, 107, 128-30; free

services 126; license fees 126-7; monetary

and non-monetary incentives 130; price

127 ; for public goods 127 ; taxes 126

private goods 128

private organizations, strategic development process 91

production orientation 45-6; symptoms of 48

product life cycle 18

project communications 155

promotional measures, potential effects of 211

providers, relationships with users 24

psychographic criteria 98

public communications 141-2; aimed at deciders 188-9, 189; audience 181; basic principles of 147-9; classical methods of 201; in connection with citizens' rights and obligations 153; control over content 181-2; credibility of the medium 181 ; crisis communications 156; elements of $\mathbf{1 4 4}$; 
examples of 143; frequency 181; functions of 143-5; for the general public 189, 190; government communications 150-3; individualized vs. mass 188 ; institutional 154; as instrument of public policy 153-4; internal communications 155; levels of 149-50, 151; and the marketing of money 249-55; objectives of 178; period and duration 181; project communications 155 ; reasons for development of 145-6; regarding services 154-5; for staff 188, 189; through the media 197; types of 149 ; unilateral, bilateral or multilateral 188; and the use of foreign languages 148

public goods, and types of price 127

public management 22; and public marketing 21

public marketing: bases of the development of

21; characteristics of 28-9, 30; limits of

31-4; and marketing for public services 28;

reasons for development of 29-30;

relationships with beneficiaries 24-8, 25, 31,32

public organizations: interaction between political and strategic levels 93; possible strategies 94; strategic development process 91

public policies 9

public relations (PR) 219

public sector: growth of 4-5; marketing in

20-1; provider-user relationships 24

public service organizations 3-4; development and characteristics of 4-5; environment 6; objectives of 5-6; status of 5; tasks 6 public services 115; access to 130-3; components of 119; defining public issues 124; inability to store services 118 ; indivisibility of 117 ; intangibility 117 ; key role of personnel 118; managerial definition 117; politico-legal definition 116; pricing of 126-30; quality criteria 125; quality of $124-6$; structuring according to components 119-20; structuring in an administrative unit 121; structuring in groups of services, services, and activities 120-1; structuring of services linked to protection of cultural goods 122-3; tangible vs. intangible 118; ways of improving service quality 118-19

qualitative surveys $70-1,76-7$

quantitative surveys $70-1$; designing a questionnaire $84-5$

quota sampling 79; compared to random sampling 81 ; example of $\mathbf{8 0}$ random sampling: cluster 79; compared to quota sampling 81 ; simple 78 ; stratified 79

relational marketing 20, 22, 25

restricted exchange 19

roles: the administered 54-5; citizen-partner 57-8; the consumer 56-7; marketing adaptation to 58-9; typologies of 54; the user 55-6

Sacajawea coin: barriers to public acceptance 251-2; introduction of 249-51; results of introduction 252-3

sample selection: cluster random sampling 79; convenience sampling 79; formula to calculate samples 82; quota sampling 79, 80; random sampling compared to quota sampling 81; sample size 80-2; simple random sampling 78; stratified random sampling 79

sampling errors 82

segmentation criteria 98-9, 98

segmentation strategy 90,95

services: costs of producing 65; of general interest 114

Singapore, government advertising in 191

Smart City program 70

smoking ban in California 179

social consumerism 56

sociodemographic criteria 98

socioeconomic criteria 98

sociogeographic criteria 98

Spain, oil tanker shipwreck 230, 232-3

strained transparency 163

strategic development, comparison between private and public organizations 91

strategies: differentiation 90, 95; see also communications strategies; marketing strategies

structuration 101

substitutability 102

surveys 62, 67-8; of children and seniors 214; designing a questionnaire 84-5;

Eurobarometer 72-3; EU study on citizens and the Euro 76; focus groups 77;

interpretation of 214; omnibus 77; panels 77-8; personal interviews 73; postal or correspondence 73-4; qualitative 67-8, 70-1, 76-7; quantitative 67, 70-1; telephone (CATI) 73; typical objectives of 71

Sweden, Freedom of the Press Act (1766) 159

Swiss unemployment funds 23 
Switzerland: access to information rights 159 ; campaign against illegal employment 218; government communications 147; health insurance in 44, 45; information management crisis at the University of Geneva 231, 235-6, 235; perception of in China 75; tunnel building 150

SWOT analysis 49, 104

systemic analysis 39

systems theory 40

tangible services 25, 117

target groups 106, 107; for communications instruments 187-8; for communications strategies 174-5; for government advertising 192; and public communication 149; reached and dispersion loss 175 technology: and crisis management 224; and IT resources 50

telephone surveys (CATI) 73

tests 63, 69-70

tourism: in New York 29; in Valais 33

translation 90, 93, 93

transparency 10, 156-7; of action and administrative responsibilities 159; analytical framework for laws 160-1; in crisis communications 241; different forms of 158-9; reasons underlying the development of 158 ; resistance to $161,162,163$

Tunisia, access to information rights 159 unemployment funds 23

unilateral communications 188

unique selling proposition (USP) 108

United Kingdom: access to information rights 159; Cameron's tax-evasion scandal 234; Digital by Default Strategy 201

United States: access to information rights 159; dollar coins produced 250; government advertising 192, 250-1; health insurance in 44,45 ; introduction of the Sacajawea coin 249-53; and the modernization of bank notes 253-5; perception of in China 75; role of the consumer in 56

University of Geneva, information management crisis 231, 235-6, 235

users: definition of 42-3; relationships with providers 24; typology of 55-6; see also beneficiaries of services; consumers

Valais tourism law 33

Weber, Max 4, 6

Weberian model 4, 6, 7, 8, 10, 11; criticism of 7

website design: coordination of internet tools with other communication tools 205; homogenization of rules 203; important elements in website creation 204; quality of information 203

Wilson, Woodrow 4 